DOUGLAS LIMA DANTAS

\title{
SToIC: Portabilidade e interoperabilidade na camada de aplicação de plataformas de Internet das Coisas
}

Dissertação apresentada à Escola Politécnica da Universidade de São Paulo para obtenção do Título de Mestre em Ciências. 


\title{
SToIC: Portabilidade e interoperabilidade na camada de aplicação de plataformas de Internet das Coisas
}

\author{
Versão Corrigida
}

Dissertação apresentada à Escola Politécnica da Universidade de São Paulo para obtenção do Título de Mestre em Ciências.

Área de concentração:

Engenharia de Computação

Orientador:

Prof ${ }^{a}$ Dr. ${ }^{a}$ Anarosa Alves Franco Brandão 
Autorizo a reprodução e divulgação total ou parcial deste trabalho, por qualquer meio convencional ou eletrônico, para fins de estudo e pesquisa, desde que citada a fonte.

Este exemplar foi revisado e corrigido em relação à versão original, sob responsabilidade única do autor e com a anuęncia de seu orientador.

São Paulo, 16 de novembro de 2020

Assinatura do autor:

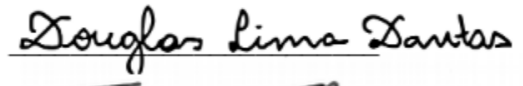

Assinatura do orientador:

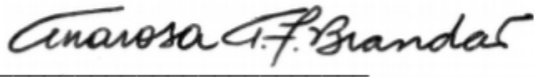

Catalogação-na-publicação

Dantas, Douglas

SToIC: Portabilidade e interoperabilidade na camada de aplicação de plataformas de Internet das Coisas / D. Dantas -- versão corr. -- São Paulo, 2020.

$198 \mathrm{p}$.

Dissertação (Mestrado) - Escola Politécnica da Universidade de São Paulo. Departamento de Engenharia de Computação e Sistemas Digitais.

1.Internet das Coisas 2.Interoperabilidade 3.Portabilidade de Software I.Universidade de São Paulo. Escola Politécnica. Departamento de Engenharia de Computação e Sistemas Digitais II.t. 


\section{AGRADECIMENTOS}

Primeiramente, agradeço a Deus por ter me dado forças, me protegido e permitido que eu concluísse esta etapa com saúde física e mental, provendo todos os meios para que isso fosse possível e me guiando diante das incertezas.

À professora Anarosa Brandão, por ter me recebido em seu laboratório, pela confiança e pelo largo conhecimento transmitido durante toda a sua orientação. Ao professor Leônidas Brandão, pela breve estada em seu laboratório, porém muito significativa para mim.

À professora Lucia Filgueiras, por ter aceitado o desafio de me co-orientar para, juntos, levarmos este projeto de pesquisa adiante. Pela sua paciência, pelos ensinamentos, por guiar em meio às muitas dúvidas e incertezas pelas quais passam um estudante de mestrado e, claro, por incrementar meu vocabulário com expressões desconhecidas por mim.

Ao professor Sergio Kofuji, por ter sido minha porta de entrada para a PósGraduação, ainda em Manaus, e por ter me recebido em seu laboratório e me envolvido em projetos de alta relevância. Com ele aprendi lições de vida e passei momentos que serão eternizados em minha memória.

Aos professores Maria Cristina Domingues, Maria Rosilene Ferreira e Alessandro dos Santos, do Instituto de Pesquisas Tecnológicas do Estado de São Paulo (IPT), por terem me permitido fazer parte de um projeto de desenvolvimento institucional de grande relevância e provido meios para viabilizar a execução do meu projeto de pesquisa.

À FAPESP, pelo apoio financeiro concedido através do processo no 2018/23052-0, Fundação de Amparo à Pesquisa do Estado de São Paulo (FAPESP), vinculado ao processo no 2017/50343-2, Fundação de Amparo à Pesquisa do Estado de São Paulo (FAPESP).

À Universidade de São Paulo (USP), pela oportunidade de cursar um mestrado em um centro de excelência em Ensino, Pesquisa e Extensão.

À minha mãe, Ivanilda, por todo o amor, paciência, apoio, dedicação, a educação que me deu e por poder dividir com ela minhas alegrias e lamentar minhas frustrações. Sei que the doeu muito a minha ausência. A meu pai, Ciro, pela ajuda que me deu, inclusive financeira, em momentos difíceis.

À minha namorada, Katerine, por me amar e estar sempre ao meu lado, me apoi- 
ando durante esta etapa tão importante, vivenciando comigo momentos complicados dessa jornada e, também, muitos momentos de alegria.

Aos meus amigos, também do PPGEE, Albérico, Cláudia, Isaac, Renata, Alejandra, Miguel, Rosa e Luis, por todos os ótimos e inesquecíveis momentos que me proporcionaram. Com vocês, a vida fica bem mais leve. 
"It was the best of times, it was the worst of times,

it was the age of wisdom, it was the age of foolishness,

it was the epoch of belief, it was the epoch of incredulity,

it was the season of Light, it was the season of Darkness,

it was the spring of hope, it was the winter of despair,

we had everything before us, we had nothing before us,

we were all going direct to Heaven, we were all going direct the other way

in short, the period was so far like the present period, that some of its noisiest authorities insisted on its being received, for good or for evil, in the superlative degree

of comparison only."

(DICKENS, 2007) 


\section{RESUMO}

DANTAS, Douglas L., SToIC: Portabilidade e interoperabilidade na camada de aplicação de plataformas de Internet das Coisas. 2020. 190 p. Dissertação (Mestrado em Engenharia da Computação e Sistemas Digitais) - Escola Politécnica da Universidade de São Paulo, São Paulo, 2020.

A Internet das Coisas (IOT) está criando um ambiente onde dispositivos formam uma rede inteligente, gerando demanda pelo desenvolvimento de novas aplicações. Para facilitar o desenvolvimento, as plataformas de loT oferecem recursos que abstraem a complexidade do ponto de vista do desenvolvedor de aplicações. Atualmente, existem diferentes plataformas de loT, públicas e privadas, sobre as quais se implementam aplicações para a indústria, cidades inteligentes, entre outros domínios de negócio. Porém, aplicações ou serviços desenvolvidos em uma plataforma não necessariamente interagem com aplicações e serviços desenvolvidos em outra plataforma. Desta forma, este trabalho propõe o SToIC, um modelo de camada de interoperabilidade e portabilidade que atua na camada de aplicação de diferentes plataformas de loT e provê uma interface que pode ser usada para criar aplicações multiplataformas, permitindo maior reuso e economia de recursos, além da interoperabilidade entre as mesmas. Para chegar-se ao SToIC, a pesquisa partiu do reconhecimento do estado da arte em plataformas de loT e seus recursos por meio de uma revisão terciária de literatura, na qual foram identificadas 49 plataformas e detectou-se 11 categorias de recursos oferecidos ao desenvolvedor. Em seguida, o SToIC foi projetado e definiu-se o processo através do qual se poderia chegar à portabilidade e interoperabilidade na camada de aplicação. Logo depois, através de dinâmica realizada com membros de 8 diferentes projetos do Instituto de Pesquisas Tecnológicas do Estado de São Paulo (IPT), selecionou-se o projeto de análise e mapeamento de ruídos, o Barulhômetro, para criação de prova de conceito do SToIC. Em seguida, realizou-se uma implementação do SToIC tendo como base as plataformas Fiware e Watson loT Platform (WIP), além dos recursos necessários pela aplicação do Barulhômetro e foram realizadas modificações nesta aplicação, para que se tornasse multiplataforma, sendo compatível com a implementação do SToIC. O SToIC alcançou o nível de interoperabilidade semântico e implementou os padrões de interoperabilidade "acesso interplataforma", "independência de plataforma" e "fachada de alto nível de serviços".

Palavras-chave: Internet das Coisas. Interoperabilidade. Portabilidade de Software. 


\begin{abstract}
DANTAS, Douglas L., SToIC: Portabilidade e interoperabilidade na camada de aplicação de plataformas de Internet das Coisas. 2020. 190 p. Dissertação (Mestrado em Engenharia da Computação e Sistemas Digitais) - Escola Politécnica da Universidade de São Paulo, São Paulo, 2020.

Internet of Things (loT) is creating an environment where devices form an intelligent network, generating demand for the development of new applications. To facilitate development, loT platforms offer features that abstract complexity from the application developer's point of view. Currently, there are different loT platforms, public and private, on which applications for industry, smart cities, among other business domains are implemented. However, applications or services developed on one platform do not necessarily interact with applications and services developed on another platform. In this way, this work proposes SToIC, a model of interoperability and portability layer that acts in the application layer of different loT platforms and provides an interface that can be used to create multiplatform applications, allowing greater reuse and resource savings, in addition to interoperability between them. To arrive at SToIC, the research started from the recognition of the state of the art in loT platforms and their resources through a tertiary literature review, in which 49 platforms were identified and 11 categories of resources offered to the developer were detected. Then, SToIC was designed and the process was defined by which portability and interoperability in the application layer could be achieved. Soon after, through dynamics carried out with members of 8 different projects of the Technological Research Institute of the State of São Paulo (IPT), the noise analysis and mapping project, the Barulhômetro, was selected to create the SToIC proof of concept. Then, implementation of SToIC was carried out based on the Fiware and Watson loT Platform (WIP) platforms, in addition to the resources required by the Barulhômetro application and modifications that were made to this application, so that it became multiplatform, being compatible with the implementation SToIC. SToIC reached the level of semantic interoperability and implemented the interoperability standards "interplatform access", "platform independence" and "high level of service facade".
\end{abstract}

Keywords: Internet of Things. Interoperability. Software Portability. 


\section{LISTA DE FIGURAS}

1 Visão representativa da solução proposta. . . . . . . . . . . . . . . . . . 6

2 Modelo de arquitetura de referência de acordo com a International Telecommunication Union (ITU) . . . . . . . . . . . . . . . . . . . . . . . 10

3 Modelo de arquitetura de referência de acordo com Guth et al. (2016). . 12

4 String de busca definida no trabalho, com campos de metadados onde a busca foi realizada. . . . . . . . . . . . . . . . . . . . . . . 17

5 Gráficos apresentando os estudos selecionados em cada etapa do processamento dos resultados da busca na revisão terciária.

6 Gráficos apresentando os estudos selecionados em cada etapa do processamento dos resultados da busca na revisão sistemática. . . . . . . . 20

7 Visão geral das categorias de recursos oferecidos na camada de suporte a aplicação e verticais de mercado mais comuns das plataformas encontradas.

8 Diferentes padrões de interoperabilidade. . . . . . . . . . . . . . .

9 Representação de implementação de uma aplicação para três plataformas diferentes. . . . . . . . . . . . . . . . . . . . .

10 Representação de implementação de uma aplicação para três plataformas diferentes utilizando a camada proposta neste trabalho.

11 Exemplo da análise comparativa dos recursos oferecidos na camada de suporte de aplicação as plataformas. $\ldots \ldots$

12 Visão resumida do funcionamento do Tangle. . . . . . . . . . . . . . . . .

13 Visão arquitetural da solução proposta. Em azul, os componentes desenvolvidos neste trabalho.

14 Visão geral do processo para desenvolvimento de solução de portabilidade e interoperabilidade neste trabalho. 
15 Cenários possíveis de interação dos componentes do projeto baseandose nos padrões explicados na Seção $3.3 \ldots \ldots$. . . . . . . . . . 52

16 Visão contextual da solução implementada. Em azul, os componentes desenvolvidos neste trabalho. . . . . . . . . . . . . . . . . . . 56

17 Tela inicial. . . . . . . . . . . . . . . . . . . . . . . . . 59

18 Tela de plataformas. . . . . . . . . . . . . . . . . . . . 59

19 Tela de dispositivos. . . . . . . . . . . . . . . . . . 60

20 Tela de entidades. . . . . . . . . . . . . . . . . . . 60

21 Tela de tarefas. . . . . . . . . . . . . . . 61

22 Tela de dashboard. . . . . . . . . . . . . . . . . . . . 61

23 Sequência de obtenção de lista de plataformas através do Services on Top of Interoperability Components (STolC) Panel. . . . . . . . . . . 62

24 Sequência de obtenção de lista de plataformas através do SToIC Panel. 62

25 Sequência para inserção de nova instância de plataforma através do STolC Panel. . . . . . . . . . . . . . . . . . . . . . . 62

26 Sequência para inserção de novo dispositivo através do SToIC Panel. . 63

27 Sequência para criação de entidade em uma instância de plataforma do tipo Fiware e outra do tipo Watson loT Platform (WIP) através do SToIC Panel. . . . . . . . . . . . . . . . . . . . . . . . . . . . . 6 64

28 Sequência para criação de nova associação entre dispositivo e entidade em uma instância Fiware através do SToIC Panel. . . . . . . . . . . . . 64

29 Sequência para criação de nova associação entre dispositivo e entidade em uma instância WIP através do SToIC Panel. . . . . . . . . . . . . . . 64

30 Sequência para criação de uma task em uma instância Fiware através do STolC Panel. . . . . . . . . . . . . . . . . . . . . . . . . . . . . . 65

31 Sequência para criação de uma task em uma instância WIP através do STolC Panel. . . . . . . . . . . . . . . . . . . . . . . . . . . 65 
32 Tema, eixos e linhas de pesquisa do Plano de Desenvolvimento Institucional na Área de Transformação Digital: Manufatura Avançada e Cidades Inteligentes e Sustentáveis (PDIP). . . . . . . . . . . . . 67

33 Uma das jornadas do usuário criadas. Em vermelho, as ações do usuário e oportunidades encontradas. Em verde, os pontos de contato com o sistema.

34 Duas notas autoadesivas com questões How Might We (HMW) elaboradas por um dos times. . . . . . . . . . . . . . . . . . 73

35 Mural com as questões de HMW agrupadas por categorias de recursos. 73

36 Arquitetura do Barulhômetro . . . . . . . . . . . . . 75

37 Modelo de Dados do Fiware. . . . . . . . . . . . . . . . . . . . . 81

38 Modelo de Dados do WIP. . . . . . . . . . . . . . . . . . . . . 81

39 Modelo de dados implementado. . . . . . . . . . . . . . 83

40 Instâncias de plataformas registradas no STOIC Panel . . . . . . . . . . 85

41 Dispositivos registrados no STOIC Panel. . . . . . . . . . . . . . 86

42 Entidades registradas no STOIC Panel. . . . . . . . . . . . . . . . 86

43 Associações realizadas entre os dispositivos e entidades no Panel. . . 87

44 Tarefas registradas no Panel. . . . . . . . . . . . . . . . . . 87

45 Dashboard do Panel apresentando os gráficos com medições das entidades Barulhometro001 e Barulhometro002. . . . . . . . . . . . . 88

46 Tela do Barulhômetro com medições de ruído do parque A. . . . . . . 88

47 Tela do Barulhômetro com medições de ruído do parque B. . . . . . . 89 


\section{LISTA DE TABELAS}

1 Desafios confrontados e as respectivas contribuições propostas neste trabalho. . . . . . . . . . . . . . . . . . . 5

2 Níveis de TRL e suas descrições. . . . . . . . . . . . . . . . . . . . . . . 18

3 Plataformas de loT encontradas nos estudos secundários. . . . . . . . 22

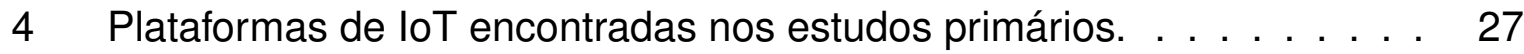

5 Tabela comparativa entre as plataformas de loT quanto aos seus recursos. 33

6 Comparação dos diferentes projetos de interoperabilidade presentes no loT-European Platforms Initiative (IoT-EPI). . . . . . . . . . . . . . 43

7 Endpoints da interface disponibilizada pelo SToIC às aplicações. . . . . 55

8 Métodos dos adaptadores no SToIC Core para as plataformas WIP e o nível de implementação do recurso utilizado. . . . . . . . . . . . . . . . . 57

9 Comparação entre o SToIC e diferentes projetos de interoperabilidade presentes no loT-EPI. . . . . . . . . . . . . . . . . . . 97 


\section{LISTA DE ABREVIAÇÕES}

API Application Programming Interface

CIAM-IPT Centro de Tecnologia da Informação, Automação e Mobilidade

CoT Cloud of Things

DARE Database of Abstract of Reviews of Effects

DT Design Thinking

EIF European Interoperability Framework

ETSI European Telecommunications Standards Institute

FAPESP Fundação de Amparo à Pesquisa do Estado de São Paulo

GSN Global Sensor Network

HMW How Might We

IA Inteligência Artificial

IEEE Instituto de Engenheiros Eletricistas e Eletrônicos

IPT Instituto de Pesquisas Tecnológicas do Estado de São Paulo

ITU International Telecommunication Union

IoT-EPI loT-European Platforms Initiative

IoT Internet das Coisas

LCIM Levels of Conceptual Interoperability Model

LSM Linked Sensor Middleware

ML Machine Learning

NGSI Next Generation Service Interface

NIST National Institute of Standards and Technology

ONU Organização das Nações Unidas

OSI Open System Interconnection 
PDIP Plano de Desenvolvimento Institucional na Área de Transformação Digital: Manufatura Avançada e Cidades Inteligentes e Sustentáveis

PICO Polulação, Intervenção, Controle, Outcome

POV Point of View

PPI Pivotal Points of Interoperability

REST Representational State Transfer

SCF Sistema Cíber-Físico

SDK Software Development Kit

SGBD Sistema de Gerenciamento de Banco de Dados

SToIC Services on Top of Interoperability Components

TRL Technology Readiness Level

UE União Europeia

WIP Watson loT Platform 


\section{SUMÁRIO}

1 Introdução 1

1.1 Motivação e Justificativa . . . . . . . . . . . . . . . . . . . . 2

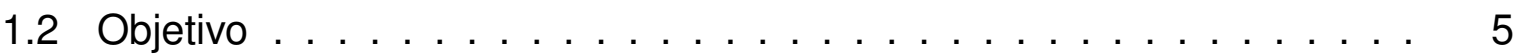

1.2.1 Objetivos Específicos . . . . . . . . . . . . . . . . 6

1.3 Metodologia . . . . . . . . . . . . . . . 6

1.4 Estrutura do Trabalho . . . . . . . . . . . . . . . . . . . . 7

2 Recursos Oferecidos na Camada de Aplicação de Plataformas de Internet $\begin{array}{lc}\text { das Coisas (IoT) } & 8\end{array}$

2.1 Internet das Coisas (IoT) $\ldots \ldots \ldots$

2.2 Modelos de Arquitetura de Referência loT . . . . . . . . . . . . . . . . . 9

2.3 Metodologia e Protocolo de Revisão . . . . . . . . . . . . . . . . . . . . 12

2.3.1 Questões de Pesquisa . . . . . . . . . . . . . . . . . . . . . . 13

2.3.2 Critérios de Inclusão e Exclusão . . . . . . . . . . . . . . . . . . 14

2.3.3 Avaliação de Qualidade . . . . . . . . . . . . . . . . . . . . . . 15

2.3.4 Fontes e Método de Busca . . . . . . . . . . . . . . . . . . . . . 15

2.3.5 Extração de Dados . . . . . . . . . . . . . . . . . . . . . . . . . 17

2.3.6 Technology Readiness Level (TRL) . . . . . . . . . . . . . . . . 18

2.3.7 Processo de Seleção . . . . . . . . . . . . . . . . . . . . . . . . 19

2.4 Estudos Selecionados . . . . . . . . . . . . . . . . . . . . . . . . . . 20

2.5 Respostas à Questão Principal . . . . . . . . . . . . . . . . . . . . . . . . 21

2.6 Respostas à Questão Secundária $1 \ldots$. . . . . . . . . . . . . . . . . . . . . . 34

2.7 Respostas à Questão Secundária $2 \ldots$. . . . . . . . . . . . . . . . . . . . 34 
2.8 Respostas à Questão Secundária $3 \ldots \ldots \ldots \ldots \ldots$

2.9 Considerações do Capítulo . . . . . . . . . . . . . . . . . 35

3 Portabilidade e Interoperabilidade na Camada de Aplicação 37

3.1 Definições . . . . . . . . . . . . . . . . . . . . . . 37

3.2 Níveis de Interoperabilidade . . . . . . . . . . . . . . . . . . 38

3.3 Padrões de Interoperabilidade $\ldots \ldots \ldots \ldots \ldots$

3.4 Iniciativas de Interoperabilidade . . . . . . . . . . . . . 39

3.4.1 National Institute of Standards and Technology (NIST) _ . . . . 40

3.4 .2 IOT-EPI $\ldots \ldots \ldots \ldots \ldots \ldots \ldots \ldots \ldots \ldots \ldots \ldots$

3.4.3 Next Generation Service Interface (NGSI) . . . . . . . . . . 44

3.5 Considerações do Capítulo . . . . . . . . . . . . . . . . . . 44

4 Proposta e Projeto da Camada de Portabilidade e Interoperabilidade $\quad 45$

4.1 Portabilidade $\ldots \ldots \ldots \ldots \ldots \ldots \ldots \ldots \ldots \ldots$

4.2 Interoperabilidade $\ldots \ldots \ldots \ldots \ldots \ldots \ldots \ldots \ldots$

4.3 Modelo SToIC de Portabilidade e Interoperabilidade . . . . . . . . 49

4.4 Cenários Possíveis . . . . . . . . . . . . . . . . . . . . 52

4.5 A Implementação da Solução . . . . . . . . . . . . . . . 53

4.5 .1 STolc Core . . . . . . . . . . . . . . . . . . . . 54

4.5 .2 STolC Tangle . . . . . . . . . . . . . . . . . 56

4.5 .3 STolC Panel . . . . . . . . . . . . . . . . . . . 57

4.5.4 Diagramas de Sequência da Solução . . . . . . . . . . 58

4.6 Considerações do Capítulo $\ldots \ldots \ldots \ldots$

5 Mapeamento da aplicabilidade do SToIC no PDIP-Instituto de Pesquisas Tecnológicas do Estado de São Paulo (IPT) 
5.1 Design Thinking (DT) e Técnicas Utilizadas . . . . . . . . . . . 68

5.2 Projetos Convidados . . . . . . . . . . . . . . . . 70

5.3 Relato do Experimento . . . . . . . . . . . . . . . . 70

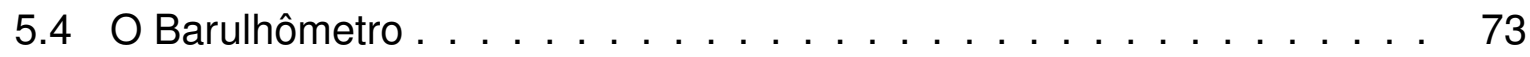

5.5 Escolha das Plataformas $\ldots \ldots \ldots \ldots \ldots \ldots$

5.6 Considerações do Capítulo . . . . . . . . . . . . . . . . 76

6 A Prova de Conceito $\quad 78$

6.1 Análise comparativa dos modelos de dados . . . . . . . . . . . 78

6.2 Análise comparativa dos recursos oferecidos na camada de aplicação . 80

6.3 Modelagem e codificação do adaptador abstrato . . . . . . . . . 82

6.4 Implementação dos adaptadores de cada plataforma . . . . . . . . . 83

6.5 Registro dos Elementos Necessários no STOIC Panel . . . . . . . . . 84

6.6 Considerações do Capítulo . . . . . . . . . . . . . . . . . . 87

$\begin{array}{lll}7 & \text { Discussão } & 90\end{array}$

7.1 Níveis de Interoperabilidade Alcançados . . . . . . . . . . . . . 90

7.2 Padrões de Interoperabilidade Implementados . . . . . . . . . . 91

7.3 Aspectos de Portabilidade . . . . . . . . . . . . . . . . . 92

7.4 Limitações . . . . . . . . . . . . . . . . . . . . . . 94

7.5 Comparação com Trabalhos Relacionados . . . . . . . . . . . . 95

8 Conclusão 98

$\begin{array}{ll}\text { Referências } & 102\end{array}$

Apêndice A - Recursos Encontrados nas Plataformas Analisadas na Revisão $\begin{array}{ll}\text { da Literatura Agrupados por Categoria } & 109\end{array}$ 
A.1 Abstrações de Dispositivos . . . . . . . . . . . . . . . . . . . 109

A.2 Painéis de Controle . . . . . . . . . . . . . . . . . . . . . 110

A.3 Serviços. . . . . . . . . . . . . . . . . . . 113

A.4 Wiring Tools . . . . . . . . . . . . . . . . . . . . . . . 116

A.5 Disparadores de Mensagens e Notificações . . . . . . . . . . . 117

A.6 Software Development Kit (SDK) _ . . . . . . . . . . . . . 118

A.7 BigData e Analytics . . . . . . . . . . . . . . . . . . . . . . . 122

A.8 Inteligência Artificial (IA) e Machine Learning (ML) . . . . . . . . . . 124

A.9 Marketplaces . . . . . . . . . . . . . . . . . . . . . . . . 124

A.10 Dashboards . . . . . . . . . . . . . . . . . . . . . . . . . 126

A.11 Agendadores e Disparadores . . . . . . . . . . . . . . . . . 127

Apêndice B - Apresentação dos Conceitos de Jornada do Usuário 129

Apêndice C - Apresentação dos Conceitos de How Might We 134

Apêndice D - Apresentação das Categorias de Recursos 144

Apêndice E - Jornadas do Usuário (Indústria 4.0) 151

Apêndice F - Jornadas do Usuário (Poluição) 154

Apêndice G - Jornadas do Usuário (Desastres Ambientais) 159

Apêndice H - Jornadas do Usuário (Gestão Ambiental) 161

Apêndice I - Transcrição das questões de HMW Obtidas nas Dinâmicas e Agrupadas por Categorias de Recursos 163 


\section{INTRODUÇÃO}

Esta dissertação resulta do projeto de pesquisa de mestrado desenvolvido no âmbito do Plano de Desenvolvimento Institucional na Área de Transformação Digital: Manufatura Avançada e Cidades Inteligentes e Sustentáveis (PDIP) do Instituto de Pesquisas Tecnológicas do Estado de São Paulo (IPT) de São Paulo, na linha de pesquisa "Sistemas Ciber-Físicos". Sua realização estava prevista na proposta PDIP submetida à Fundação de Amparo à Pesquisa do Estado de São Paulo (FAPESP) (Processo FAPESP 2017/50348-2) (IPT, 2017), conforme o plano de bolsa intitulado "Adequação da camada de software dos Sistemas Ciber-Físicos".

A evolução desta pesquisa e do PDIP levaram à readequação do foco desta pesquisa, para melhor aderência aos experimentos propostos pelo IPT, passando a investigar especificamente a portabilidade e interoperabilidade na camada de aplicação em Sistema Cíber-Físicos (SCFs).

Um SCF é um conjunto de tecnologias que integra processos físicos com sistemas computacionais e recursos de comunicação (SHI et al., 2011; BAHETI; GILL, 2011; LEE; BAGHERI; KAO, 2015), permitindo uma vasta gama de novas formas de interação entre as máquinas e homem-máquina. Possui potencial de aplicação em diversos setores, como o desenvolvimento de carros autônomos, dispositivos médicos, tecnologias aeroespaciais, próteses controladas por sinais cerebrais, transformação digital de indústrias e cidades inteligentes, entre outros, sendo que este trabalho focará neste último campo. Com a necessidade de alto grau de personalização de produtos, automatização e otimização de processos, integração entre os diferentes elementos da cadeia produtiva, como, por exemplo, os sistemas de fornecedores de peças e fabricantes, além outras demandas, os SCFs despontam como soluções para a transformação digital de indústrias, um dos princípios da chamada Indústria 4.0 (CHEN et al., 2018; ZHENG, 2015). Além disso, no tocante a cidades inteligentes, SCFs podem auxiliar no controle, regulação e monitoramento de processos em ambiente urbano, melhorando a qualidade de vida do cidadão, o uso de recursos, além de gerar maior sustentabilidade ambiental. Devido a possibilidades como essas, os governos de países como a China e a Alemanha, além de várias universidades ao redor do mundo, 
têm considerado pesquisas relacionadas a SCFs como grande prioridade, destinando muitos recursos a elas e proporcionando uma corrida (SHI et al., 2011).

Quando os SCFs estão conectados à Internet, eles são frequentemente chamados de sistemas de Internet das Coisas (IoT) (JAZDI, 2014). Assim, neste trabalho será chamado de loT especificamente aqueles SCFs conectados à Internet, ao passo que a nomenclatura SCFs será relacionada aos SCFs em geral, conectados ou não.

Todas as atividades previstas no projeto de pesquisa foram conduzidas nas instalações do IPT, mais precisamente no Centro de Tecnologia da Informação, Automação e Mobilidade (CIAM-IPT), sob a supervisão do pesquisador-líder Alessandro Santiago dos Santos e com o apoio das pesquisadoras Maria Rosilene Ferreira e Maria Cristina Machado Domingues.

Nesta introdução, a Seção 1.1 apresenta as razões pelas quais o tema foi selecionado para pesquisa. A Seção 1.2 apresenta os objetivos geral e específicos desta pesquisa. A Seção 1.3 apresenta a metodologia através da qual a pesquisa será executada. Por fim, a Seção 1.4 apresenta a estrutura da divisão deste trabalho.

\subsection{Motivação e Justificativa}

A loT está fazendo com que bilhões de dispositivos sejam interconectados de forma a criar uma rede inteligente que possibilita a troca de informações, permitindo soluções em identificação inteligente, localização, rastreamento, monitoramento, entre outros (CHEN et al., 2014). Além disso, essa grande rede de dispositivos gera uma quantidade massiva de dados, exigindo novas formas de coleta, gerenciamento, processamento e visualização desses dados (CAl et al., 2017). Faz-se necessário o desenvolvimento de aplicações que atendam a essas novas demandas e a outras que poderão surgir, uma vez que a loT tem o potencial de mudar a forma como as tarefas humanas são realizadas.

No entanto, o desenvolvimento de aplicações de loT é complexo, uma vez que a gama de tecnologias distintas envolvidas no processo pode ser numerosa, com vários tipos diferentes de dispositivos de hardware, protocolos de comunicação, algoritmos e outras tecnologias. Além disso, buscam-se princípios tais como escalabilidade, segu- 
rança, privacidade, consistência em comunicação e alta integração entre a heterogeneidade de dispositivos (KRANENBURG; BASSI, 2012).

Neste contexto, as plataformas ${ }^{1}$ de loT surgem como soluções onde um conjunto de recursos para desenvolvimento de aplicações são oferecidos, abstraindo a complexidade de desenvolvimento em maior ou menor grau, com a finalidade de permitir ao desenvolvedor a criação de aplicações orientadas ao negócio. Resumidamente, podese definir a plataforma de loT como um software que permite o controle e monitoramento de endpoints de loT e a construção de aplicações que atendam aos requisitos de negócio (VELOSA et al., 2015).

Dentre os objetivos de pesquisa contemplados no PDIP-IPT está o de selecionar e testar plataformas computacionais capazes de dar suporte a aplicações de cidades inteligentes e de indústria avançada, com elaboração de experimento para cada uma dessas áreas. Essas plataformas precisam contemplar, entre outras, as necessidades de aplicações envolvendo sistemas conhecidos como loT, os quais envolvem grande quantidade de dispositivos heterogêneos como sensores, atuadores, microcontroladores, smartphones, tablets, enlaces, etc.

Atualmente, existem diferentes plataformas de loT, públicas e privadas, sobre as quais se implementam aplicações para indústria, cidades inteligentes, entre outros domínios de negócio, através de um conjunto de recursos oferecidos por cada uma delas. No entanto, essa variedade de plataformas introduz problemas quanto à portabilidade das aplicações construídas tendo como base alguma dessas plataformas, uma vez que cada uma tem suas especificações e protocolos próprios, dificultando a migração de aplicações entre elas. Além disso, a interoperabilidade também é um desafio, uma vez que pelos mesmos motivos aplicações de diferentes plataformas podem não trocar informações entre si. Há, ainda, o problema do vendor lock (Opara-Martins; Sahandi; Tian, 2014), situação na qual uma organização se vê virtualmente obrigada a usar a plataforma de um determinado fornecedor, seja por razões legais, seja pelo alto custo de migrar suas aplicações para outro fornecedor, uma vez que necessitaria fazer uma nova implementação das mesmas, necessitando de recursos monetários, humanos, infraestrutura, tempo, entre outros.

\footnotetext{
${ }^{1}$ Uma plataforma é um ambiente virtual sobre o qual um software pode ser executado ou instalado (ISO, 2017).
} 
Neste trabalho, define-se portabilidade como a capacidade de um programa, chamado neste trabalho de aplicação, ser executado em vários tipos de sistemas, sem converter o programa para outra linguagem, com pouca ou nenhuma modificação. Como interoperabilidade, por sua vez, define-se como a capacidade de dois ou mais sistemas, produtos ou componentes poderem trocar informações usar a informação trocada (ISO, 2017).

Levando em conta que o baixo grau de portabilidade e interoperabilidade implica em custos de desenvolvimento, manutenção e capacitação de pessoal, neste projeto de pesquisa, denominado "Proposta de Camada de Portabilidade e Interoperabilidade para Aplicações em Plataformas de loT", propõe-se a criação de uma camada de portabilidade e interoperabilidade que poderá atuar na camada de aplicação de diferentes plataformas de loT e prover uma interface que possa ser usada para criar aplicações multiplataformas, permitindo maior reuso e economia de recursos, além da interoperabilidade entre as mesmas, permitindo a troca de informações. Assim, por exemplo, uma solução de cidade inteligente utilizada por um município e implementada com base em Fiware ${ }^{2}$ poderia ser utilizada ou reaproveitada em outro município com necessidades semelhantes, mas que já faz uso de outra plataforma, como a InterSCity (BATISTA et al., 2016) ou a Watson IoT Platform (WIP) ${ }^{3}$, por exemplo. Esta camada proposta foi nomeada Services on Top of Interoperability Components (SToIC).

Dentre as iniciativas que buscam endereçar questões de interoperabilidade em IoT, pode-se destacar a iniciativa loT-European Platforms Initiative (IoT-EPI) (VERMESAN, 2018), que contém um conjunto de diferentes projetos que visam prover interoperabilidade em diferentes níveis, com a finalidade de prover um ecossistema de loT no contexto da União Europeia (UE). No entanto, enquanto esses projetos focam em fazer com que os dados sejam trocados e entendidos, o presente trabalho de pesquisa foca também na portabilidade das funcionalidades oferecidas pelas plataformas na camada da aplicação, aqui chamadas de recursos.

Além disso, os projetos da loT-EPI são orientados no sentido de prover elementos para que fornecedores formem parcerias e possam integrar-se às suas soluções, que pode ser através da adoção e implementação de padrões oferecidos para tro-

\footnotetext{
${ }^{2}$ www.fiware.org

${ }^{3}$ internetofthings.ibmcloud.com
} 
cas de dados ou da utilização de bibliotecas. Este trabalho, por sua vez, oferece um processo definido que leva à integração de plataformas existentes à solução implementada, apresentado no Capítulo 4, sem que se necessite de convencimento do fornecedor. Além disso, embora haja um trabalho que busca endereçar a portabilidade de aplicações em Platform as a Services (PaaSs) (Kolb; Wirtz, 2014), não se encontraram trabalhos focados em portabilidade de aplicações em plataformas de loT em específico. A Tabela 1 apresenta três dos desafios listados pelo PDIP juntamente com a contribuição deste trabalho em relação aos mesmos.

Tabela 1: Desafios confrontados e as respectivas contribuições propostas neste trabalho.

\begin{tabular}{|c|c|}
\hline Desafio & Contribuição \\
\hline $\begin{array}{l}\text { Suporte em tempo real em comunicação, } \\
\text { processamento, observação, tomada de } \\
\text { decisão e ação. }\end{array}$ & $\begin{array}{l}\text { A camada de interoperabilidade per- } \\
\text { mitirá que aplicações multiplatafor- } \\
\text { mas possam ter acesso aos recursos } \\
\text { de comunicação, monitoramento, } \\
\text { processamento de dados e demais } \\
\text { recursos cuja demanda for detec- } \\
\text { tada em estudos de caso. }\end{array}$ \\
\hline $\begin{array}{l}\text { Incorporação de múltiplos dispositivos } \\
\text { heterogêneos como sensores, atuadores, } \\
\text { processadores, dispositivos de armaze- } \\
\text { namento de dados, microcontroladores, } \\
\text { e dispositivos de comunicação, operan- } \\
\text { do em sistemas físicos e ambientes } \\
\text { heterogêneos. }\end{array}$ & $\begin{array}{l}\text { Cada plataforma trata da comuni- } \\
\text { cação com sensores, atuadores, in- } \\
\text { teração humano-máquina e entre } \\
\text { máquinas de maneira particular. A } \\
\text { camada proposta permitirá o acesso } \\
\text { desses diferentes recursos, adotan- } \\
\text { do parâmetros de qualidade da inte- } \\
\text { ração como métricas. }\end{array}$ \\
\hline $\begin{array}{l}\text { Reconhecimento do contexto do estado } \\
\text { dos recursos, do meio físico e do do- } \\
\text { mínio geral do sistema. }\end{array}$ & $\begin{array}{l}\text { Serão detectados através de revi- } \\
\text { são da literatura e estudos de casos } \\
\text { componentes em diferentes platafor- } \\
\text { mas que provejam reconhecimento } \\
\text { do contexto a aplicações. }\end{array}$ \\
\hline
\end{tabular}

Fonte: Próprio autor.

\subsection{Objetivo}

O objetivo desta pesquisa é propor um modelo de camada de interoperabilidade e portabilidade no nível da camada de aplicação de plataformas de loT.

Uma visão conceitual do modelo pretendido é exposta na Figura 1. A camada proposta oferece $\mathrm{N}$ implementações, em cinza, sendo uma para cada uma das $\mathrm{N}$ ca- 
madas de aplicação das plataformas, em azul. Uma aplicação irá encontrar a mesma interface independente da plataforma.

Figura 1: Visão representativa da solução proposta.
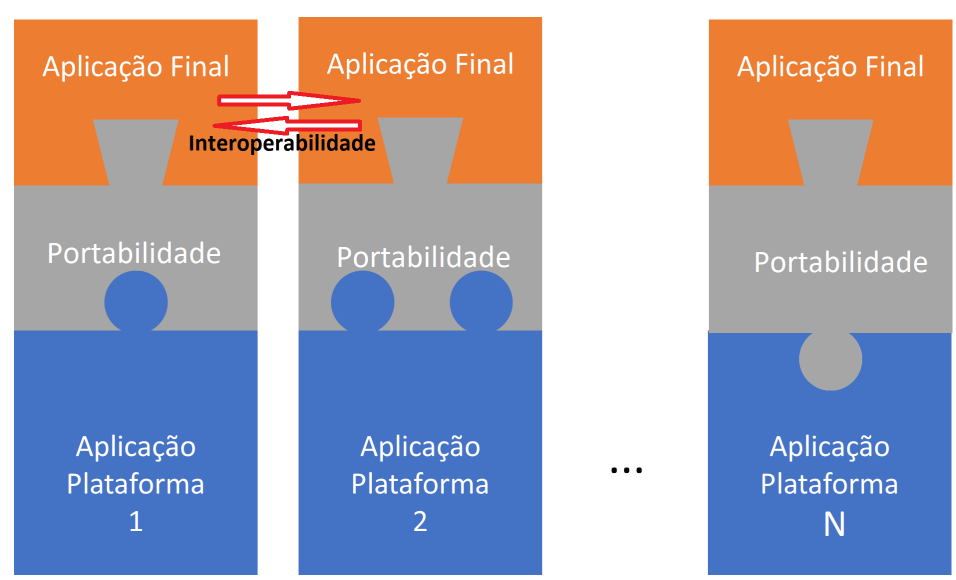

Fonte: Próprio autor.

\subsubsection{Objetivos Específicos}

1. Identificar os recursos oferecidos na camada de aplicação pelas principais plataformas de loT através de levantamento da literatura;

2. Projetar um modelo de camada de interoperabilidade e portabilidade na camada de aplicação de plataformas de loT;

3. Identificar plataformas-alvo e recursos necessários de acordo com os requisitos do estudo de caso selecionado;

4. Desenvolver uma prova de conceito do modelo de portabilidade e interoperabilidade para duas plataformas-alvo;

5. Discutir a prova de conceito desenvolvida;

6. Disseminar os resultados obtidos.

\subsection{Metodologia}

A metodologia desenvolvida para alcançar os objetivos desse trabalho consiste nas seguintes fases: 
1. Fazer uma revisão bibliográfica da literatura com a finalidade de identificar o estado da arte em recursos de plataformas de loT para a implementação de aplicações nas suas camadas de aplicação;

2. Definir critérios para seleção das plataformas de loT de interesse e, então, seleção das mesmas;

3. Gerar um estudo de caso em um campo de aplicação de loT para realizar os estudos das demandas por aplicações e serviços de cada uma das mesmas;

4. Desenvolver os modelos de camada de interoperabilidade para cada uma das plataformas selecionadas e adotando como alvo o estudo de caso gerado na fase 3 , fazendo uso dos recursos conforme encontrado na fase 1 ;

5. Analisar o modelo de camada proposto de acordo com parâmetros de interoperabilidade e portabilidade definidos de acordo com estudo da literatura;

\subsection{Estrutura do Trabalho}

Este trabalho está dividido em 9 capítulos. O Capítulo 1 é esta introdução. $O$ Capítulo 2 apresenta o estado da arte em recursos de plataformas de loT. O Capítulo 3 apresenta estudos de portabilidade e interoperabilidade com base na literatura. $O$ Capítulo 4 apresenta o projeto da camada de interoperabilidade e portabilidade, bem como o processo de implementação de prova de conceito da mesma. O Capítulo 5 apresenta uma dinâmica realizada para detecção de necessidades de projetos dos IPT e oportunidades de aplicações de loT. O Capítulo 6 apresenta os resultados da prova de conceito. Por fim, os Capítulos 7 e 8 apresentam a discussão e a conclusão, respectivamente. 


\title{
2 RECURSOS OFERECIDOS NA CAMADA DE APLICAÇÃO DE PLATAFORMAS DE INTERNET DAS COISAS (IOT)
}

Ao longo do tempo, diferentes plataformas de loT surgiram, com focos em diferentes soluções. Vários estudos secundários ${ }^{1}$ na literatura catalogaram plataformas de loT, focados em diferentes domínios de negócio, arquitetura, entre outros aspectos. Com a finalidade de prover uma visão geral do estado da arte em recursos ${ }^{2}$ de plataformas de loT, este capítulo apresenta uma revisão bibliográfica de natureza sistemática e terciária.

Este capítulo está dividido em seções. A Seção 2.1 apresenta um referencial teórico sobre loT, enquanto a Seção 2.2 apresenta modelos de referência que serão levados em consideração neste estudo. A Seção 2.3 apresenta a metodologia e o protocolo desenvolvidos para levantamento desta revisão terciária. As Seções 2.5 a 2.8 apresentam as respostas as questões de pesquisa. Por fim, a Seção 2.9 apresenta a conclusão do trabalho.

\section{$2.1 \quad$ IoT}

Segundo ITU-T (2017, p. 1), loT é

\begin{abstract}
Uma infraestrutura global para a sociedade da informação, permitindo serviços avançados ao intercomunicar elementos físicos e virtuais com base em tecnologias de informação e comunicação interoperáveis existentes e em evolução.
\end{abstract}

A loT abriu um vasto leque de possibilidades de pesquisa e desenvolvimento em vários campos diferentes do conhecimento tais como Redes, Inteligência Artificial, Computação Sensível ao Contexto e Sensores (AGGARWAL, 2013; YAN; ZHANG; VASILAKOS, 2014; GUBBI et al., 2013; CHEN, 2012). Nas áreas de aplicação, observam-se trabalhos em vários campos do conhecimento, das quais destaca-se, neste trabalho, a de Cidades Inteligentes, pelo interesse desta pesquisa.

\footnotetext{
${ }^{1}$ Um estudo secundário é uma revisão de artigos relacionados a um determinado tema que se quer pesquisar ou a questões de pesquisa (KITCHENHAM; CHARTERS, 2007).

${ }^{2}$ Neste trabalho, recursos são funcionalidades providas pelas plataformas de loT para uso das aplicações para que estas possam executar suas atividades.
} 
Cidades Inteligentes (ZANELLA et al., 2014) é um termo usado para nomear um ecossistema de dispositivos inteligentes conectados provendo serviços que melhorem a qualidade de vida dos cidadãos em diversos cenários, tais como economia de uso de recursos energéticos, semáforos trabalhando em conjunto, entre outros. Várias iniciativas nesse sentido têm sido desenvolvidas, como a Cidade Inteligente de Pádua, Itália, relatada por Zanella et al. (2014), onde se desenvolveram sistemas para saúde, redução do desperdícios de recursos, monitoramento de qualidade do ar, ruídos, engarrafamentos, estacionamentos, eficiência energética e insalubridade dos prédios.

Devido ao rápido crescimento da loT e desenvolvimento de soluções por diferentes players de mercado, surgiu uma variedade de tecnologias utilizadas e áreas de aplicação em loT. Devido a isso, diferentes organizações buscaram criar padrões dentro da área. Uma das formas que isso se deu foi através da criação de modelos de referência, que buscam oferecer uma visão conceitual e genérica dos componentes que integram uma arquitetura de loT, e será abordada na seção seguinte.

\subsection{Modelos de Arquitetura de Referência loT}

Na literatura, relata-se que o rápido crescimento da loT tornou difícil sua padronização e especificação, de forma que não há um modelo único de referência que seja um consenso entre a comunidade (BANAFA, 2016; BANDYOPADHYAY; SEN, 2011; XU; HE; LI, 2014). No entanto, pesquisas e órgãos reguladores de diferentes países mostram propostas de modelos de referência ou arquiteturas de loT. A International Telecommunication Union (ITU), órgão da Organização das Nações Unidas (ONU) representativo no nível mundial, define um modelo de arquitetura de referência em camadas para sistemas loT, conforme mostrado na Figura 2. Ele está dividido em quatro camadas e dois pilares transversais a estas camadas, sendo esta a descrição das mesmas:

\section{- Camadas}

- Aplicação: Contém as aplicações loT, que são programas diretamente relacionados à solução de problemas de negócio.

- Suporte a serviço e aplicação: São pacotes de recursos utilizados para 
Figura 2: Modelo de arquitetura de referência de acordo com a ITU.

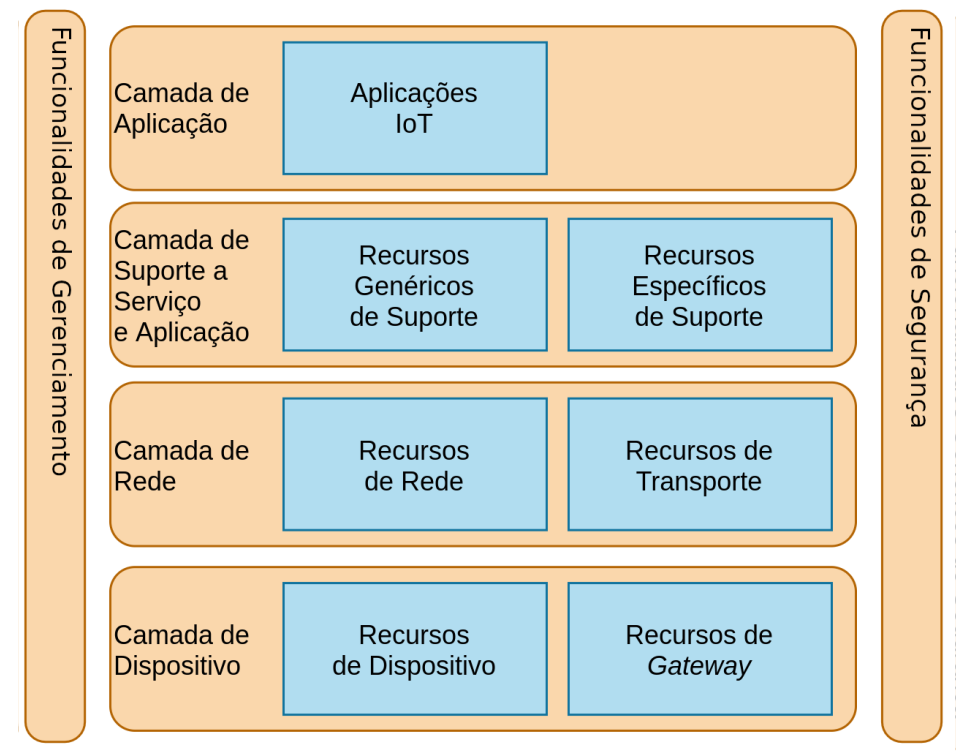

Fonte: ITU-T (2012).

dar assistência às aplicações, e estão divididos em dois grupos, recursos genéricos de suporte e recursos específicos de suporte. O primeiro grupo é formado por pacotes de uso geral de várias aplicações de loT, como processamento e armazenamento de dados, enquanto o segundo agrupa pacotes utilizados por aplicações específicas da área de negócio da aplicação.

- Rede Divide-se em dois grupos, recursos de rede e recursos de transporte. O primeiro se refere a funções de controle de rede, mobilidade, autenticação, autorização e gerenciamento de contas, enquanto o segundo trata de disponibilizar conectividade para o tráfego de dados das aplicações de loT e de informações de controle.

- Dispositivo: Também se divide em dois grupos, recursos de dispositivo e recursos de gateway. O primeiro inclui as funções de acesso direto a rede de dispositivos (como sensores, atuadores, entre outros), criação e manutenção de redes ad-hoc e ciclos de trabalho para economizar energia, enquanto o segundo trata-se de dispositivos de acesso ao meio físico via protocolos como LTE, PSTN, 2G, 3G, bluetooth, Zigbee, entre outros.

\section{- Pilares Transversais}

- Recursos de Gerenciamento: Este pilar transversal às camadas trata de funções gerenciais como transferência de dados sobre falhas, configura- 
ções, análise de desempenho, segurança, diagnósticos, ativação e desativação remota e gerenciamento de segurança. Podem ser genéricos, de uso geral, ou específicos, associados a uma aplicação em especial.

- Recursos de Segurança: O grupo dos recursos genéricos de segurança é independente de aplicação e tem funções diferentes de acordo com a camada. Na camada de aplicação, trata da autorização, autenticação, confidencialidade e integridade dos dados, privacidade, segurança e antivírus. Já na camada de rede, trata da autorização, autenticação, confidencialidade de dados de aplicação e sinalização. Por fim, na camada de dispositivos, trata da autenticação, autorização, validação da integridade do dispositivo, controle de acesso, confidencialidade, entre outros. Já o grupo dos recursos específicos de segurança é altamente atrelado a aplicações em específico.

O modelo de referência do ITU pode servir como um arcabouço para generalização das arquiteturas de plataformas de loT. Na dificuldade de encontrar um modelo de referência mais abstrato, (GUTH et al., 2016) propôs outro modelo de arquitetura, que é apresentado na Figura 3. Nele, a arquitetura consiste em uma camada de aplicação, onde estão os softwares finais que cuidam diretamente do negócio. Em seguida, vem o middleware de integração loT, que processa os dados de sensores de acordo com as regras definidas pelas aplicações e traduz dados vindo da aplicação em comandos para atuadores, podendo ainda enviar dados para a rede através do gateway. O gateway permite comunicação com outras redes e a Internet, fazendo interfaceamento entre vários protocolos, inclusive dos dispositivos. Por fim, o dispositivo se comunica diretamente com os sensores e atuadores, fazendo conversão analógica para digital (e vice-versa) e outras operações para transmissão e recebimento de dados dos dispositivos.

Ambos os modelos apresentados são suficientemente abstratos e genéricos, de forma que é possível representar as plataformas loT sob o ponto de vista dos mesmos. É recorrente nesses modelos e nas arquiteturas das plataformas uma camada geralmente chamada de aplicação, onde ficam os softwares que tratam diretamente da solução de problemas do domínio do negócio e fazem uso dos recursos providos pelas camada imediatamente abaixo. 
Figura 3: Modelo de arquitetura de referência de acordo com Guth et al. (2016).

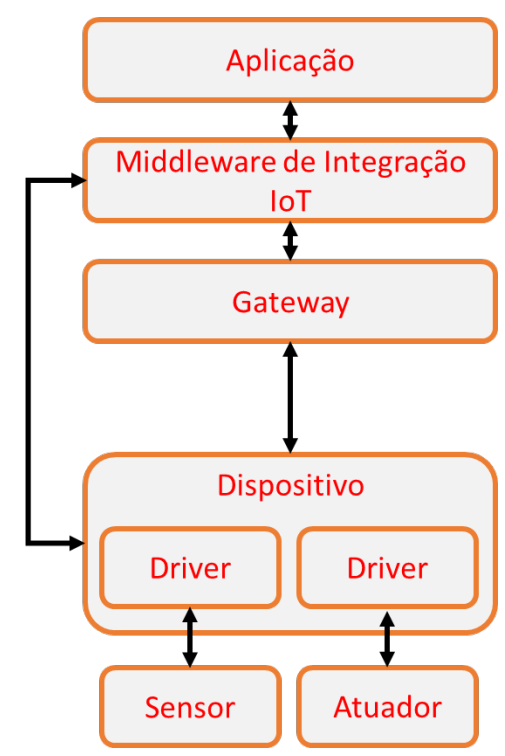

Fonte: Guth et al. (2016).

Com o objetivo de identificar os recursos disponíveis aos desenvolvedores de aplicações loT nas camadas de suporte a aplicação das diversas plataformas, procedeuse a uma revisão bibliográfica, que se apresenta na próxima seção.

As plataformas de loT levantadas na revisão da literatura são comparadas, utilizando como base o modelo de arquitetura de referência da ITU, de forma a evidenciar os recursos oferecidos na camada de suporte à aplicação.

\subsection{Metodologia e Protocolo de Revisão}

A busca original resultou em 3045 artigos, vários deles sendo estudos secundários relatando plataformas de loT existentes. Como vários destes trabalhos eram revisões, decidiu-se por realizar uma revisão terciária, isto é, uma análise de artigos de revisão no tema. Para realizar esta revisão terciária, utilizou-se o conjunto de diretrizes indicadas em Kitchenham et al. (2010), que consiste em uma sequência de passos bem definidos e replicáveis para gerar estudos baseados em evidências na área de Engenharia de Software. São estes:

1. Definição das questões de pesquisa;

2. Definição dos critérios de inclusão e exclusão;

3. Definição dos critérios de qualidade; 
4. Definição das fontes de dados, palavras-chave e string de busca;

5. Seleção de estudos;

6. Extração e síntese de dados;

Após isso, a partir dos estudos selecionados, listaram-se todas as plataformas de loT encontradas, desde as que estavam relatadas em artigos ou aquelas disponíveis na Internet, para uso comercial ou não, analisando os recursos disponibilizados na camada de suporte a aplicações e serviços, de forma a prover ao desenvolvedor de software loT uma visão geral destes recursos.

Ajustes na Metodologia Ao verificar-se o período da literatura coberta nos estudos selecionados pela revisão terciária, detectou-se uma lacuna nos anos de 2017 a 2019. Devido a isso, realizou-se uma revisão sistemática, isto é, com os estudos primários, nesse mesmo período, com a finalidade de detectar o estado da arte em plataformas de loT e recursos. A revisão realizada segue as diretrizes propostas por Kitchenham e Charters (2007). Estes serão descritos juntamente com os da revisão terciária nas seções 2.3.1 a 2.3.7, a seguir. Posteriormente, no ano de 2020, adicionou-se novos artigos que foram encontrados relacionados à string de busca.

\subsubsection{Questões de Pesquisa}

Para estruturação das Questões de Pesquisa (QP), usou-se o critério Polulação, Intervenção, Controle, Outcome (PICO), definindo cada item conforme segue:

- População - Desenvolvedores de Aplicações loT;

- Intervenção - Plataformas e Recursos de loT;

- Controle - Não se aplica;

- Outcome - Lista de estudos secundários com pontuação de qualidade e respostas às QPs;

A partir desta estrutura, definimos as seguintes QPs: 
Questão principal: Quais as plataformas de loT encontradas nos estudos secundários e quais os seus recursos na camada de aplicação?

\section{Questões secundárias:}

1. Como os estudos classificam as plataformas de loT e seus recursos?

2. Que tipo de projetos têm utilizado estas plataformas?

3. Quais os graus de maturidade destas plataformas e recursos?

Revisão Sistemática Na revisão dos artigos primários entre 2017 e 2019, mantiveram-se as mesmas questões da revisão terciária, com exceção da primeira questão secundária, que trata do agrupamento dos estudos. Assim,foram utilizadas as seguintes questões:

Questão principal: Quais as plataformas de loT encontradas nos estudos primários e quais os seus recursos na camada de aplicação?

\section{Questões secundárias:}

1. Que tipo de projetos têm utilizado estas plataformas?

2. Quais os graus de maturidade destas plataformas e recursos?

\subsubsection{Critérios de Inclusão e Exclusão}

Para a revisão terciária, selecionaram-se os seguintes critérios de inclusão e exclusão:

1. (I) Surveys e revisões sistemáticas da literatura relacionados a plataformas de loT publicados no período entre 2013 (inclusive) e 2019 (inclusive);

2. (I) Estudos disponíveis na Internet, em bases de artigos reconhecidas pela comunidade acadêmica;

3. (I) Estudos em língua inglesa;

1. (E) Artigos primários; 
Para a revisão sistemática, os seguintes critérios de inclusão e exclusão foram utilizados:

1. (I) Artigos relacionados a plataformas de loT publicados no período entre 2017 (inclusive) e 2019 (inclusive);

2. (I) Estudos disponíveis na Internet, em bases de artigos reconhecidas pela comunidade acadêmica;

3. (I) Estudos em língua inglesa;

1. (E) Artigos secundários;

2. (E) Trabalhos em andamento;

\subsubsection{Avaliação de Qualidade}

Para avaliação da qualidade do estudos secundários selecionados, definiu-se como método os critérios de Database of Abstract of Reviews of Effects (DARE). Quatro perguntas foram respondidas para cada um dos artigos, podendo ser respondidas com sim (valendo 1 ponto), não (valendo 0 ponto) e parcialmente (valendo 0,5 ponto). A lista a seguir apresenta as perguntas utilizadas para a avaliação:

1. Os critérios de inclusão e exclusão estão descritos e são apropriados?

2. A busca na literatura cobriu todos os estudos relevantes?

3. Os revisores avaliaram a qualidade dos estudos incluídos?

4. Os dados foram adequadamente descritos?

\subsubsection{Fontes e Método de Busca}

Selecionaram-se fontes de busca consideradas respeitadas pela comunidade acadêmica na área de Computação, conforme segue:

- ACM, em dl.acm.org; 
- IEEE Xplore, em ieeexplore.ieee.org;

- Web of Science, em webofknowledge.com;

- ScienceDirect, em sciencedirect.com

- Scopus, em scopus.com

A partir de busca exploratória, um conjunto de palavras-chave foi selecionado:

- Application

- Architecture

- Cyber Physical System

- Developer

- Ecosystem

- End User

- Framework

- Internet of Things

- IoT

- Middleware

- OS

- Operating System

- Platform

- Review

- Service

- State of the Art

- Survey 
Essas palavras foram combinadas em uma string de busca, com a finalidade de encontrar os estudos secundários desejados, conforme mostra a Figura 4. A string foi utilizada para busca nos campos de metadados, compreendendo o título, o resumo e as palavras-chave dos artigos.

Figura 4: String de busca definida no trabalho, com campos de metadados onde a busca foi realizada.

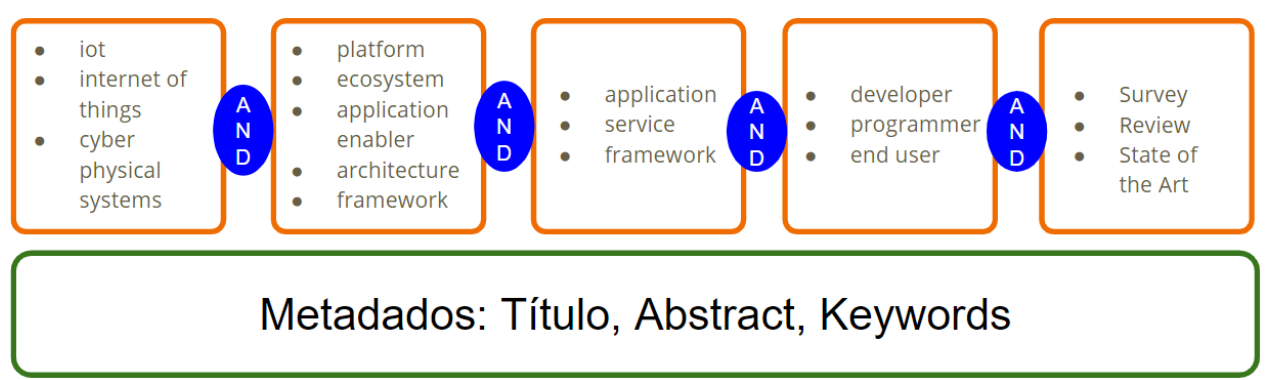

Fonte: Próprio autor.

Revisão Sistemática Utilizou-se a mesma string de busca, exceptuando-se pelas três últimas palavras-chave, que são relacionadas exclusivamente a revisão terciária.

\subsubsection{Extração de Dados}

Uma lista de dados foram extraídos dos estudos. Algumas vezes nem todos os dados estavam presentes em um trabalho. Foram eles:

- Fonte;

- Autores;

- Título;

- Resumo;

- Ano de publicação;

- Filiações dos autores;

- Tipo (survey ou revisão sistemática);

- Anos inicial e final de abrangência;

- Questões de pesquisa; 
- Diretrizes usadas;

- Quantidade de plataformas analisadas;

Revisão Sistemática Dos estudos primários, extraiu-se a seguinte lista de dados:

- Fonte;

- Autores;

- Título;

- Resumo;

- Ano de publicação;

- Filiações dos autores;

\subsubsection{Technology Readiness Level (TRL)}

Com a finalidade de medição dos graus de maturidades das plataformas selecionadas, utilizou-se a escala Technology Readiness Level (TRL) (NASA, 2012), criada pela NASA em 1974 como métrica de graus de maturidade de tecnologias espaciais, e adotada pela União Europeia no seu programa H2019, para medir graus de maturidade de tecnologias-chave. A Tabela 2 apresenta os diferentes níveis de TRL com suas descrições, indo do nível 1 , formulação da ideia, até o nível 9, ideia implementada em ambiente de produção final.

Tabela 2: Níveis de TRL e suas descrições.

\begin{tabular}{cc}
\hline TRL & Descrição \\
\hline 1 & Princípios básicos são observados \\
2 & Conceitos de tecnologia são formulados \\
3 & Prova de conceito em ambiente experimental \\
4 & Validação da tecnologia em laboratório \\
5 & Validação da tecnologia em ambiente relevante \\
6 & Tecnologia demonstrada em ambiente relevante \\
7 & Protótipo em ambiente de operação \\
8 & Sistema completo e qualificado \\
9 & Sistema comprovado em ambiente operacional \\
\hline & Fonte: NASA (2012).
\end{tabular}




\subsubsection{Processo de Seleção}

A lista inicial da revisão terciária incluiu 221 artigos resultante das buscas, cujas bases de origem são apresentadas no gráfico da Figura 5a. Para filtrar os estudos secundários de interesse a partir dessa lista inicial, utilizou-se de uma sequência de passos aplicando os critérios de inclusão e exclusão a cada etapa. Primeiramente, houve uma análise dos títulos, resumos e palavras-chave, conforme mostra a Figura 5b, e eliminação de duplicatas, resultando em 38 artigos. Em seguida, a introdução e conclusão de cada trabalho foram lidas para se verificar a aderência aos critérios de interesse, resultando em 36 artigos, como visto na Figura 5c. Por fim, analisando o corpo do artigo, chegou-se a 5 estudos secundários relevantes, conforme a Figura $5 \mathrm{~d}$.

Figura 5: Gráficos apresentando os estudos selecionados em cada etapa do processamento dos resultados da busca na revisão terciária.

(a) Origem dos resultados

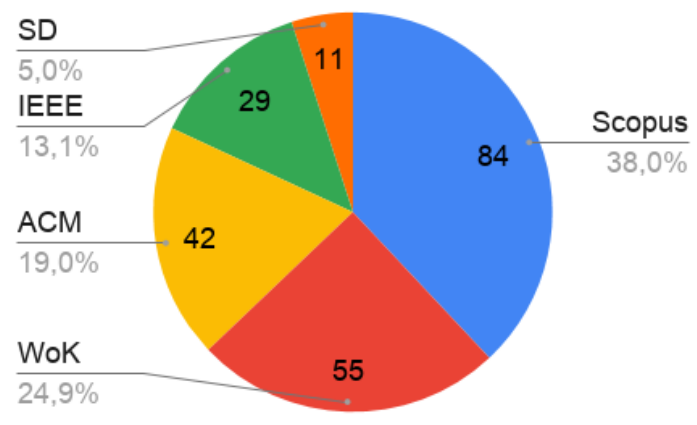

(c) Seleção por introdução e conclusão

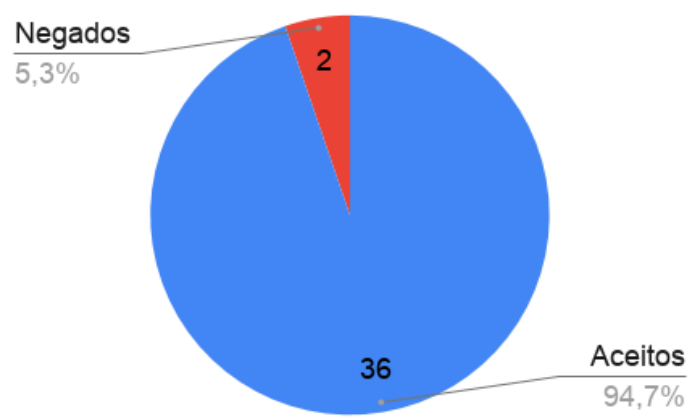

(b) Seleção por metadados

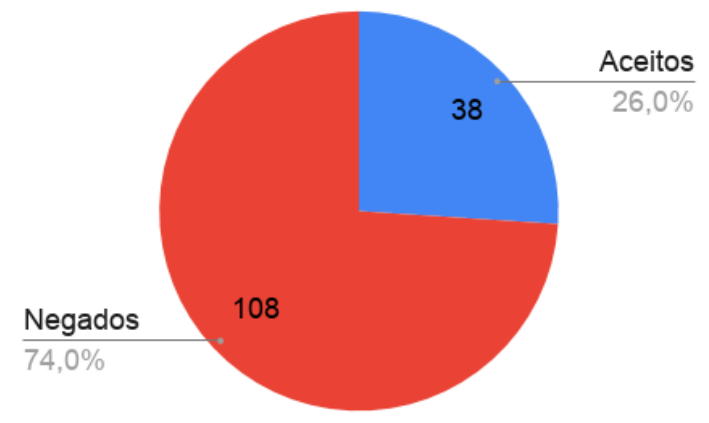

(d) Seleção por corpo do texto

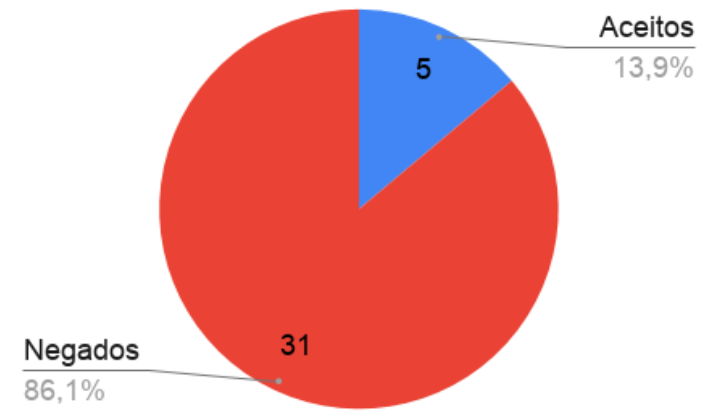

Fonte: Próprio autor.

Para a revisão sistemática, analogamente aos passos adotados para seleção de artigos na revisão terciária, partindo da lista inicial de 2642 estudos primários obtidos através das buscas. Na Figura 6 a tem-se as origens das bases. Em seguida, na Figura $6 \mathrm{~b}$ tem-se o resultado da seleção por metadados, isto é, título, resumo e palavras- 
chave. Logo depois, a Figura 6d apresenta o resultado da seleção por leitura da introdução e conclusão. Por fim, a Figura $6 \mathrm{~d}$ apresenta o resultado da leitura do corpo do texto, com 24 artigos selecionados.

Figura 6: Gráficos apresentando os estudos selecionados em cada etapa do processamento dos resultados da busca na revisão sistemática.

(a) Origem dos resultados

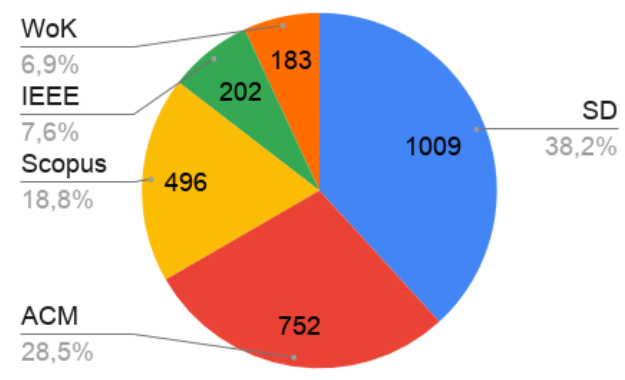

(c) Seleção por introdução e conclusão

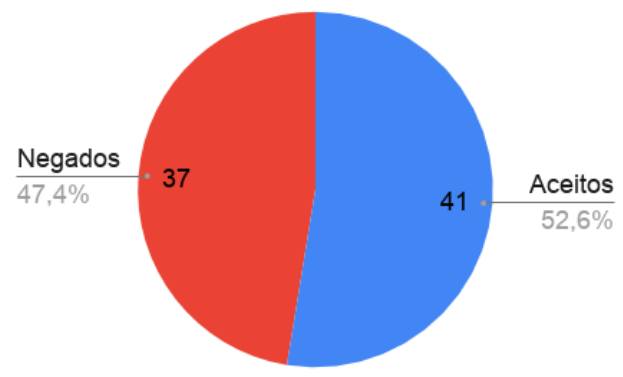

(b) Seleção por metadados

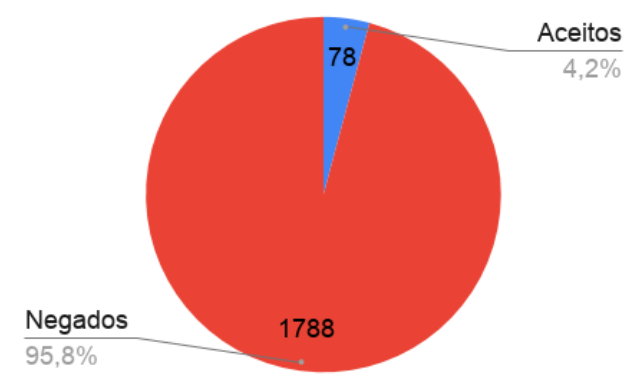

(d) Seleção por corpo do texto

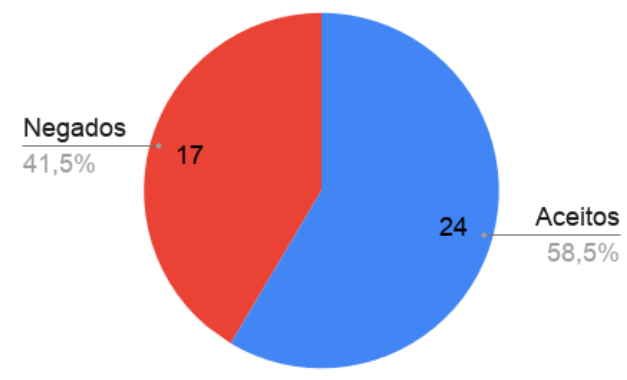

Fonte: Próprio autor.

\subsection{Estudos Selecionados}

Um arquivo com planilhas eletrônicas contendo dados dos estudos selecionados foi disponibilizado em um repositório online ${ }^{3}$. A primeira planilha apresenta a lista com os 5 estudos selecionados e seus atributos. Eles permitiram acesso a um conjunto de plataformas de loT, que foram analisadas e relatadas neste trabalho. A segunda planilha apresenta a abrangência dos estudos, considerando-se o ano em que os autores buscaram informações sobre as plataformas, como ano da publicação, quando a plataforma é descrita em um artigo, e ano de acesso, quando referenciou-se o sítio online da plataforma. Verificou-se que a literatura levantada pela revisão terciária não abrangeu a o período entre 2017, inclusive, e 2019, inclusive, o que motivou a revisão

\footnotetext{
${ }^{3} \mathrm{https}: / /$ gitlab.com/douglasllima/stoic-material-de-apoio-da-dissertacao
} 
sistemática. A terceira planilha apresenta os estudos encontrados nesta revisão. Por fim, a quarta planilha apresenta estudos adicionados à revisão em 2020.

\subsection{Respostas à Questão Principal}

Esta Seção responde à questão: "Quais as plataformas de loT encontradas nos estudos primários e quais os seus recursos na camada de aplicação?”.

As Tabelas 3 e 4 apresentam uma visão geral das plataformas de loT encontradas nos trabalhos secundários e primários, respectivamente, bem como os tipos de projetos onde estão sendo utilizadas, grau de maturidade, licença e forma de utilização das mesmas. Não entraram na lista plataformas que não estão mais em funcionamento. Além disso, algumas plataformas foram compradas e incorporadas a outras empresas ou tiveram seus nomes substituídos. 


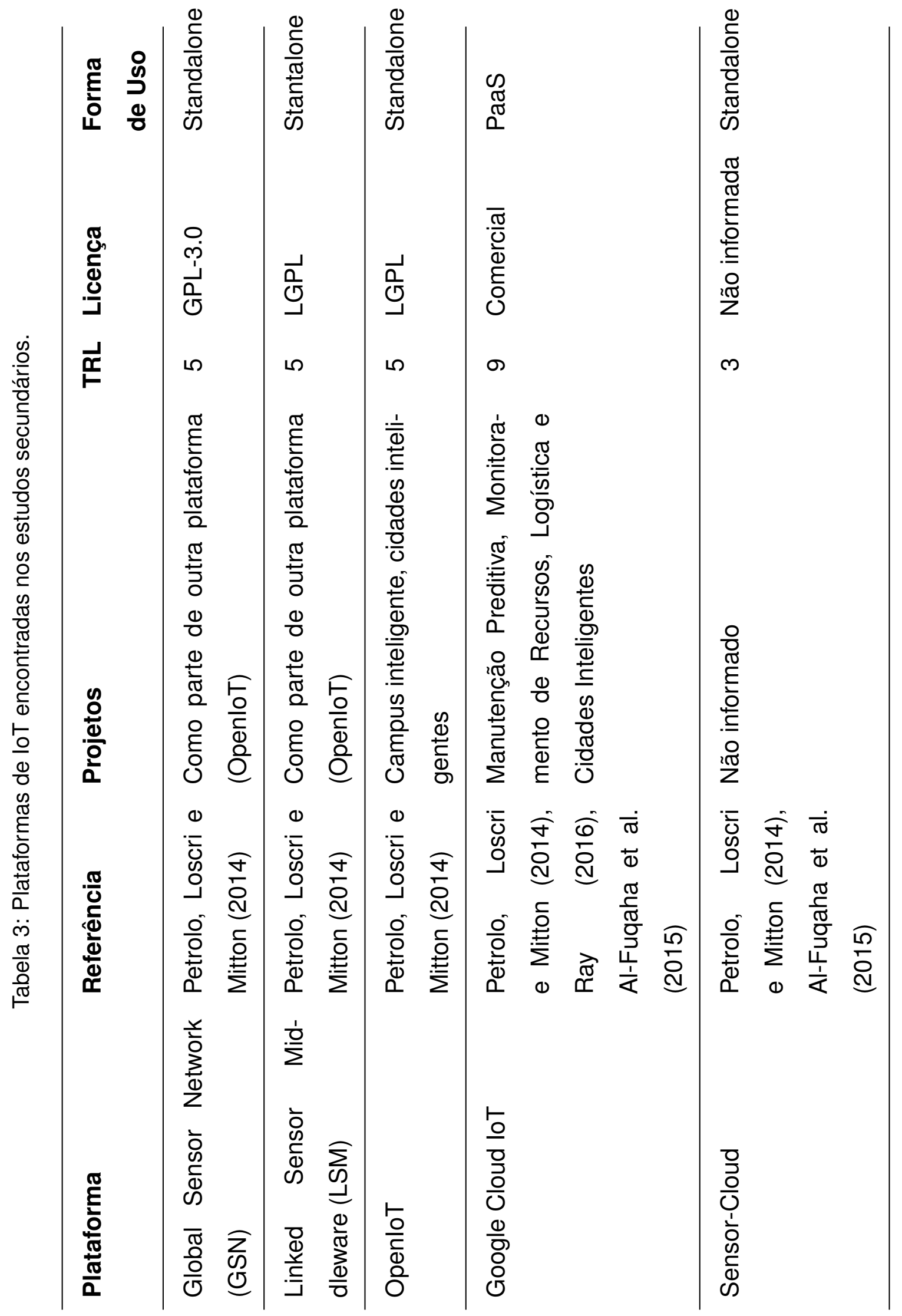




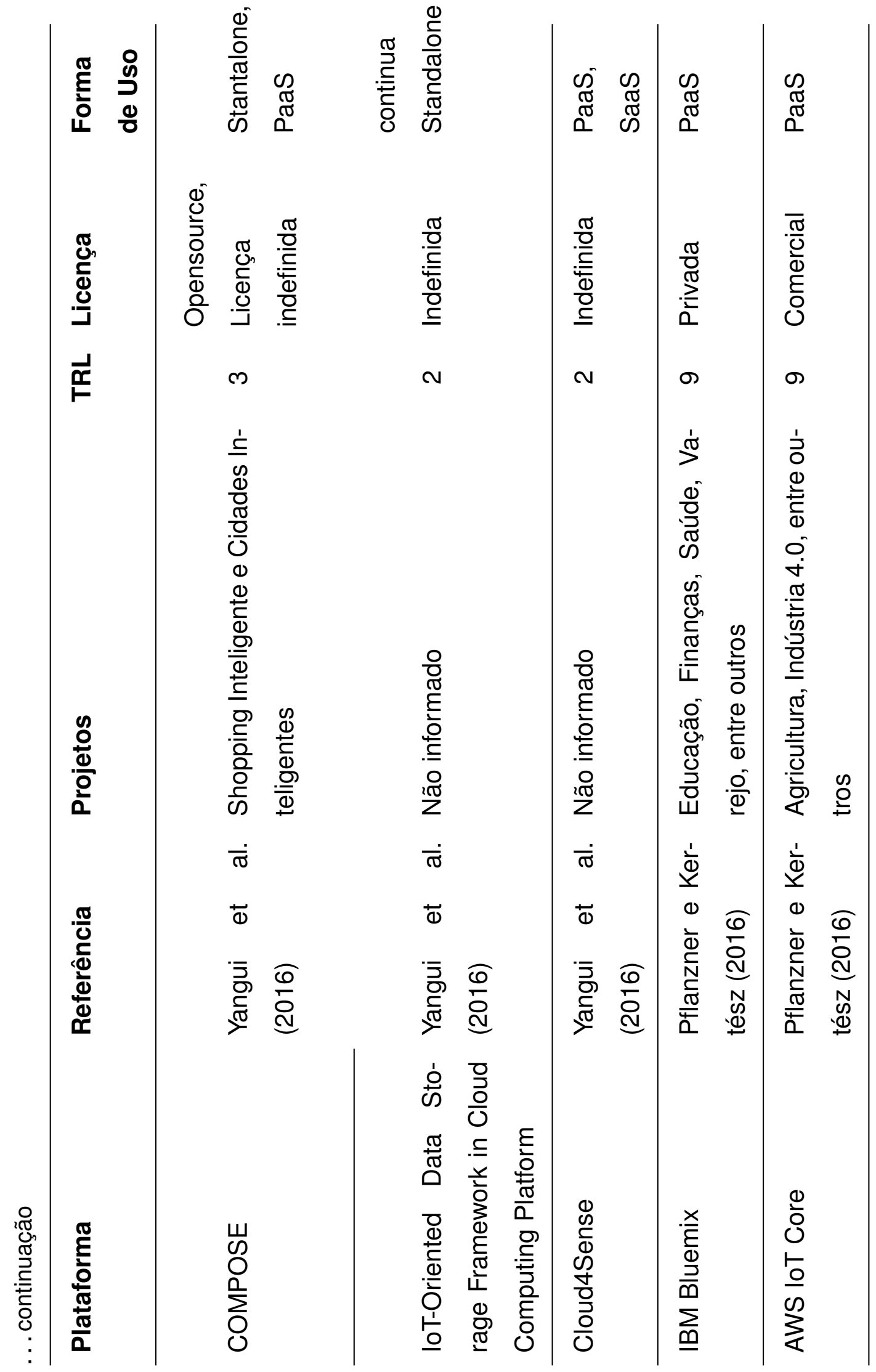




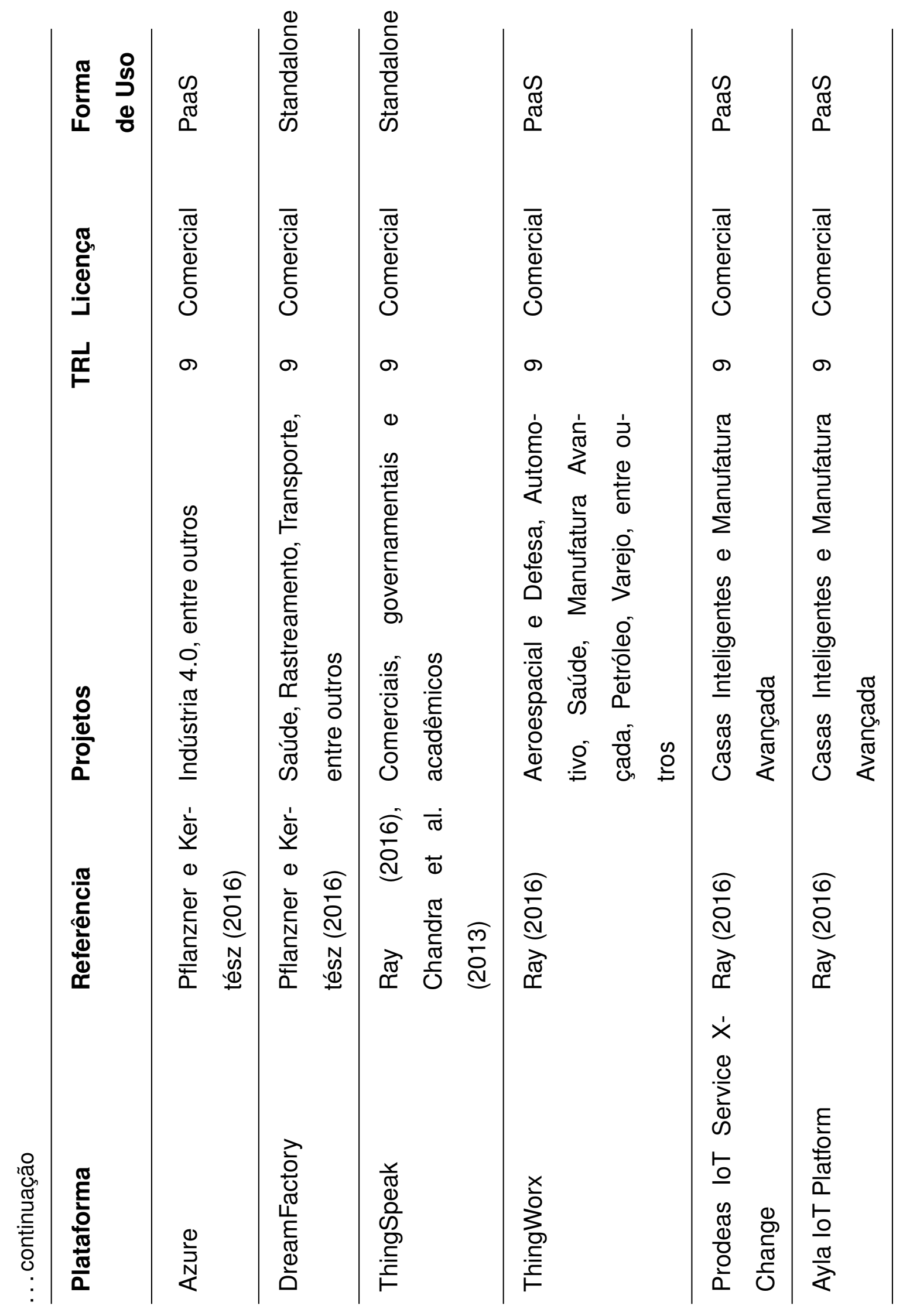




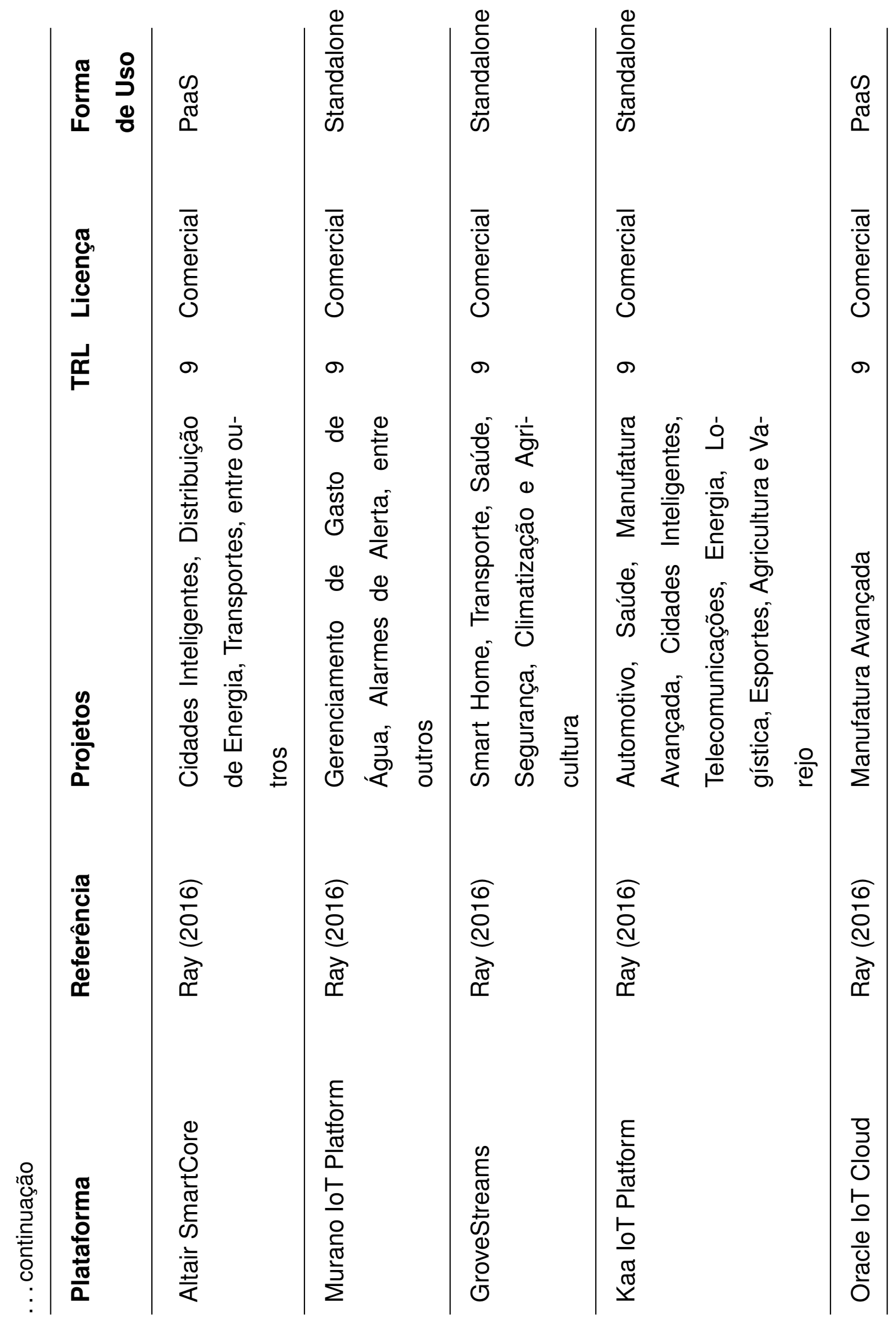




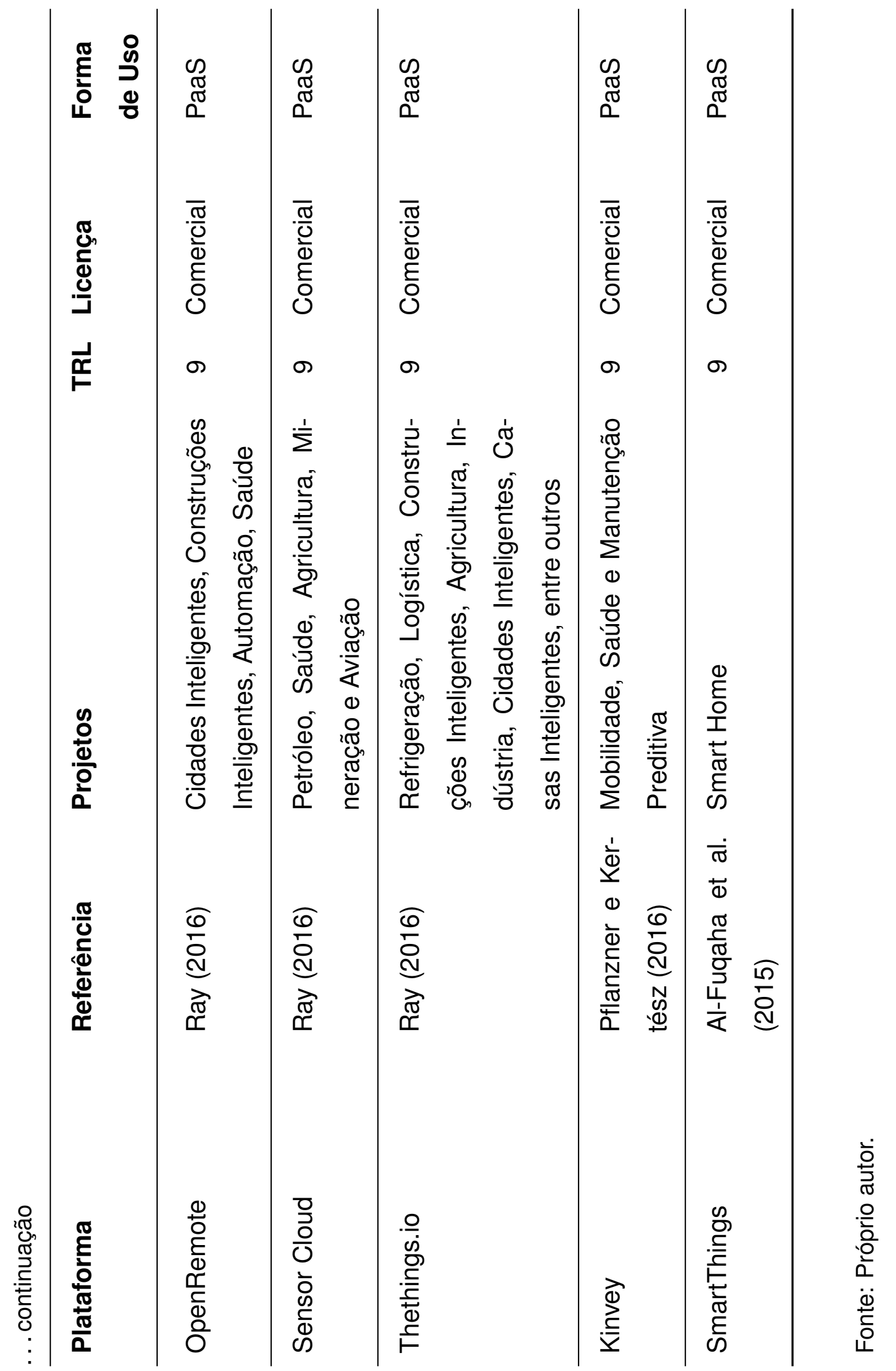




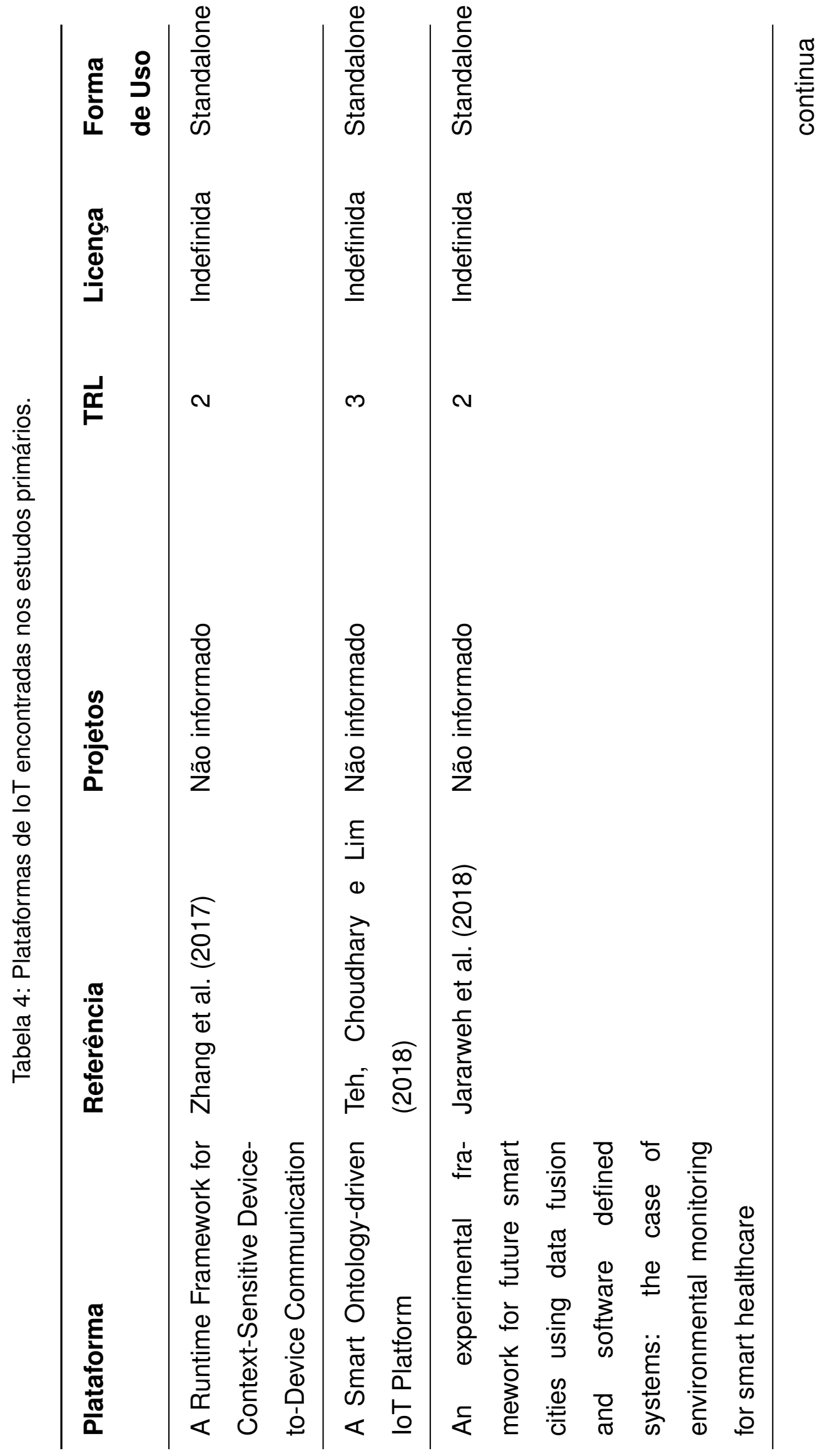




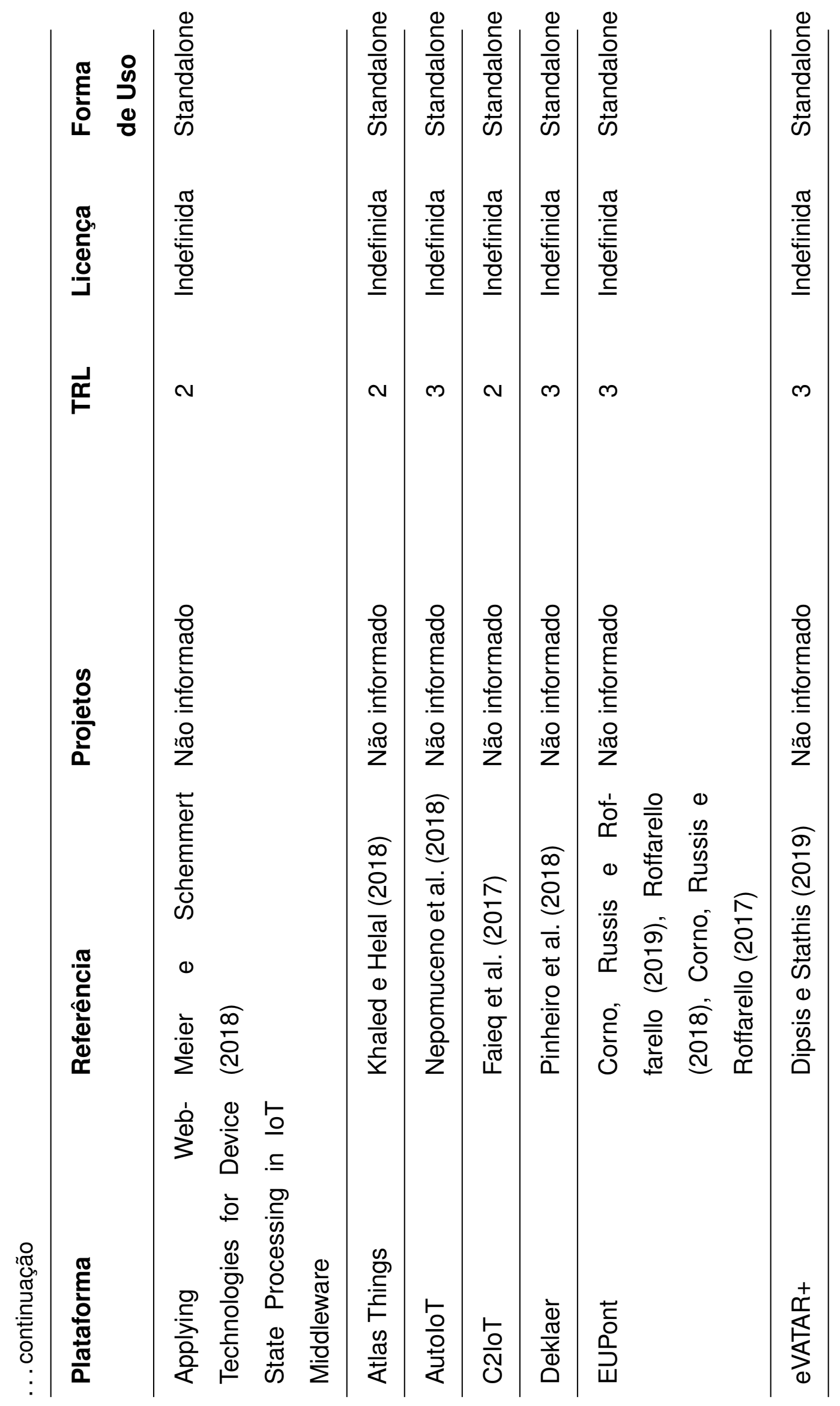




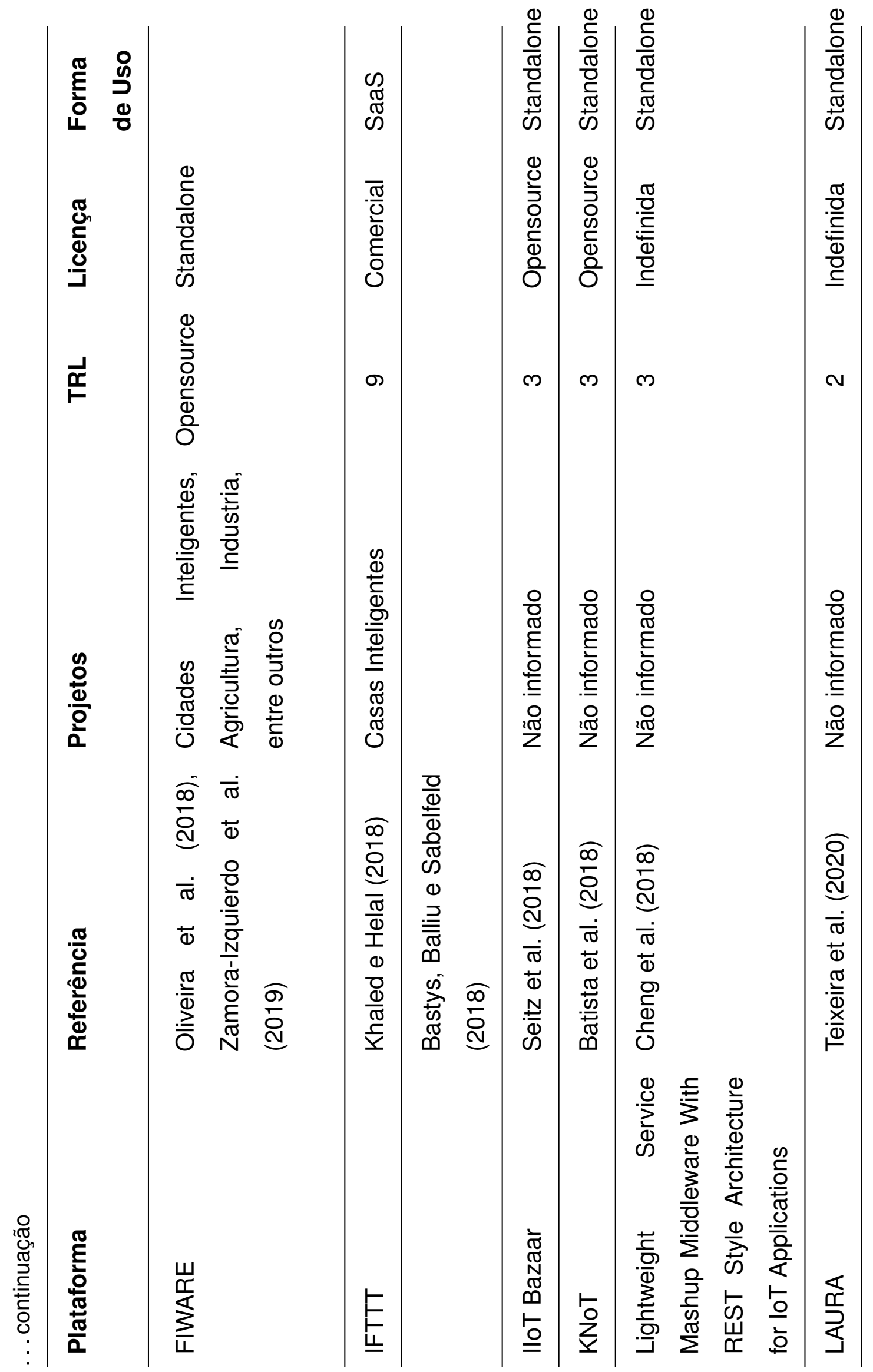




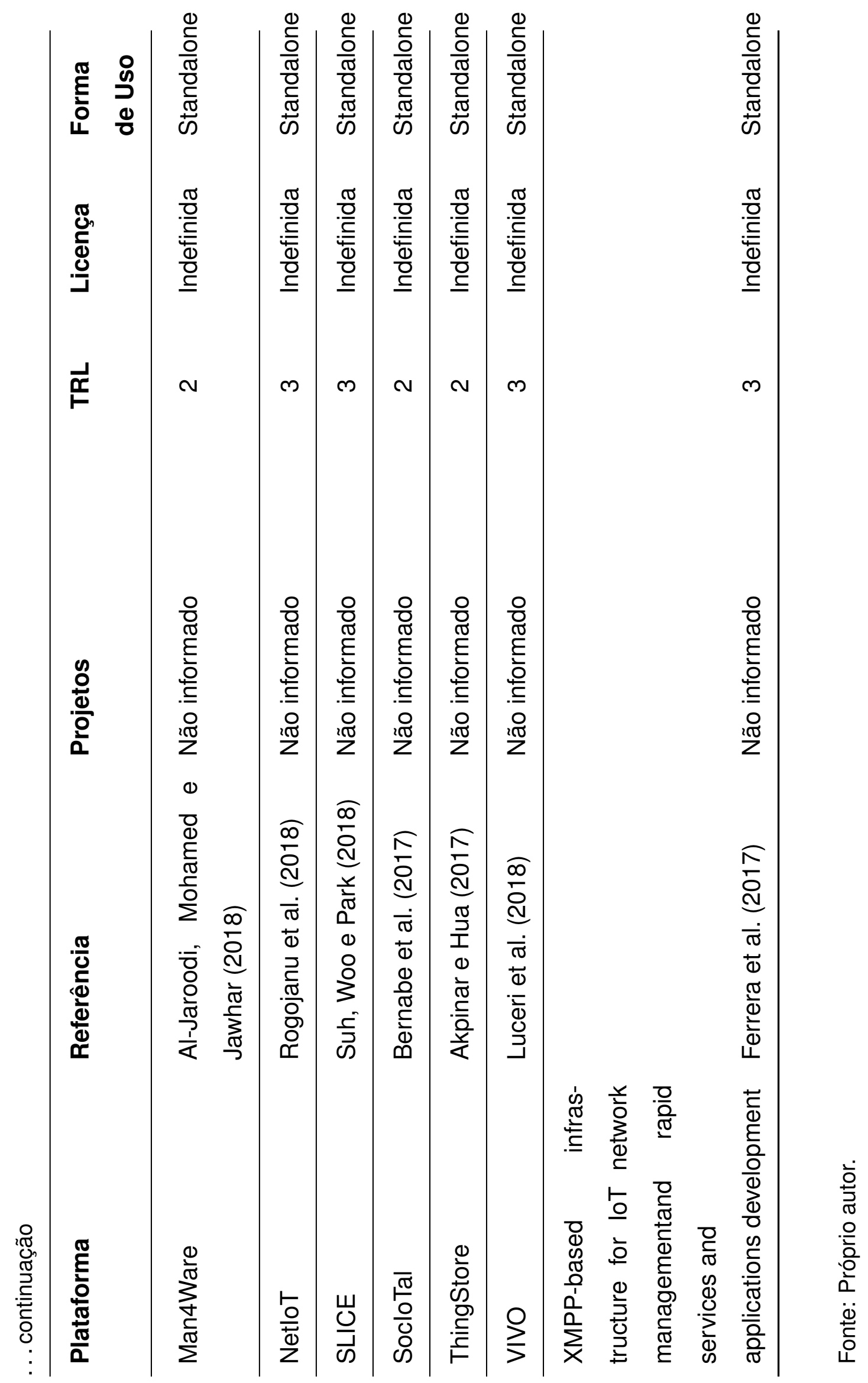


A partir das plataformas levantadas, detectou-se diferentes recursos oferecidos pelas mesmas aos desenvolvedores, disponibilizando-se a relação dos mesmos no $A$. Em seguida, agrupou-se estes recursos em 11 diferentes categorias, utilizando como critério o grau de similidade entre eles quanto às funcionalidades e propósitos dos mesmos, podendo um recurso pertencer a mais de uma categoria simultaneamente. A Tabela 5 apresenta comparativamente as categorias de recursos detectadas e esta seção também apresenta a definição de resumos das categorias de recursos presentes nas plataformas.

- Abstrações de Dispositivos: São recursos que abstraem a funcionalidades de dispositivos, fazendo com que a complexidade inerente a variedade de dispositivos se torne menor.

- Painéis de Controle: São recursos que auxiliam o administrador no gerenciamento e manutenção da plataforma e seus recursos, podendo estes serem de hardware, software, rede, energia, entre outros. Nas plataformas de loT, estes painéis de controle recorrentemente proveem gerenciamento de dispositivos, usuários, autenticação, autorização, configuração de computação em borda e conexões através de protocolos.

- Serviços: São interfaces de comunicação através das quais funcionalidades são disponibilizadas através de endpoints, para comunicação com outras aplicações. A forma mais recorrente é através de webservices HTTP REST e SOAP, no modelo cliente-servidor, ou MQTT, no modelo publish-subscribe.

- Wiring Tools: São ferramentas visuais de programação de alto-nível que consistem em ligações entre blocos que representam comandos ou criação de fluxogramas.

- Disparadores de Mensagens e Notificações: São recursos que visam o envio massivo de mensagens e notificações para os mais variados tipos de dispositivos. Estas informações podem ser mensagens de controle, alertas de eventos ou simplesmente com foco em interação com o usuário.

- Software Development Kit (SDK): São bibliotecas, códigos-fonte, templates e 
afins para facilitar o desenvolvimento de aplicações, permitindo utilizar funcionalidades das plataformas dentro das aplicações finais.

- Big Data e Analytics: São recursos que tratam do processamento e armazenamento de grandes volumes de dados, com a finalidade de dar sentido e extrair conhecimento dos mesmos, gerando relatórios e estratégias de negócio.

- Inteligência Artificial (IA) e Machine Learning (ML): São recursos que permitem integrar classificadores e algoritmos de aprendizagem em aplicações.

- Marketplaces: No contexto deste trabalho, são diretórios onde o desenvolvedor ou usuário final pode encontrar ou disponibilizar componentes, aplicações, dados e outros produtos, que podem ou não ser comercializados, em forma de catálogo. Estes itens disponíveis podem ser integrados nas aplicações ou utilizadas como aplicações finais, dependendo da plataforma.

- Dashboards: São recursos de interface gráfica para criar painéis de visualização de dados através de gráficos, permitindo o monitoramento.

- Agendadores e Disparadores: São recursos que disparam ações à partir de um horário determinado, ou um evento esperado. 
Tabela 5: Tabela comparativa entre as plataformas de loT quanto aos seus recursos.

\begin{tabular}{|c|c|c|c|c|c|c|c|c|c|c|c|}
\hline Plataforma & $\begin{array}{c}\text { Abstração } \\
\text { de } \\
\text { Dispositivos }\end{array}$ & $\begin{array}{c}\begin{array}{c}\text { Painel } \\
\text { de } \\
\text { Controle }\end{array} \\
\end{array}$ & Serviços & $\begin{array}{l}\text { Wiring } \\
\text { Tools }\end{array}$ & $\begin{array}{c}\text { Mensagens } \\
\text { e } \\
\text { Notificações }\end{array}$ & SDK & $\begin{array}{c}\text { Bigdata } \\
\text { e } \\
\text { Analytics }\end{array}$ & $\begin{array}{l}\text { IA } \\
\text { e } \\
\text { ML }\end{array}$ & Marketplace & Dashboards & $\begin{array}{c}\text { Agendadores } \\
\text { e } \\
\text { Disparadores }\end{array}$ \\
\hline $\begin{array}{l}\text { A Runtime Framework for } \\
\text { Context-Sensitive Device- } \\
\text { to-Device Communication }\end{array}$ & & & & & & $x$ & & & & & \\
\hline $\begin{array}{l}\text { A Smart Ontology-driven } \\
\text { loT Platform }\end{array}$ & & & $x$ & & & & & & & & \\
\hline Altair SmartCore & & $x$ & & & & $x$ & & & & $x$ & $x$ \\
\hline $\begin{array}{l}\text { An experimental framework for } \\
\text { future smart cities using data } \\
\text { fusion and software defined } \\
\text { systems: the case of environmental } \\
\text { monitoring for smart healthcare }\end{array}$ & & & & & & & $x$ & & & & \\
\hline $\begin{array}{l}\text { Applying Web-Technologies for } \\
\text { Device State Processing in loT } \\
\text { Middleware }\end{array}$ & & & $x$ & & & $x$ & & & & & \\
\hline AutoloT & & & $x$ & & & $x$ & $\mathrm{x}$ & & & & \\
\hline Atlas Things & $x$ & & & & & $x$ & & & & & \\
\hline AWS IoT Core & & $x$ & & & & $x$ & & & & & \\
\hline Ayla loT Platform & & & & & & $x$ & & & & & \\
\hline Azure & & $x$ & $x$ & $x$ & $x$ & $x$ & $x$ & $x$ & & $x$ & $\mathrm{x}$ \\
\hline C2loT & & & & & & $x$ & & & & & \\
\hline Cloud4Sense & $x$ & & $x$ & & & & & & & & \\
\hline COMPOSE & & & & & & & & & $x$ & & \\
\hline Deklaer & & & & & & $x$ & & & & & \\
\hline DreamFactory & & $x$ & $x$ & & $x$ & $x$ & $x$ & & & $x$ & \\
\hline EUPont & & & & & & & & & & & $x$ \\
\hline eVATAR + & $x$ & & $x$ & & & $x$ & & $x$ & & & \\
\hline FIWARE & & $x$ & $x$ & & $x$ & $x$ & $x$ & & $x$ & $x$ & \\
\hline GSN & $x$ & & $x$ & & & $x$ & & & & & \\
\hline Google Cloud loT & $x$ & $x$ & $x$ & & & $x$ & $x$ & $x$ & $x$ & & \\
\hline GroveStreams & & $x$ & $x$ & & & & $x$ & & & $x$ & \\
\hline IBM Bluemix & & $x$ & & $x$ & & & $x$ & $x$ & $x$ & & \\
\hline IFTTT & & & & $x$ & & & & & & & $x$ \\
\hline IloT Bazaar & & & $x$ & & & & & & $x$ & & \\
\hline $\begin{array}{l}\text { loT-Oriented Data Storage } \\
\text { Framework in Cloud } \\
\text { Computing Platform }\end{array}$ & & & $x$ & & & & & & & & \\
\hline Kaa loT Platform & & & $x$ & & & $x$ & & & & & \\
\hline Kinvey & & $x$ & & & $x$ & & $x$ & & & & $\mathrm{x}$ \\
\hline KNoT & $x$ & & $x$ & & & & & & & & \\
\hline $\begin{array}{l}\text { Lightweight Service Mashup } \\
\text { Middleware With REST } \\
\text { Style Architecture for loT } \\
\text { Applications }\end{array}$ & & & $x$ & & & & & & & & \\
\hline LSM & & & $x$ & & & & $x$ & & & & \\
\hline LAURA & $x$ & & $x$ & $x$ & & $x$ & & & & & \\
\hline Man4Ware & & & $x$ & & & & & & & & \\
\hline Murano loT Platform & & & & & & & & & $x$ & & \\
\hline NetloT & & & $x$ & & & & & & & & \\
\hline OpenloT & & $x$ & & $x$ & & & $x$ & & & $x$ & \\
\hline OpenRemote & & & $x$ & $x$ & $\mathrm{x}$ & $\mathrm{x}$ & & & & $\mathrm{x}$ & \\
\hline Oracle loT Cloud & & & $x$ & & $x$ & $x$ & $x$ & & & $x$ & \\
\hline Prodeas loT Service X-Change & & & $x$ & & & & & & & $x$ & \\
\hline Sensor Cloud & & & $x$ & & & $\mathrm{x}$ & & & & & $\mathrm{x}$ \\
\hline Sensor-Cloud & $x$ & & & & & & & & & & \\
\hline SLICE & & & & & & $x$ & & & & & \\
\hline SmartThings & & $x$ & & & & $\mathrm{x}$ & & & & & \\
\hline SocloTal & & & & & & $x$ & & & & & $x$ \\
\hline Thethings.io & $\mathrm{x}$ & & & & & $x$ & & & & $x$ & \\
\hline ThingSpeak & & & $x$ & & & & $\mathrm{x}$ & & & $\mathrm{x}$ & $\mathrm{x}$ \\
\hline ThingStore & & & & & & & & & $x$ & & $x$ \\
\hline ThingWorx & & & & & & $\mathrm{x}$ & & & $\mathrm{x}$ & & \\
\hline VIVO & & & & & & $x$ & & & & & \\
\hline $\begin{array}{l}\text { XMPP-based infrastructure for } \\
\text { loT network management and } \\
\text { rapid services and applications } \\
\text { development }\end{array}$ & & $x$ & & $x$ & & & & & & & \\
\hline
\end{tabular}

Fonte: Próprio autor. 


\subsection{Respostas à Questão Secundária 1}

Esta Seção responde à questão: "Como os estudos classificam as plataformas de loT e seus recursos?".

Os estudos classificam plataformas de loT de diferentes formas, sendo mais evidente por propósito em termos de aplicações verticais, isto é, os domínios aos quais se destinam, ou por forma de infraestrutura. Petrolo, Loscri e Mitton (2014), Ray (2016), Al-Fuqaha et al. (2015) classificam as plataformas em domínios principais.

Yangui et al. (2016) classifica as plataformas em três categorias principais. A primeira delas é a "virtual vertical-based approach", quando vários recursos de infraestrutura são reunidos e oferecidos como um único recurso na camada de aplicação, relacionado a um domínio de negócio. A segunda trata-se da "service composition approach", que é quando a plataforma oferece um catálogo de recursos e o desenvolvedor os integra para formar sua aplicação. Por último, há a categoria "focus on sub-set of functionality", onde a plataforma se preocupa em alguma finalidade específica, mas não uma solução completa, como por exemplo monitoramento, visualização, entre outros. Pflanzner e Kertész (2016) não apresentou uma proposta de classificação.

\subsection{Respostas à Questão Secundária 2}

Esta Seção responde à questão: "Que tipo de projetos têm utilizado estas plataformas?".

De acordo com as Tabelas 5 e 6 do repositório online, as plataformas encontradas destinam-se aos mais diferentes domínios de aplicação, sendo os mais comuns Manufatura Avançada, Cidades Inteligentes e Casas Inteligentes. Algumas plataformas comerciais, como Azure, Bluemix e AWS, têm projetos críticos com grandes corporações. Um projeto ${ }^{4}$ entre a LG e a Amazon, por exemplo, utiliza o AWS IoT Core para dar suporte a uma estrutura onde diferentes dispositivos da LG se comunicam entre si via Wi-Fi para traçar um perfil comportamental do usuário. Outro projeto ${ }^{5}$,

\footnotetext{
${ }^{4}$ aws.amazon.com/pt/solutions/case-studies/lg-electronics

${ }^{5}$ computerworld.com/article/3487991/iot-cloud-and-machine-learning-giving-elevator-giants-a-
} 
entre a Kone e a plataforma Azure, conectam vários elevadores e permitem o controle da manutenção preditiva dos mesmos. Plataformas como o OpenloT, que estão sendo desenvolvidas em ambiente acadêmico, estão desenvolvendo projetos controlados dentro de ambientes universitários, relacionadas a Campus Inteligentes, como reserva de salas e identificação das mesmas utilizando RFID.

\subsection{Respostas à Questão Secundária 3}

Esta Seção responde à questão: "Quais os graus de maturidade destas plataformas e recursos?".

Conforme observado nas Tabelas 5 e 6 do repositório online, o grau de maturidade (TRL) das plataformas de loT encontradas estão entre 2 e 9 . O grau de maturidade máximo é encontrado principalmente entre as plataformas comerciais, previamente utilizadas em projetos críticos, inclusive de grandes corporações. Cloud4Sense, cujo grau de maturidade é 2, apresenta apenas a formulação da ideia, sem indicar a existência de uma prova de conceito. Projetos como Sensor-Cloud e COMPOSE, com grau de maturidade 2, apresentação provas de conceito, mas não apresentaram projetos em ambiente relevante. GSN, LSM e OpenloT, com grau de maturidade 5, foram testados em ambiente relevante.

\subsection{Considerações do Capítulo}

Neste capítulo fez-se uma revisão terciária, onde ao final de uma série de etapas selecionou-se cinco estudos secundários, de onde extraiu-se uma lista de plataformas e seus recursos para desenvolvimento de aplicações. Notou-se que os recursos mais recorrentes são os de disponibilização de webservices e criação de painéis de monitoramento. Além disso, introduziu-se duas plataformas de IoT que não foram encontradas na revisão terciária.

As plataformas com maior grau de maturidade são as comerciais, havendo vários projetos em ambientes críticos com grandes indústrias. Também há plataformas que estão funcionando em ambiente controlado de laboratório ou não apresentaram prova lift.html 
de conceito. Dado o grande número de plataformas competidoras no mercado de loT e a diversidade de aplicações, fica evidente a necessidade de estudar os conceitos de portabilidade e a interoperabilidade em plataformas de loT, tema da próxima seção.

A Figura 7 apresenta uma adaptação do modelo de referência da ITU com as onze categorias de recursos oferecidas pelas camadas de aplicação como resposta à questão principal e os domínios para as quais as plataformas se destinam, que é uma das duas formas de classificação encontradas ao responder a questão secundária 2.

Figura 7: Visão geral das categorias de recursos oferecidos na camada de suporte a aplicação e verticais de mercado mais comuns das plataformas encontradas.

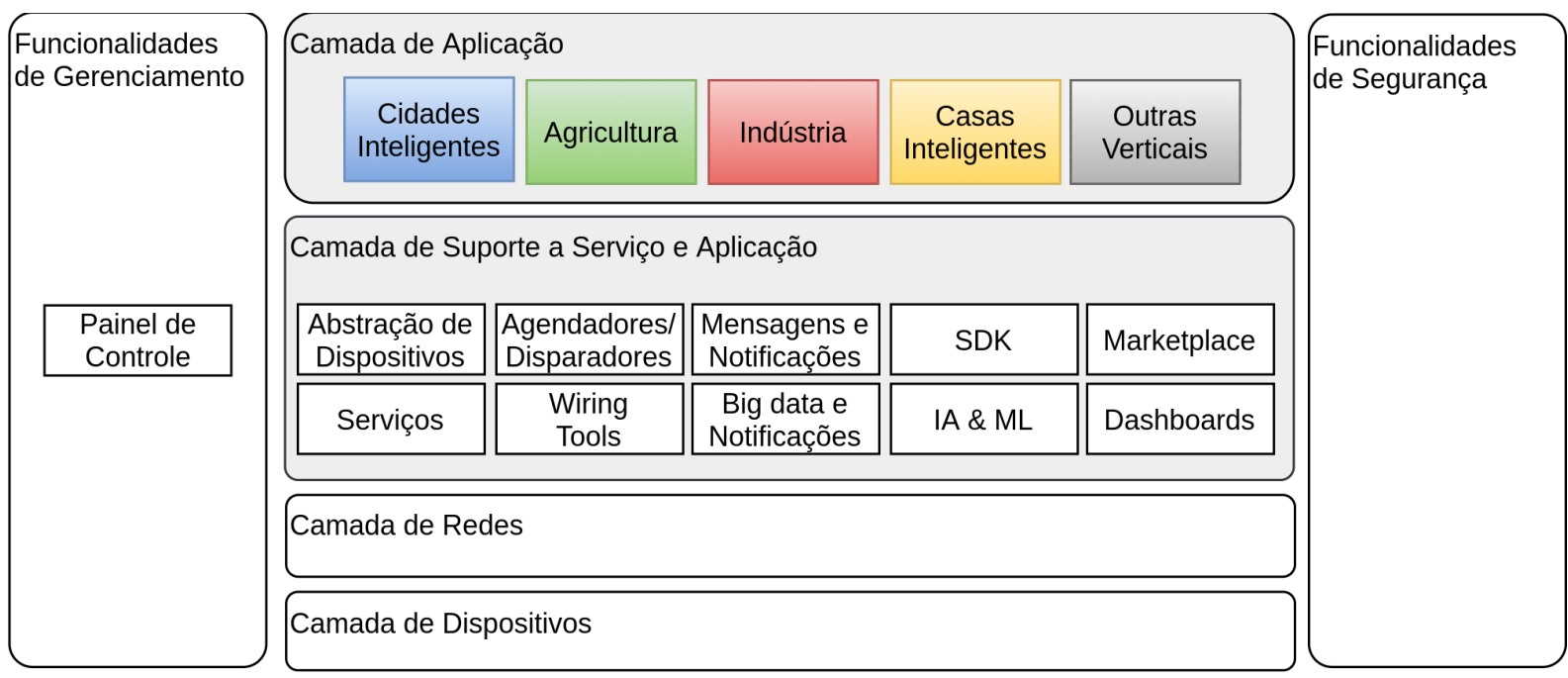

Fonte: Próprio autor. 


\section{PORTABILIDADE E INTEROPERABILIDADE NA CAMADA DE APLICAÇÃO}

Este capítulo apresenta o referencial teórico sobre os temas de portabilidade e interoperabilidade em loT.

A Seção 3.1 apresenta definições de portabilidade e interoperabilidade. A Seção 3.2, por sua vez, mostra os diferentes níveis em que a interoperabilidade pode ser implementada. Em seguida, a Seção 3.3 lista diferentes padrões de interoperabilidade. A Seção 3.4 exibe diferentes iniciativas de interoperabilidade e projetos. Por fim, a Seção 3.5 encerra o capítulo com as considerações finais.

\subsection{Definições}

A norma ISO/IEC 2382:2025 (ISO, 2015) define interoperabilidade como "capacidade de comunicar, executar programas ou transferir dados entre várias unidades funcionais de maneira que demanda que o usuário tenha pouco ou nenhum conhecimento das características únicas destas unidades". A norma ISO/IEC 25010:2011 (ISO, 2017) define portabilidade como a "capacidade de um programa ser executado em vários tipos de sistema de processamento de dados sem converter o programa para uma linguagem diferente e com pouca ou nenhuma modificação". Nessa norma, portabilidade se expressa com suas sub-características adaptabilidade, instalabilidade e facilidade de substituição.

As três sub-características de portabilidade são:

- Adaptabilidade: Grau em que um sistema pode ser adaptado para diferentes ambientes de hardware ou software.

- Capacidade de Instalação: Grau em que um sistema pode ser instalado ou desinstalado em um ambiente específico.

- Capacidade de Substituição: Grau em que um sistema pode substituir outro produto de mesmo propósito no mesmo ambiente. Pode incluir os dois itens anteriores. 


\subsection{Níveis de Interoperabilidade}

Diferentes projetos definiram métricas de interoperabilidade, tais como o Levels of Conceptual Interoperability Model (LCIM), que foi definido no contexto de modelagem e simulação (TOLK; MUGUIRA, 2003), European Interoperability Framework (EIF), criado para definir graus de maturidade no contexto das organizações da UE (IDABC, 2004) e European Telecommunications Standards Institute (ETSI) (VEER; WILES, 2008), criada para ser utilizada no contexto de IoT (VERMESAN, 2018) e definindo os quatro seguintes níveis de interoperabilidade:

- Técnico: Relacionado com protocolos de comunicação, infraestrutura e comunicação entre máquinas.

- Sintático: Associado com formatos de dados e codificações, como JSON, XML e HTML, por exemplo.

- Semântico: Relacionado ao comum entendimento da informação trocada.

- Organizacional: Associado com a capacidade de comunicar-se mesmo através de diferentes culturas, regiões geográficas e sistemas de informação.

\subsection{Padrões de Interoperabilidade}

Padrões são soluções de projeto recorrentes para um mesmo problema, que se manifestam seguidamente em diversas situações, com projetistas diferentes e independentes. Mais que uma solução pronta, o padrão de projeto é uma definição de como um problema frequente pode ser resolvido, acompanhada de exemplos e discussões de aplicação. Frequentemente, os padrões se inter-relacionam formando uma rede que permite resolver com elegância e eficiência a maioria dos problemas comuns numa área de aplicação. O uso de padrões simplifica as comunicações no contexto do projeto e garante a estabilidade da solução. O conceito de padrões de projeto vem da Arquitetura, com o trabalho de Christopher Alexander (ALEXANDER, 1977) sobre a intemporalidade das construções humanas e foi fortemente adotado na Engenharia de Software, onde se manifesta na programação orientada a objetos (em que o trabalho da Gang of Four é o principal exemplo (GAMMA, 1995)) e na Interação 
Humano-Computador, em que se destaca o trabalho de Jeniffer Tidwell (TIDWELL, 2010). Na Arquitetura dos sistemas computacionais (Buschmann et al) (BUSCHMANN et al., 2008), como nas diversas outras aplicações do conceito, padrões são usados para absorver a experiência de projetistas em problemas semelhantes.

Na mesma linha, para alcançar o objetivo de interoperabilidade em loT nos diferentes níveis, é crucial a definição de como os componentes se relacionam dentro do sistema. Bröring et al. (2017) definem cinco padrões genéricos de interoperabilidade (e também de portabilidade, como se vê a seguir), representados na Figura 8, e que são descritos da seguinte forma:

- Acesso interplataforma (Figura 8a): É o padrão no qual a aplicação acessa dados e funcionalidades de duas ou mais plataformas, sendo que estas proveem interfaces com a mesma especificação.

- Acesso interdomínio de aplicação (Figura 8b): Este padrão estende o padrão anterior, permitindo que aplicações e serviços possam não só acessar recursos de múltiplas plataformas como também de diferentes domínios de negócio.

- Independência de plataforma (Figura 8c): Permite que uma aplicação ou serviço possa ser utilizado sobre mais uma plataforma, de maneira portável.

- Independência de escala de plataforma (Figura 8d): Permite que aplicações ou serviços possam utilizar recursos de múltiplas plataformas independentemente do nível de escala, isto é, nuvem, fog, servidor, dispositivo, entre outros.

- Fachada de alto nível de serviços (Figura 8e): Estende o padrão acesso interplataforma de maneira que um serviço ou aplicação possa não só obter informações e funcionalidades de múltiplas plataformas como também de serviços, através da composição de serviços.

\subsection{Iniciativas de Interoperabilidade}

Governos de diferentes países ou blocos econômicos e políticos destacaram SCF, loT e áreas correlatas como estratégicas, designando instituições para regular, desen- 
Figura 8: Diferentes padrões de interoperabilidade.

(a) Acesso interplataforma

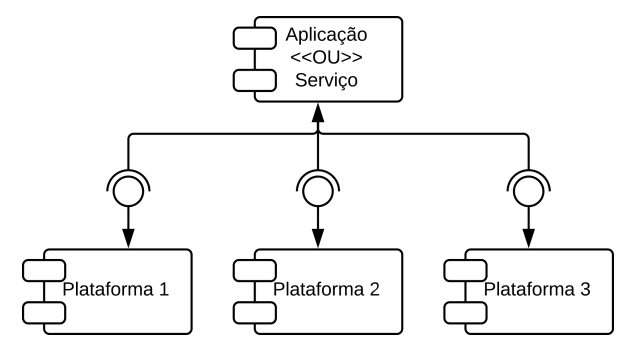

(b) Acesso interdomínio de aplicação

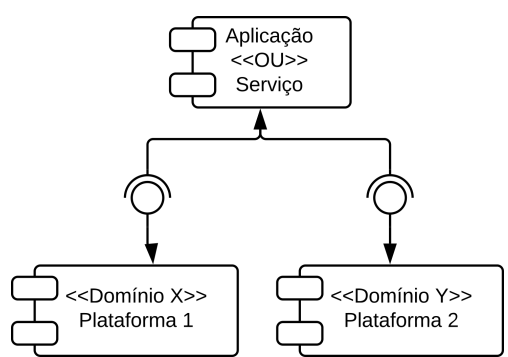

(c) Independência de plataforma

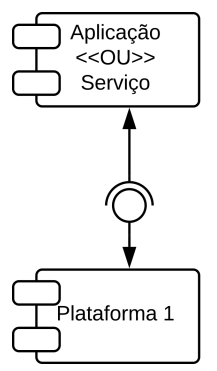

(d) Independência de escala de plataforma

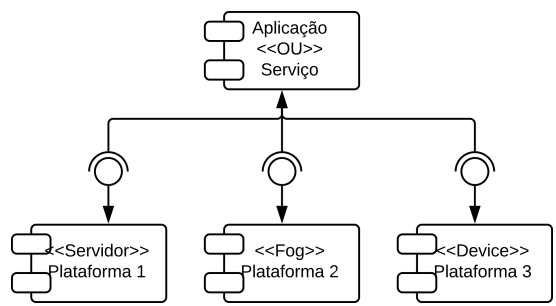

(e) Fachada de alto nível de serviços

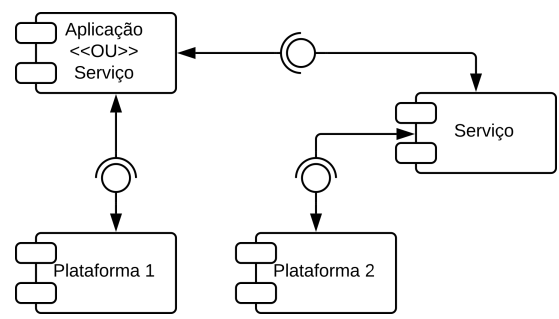

Fonte: Adaptado de Bröring et al. (2017).

volver padrões ou projetos nestas áreas, sendo uma preocupação recorrente a interoperabilidade em diferentes níveis. Esta seção apresenta algumas entre as principais iniciativas.

\subsubsection{National Institute of Standards and Technology (NIST)}

O International Technical Working Group on loT-Enabled Smart City Framework, pertencente ao NIST, busca remover dois obstáculos que dificultam a criação de soluções efetivas de cidades inteligentes, que são, segundo eles, o fato de que aplicações deste meio são baseadas em sistemas customizados, não-interoperáveis e não-portáveis entre as cidades; e o fato de as arquiteturas em desenvolvimento por 
diferentes organizações não se integrarem. Desta forma, o grupo compara diferentes padrões, especificações, arquiteturas, frameworks, modelos conceituais, plataformas, protocolos e outros para criar um framework consensual de funcionalidades em comum, que permite a criadores de soluções verificarem quais parâmetros seguir para se integrar a maior quantidade possível de soluções existentes, além de identificar potenciais pontos essenciais de interoperabilidade, chamados Pivotal Points of Interoperability (PPI) permitindo um melhor direcionamento de organizações ao criar padrões mais uniformes (FRAMEWORK, 2018).

\subsubsection{IOT-EPI}

Os projetos da loT-EPI ${ }^{1}$ abordam temas relacionados à criação de uma rede de plataformas de loT para dispositivos e objetos conectados que ofereça suporte a um ecossistema de serviços inteligentes. As áreas específicas de pesquisa são arquiteturas e interoperabilidade semântica. O objetivo do loT-EPI é aumentar o impacto da pesquisa e inovação europeias relacionadas a loT, e busca alcançá-lo através dos seguintes projetos:

- symbloTope ${ }^{2}$ : Provê uma camada de abstração para várias plataformas e recursos de sensoriamento e atuação. Aplicações podem utilizar plataformas compatíveis com o symbloTe e acessar recursos virtuais das mesmas para obter dados e atuar.

- bloTope ${ }^{3}$ : Oferece uma arquitetura e recomendações para o uso de padrões abertos, bem como implementações de casos de uso que permitem criar sistemas loT e serviços. Além disso, desenvolve Application Programming Interfaces (APIs) abertas para oferecer interoperabilidade. O padrão de interoperabilidade é o acesso interdomínio de aplicação.

- BIG IoT": Desenvolve uma API Web genérica e unificada para 8 plataformas parceiras e outras que colaboram através da comunidade. O projeto foca nas

\footnotetext{
1 iot-epi.eu

${ }^{2}$ symbiote-h2020.eu

${ }^{3}$ biotope-project.eu

${ }^{4}$ big-iot.eu
} 
camadas superiores e lida com questões de gerenciamento de segurança, APIs, integração de serviços, serviços externos, aplicações e o negócios.

- AGILE $^{5}$ : Desenvolve um gateway de hardware e software focando nas camadas física, rede, processamento, armazenamento e aplicação, e funcionalidades de gerenciamento de dispositivo, redes de comunicação para armazenamento distribuído.

- VICINITY6: Busca desenvolver interoperabilidade como um serviço para ecossistemas de loT. Seus trabalhos são nas áreas de integração de serviços, lógica de negócio, virtualização, armazenamento, APls, ferramentas, serviços externos de sistema, aplicação, análise de dados e serviços de nuvem.

- Inter-loT ${ }^{7}$ : Permite que diferentes plataformas possam ser interconectadas e interoperáveis em qualquer camada, inclusive semântica. Provê APIs e metodologias para que fornecedores de plataforma possam implementar interoperabilidade, inclusive diferentes domínios.

A Tabela 6 apresenta uma comparação entre os projetos da loT-EPI citados, considerando os níveis de interoperabilidade alcançados, como descritos na Seção 3.2, os padrões de interoperabilidade implementados, como descritos na Seção 3.3, e as camadas cujos projetos são focados, conforme o modelo de referência da ITU.

\footnotetext{
${ }^{5}$ agile-project.eu

${ }^{6}$ vicinity2020.eu

${ }^{7}$ inter-iot.eu
} 


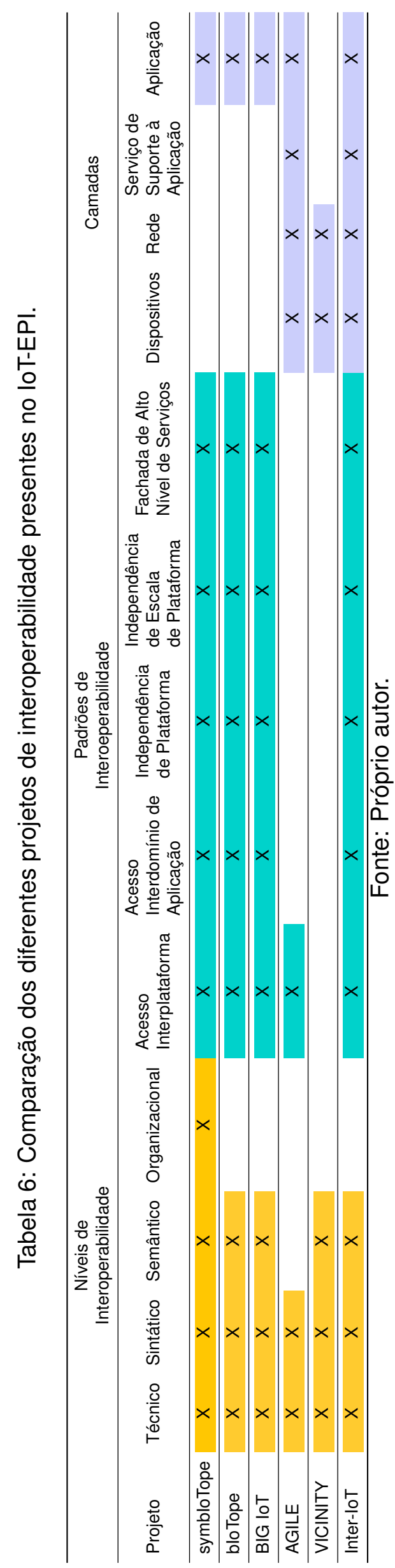




\subsubsection{Next Generation Service Interface (NGSI)}

O objetivo do NGSI é definir um padrão aberto de APIs de serviço que permita com que um serviço que o implemente possa fazer uso de outros serviços ou plataformas que também implementaram o padrão NGSI. Define um modelo de dados que abstrai elementos do mundo real como entidades e um modelo RESTful para acesso às informações ou funcionalidades. É utilizado pela plataforma Fiware como API padrão, sendo que o seu módulo Orion Context Broker uma implementação do padrão, de tal forma que qualquer habilitador, para ser compatível com o Fiware, basta que seja compatível com o padrão. O padrão também define princípios de subscrição e notificação, que permite que serviços possam receber dados de interesse, além do registro, que permite a uma plataforma utilizando NGSI, ao ser-Ihe solicitada uma entidade que não Ihe pertença, possa buscar outras plataformas que a contenha, sendo estas chamadas de Context Providers.

\subsection{Considerações do Capítulo}

Neste capítulo, apresentou-se o conceito de portabilidade e interoperabilidade, características da portabilidade, níveis, padrões de interoperabilidade e projetos que estão ligados a portabilidade e interoperabilidade.

Os níveis e padrões de interoperabilidade apresentados são utilizados no projeto do conceito de camada de portabilidade e interoperabilidade, que se apresenta no Capítulo 4. Além disso, a estratégia de analisar diferentes características de um conjunto de soluções para encontrar pontos em comum de interoperabilidade é abordada neste trabalho, diferindo pelo fato de que buscou-se analisar recursos oferecidos na camada de suporte a aplicação das diferentes plataformas de loT, como apresentado no Capítulo 2. 


\section{PROPOSTA E PROJETO DA CAMADA DE PORTABILIDADE E INTEROPERABILIDADE}

Este capítulo apresenta o projeto do modelo de camada de portabilidade e interoperabilidade para a camada de aplicação de plataformas de loT proposta neste trabalho. A este modelo, por facilidade, denominamos SToIC.

A Figura 9 apresenta um exemplo da abordagem de desenvolvimento de aplicações IoT tradicional, sem uso do SToIC. Cada plataforma tem um conjunto de recursos, como foi possível perceber no Capítulo 2. Para desenvolver uma aplicação de loT que possa ser executada sobre três diferentes plataformas, por exemplo, seria preciso criar três implementações da mesma aplicação, uma para cada plataforma, cada uma delas fazendo uso dos recursos próprios da plataforma em que foi implementada. Isto faz com que os custos de soluções para múltiplas plataformas sejam maiores, tanto em termos de tempo quanto financeiramente e em curva de aprendizado.

Figura 9: Representação de implementação de uma aplicação para três plataformas diferentes.

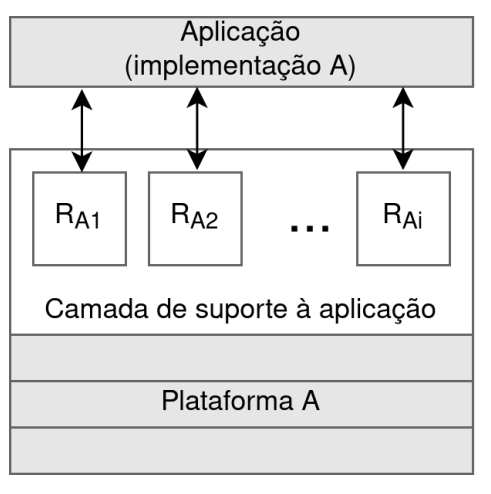

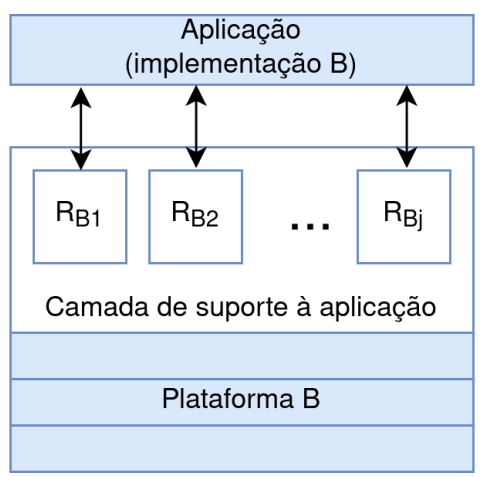

Fonte: Próprio autor.

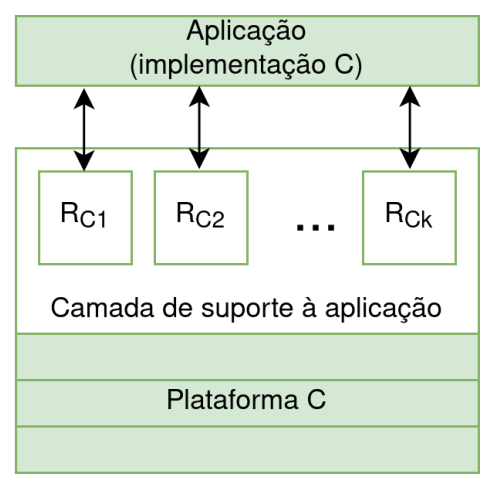

Plataforma C

Estas questões demandam uma solução que permita a criação de aplicações multiplataformas, conforme mostra a Figura 10. No exemplo da Figura 10, seja $R_{A n}$, sendo um recurso pertencente à plataforma $A$. Suponha-se que exista um recurso análogo a ele que pertence à plataforma $\mathrm{B}$ e outro na plataforma $\mathrm{C}, R_{B n}$ e $R_{C n}$, respectivamente. Um recurso genérico que abstrai as funcionalidades desses recursos é criado na camada de portabilidade, o SToIC, chamado $S_{A n}$. Este recurso abstrato terá, neste caso, três implementações, um para cada plataforma representada. Durante a execução da aplicação em uma camada construída numa determinada plataforma, o recurso abstrato $S_{A n}$ estará, de maneira transparente, utilizando o recurso abstraído na camada 
de suporte à aplicação da plataforma onde está sendo executada. O recurso $S_{A n}$, por sua vez, será utilizado pela aplicação multiplataforma, que poderá ser executada de maneira transparente nas plataformas compatíveis com a camada, o que levaria à economia orçamentária, menor curva de aprendizado e tempo de desenvolvimento, aumentando a produtividade geral.

Figura 10: Representação de implementação de uma aplicação para três plataformas diferentes utilizando a camada proposta neste trabalho.

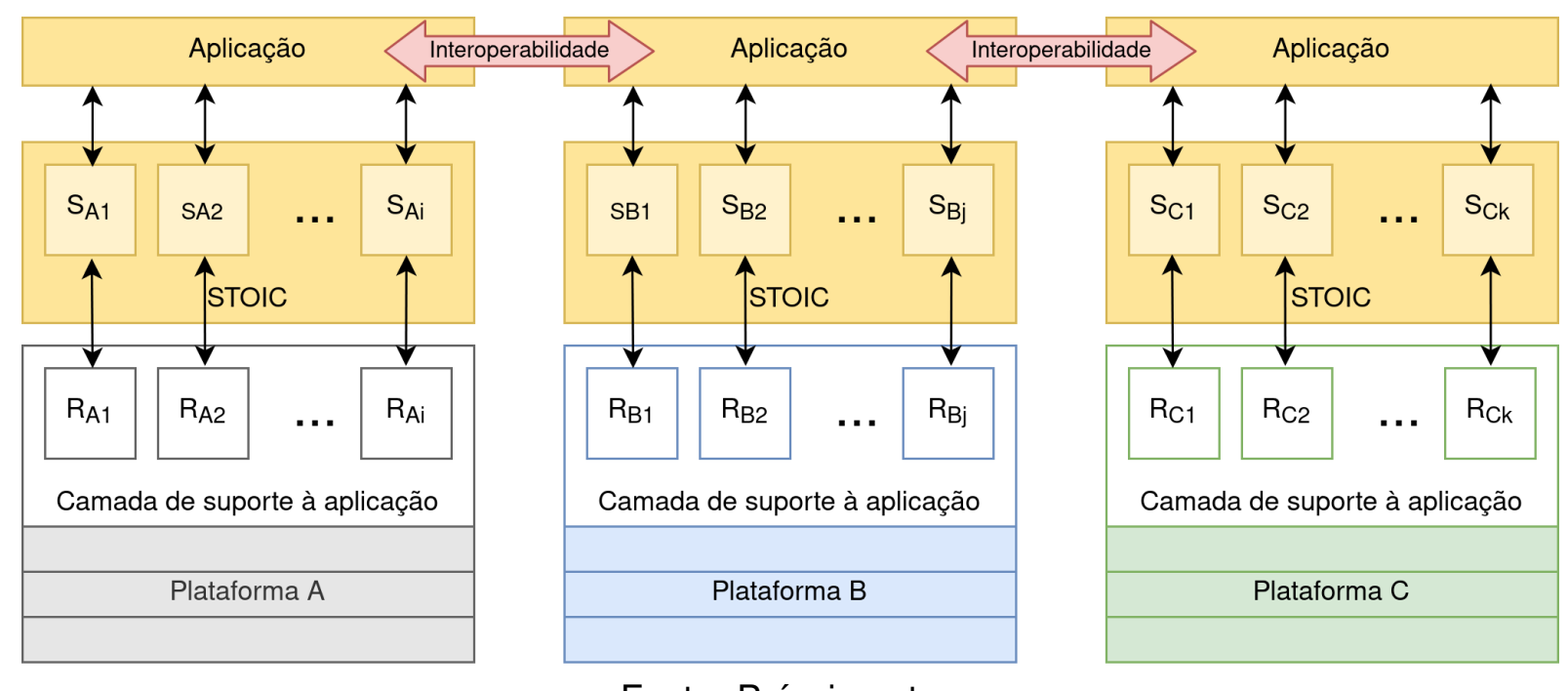

Fonte: Próprio autor.

As Seções a seguir apresentam o projeto do SToIC, que busca resolver o problema levantado nesta seção. As Seções 4.1 e 4.2 apresentam questões de portabilidade e interoperabilidade levadas em conta pelo conceito proposto. A Seção 4.3 apresenta o modelo de referência do conceito de portabilidade e interoperabilidade proposto. A Seção 4.4 apresenta cenários possíveis de interação entre os componentes da solução. Por fim, 4.6 apresenta as considerações finais do Capítulo.

\subsection{Portabilidade}

Para alcançar a portabilidade, propõe-se a criação de recursos abstratos no SToIC, chamados adaptadores abstratos. Para obter esses adaptadores, faz-se necessário analisar comparativamente os recursos oferecidos pela camada de suporte à aplicação das diferentes plataformas-alvo.

A Figura 11 apresenta o processo usado nesta análise. Primeiramente, deve-se listar quais são os recursos oferecidos pelas plataformas-alvo conforme mostrado na 
Figura 11a, tarefa que pode ser auxiliada pela lista de categorias encontradas no Capítulo 2 e na Tabela 5, que apresenta a lista de recursos oferecidas pelas plataformas levantadas na revisão descrita no Capítulo 2. Em seguida, deve-se detectar os recursos correlatos entre as plataformas-alvo, conforme a Figura 11b, verificando como os mesmos se comportam em cada plataforma. Por fim, como apresentado na Figura 11c, deve-se selecionar os recursos desejados para portabilidade.

O próximo passo é a modelagem do adaptador abstrato, que será a interface unificada que será utilizada pelas aplicações multiplataformas, projetando também os recursos abstratos que serão oferecidos, baseados nos recursos selecionados anteriormente, além da forma como estes recursos serão disponibilizados.

Após a definição do adaptador abstrato, faz-se a implementação de adaptadores para cada plataforma, para processar as chamadas das aplicações multiplataformas aos recursos abstratos mapeando-as para recursos reais na camada de suporte a aplicação nas plataformas, quando estas existem, ou realizando o processo localmente, quando o recurso real é faltante na plataforma.

Figura 11: Exemplo da análise comparativa dos recursos oferecidos na camada de suporte de aplicação as plataformas.

(a) Listagem dos recursos

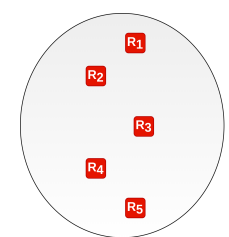

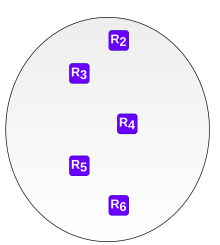

(b) Associação dos recursos

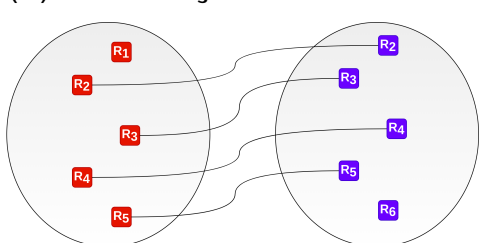

(c) Seleção de recursos desejados

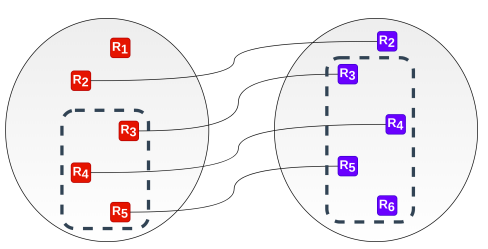

Fonte: Próprio autor.

Estas etapas permitem alcançar a portabilidade, de tal forma que uma aplicação multiplataforma pode utilizar os recursos das diversas plataformas atendidas pelos adaptadores abstratos. No entanto, necessita-se alcançar a interoperabilidade semântica entre estas plataformas, de tal forma que a informação trocada possa ser corretamente interpretadas e utilizadas, processo que será descrito na próxima se- 
ção.

\subsection{Interoperabilidade}

A Seção 3.2 mostrou que a interoperabilidade pode ser implementada em diferentes níveis, de tal forma que um nível depende da implementação dos anteriores. Desta forma, o nível semântico, que está relacionado ao entendimento mútuo da informação trocada, depende antes que os níveis técnico, relacionado aos protocolos de comunicação utilizados, e o sintático, relativo ao formato do dado transmitido, sejam obtidos. Estes três níveis foram considerados durante o projeto conceito de portabilidade e interoperabilidade.

Uma das formas mais comuns de alcançar a interoperabilidade semântica é através de ontologias, como mostrado por Serrano et al. (SERRANO et al., 2015), sendo um exemplo desta abordagem a Web Semântica (BERNERS-LEE; HENDLER; LASSILA, 2001), havendo também iniciativas em loT neste sentido (Palavalli; Karri; Pasupuleti, 2016). No entanto, esta abordagem depende do convencimento de fabricantes de plataformas de loT para adoção de padrões de ontologia e que estes sejam similares, para que a informação trocada possa ser corretamente interpretada.

No conceito apresentado neste trabalho, a abordagem para alcançar a interoperabilidade semântica consiste na análise comparativa dos modelos de dados das diferentes plataformas-alvo. Primeiramente, verifica-se as semelhanças e diferenças entre os modelos de dados das mesmas, procurando correlação entre os elementos. Desta correlação, redesenha-se um modelo de dados resultante, a ser utilizado pela aplicação multiplataforma. Por fim, cria-se um serviço, aqui chamado de Tangle ${ }^{1}$, cuja finalidade é observar mudanças nos elementos de interesse em cada plataforma e atualizar os elementos correlatos em todas as outras plataformas lidando com os protocolos, formato de dados e reestruturação dos dados corretos específicos de cada uma delas. Este comportamento pode ser resumido na Figura 12: ao ocorrer uma mudança de estado em uma entidade presente em uma das instâncias de plataforma, o Tangle é notificado e este (passo 1), por sua vez, envia requisições para outras ins-

\footnotetext{
${ }^{1}$ nome inspirado no fenômeno da Física Quâtica chamado emaranhamento quântico (quantum entanglement) (HORODECKI et al., 2009).
} 
tâncias de plataformas de loT para alterar as contrapartes da entidade nelas (passos 2 e 3).

Figura 12: Visão resumida do funcionamento do Tangle.

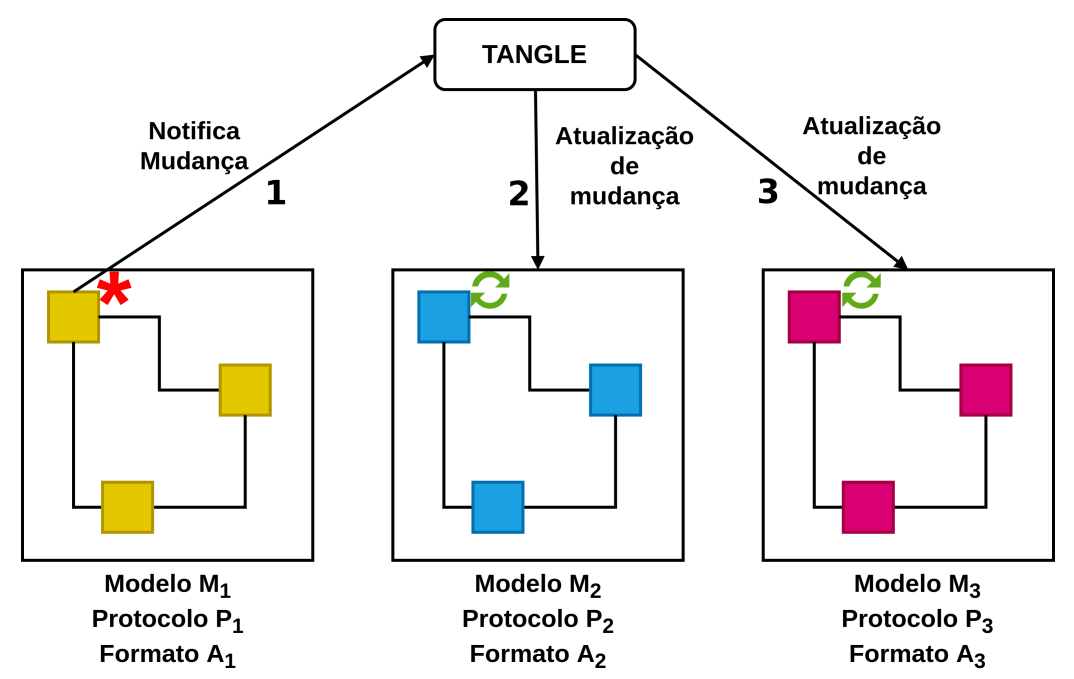

Fonte: Próprio autor.

\subsection{Modelo SToIC de Portabilidade e Interoperabilidade}

Após a definição de como se dá a portabilidade e interoperabilidade na camada de aplicação de plataformas de loT, determinou-se o modelo de referência exibido na Figura 13. Cada plataforma-alvo contém um adaptador na sua camada de aplicação que herda a interface abstrata e faz uso dos recursos na sua camada de suporte à aplicação. Convencionou-se chamar o serviço que gerencia os adaptadores de Core. Tangle é o serviço que fornece interoperabilidade semântica interagindo com o Core para trocar dados entre as plataformas. As aplicações multiplataformas interagem com o Core através de endpoints que disponibilizam os recursos abstratos. 


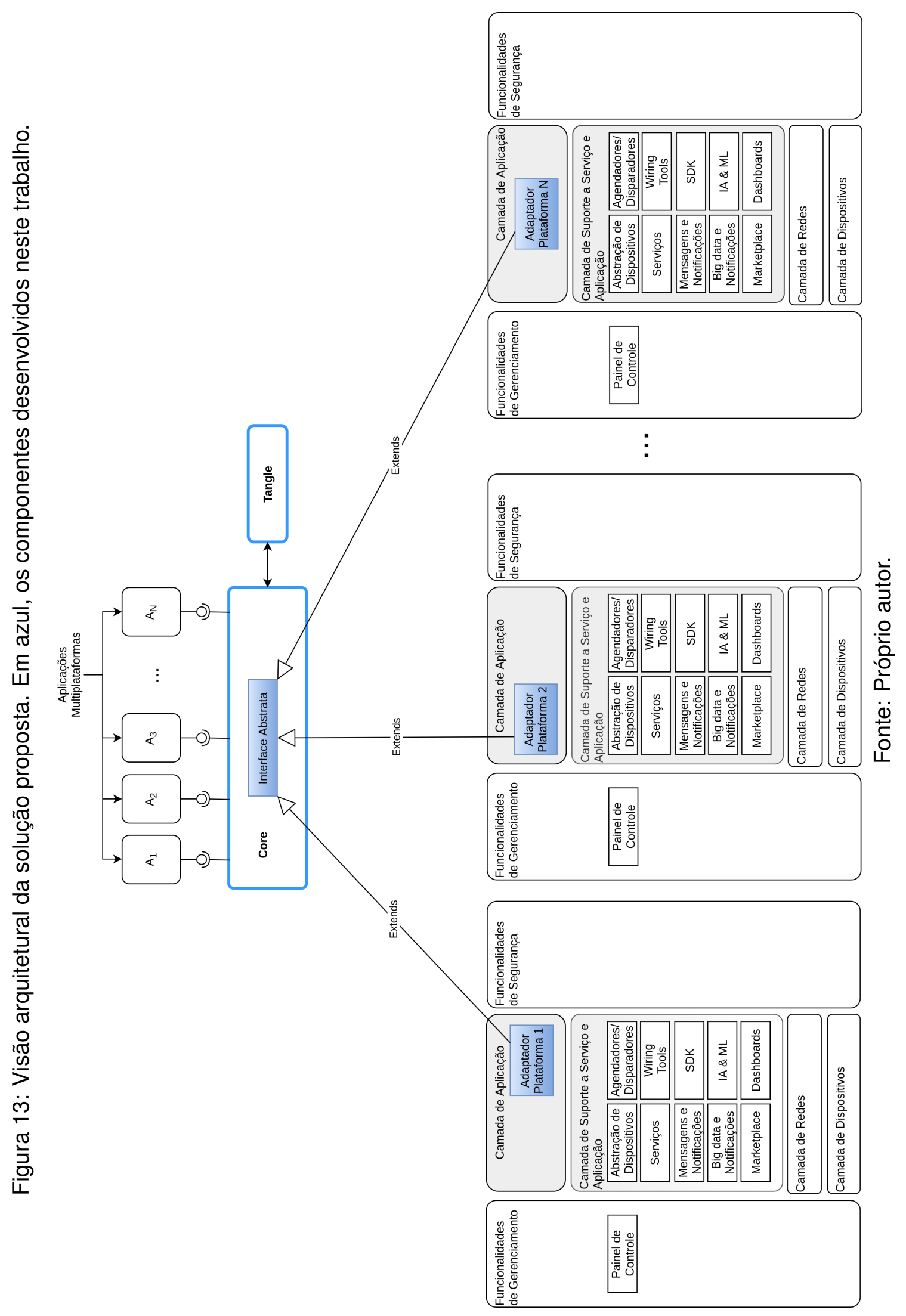


Além disso, a partir das questões de portabilidade e interoperabilidade expostas delineou-se o processo apresentado na Figura 14, que define quatro passos que permitem alcançar a portabilidade e interoperabilidade, inclusive com sugestões de questionamentos que guiam a execução de cada um deles. Uma vez selecionado um conjunto de plataformas-alvo, o processo começa com a "Análise Comparativa de Modelo de Dados", no qual se analisa os diferentes modelos de dados das plataformas, com seus elementos, a estrutura de dados, pontos de similidade e diferença, entre outras particularidades de cada um dos modelos. Em seguida, tem-se a "Análise Comparativa dos Recursos Oferecidos na Camada de Aplicação", o qual se trata da análise das funcionalidades providas pelos recursos das plataformas, similaridades e diferenças no comportamento dos mesmos e se há um ou mais recursos desejados faltantes em alguma das plataformas. Neste passo a Tabela 5 pode auxiliar na comparação dos diferentes recursos oferecidos, desde que as plataformas-alvo estejam entre as plataformas levantadas na mesma. Logo depois, o próximo passo é a "Modelagem de Adaptador Abstrato", no qual se define a interface unificada que será provida para que as aplicações possam utilizar os recursos abstratos e dados. Por fim, há a "Implementação dos Adaptadores de cada Plataforma", que consiste na implementação da interface modelada no passo anterior.

Figura 14: Visão geral do processo para desenvolvimento de solução de portabilidade e interoperabilidade neste trabalho.

\begin{tabular}{|c|c|c|c|}
\hline $\begin{array}{l}\text { Análise Comparativa de } \\
\text { Modelos de Dados }\end{array}$ & $\begin{array}{l}\text { Análise Comparativa dos } \\
\text { Recursos Oferecidos na } \\
\text { Camada de Aplicação }\end{array}$ & $\begin{array}{l}\text { Modelagem de Adaptador } \\
\text { Abstrato }\end{array}$ & $\begin{array}{l}\text { Implementação dos } \\
\text { Adaptadores de cada } \\
\text { Plataforma }\end{array}$ \\
\hline $\begin{array}{l}\text { - Qual o modelo de dados } \\
\text { de cada plataforma? } \\
\text { - Quais as semelhanças e } \\
\text { diferenças entre os mode- } \\
\text { los de dados? } \\
\text { - Quais as entidades e co- } \\
\text { mo se correalacionam nos } \\
\text { diferentes modelos? } \\
\text { - Quais entidades serão por- } \\
\text { tadas? } \\
\text { - Das entidades a serem por- } \\
\text { tadas, alguma está em falta } \\
\text { entre as plataformas? } \\
\text { - Como esta será portada? }\end{array}$ & $\begin{array}{l}\text { - Considerando a lista de re- } \\
\text { cursos sugeridos pela Tab. } \\
\text { 7, que recursos cada plata- } \\
\text { forma oferece em sua ca- } \\
\text { mada de aplicação? } \\
\text { - Que recursos deseja-se por- } \\
\text { tar? } \\
\text { - Como os recursos desejados } \\
\text { se comportam em cada pla- } \\
\text { taforma? } \\
\text { - Quais as semelhanças e di- } \\
\text { ferenças destes comporta- } \\
\text { mentos? } \\
\text { - Há recursos desejados que } \\
\text { estão faltantes em alguma } \\
\text { plataforma? }\end{array}$ & $\begin{array}{l}\text { - Como será a interface uni- } \\
\text { ficada a ser provida? }\end{array}$ & $\begin{array}{l}\text { - Como os recursos virtuais } \\
\text { interagem transmitirão as } \\
\text { funcionalidades dos recur- } \\
\text { sos reais? } \\
\text { - Como serão implementados } \\
\text { os recursos faltantes? }\end{array}$ \\
\hline
\end{tabular}

Fonte: Próprio autor. 


\subsection{Cenários Possíveis}

Considerando-se os padrões de interoperabilidade descritos na Seção 3.3, podese estabelecer os seguintes cenários de relacionamento entre serviços ou aplicações e as plataformas para as quais se deseja implementar o projeto de portabilidade e interoperabilidade descrito neste capítulo, conforme relatado na Figura 15. Nos exemplos, tem-se casos de aplicação em cidades inteligentes.

Figura 15: Cenários possíveis de interação dos componentes do projeto baseando-se nos padrões explicados na Seção 3.3

(a) Acesso interplataforma

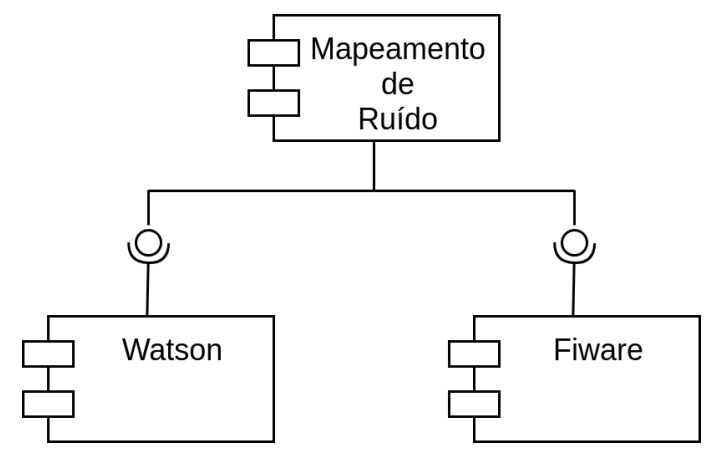

(c) Fachada de alto nível de serviços
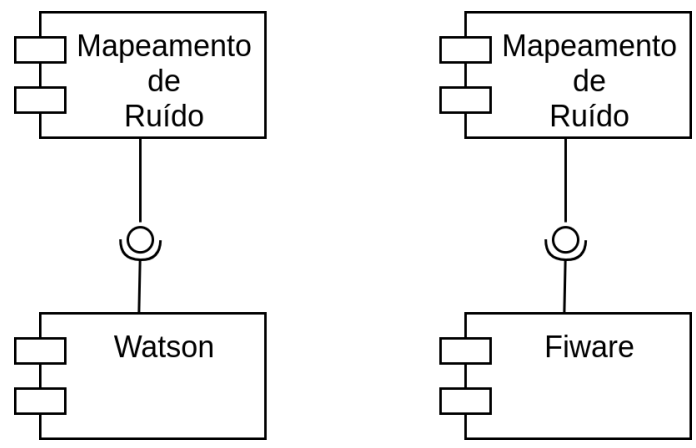

Aplicação

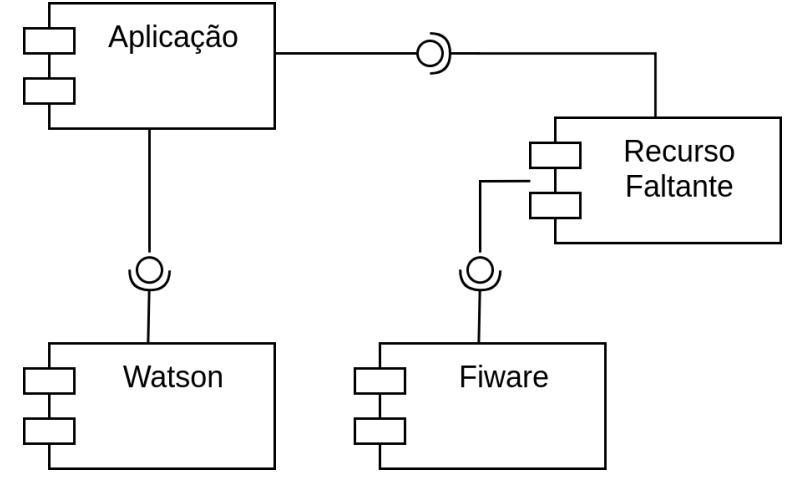

Fonte: Adaptado de Bröring et al. (2017).

- Acesso interplataforma (Figura 15a): A aplicação utiliza recursos de múltiplas plataformas simultaneamente. Seja uma certa cidade A, por exemplo, utiliza-se a plataforma Fiware e, em uma cidade B, faça-se uso de Azure. Supondo-se que se queira criar uma aplicação que utilize dados e recursos de ambas as plataformas, havendo adaptadores para elas, bastaria que a aplicação se integrasse ao SToIC, que estaria integrado às plataformas. Isto traz benefícios tais como: i) economia orçamentária, uma vez que se pode utilizar os recursos mais ba- 
ratos de cada plataforma; ii) maior disponibilidade, uma vez que se um serviço oferecido por uma plataforma estiver indisponível, a contraparte em outra plataforma poderia entrar em operação, mantendo a aplicação com suas operações normais; iii) melhor qualidade de serviço, uma vez que os recursos podem ter desempenho e qualidade diferentes nas diversas plataformas plataformas.

- Independência de plataforma (Figura 15b): Neste cenário, a mesma aplicação poderia ser transferida de uma plataforma para outra modificando-se apenas a configuração, desde que sua programação utilize a interface provida pela camada implementada. Desta forma, uma aplicação em um parque localizado em uma certa cidade fazendo uso da plataforma Amazon poderia ser replicada em um parque de outra cidade que utiliza InterSCity, por exemplo.

- Fachada de alto nível de serviços (Figura 15c): Neste caso, a camada proposta pode oferecer um recurso que falta em uma plataforma implementando as funcionalidades do mesmo no adaptador dela. Neste caso, por exemplo, se uma aplicação está interagindo com o adaptador para WIP e realizando uma determinada função que não está presente no Fiware, mas necessita desta funcionalidade, o adaptador para Fiware pode fazer o papel de um proxy, de tal forma que a funcionalidade é implementada ao nível do adaptador Fiware, suprindo o recurso faltante.

\subsection{A Implementação da Solução}

A partir arquitetura projetada e o processo descritos nas seções anteriores, construiu-se uma implementação do modelo de camada de portabilidade e interoperabilidade SToIC, tendo o Fiware e o WIP como plataformas-alvo. A Figura 16 apresenta uma visão contextual dos componentes desenvolvidos, em azul, em conjunto aos demais elementos que interagem com eles. Esta visão se divide em camadas conforme descrito a seguir:

- Dispositivos: São os sensores e atuadores presentes em um ou mais ambientes em que se deseja monitorar variáveis ou fazer intervenção. Os diferentes dispositivos enviam seus dados e recebem comandos de diferentes plataformas. 
É possível que um dispositivo interaja com mais de uma plataforma, porém cada plataforma terá sua própria representação do mesmo.

- Plataformas: Contém instâncias de diferentes plataformas. No momento, a solução desenvolvida se integra com WIP e com Fiware, podendo ser extensível a outras plataformas futuramente. Oferecem recursos através de APIs, que são utilizados pela camada de Portabilidade e Interoperabilidade.

- SToIC: Contém os componentes centrais da solução desenvolvida, que proveem adaptadores para os recursos reais oferecidos pelas plataformas e disponibilizam recursos virtuais oferecidos através de uma interface unificada, a ser utilizada por aplicações multiplataformas, e o SToIC Tangle, que faz com que dados de interesse possam ser interoperáveis e compartilhados entre as diferentes plataformas. Ambos os componentes utilizam um banco de dados MongoDB para persistência de dados de suas operações.

- Aplicações Multiplataformas: São as diferentes aplicações possíveis que utilizam os recursos oferecidos pela camada anterior, através da interface oferecida pelo SToIC Core. Aqui, desenvolveu-se o SToIC Panel, que, além de ser uma aplicação multiplataforma, é uma ferramenta de auxílio ao desenvolvedor para criação de soluções.

\subsubsection{SToIC Core}

O SToIC Core é o componente principal da solução desenvolvida e trata-se de um serviço web que contém os adaptadores para recursos de cada plataforma, comunicando-se com cada plataforma e expondo uma interface única para acesso de aplicações multiplataformas, através de endpoints RESTful, conforme demonstrado na Tabela 7. Faz uso do Sistema de Gerenciamento de Banco de Dados (SGBD) Mongo² para guardar suas informações.

Os adaptadores foram implementados na forma de classes. Após o registro de uma nova instância de plataforma, cria-se um objeto da classe do tipo da plataforma e, a partir deste objeto, interage-se com a plataforma alvo do adaptador. A Tabela

\footnotetext{
${ }^{2}$ www.mongodb.com
} 
Tabela 7: Endpoints da interface disponibilizada pelo SToIC às aplicações.

\begin{tabular}{|c|c|c|}
\hline Registros & Endpoints & Descrição \\
\hline \multirow{6}{*}{ Plataformas } & GET /broker & $\begin{array}{l}\text { Lista todas as instâncias } \\
\text { de plataformas cadastradas. }\end{array}$ \\
\hline & POST /broker & $\begin{array}{l}\text { Insere uma nova instância } \\
\text { de plataforma. }\end{array}$ \\
\hline & PUT /broker & $\begin{array}{l}\text { Atualiza uma instância de } \\
\text { plataforma registrada. }\end{array}$ \\
\hline & GET /broker/brokerld & $\begin{array}{l}\text { Recupera o registro de } \\
\text { uma instância de plataforma. }\end{array}$ \\
\hline & DELETE /broker/brokerld & $\begin{array}{l}\text { Remove o registro de uma } \\
\text { instância de plataforma. }\end{array}$ \\
\hline & GET/broker/schema/brokerType & $\begin{array}{l}\text { Recupera o esquema dos campos } \\
\text { para registrar uma instância de um } \\
\text { determinado tipo de plataforma. }\end{array}$ \\
\hline \multirow{4}{*}{ Dispositivos } & GET /device & $\begin{array}{l}\text { Recupera dispositivos } \\
\text { registrados nas diferentes } \\
\text { instâncias de plataformas. }\end{array}$ \\
\hline & POST /device & $\begin{array}{l}\text { Registra um novo dispositivo } \\
\text { em uma instância de plataforma. }\end{array}$ \\
\hline & GET /device/deviceld & $\begin{array}{l}\text { Recupera um dispositivo } \\
\text { em uma instância de plataforma. }\end{array}$ \\
\hline & DELETE /device/deviceld & $\begin{array}{l}\text { Remove um dispositivo } \\
\text { de uma instância de plataforma. }\end{array}$ \\
\hline \multirow{5}{*}{ Entidades } & GET /entity & $\begin{array}{l}\text { Recupera entidades de uma } \\
\text { instância de plataforma. }\end{array}$ \\
\hline & POST /entity & $\begin{array}{l}\text { Registra uma nova entidade } \\
\text { em uma instância de plataforma. }\end{array}$ \\
\hline & PUT /entity & $\begin{array}{l}\text { Atualizar uma entidade em } \\
\text { uma instância de plataforma. }\end{array}$ \\
\hline & GET /entity/entityld & $\begin{array}{l}\text { Recuperar uma entidade em } \\
\text { uma instância de plataforma. }\end{array}$ \\
\hline & DELETE /entity/entityld & $\begin{array}{l}\text { Remove uma entidade em } \\
\text { uma instância de plataforma. }\end{array}$ \\
\hline \multirow{5}{*}{ Associações } & GET /association & $\begin{array}{l}\text { Recupera associações entre } \\
\text { dispositivos e entidades. }\end{array}$ \\
\hline & POST /association & Registra uma nova associação. \\
\hline & PUT /association & Atualiza uma associação. \\
\hline & GET /association/associationld & Recupera uma associação. \\
\hline & DELETE /association/associationld & Remove uma associação. \\
\hline \multirow{5}{*}{ Tarefas } & GET /task & $\begin{array}{l}\text { Recupera todas as tarefas de } \\
\text { uma instância de plataforma. }\end{array}$ \\
\hline & POST /task & Cria uma nova tarefa. \\
\hline & GET/task/taskld & $\begin{array}{l}\text { Recupera uma tarefa de uma } \\
\text { instância de plataforma. }\end{array}$ \\
\hline & PUT /task/taskld & $\begin{array}{l}\text { Atualiza uma tarefa em uma } \\
\text { instância de plataforma. }\end{array}$ \\
\hline & DELETE /task/taskld & Remove uma tarefa. \\
\hline
\end{tabular}


Figura 16: Visão contextual da solução implementada. Em azul, os componentes desenvolvidos neste trabalho.

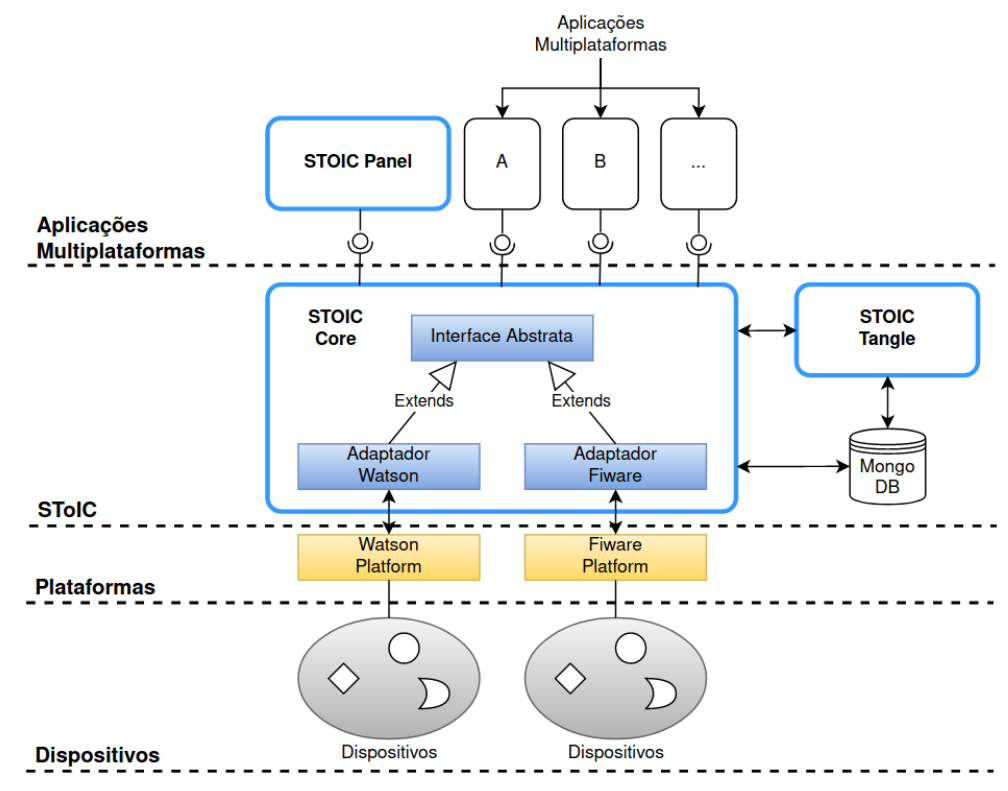

Fonte: Próprio autor.

8 apresenta uma listagem resumida dos métodos dos adaptadores para ambas as plataformas.

Foi construído em Python 3 (ROSSUM et al., 2007) utilizando o arcabouço Flask ${ }^{3}$. Resumidamente, cada um dos adaptadores está implementado em um módulo diferente, sendo importados e utilizados na API RESTful, sendo este uma fachada de acesso aos adaptadores a ser utilizada pelas aplicações multiplataformas.

\subsubsection{STolC Tangle}

O SToIC Tangle é de um serviço web que permite a sincronização de dados entre as plataformas integradas à solução, trabalhando de forma a auxiliar o SToIC Core. Ao solicitar a criação de uma entidade, o desenvolvedor pode fazer com que ela seja criada em múltiplas plataformas e seus atributos se mantenham consistentes entre elas. Se optar por isso, isto é, a criação de uma entidade em duas ou mais plataformas, o SToIC Core solicitará ao SToIC Tangle o registro do nome e tipo da entidade e a lista de plataformas no banco de dados. Após o registro, o SToIC Tangle solicitará ao SToIC Core a criação de tarefas que o notifiquem, dado cada plataforma, as mudanças da entidade.

\footnotetext{
${ }^{3}$ flask.palletsprojects.com
} 
Tabela 8: Métodos dos adaptadores no SToIC Core para as plataformas WIP e o nível de implementação do recurso utilizado.

\begin{tabular}{|c|c|c|c|}
\hline \multirow[t]{2}{*}{ Método do Adaptador } & \multirow[t]{2}{*}{ Descrição } & \multicolumn{2}{|c|}{$\begin{array}{l}\text { Implementação do } \\
\text { recurso utilizado }\end{array}$} \\
\hline & & WIP & Fiware \\
\hline $\begin{array}{l}\text { create_device() } \\
\text { get_device() } \\
\text { list_devices() } \\
\text { delete_device() }\end{array}$ & $\begin{array}{l}\text { Manutenção do registro } \\
\text { de dispositivos }\end{array}$ & Nativo & Nativo \\
\hline $\begin{array}{l}\text { create_entity() } \\
\text { get_entity() } \\
\text { list_entities() } \\
\text { update_entity() } \\
\text { delete_entity() }\end{array}$ & $\begin{array}{l}\text { Manutenção do registro } \\
\text { de entidades }\end{array}$ & Adaptador & Nativo \\
\hline $\begin{array}{l}\text { create_association() } \\
\text { get_association() } \\
\text { list_associations() } \\
\text { update_association() } \\
\text { delete_association() }\end{array}$ & $\begin{array}{l}\text { Manutenção da associação } \\
\text { entre dispostivos e } \\
\text { entidades }\end{array}$ & Adaptador & Nativo \\
\hline $\begin{array}{l}\text { create_task() } \\
\text { get_task() } \\
\text { list_tasks() } \\
\text { update_task() } \\
\text { delete_task() }\end{array}$ & Manutenção de tarefas & Adaptador & Nativo \\
\hline
\end{tabular}

Fonte: Próprio autor.

Quando uma entidade for atualizada, por meio de seu nome e tipo e de sua plataforma, o SToIC Tangle é notificado da mudança, busca qual o grupo de plataformas de interesse, dado a entidade, e atualiza as entidades correspondentes de mesmo nome em cada plataforma do grupo. Desta forma, uma plataforma A pode processar dados gerados por dispositivos que pertencem a uma plataforma $\mathrm{B}$ e a plataforma $\mathrm{A}$ pode utilizar estes dados processados, por sua vez.

O SToIC Tangle também utiliza o SGBD Mongo para guardar informações e apoiar suas operações.

\subsubsection{STolC Panel}

Para auxiliar o uso da camada proposta pelo desenvolvedor de aplicação, criouse um painel de controle gráfico, na forma de um serviço web, para manutenção das 
credenciais das plataformas e seus serviços, dispositivos, entidades e visualização de dados em um dashboard e em tabelas.

Este painel é, por sua natureza, uma aplicação multiplataforma do SToIC e todas as suas operações são realizadas utilizando a API provida pelo SToIC Core, de tal forma que qualquer aplicação multiplataforma poderia realizar as mesmas operações.

As Figuras 17 à 22 apresentam o aspecto das telas do SToIC Panel, cuja descrição encontra-se a seguir:

- Home: Tela inicial, contendo informações de apresentação e formulário de autenticação do usuário.

- Platforms: Inserção, visualização, edição e exclusão de instâncias de plataformas, com cada uma contendo um identificador único, tipo da plataforma, sendo neste caso WIP e Fiware, endpoints de serviços e credenciais da autenticação. Cada tipo de plataforma tem seu próprio esquema de geração de formulário de preenchimento.

- Devices: Criação e exclusão de dispositivos.

- Links: Criação, edição, visualização e exclusão de associações entre dispositivos e entidades.

- Tasks: Criação, edição, visualização e remoção de tarefas a serem disparadas.

- Charts: Painel com gráficos de dados das entidades. Tem como propósito a visualização dos dado pelo desenvolvedor, não para usuário final.

\subsubsection{Diagramas de Sequência da Solução}

Esta seção apresenta diagramas de sequência das principais interações entre os componentes do SToIC, representados nas Figuras 24 à 29. Qualquer destes fluxos poderia ser realizado por uma aplicação multiplataforma, estando esse no lugar do SToIC Panel. Os elementos em azul estão relacionados ao SToIC Panel, com sua apresentação no navegador web e seu servidor, enquanto os elementos em verde são as camadas de controle de requisição e de serviço do SToIC Core. Em cinza, o banco 
Figura 17: Tela inicial.

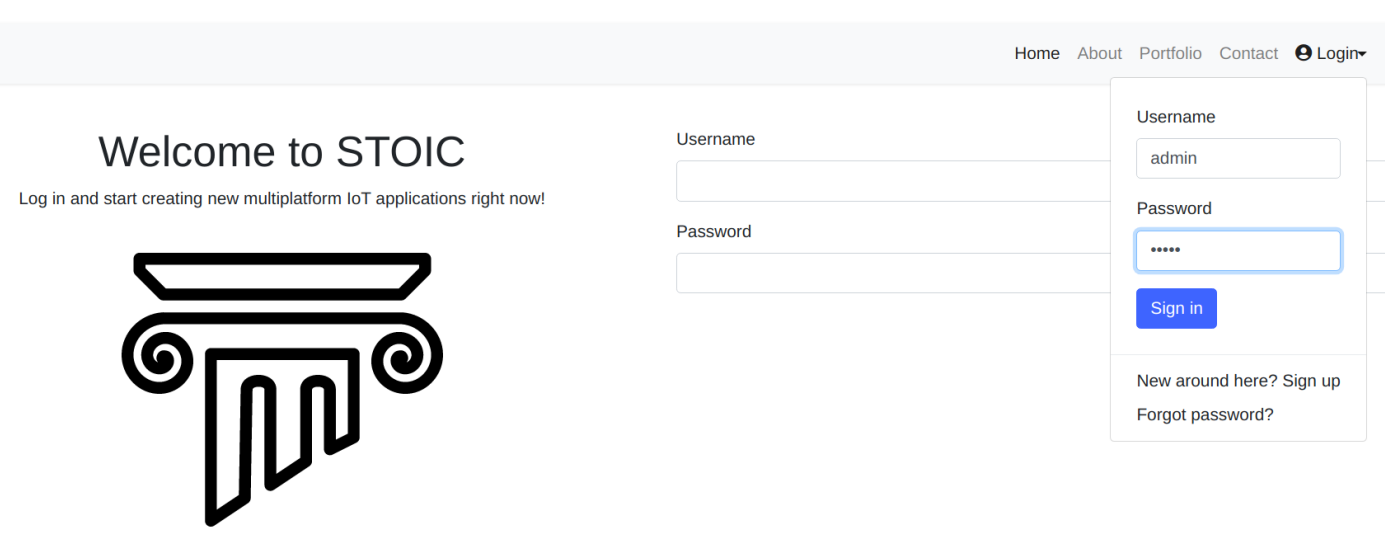

Fonte: Próprio autor.

Figura 18: Tela de plataformas.
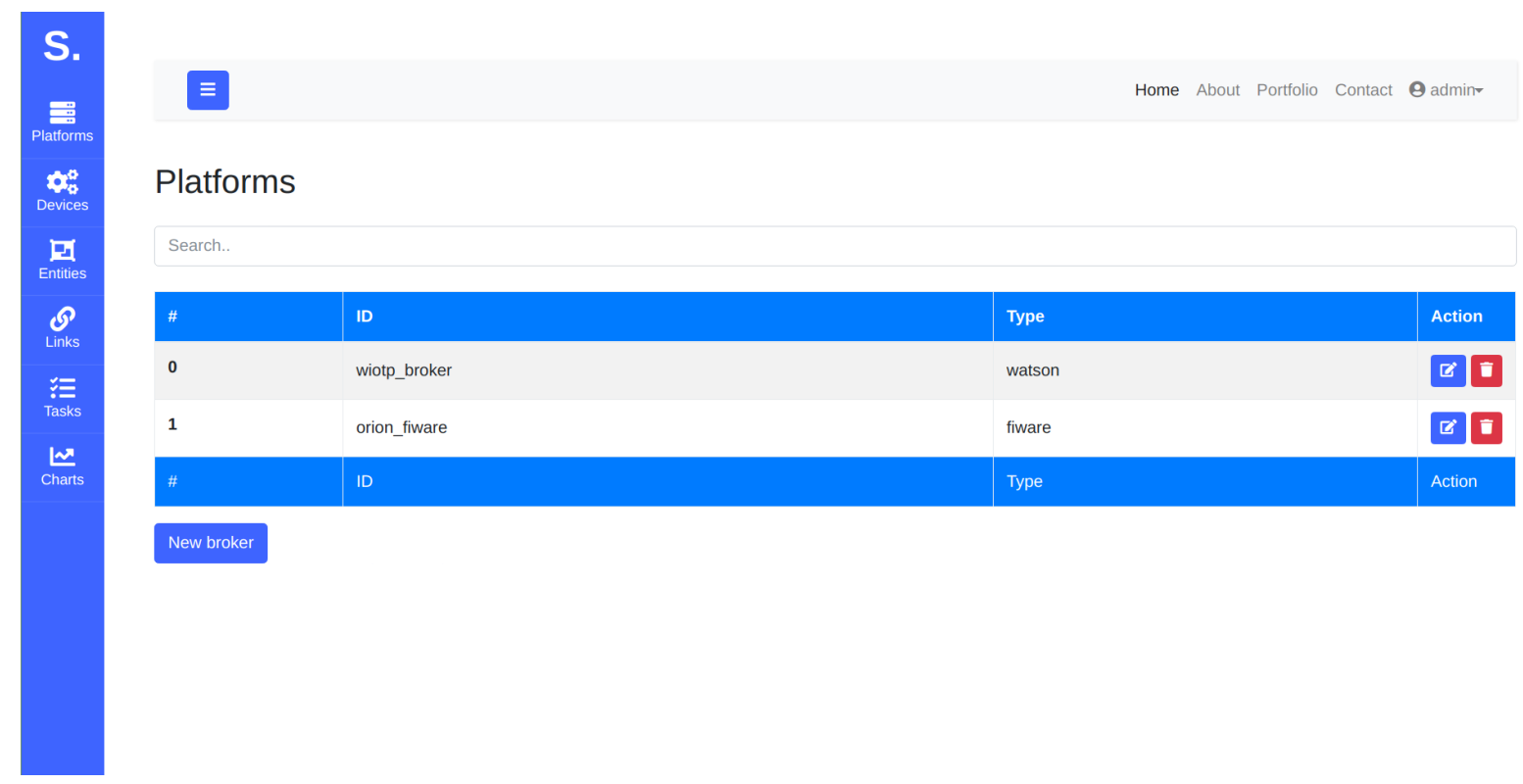

Fonte: Próprio autor.

de dados que apoia as operações. Em azul, o navegador e o Panel. Em seguida, em verde, o Core dividindo-se nos seguintes componentes internos: Controller, responsável por receber as requisições, Service, responsável pelo processar as requisições, e interface para recursos de cada tipo de plataforma, Fiware e WIP, terminados com o sufixo middleware. Em amarelo, Tangle e, em cinza, os SGBDs de apoio.

A Figura 24 apresenta o fluxo de obtenção da lista de instâncias de plataformas. Primeiramente, através do navegador solicita-se a página com a lista de instâncias 
Figura 19: Tela de dispositivos.

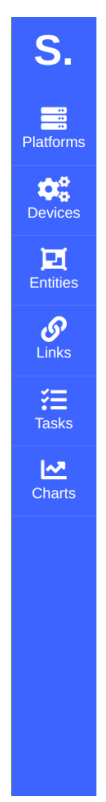

Fonte: Próprio autor.

Figura 20: Tela de entidades.
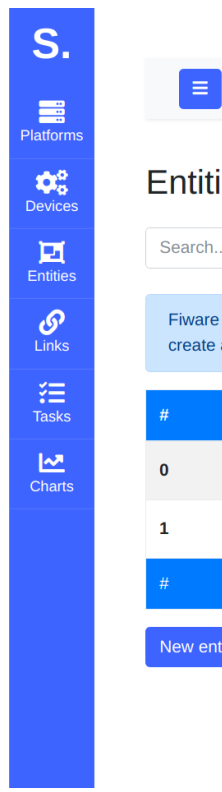

Home About Portfolio Contact 9 adminv

Entities

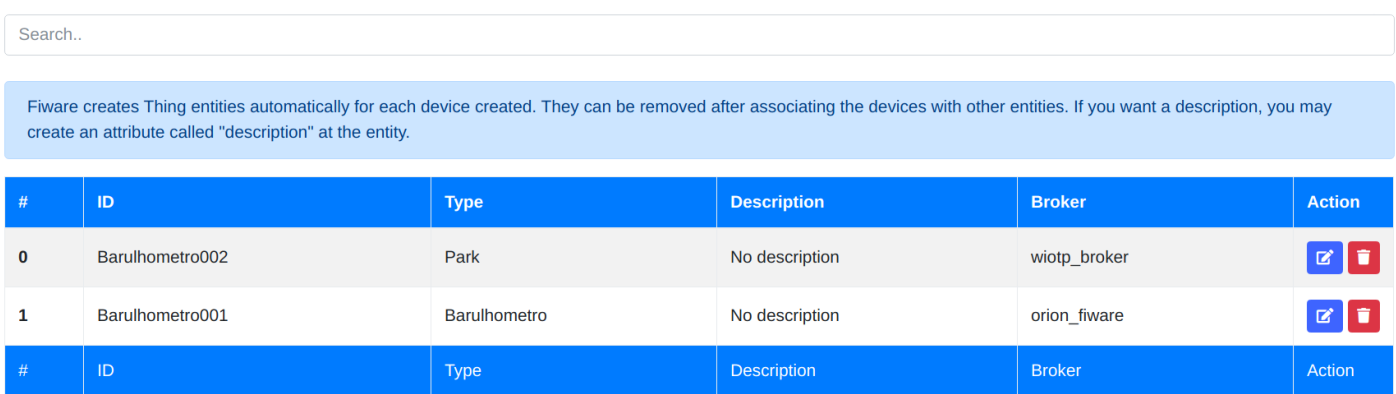

New entity

Fonte: Próprio autor.

ao serviço do Panel. Este, por sua vez, solicita a lista de instâncias do Core, que busca em uma instância do SGBD MongoDB a lista de instância cadastradas. Após os retornos das informações, o Panel devolve ao navegador uma lista de instâncias renderizadas de plataformas em HTML.

A Figura 25 representa o processo de inserção de uma nova instância de plataforma. Primeiramente, o usuário solicita através do navegador o formulário de nova 
Figura 21: Tela de tarefas.
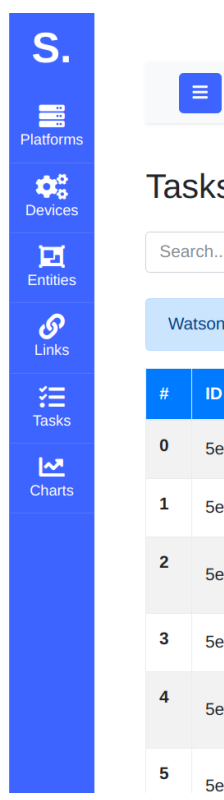

Home About Portfolio Contact 9 adminv

Tasks

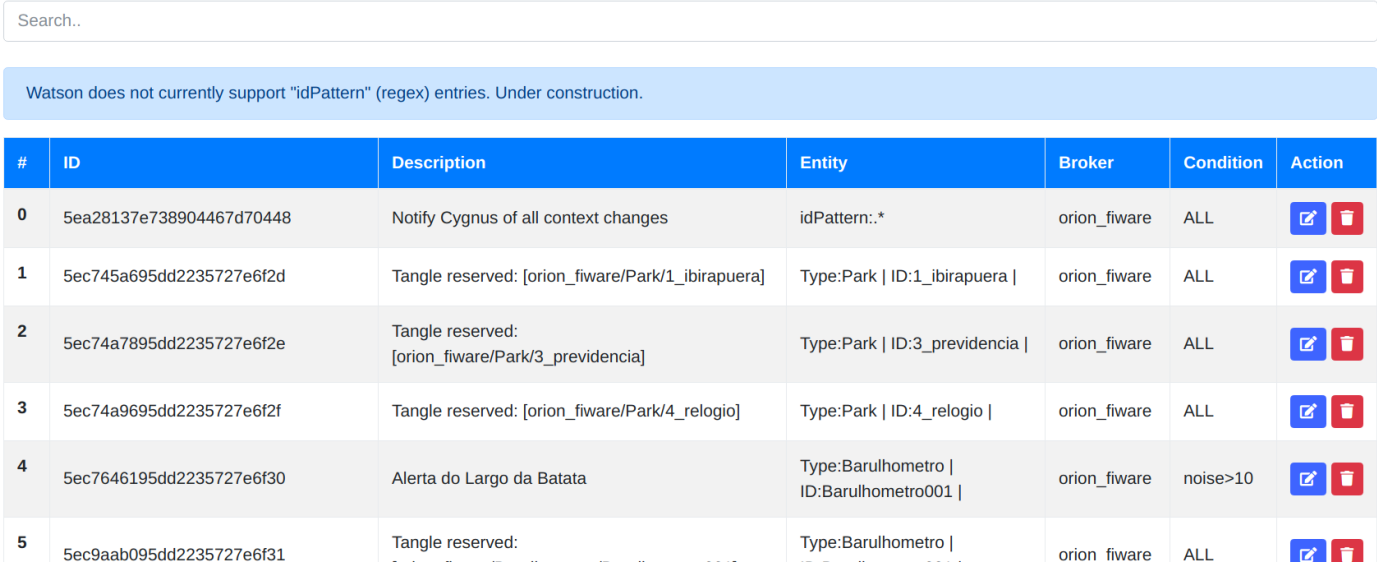

Fonte: Próprio autor.

Figura 22: Tela de dashboard.

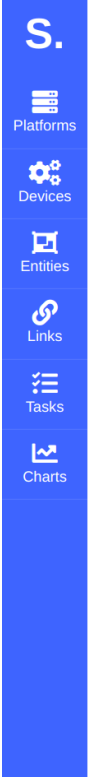

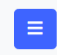

Dashboard

Graphs of entangled entities will show replicated data. This dashboard is for auditing entity data, not for end users.

\section{Barulhometro001}

address (String)

8:44:06 PM

\{"description":"Largo da Batata"\}

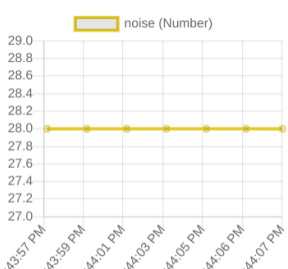

\section{3_previdencia}

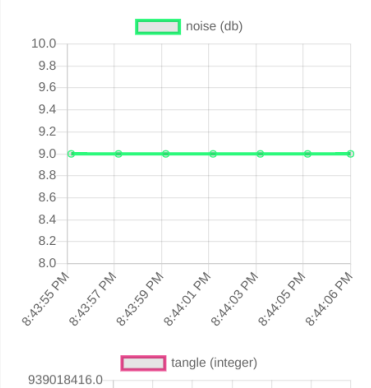

Fonte: Próprio autor.

\section{4_relogio}

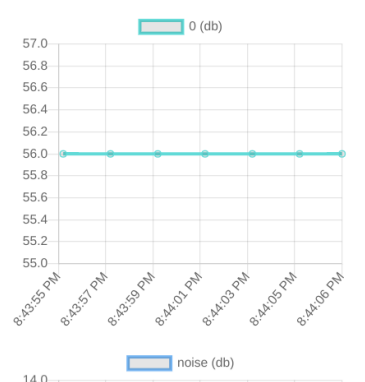

instância ao Panel. De acordo com o tipo plataforma, o Panel solicita o esquema de geração de formulário de credenciais e endpoints de serviços do Core, que busca no adaptador da plataforma esta informação. A partir deste esquema, o Panel constrói o formulário e envia para o navegador uma versão renderizada em HTML do mesmo. Após o usuário preenchê-lo, o mesmo submete o formulário ao Panel, que envia uma requisição de inserção ao Core, que grava em uma instância do MongoDB as informações inseridas. 
Figura 23: Sequência de obtenção de lista de plataformas através do SToIC Panel.

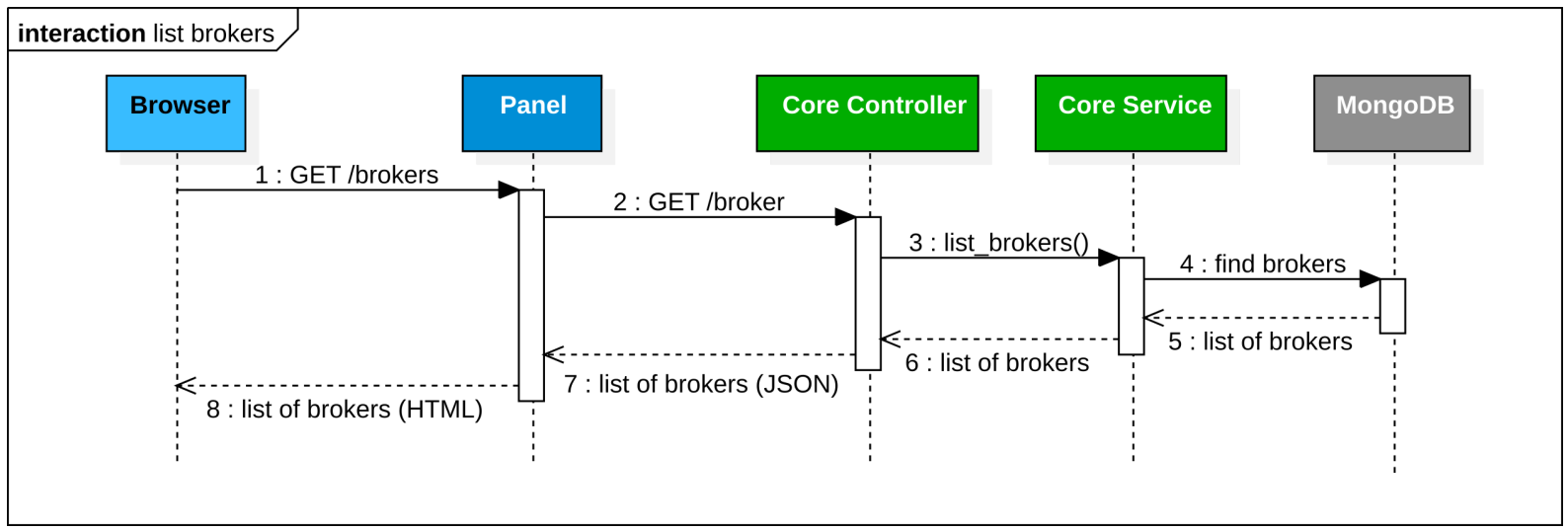

Fonte: Próprio autor.

Figura 24: Sequência de obtenção de lista de plataformas através do SToIC Panel.

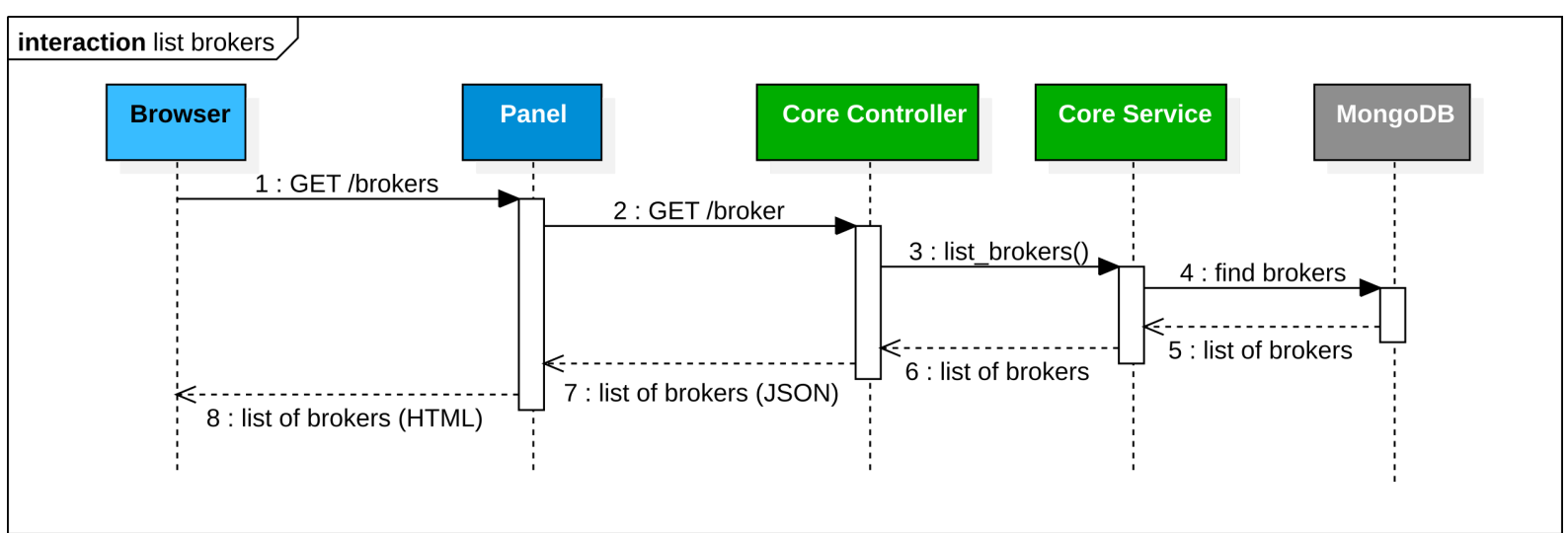

Fonte: Próprio autor.

Figura 25: Sequência para inserção de nova instância de plataforma através do SToIC Panel.

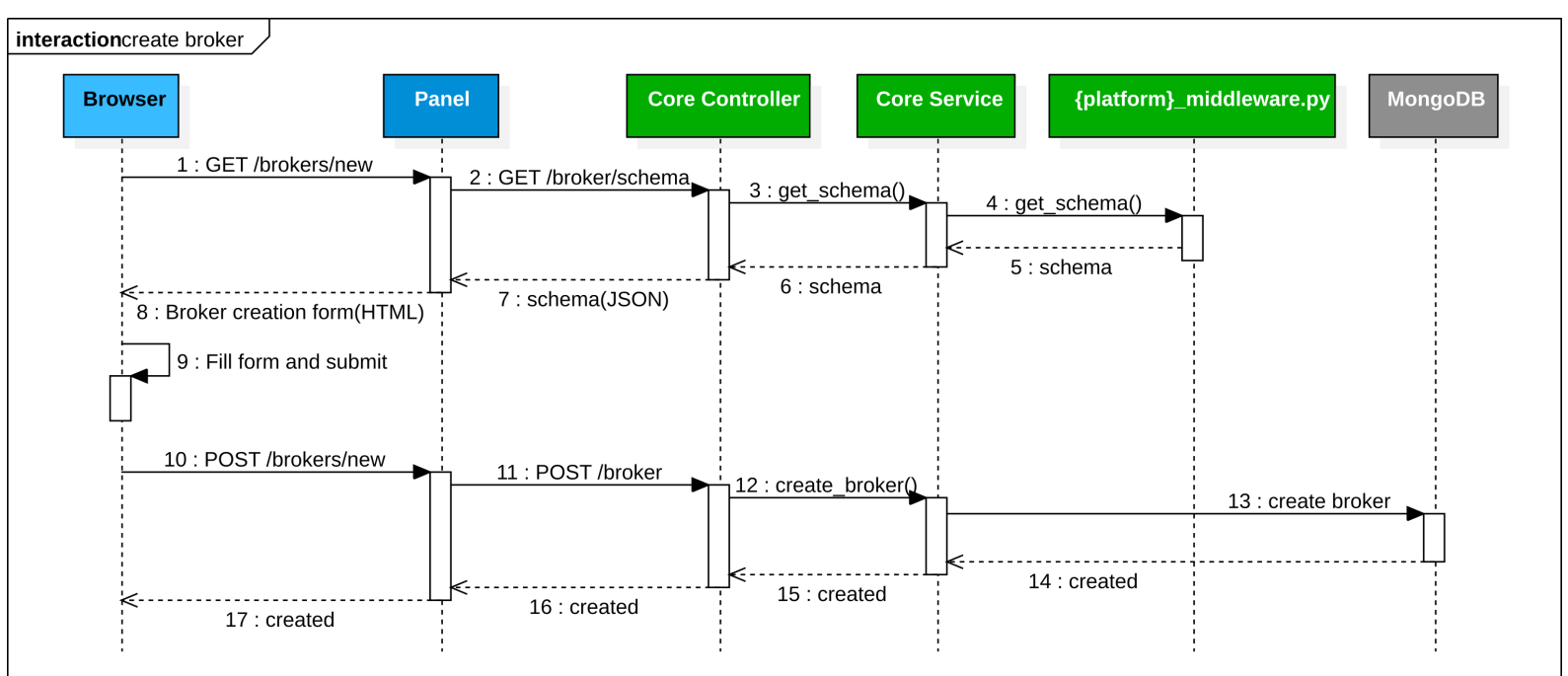

Fonte: Próprio autor.

A Figura 26 contém a sequência de passos para inserção de um novo dispositivo. Primeiramente, solicita-se o formulário de criação através do navegador ao Panel e 
este retorna a página HTML com o mesmo. Após o preenchimento e criação, o formulário é submetido ao Panel, que solicita a criação ao Core, que utiliza o método de criação ao adaptador da instância de plataforma onde se deseja inserir o dispositivo, que é, então, criado.

Figura 26: Sequência para inserção de novo dispositivo através do SToIC Panel.

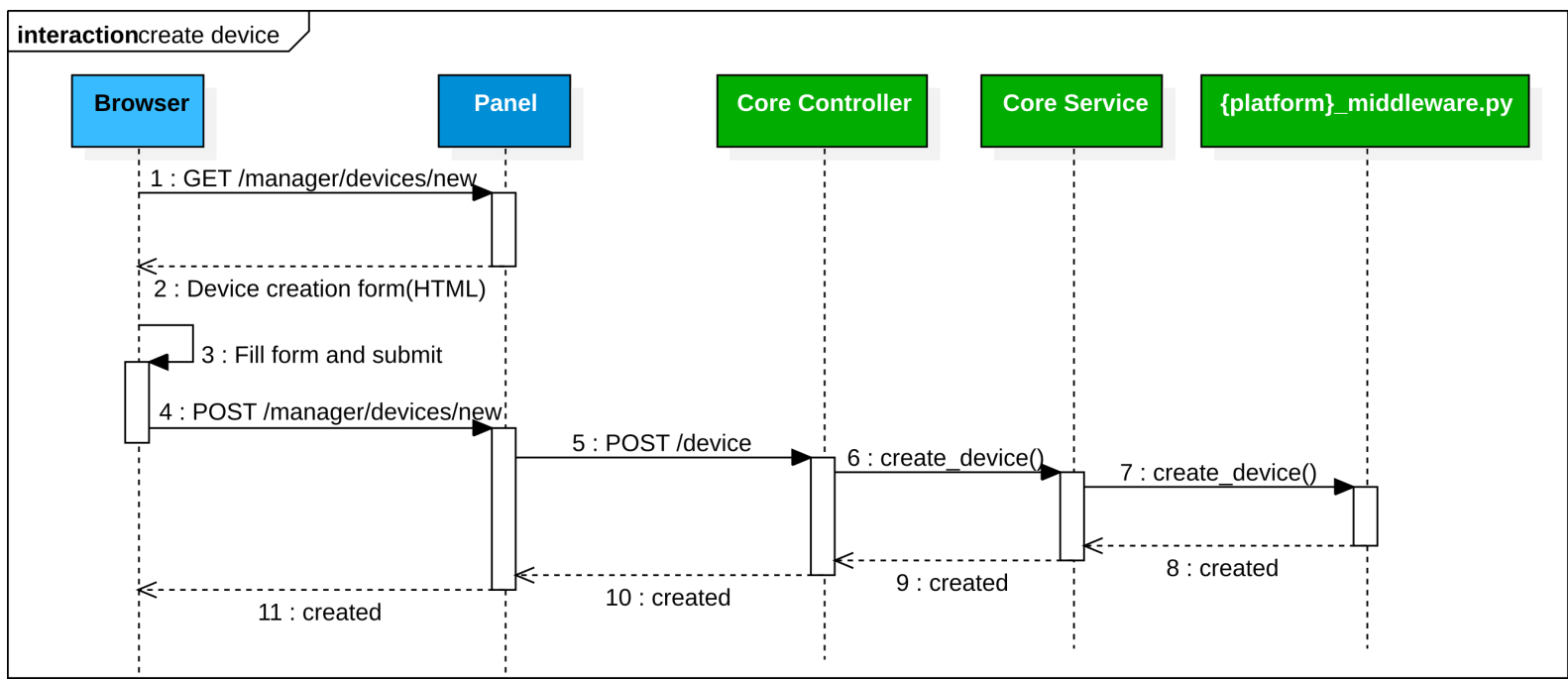

Fonte: Próprio autor.

A Figura 27 apresenta o processo de criação de uma entidade em duas instâncias de plataformas de diferentes tipos ao mesmo tempo, sendo sincronizada em ambas pelo Tangle. Omitiu-se a solicitação de formulário de criação, pressupondo-se que se executou este passo. Primeiramente, faz-se uma solicitação pelo navegador ao Panel para criação da entidade, que envia a requisição ao Core. Este, por sua vez, solicita a criação de um registro com o identificador e tipo da entidade, além dos identificadores das instâncias, ao Tangle, que o faz em uma instância do MongoDB. Após isso, o Core acessa o método de criação de entidades de cada adaptador de plataforma, realizando a inserção. No Fiware, a inserção é feita nos recursos apropriados da plataforma, ao passo que no WIP, como o recurso de criação de entidades é uma construção lógica ao nível do adaptador, realiza-se a inserção na instância SGBD Cloudant utilizada pela plataforma.

As Figuras 28 e 29 apresentam o processo de inserção de uma associação entre um dispositivo e uma entidade em instâncias das plataformas Fiware e WIP, respectivamente. A diferença é que no primeiro caso a associação é realizada internamente na plataforma, alterando o registro de dispositivos, ao passo que no segundo o mesmo é realizado no nível do adaptador, inserindo um registro no SGBD Cloudant. 
Figura 27: Sequência para criação de entidade em uma instância de plataforma do tipo Fiware e outra do tipo WIP através do SToIC Panel.

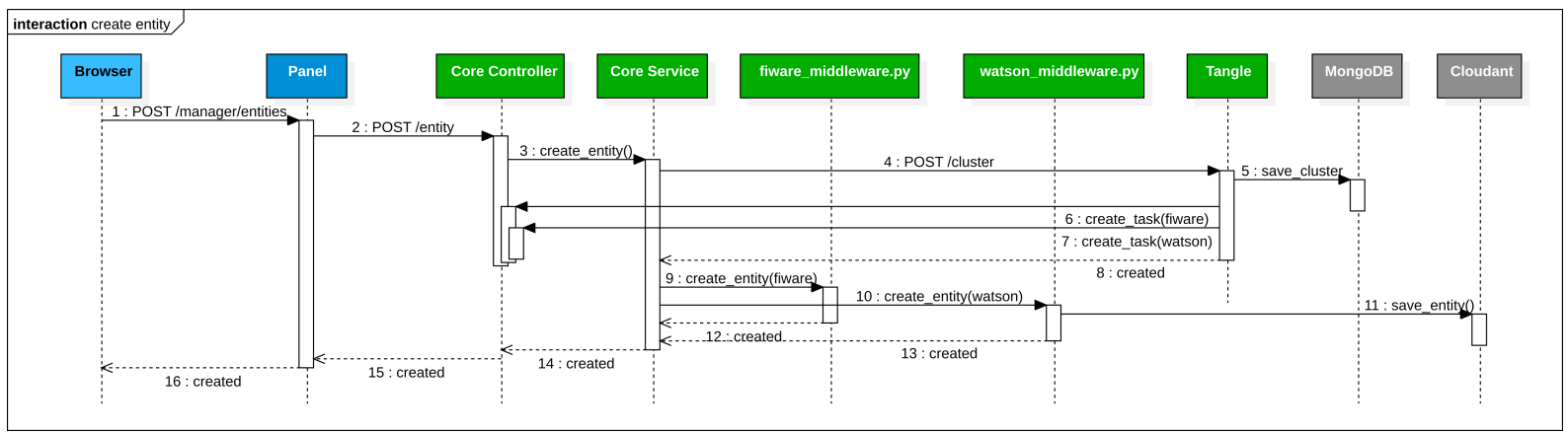

Fonte: Próprio autor.

Figura 28: Sequência para criação de nova associação entre dispositivo e entidade em uma instância Fiware através do SToIC Panel.

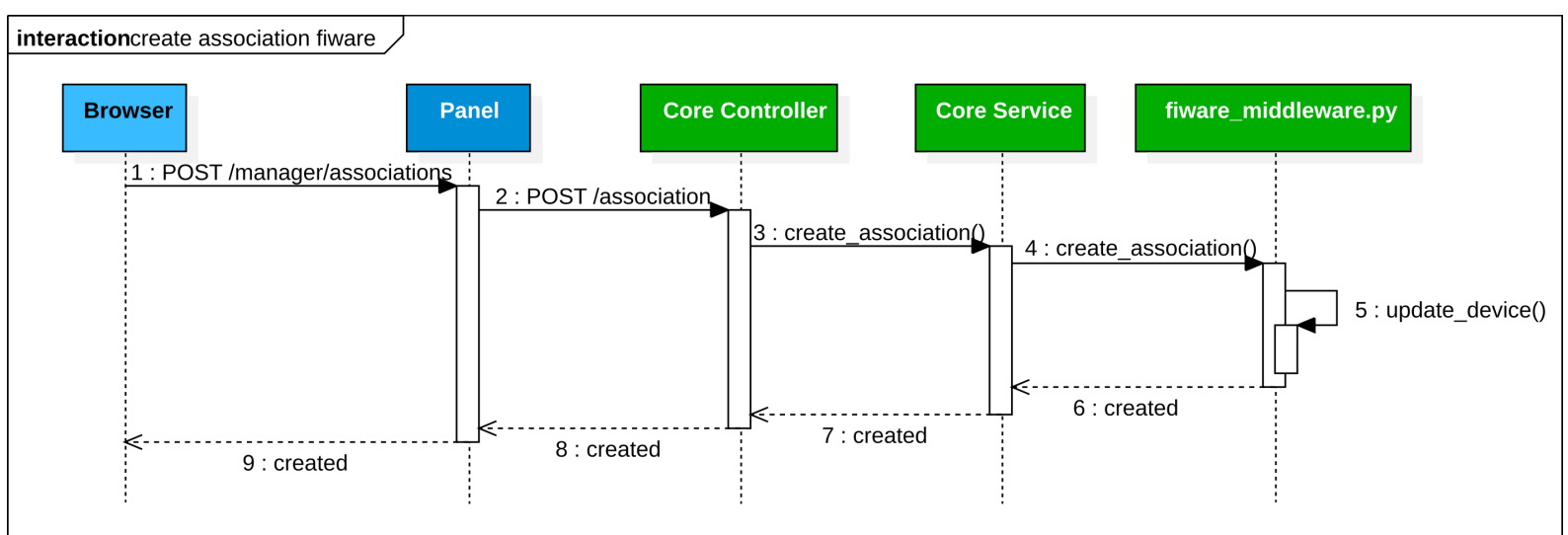

Fonte: Próprio autor.

Figura 29: Sequência para criação de nova associação entre dispositivo e entidade em uma instância WIP através do SToIC Panel.

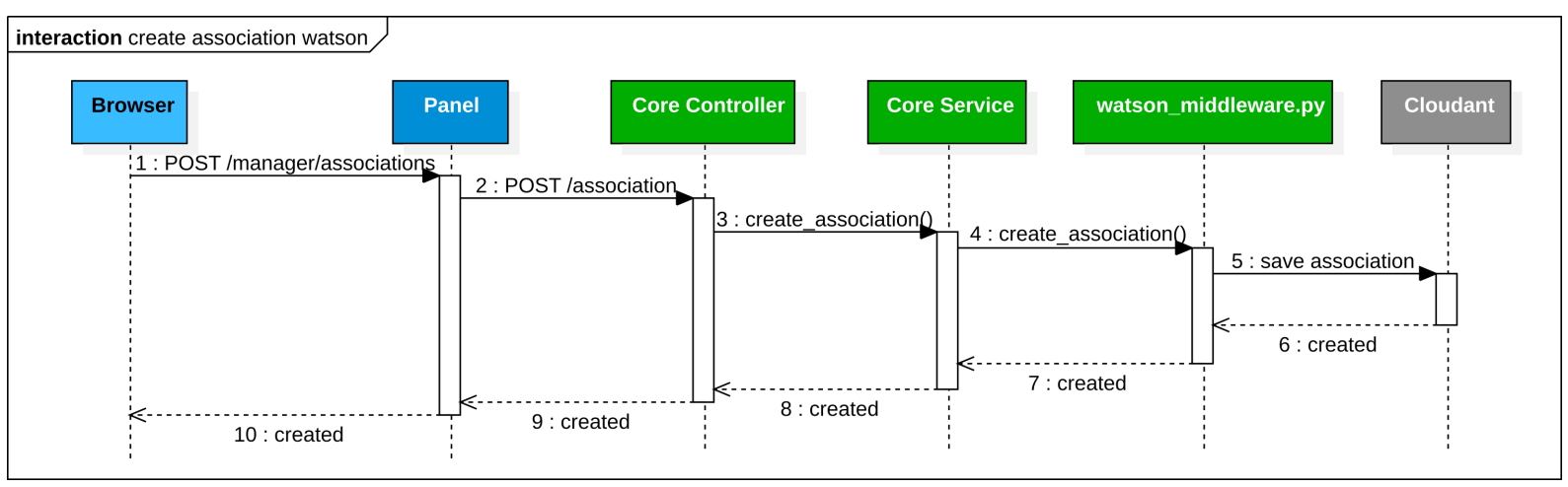

Fonte: Próprio autor.

As Figuras 30 e 31 apresentam o processo de inserção de uma task em instâncias das plataformas Fiware e WIP, respectivamente. A diferença é que no primeiro caso a criação da task é realizada internamente na plataforma, ao passo que no segundo o mesmo é realizado no nível do adaptador, inserindo um registro no SGBD Cloudant. 
Figura 30: Sequência para criação de uma task em uma instância Fiware através do SToIC Panel.

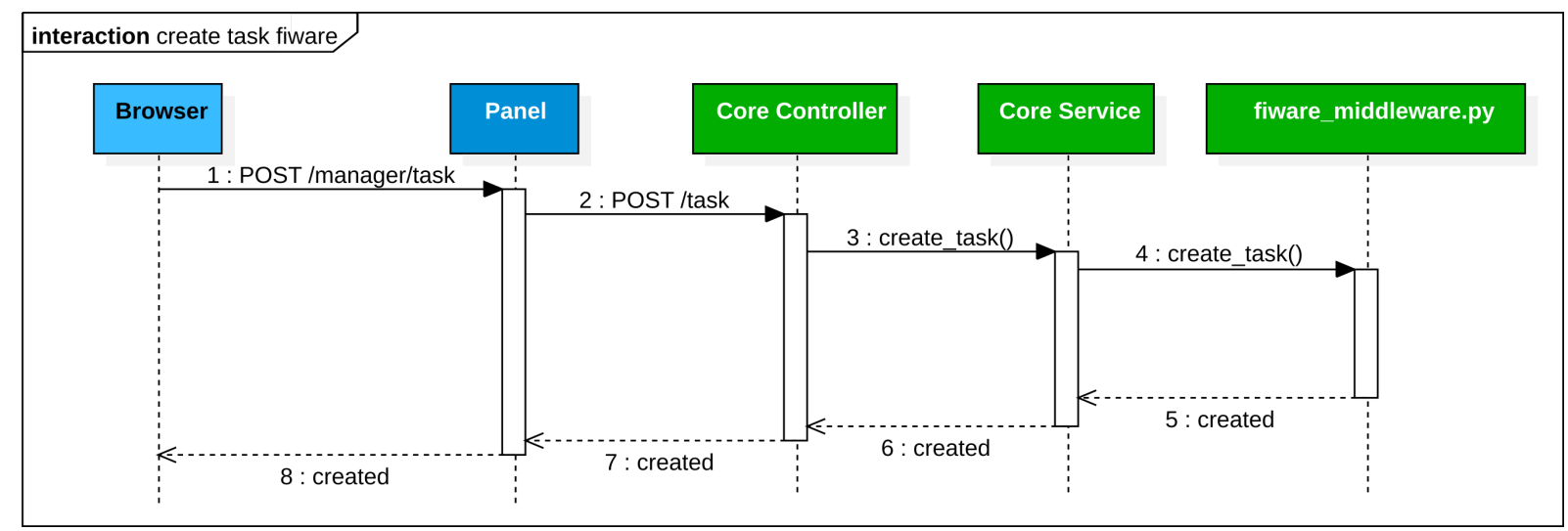

Fonte: Próprio autor.

Figura 31: Sequência para criação de uma task em uma instância WIP através do SToIC Panel.

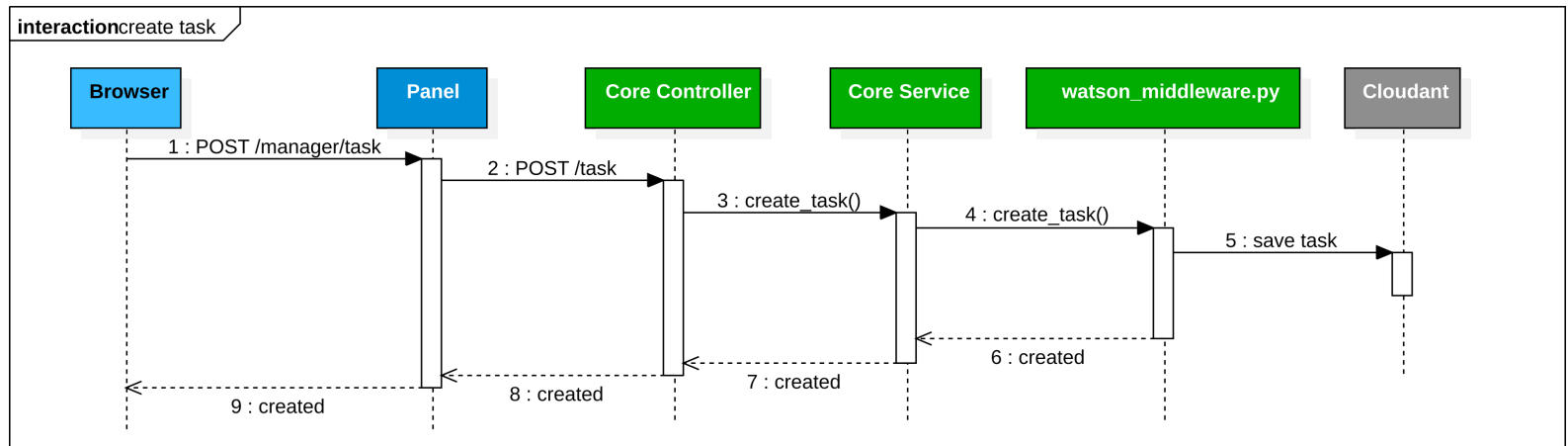

Fonte: Próprio autor. 


\subsection{Considerações do Capítulo}

Este capítulo apresentou o modelo de camada de portabilidade e interoperabilidade proposto neste trabalho, o SToIC, bem como questões relacionadas a estas duas temáticas foram tratadas, resultando na definição do projeto do conceito, com sua arquitetura e o processo que leva à portabilidade e interoperabilidade entre um conjunto definido de plataformas-alvo. Com base neste projeto, realizou-se a implementação do mesmo, com a finalidade de criar uma prova de conceito do SToIC ao criar um ambiente através do qual aplicações multiplataformas pudessem se integrar às plataformas Fiware e WIP. O próximo Capítulo dará maiores detalhes desta implementação, mostrando como se deu a escolha destas duas plataformas-alvo e como o processo apresentado na Figura 14 e a arquitetura exibida na Figura 13 foram aplicados na construção do SToIC a partir do levantamento das necessidades de diferentes projetos do IPT. 


\section{MAPEAMENTO DA APLICABILIDADE DO STOIC NO PDIP-IPT}

O Plano de Desenvolvimento Institucional na Área de Transformação Digital: Manufatura Avançada e Cidades Inteligentes e Sustentáveis (PDIP) do Instituto de Pesquisas Tecnológicas do Estado de São Paulo (IPT), ao qual está vinculado esta pesquisa, objetiva desenvolver a instituição através da "capacitação em sistemas ciberfísicos que permitam transpor os fenômenos físicos para um ambiente digital, implantando uma plataforma de suporte às soluções inteligentes para cidades e para indústria" (IPT, 2017). Conforme a Figura 32 mostra, o PDIP tem como tema a transformação digital e está dividida em dois eixos, a saber, manufatura avançada e cidades inteligentes e sustentáveis. O primeiro deles divide-se em três linhas de pesquisa: manufatura aditiva, processos de manufatura bio-físico-químicos e metrologia avançada, ao passo que o segundo divide-se em duas linhas de pesquisa: sistema de gestão ambiental e sensoriamento inercial autônomo.

Figura 32: Tema, eixos e linhas de pesquisa do PDIP.

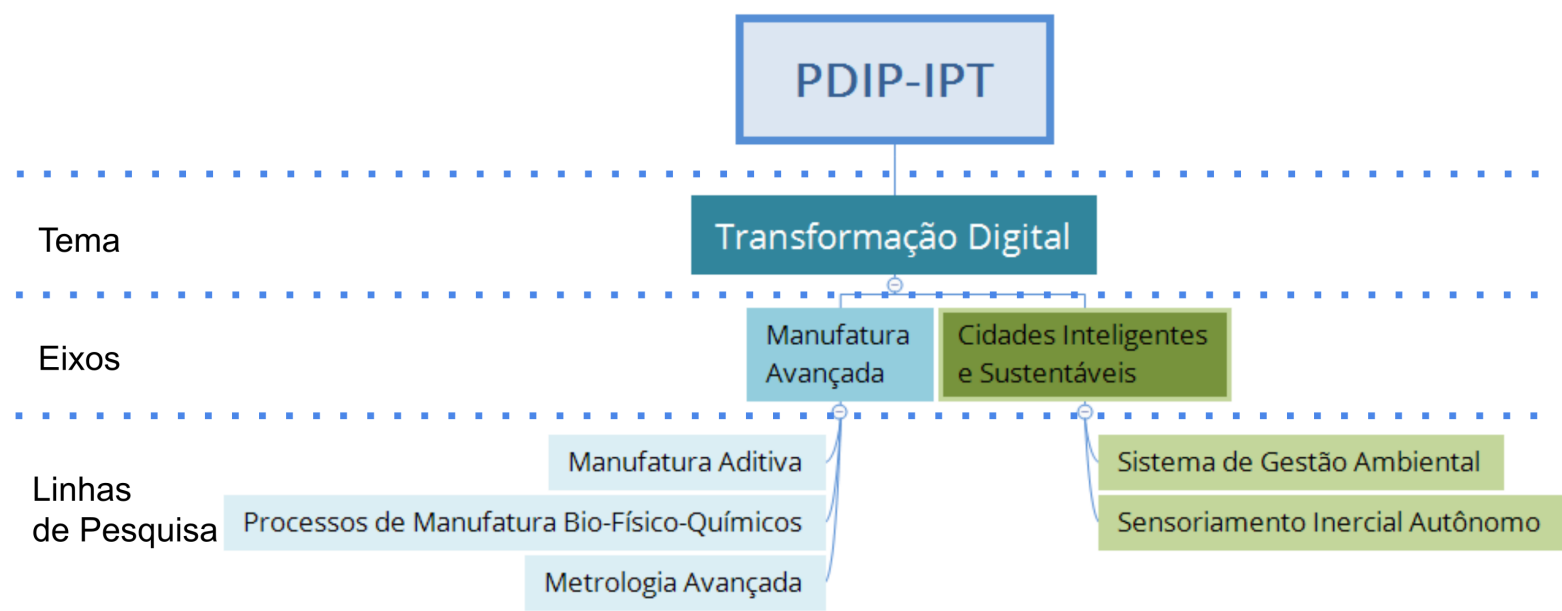

Fonte: Baseado no plano de projeto do PDIP-IPT (IPT, 2017).

Para validar os conceitos aprendidos, o PDIP prevê a criação de duas provas de conceito, uma em cada eixo. Como o IPT contém diferentes projetos relacionados às linhas de pesquisas apresentadas, faz-se necessário buscar oportunidades para 0 desenvolvimento das provas de conceito, através da detecção de necessidades desses projetos e potenciais aplicações de loT. Além disso, as provas de conceito são a oportunidade de validar técnicas que podem beneficiar organizações parceiras do 
IPT através de boas práticas para o desenvolvimento de aplicações de loT para indústria e cidades inteligentes, como por exemplo a portabilidade e interoperabilidade na camada de aplicação em plataformas de loT, foco deste trabalho.

Deste modo, este capítulo apresenta a iniciativa conduzida pelo autor desta pesquisa para detectar oportunidades de aplicações de loT e levantar as necessidades destes projetos em termos das categorias de recursos oferecidas pelas plataformas de loT encontradas no Capítulo 2. Realizou-se uma atividade baseada em técnicas de Design Thinking (DT), que são descritas em detalhe nesta seção.

Assim, esta seção está dividida desta forma: a Seção 5.1 apresenta o referencial teórico da dinâmica realizada. A Seção 5.2, por sua vez, lista os projetos convidados a participar da dinâmica. A Seção 5.3 descreve a sua execução, a Seção 5.4 apresenta o projeto selecionado para criação de prova de conceito, a Seção 5.5 mostra o processo de escolha das plataformas-alvo utilizadas para implementar o SToIC e, por fim, a Seção 5.6 apresenta as considerações finais.

\subsection{Design Thinking (DT) e Técnicas Utilizadas}

Segundo a Interaction Design Foundation (Interaction Design Foundation, 2019), DT é o processo que objetiva entender os usuários, definir problemas e desafios, além de prototipar e testar soluções inovativas, através do esforço de equipes multidisciplinares e dinâmicas específicas. Hasso-Plattner Institute of Design at Stanford (d.school) (KELLEY; BROWN, ) divide o DT em cinco fases: i) empatia: entendimento do ponto de vista do usuário (Interaction Design Foundation, 2020); ii) definição: a delimitação do desafio de design a ser focado pelo time (Interaction Design Foundation, a); iii) ideação: o esforço para geração de ideias para solucionar os desafios definidos (Interaction Design Foundation, b). iv) prototipação: a criação de artefatos em diferentes níveis de complexidade; v) teste: a apresentação dos protótipos aos usuários e coleta de feedback (Interaction Design Foundation, c). Ao longo do processo de DT, passa-se por estas etapas de maneira não-linear, inclusive revisitando-as, se necessário (Interaction Design Foundation, d).

A seguir, descrevem-se as técnicas utilizadas na atividade conduzida, descrita neste capítulo: mapeamento da jornada do usuário, levantamento de questões "how 
might we" e preparação de diagramas de afinidade.

- Mapeamento de Jornadas do Usuário: É uma técnica que consiste em mapear como o usuário interage com o produto, permitindo observar com o ponto de vista do usuário. Após a análise do perfil deste, ainda permite obter ideias de oportunidades de melhoria do produto. Os passos básicos para a criação de uma jornada do usuário consistem em: (1) definir um escopo das situações a serem analisadas; (2) definir um perfil de usuário (chamado de persona); (3) definir cenários e expectativas do usuário; (4) criar uma lista de possíveis ações e interações do usuário com o produto; (5) levar em conta as intenções do usuário; (6) rascunhar interações passo-a-passo; (7) considerar o estado emocional do usuário a cada passo da interação; (8) validar e refinar a jornada (BABICH, ). Esta técnica é uma das formas de construção do Point of View (POV), que se trata de uma descrição de um problema de forma a evidenciar o objetivo, sendo este articulado considerando o usuário para o qual o sistema é desenvolvido, suas necessidades e outras características que possam ser consideradas relevantes do mesmo (Interaction Design Foundation, a).

- How Might We (HMW): É uma técnica de brainstorming (OSBORN, 2012) criada pela Procter \& Gamble (P\&G) na década de 70, e posteriormente adotada por empresas como a Google, Facebook e IDEO (BERGER, 2012). Consiste em expressar ideias em forma de questões curtas iniciadas com a frase "How Might We...", em português "Como pderíamos...", que funciona como gatilho mental para melhor fluidez das ideias, tendo como base um POV previamente definido. Segundo o Design Kit (KIT, ), a técnica pode ser dividida em quatro fases: i) analisar materiais prévios, como POVs de usuários, por exemplo; ii) re-escrever as entradas como várias questões HMW; iii) verificar se as questões HMW permitem diferentes soluções e podem contribuir para um brainstorming; iv) verificar se as questões estão muito amplas e delimitá-las, caso seja necessário.

- Preparação de Diagramas de Afinidade: Trata-se de uma técnica que objetiva agrupar dados coletados de dinâmicas tais como brainstorming, pesquisa, entrevistas, entre outros, comparando-os em graus de similaridade e diferença, de acordo com um critério pré-definido (DAM; TEO, ). 


\subsection{Projetos Convidados}

Os membros dos diferentes projetos das linhas de pesquisa do PDIP foram convidados para a dinâmica, comparecendo 18 deles. Estes foram divididos em quatro grupos, desta forma:

1. Indústria 4.0 (6 participantes)

- Análise de degradação de pelotas de minério de ferro.

2. Desastres Ambientais (4 participantes)

- Análise de risco de deslizamento;

- Análise de risco de alagamento ou inundação;

- Fragmentos florestais.

3. Gestão ambiental (3 participantes)

- Análise de risco de queda de árvores e estudo de conservação de fragmentos florestais.

4. Poluição (5 participantes)

- Análise de mapeamento de ruídos;

- Análise de poluição do ar;

- Gerenciamento de áreas contaminadas e lixos ambientais.

\subsection{Relato do Experimento}

A dinâmica teve início às $14 \mathrm{~h}$ do dia 14 de junho de 2019 e dividiu-se em 3 fases: aquecimento, identificação dos requisitos dos projetos e agrupamento pelas categorias de recursos.

Primeiramente, recepcionou-se os participantes e expôs-se os objetivos da dinâmica. Em seguida, na rodada de apresentação, cada participante falou seu nome, sua função e sobre o projeto ao qual pertencia, além das expectativas para com a dinâmica. Após isso, o moderador os dividiu em quatro equipes relacionadas às áreas 
apresentadas, a saber: i) amarelo: Desastres Ambientais; ii) lilás: Gestão Ambiental; iii) rosa: Indústria 4.0; iv) azul: Poluição. Logo depois, apresentou-se-Ihes o conceito de jornada do usuário e, após a distribuição de quadros de jornada do usuário, lápis, borrachas e réguas, e lhes foi dado um tempo de 20 minutos para que os participantes pudessem identificar os pontos de contato dos usuários com o sistema e realizar as jornadas do usuário. Solicitou-se que, em cada quadro de jornada, selecionassem um usuário do sistema e traçassem o perfil do mesmo, considerando interações com o sistema e os atributos "fazendo", "pensando", "sentindo" e anotassem, se houvesse, ideias de oportunidades ao analisarem a jornada. Após o término do tempo, pediu-se que cada equipe selecionasse as jornadas que julgasse mais relevantes e expusesse para a sala. O Apêndice $B$ contém a apresentação utilizada para introduzir os participantes ao conceito de jornada do usuário. A Figura 33 apresenta o exemplo de uma jornada de usuário. Os demais mapas de jornada do usuário estão presentes nos Apêndices $\mathrm{E}$ a H.

Logo após, apresentou-se-Ihes a técnica de questões HMW, cuja apresentação está no Apêndice $C$, e distribuiu-se um conjunto de itens para cada equipe, a saber: notas autoadesivas (de 4 cores, uma para cada equipe) e canetas hidrográficas. Solicitou-se às equipes que escrevessem perguntas no formato HMW, considerando os POVs dos usuários mapeados nas jornadas, dentro de um tempo de 20 minutos. $\mathrm{A}$ Figura 34 apresenta o exemplo de uma questão HMW, enquanto o Apêndice I apresenta a compilação das questões criadas.

Em seguida, iniciou-se a apresentação das categorias de recursos, que está presente no Apêndice D. 7 das 11 categorias foram selecionadas para serem apresentadas, uma vez que alguns foram definidos como essenciais, logo não necessitariam passar por crivo. As selecionadas foram:

- Agendadores e disparadores;

- Notificações e mensagens;

- Big Data e analytics;

- Inteligência Artificial e Machine Learning;

- Dashboards 
- Serviços

A cada categoria de recursos apresentada aos participantes, solicitou-se que, se eles notassem que alguma pergunta de HMW pudesse ser solucionada por um recurso dela, dessem a nota autoadesiva da pergunta para afixar ao redor da etiqueta da categoria em um mural. Se em algum ponto detectassem que uma categoria solucionaria melhor o problema, eles trocariam de posição a questão. Houve, ainda, um espaço nomeado "outros", para perguntas que não encontraram solução aparente em nenhuma das categorias de recursos apresentadas. Desta forma, todas as perguntas relacionadas às necessidades dos projetos foram mapeadas para alguma categoria de recurso. A Figura 35 representa as questões agrupadas por categorias de recursos e a transcrição das questões levantadas estão presentes no Apêndice $\mathrm{H}$.

Figura 33: Uma das jornadas do usuário criadas. Em vermelho, as ações do usuário e oportunidades encontradas. Em verde, os pontos de contato com o sistema.

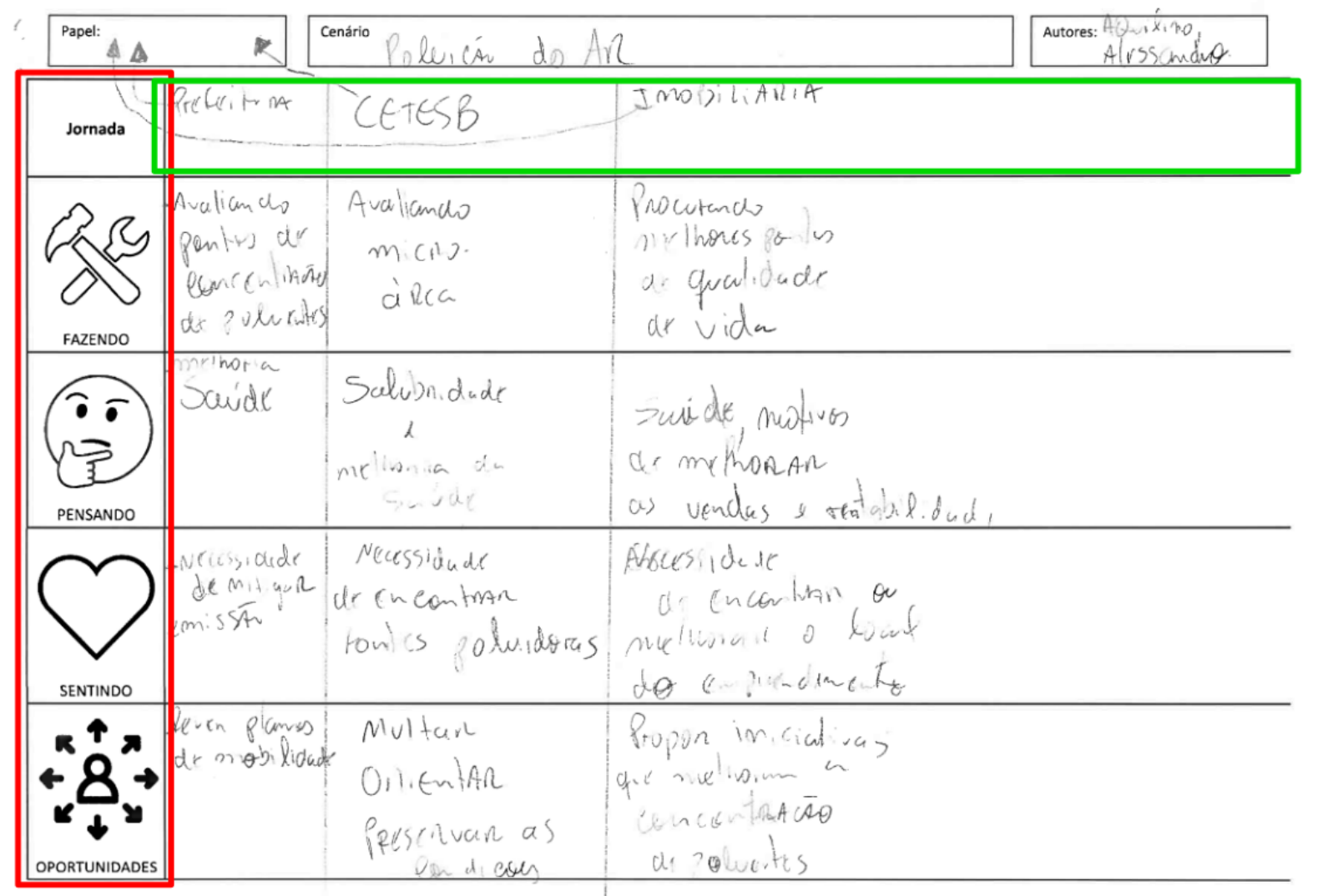

Fonte: Próprio autor. 
Figura 34: Duas notas autoadesivas com questões HMW elaboradas por um dos times.

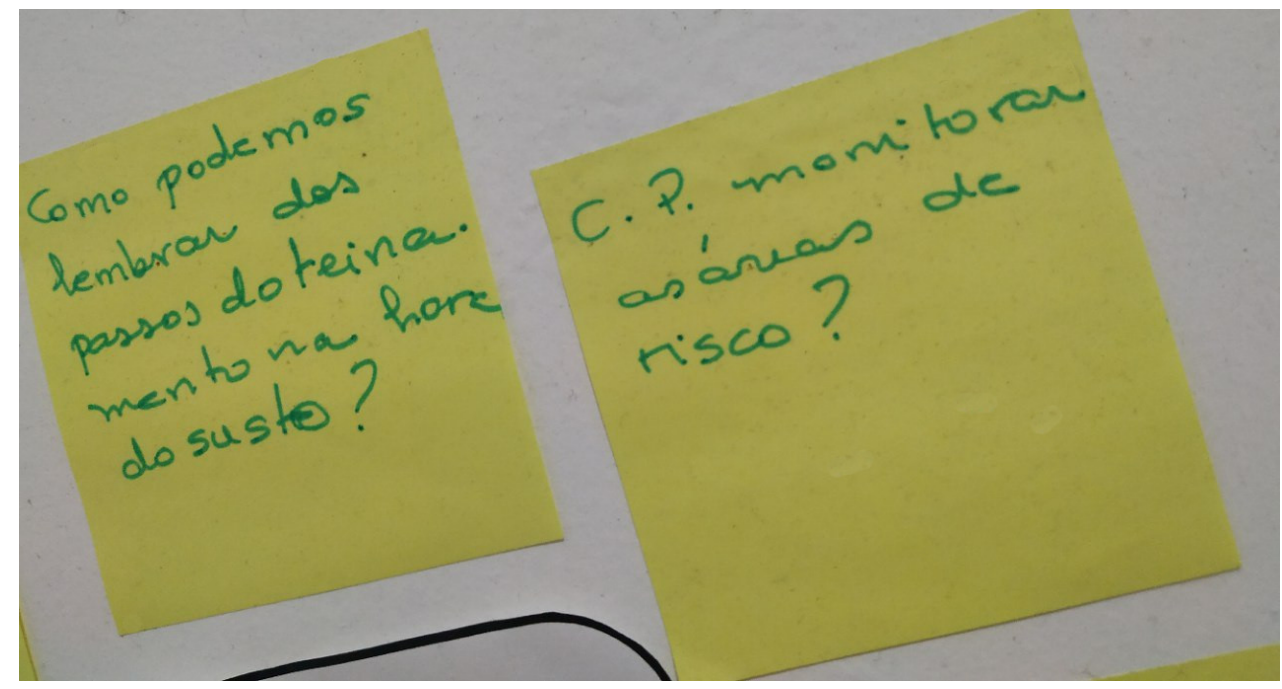

Fonte: Próprio autor.

Figura 35: Mural com as questões de HMW agrupadas por categorias de recursos.

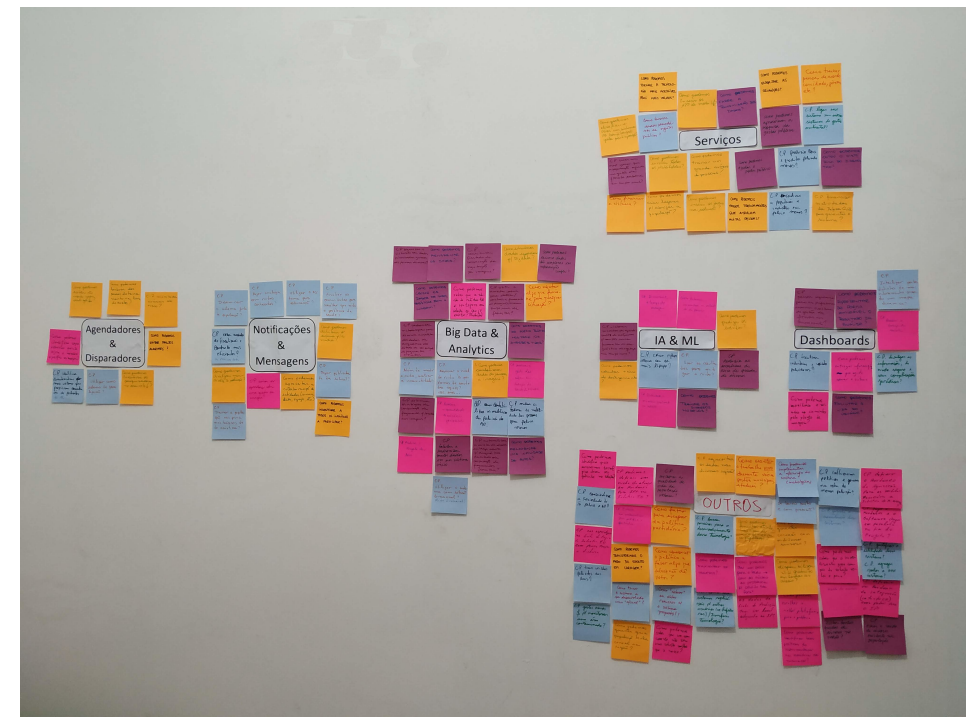

Fonte: Próprio autor.

\subsection{O Barulhômetro}

Dos projetos envolvidos, selecionou-se o projeto de análise de mapeamento de ruídos, conhecido como Barulhômetro, dentro da temática de Poluição e integrando a vertical de Cidades Inteligentes, para geração de estudo de caso. Isto se deve ao fato de o mesmo demonstrar maior maturidade de desenvolvimento e ser viável a criação de uma prova de conceito da camada do SToIC para o mesmo. Atualmente, ele está implementado utilizando a plataforma Fiware para obtenção de dados de tempo real e históricos de sensor de medição ruído de uma simulação de um parque. No entanto, 
como o foco do projeto é o mapeamento de ruídos nos vários parques da cidade de São Paulo, num cenário em que estes parques utilizem diferentes plataformas de loT, a camada proposta neste trabalho trará o benefício de permitir que esta aplicação possa obter os dados das diferentes plataformas utilizadas, garantindo maior alcance da mesma.

A dinâmica realizada permitiu detectar os recursos necessários para que a aplicação possa desempenhar seu papel, junto ao uso da própria aplicação e diálogo com seus desenvolvedores, verificando-se que o projeto utiliza dispositivos sensores de ruído, disponíveis em parques, que devem enviar seus dados as plataformas. Estas, por sua vez, armazenam os dados para posterior consulta e enviam notificações dos dados recebidos a um serviço Web, a aplicação do Barulhômetro, que recebe os dados e os disponibiliza em um gráfico de tempo real a ser observado pelos usuários, além de prover um serviço gráfico para consulta de dados históricos de ruído. Desta forma, detectou-se três categorias de recursos desejados que são descritos a seguir, no contexto das necessidades do projeto:

- Abstração de dispositivos: Registro dos dispositivos sensores de ruído dos parques.

- Agendadores e disparadores: Registro de tarefas que permite o Barulhômetro ser notificado ao ocorrer um evento nos dados dos sensores de medição ruído. Um exemplo disso seria a criação de uma tarefa que notificasse o Barulhômetro quando o nível de ruído detectado em um determinado parque for maior que $10 \mathrm{~dB}$.

- Big Data e Analytics: Os dados de medição de ruído devem ser armazenados para posterior consulta.

Já do ponto de vista do desenvolvedor desta aplicação e outras soluções de loT, estabeleceu-se como recursos desejados "painel de controle" (ferramenta gráfica para facilitar o desenvolvimento da solução), "serviços" (endpoints para uso do desenvolvedor, para auxílio da ferramenta gráfica e outra aplicação que posteriormente venha a necessitar a utilização de recursos), "SDK" (para integração dos recursos em diferentes linguagens de programação, fazendo consulta aos "serviços" internamente) e 
"dashboard" (para verificação dos dados recebidos e auditoria dos mesmos, não para usuário final).

A Figura 36 apresenta a arquitetura do Barulhômetro. Ele foi construído de forma a possibilitar a integração direta a componentes do Fiware, sendo o Orion responsável por oferecer o recurso de "agendadores e disparadores" e o Cygnus por armazenar dados históricos no SGBD Mongo DB, oferecendo um recurso da categoria "Big Data e Analytics". Os dispositivos medidores de ruído atualizam Entities registradas no Orion. Ele tem duas tarefas registradas que determinam que, quando uma Entity for atualizada, os dados da mesma sejam enviados para o Fiware Cygnus, que armazena uma cópia da mesma com data e hora no SGBD Mongo DB, e para o IPT Connector, que é o serviço web contendo a lógica de negócio do barulhômetro. Este, por sua vez, envia os dados recebidos ao Dashboard, que é uma aplicação de apresentação ao usuário e renderiza o dado como uma medição de ruído no gráfico em um navegador web e em tempo real. Através do Dashboard, o usuário pode também visualizar dados históricos. Ao requisitá-los no Dashboard, este solicita a lista de dados ao IPT Connector que, por sua vez, faz uma consulta ao Mongo DB, repassando os dados como resposta ao Dashboard, que os renderiza na forma de um gráfico. A criação de uma nova Entity era realizada através de uma requisição HTTP direta, sem auxílio de interface gráfica.

Figura 36: Arquitetura do Barulhômetro

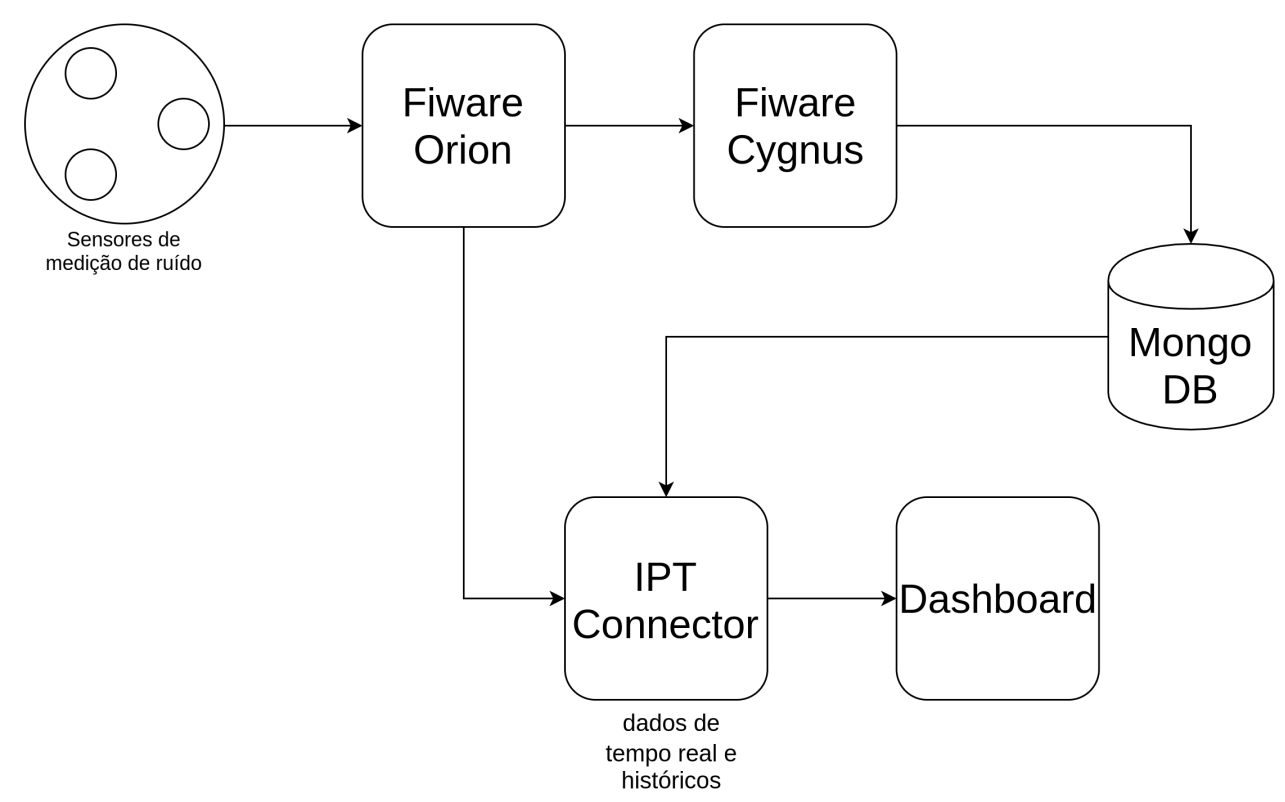

Fonte: CIAM-IPT 


\subsection{Escolha das Plataformas}

No âmbito do CIAM-IPT, considerando a revisão da literatura realizada no Capítulo 2 e decisões internas da Instituição, selecionou-se um conjunto de cinco plataformas para testes com projetos, a saber: Thingsboard ${ }^{1}$, Interscity, WIP, Fiware ${ }^{2}$ e Dojot $^{3}$. Dentre estes, optou-se por utilizar o WIP e o Helix, uma vez que o primeiro é uma plataforma comercial amplamente reconhecida, com grau de maturidade 9 na escala TRL, e o segundo é uma distribuição do Fiware, que é uma plataforma aberta realizada através de um consórcio entre universidades europeias e financiada pela UE, também com grau de maturidade 9.

\subsection{Considerações do Capítulo}

Este capítulo apresentou um relatório da dinâmica de DT realizada no âmbito do CIAM-IPT com a finalidade de levantar as necessidades dos projetos do IPT envolvidos com o PDIP e detectar oportunidades de novas aplicações de loT. Além dos benefícios gerados para os participantes do IPT e para o desenvolvimento desta pesquisa, houve a contribuição do desenvolvimento de uma abordagem baseada em DT para tornar mais fácil o levantamento de requisitos em loT, fazendo uso de materiais simples e de fácil disponibilidade como, por exemplo, notas autoadesivas, canetas, lápis e papel. Assim, resultou-se o artigo "Detecting IoT Applications Opportunities and Requirements Elicitation: A Design Thinking Based Approach”, aceito pela conferência Human-Computer Interaction International 2020 (HCII2020) para publicação na Lecture Notes in Computer Science (LNCS), com cópia disponível no Apêndice J, onde é possível encontrar maiores detalhes acerca dos resultados da dinâmica.

Dos projetos envolvidos, selecionou-se o projeto de análise de mapeamento de ruídos, conhecido como Barulhômetro, dentro da temática de Poluição e integrando a vertical de Cidades Inteligentes, para geração de estudo de caso. Isto se deve ao fato de o mesmo demonstrar maior maturidade de desenvolvimento e ser viável a criação de uma prova de conceito da camada do SToIC para o mesmo. Atualmente, ele está

\footnotetext{
${ }^{1}$ thingsboard.io

${ }^{2} \mathrm{O}$ Fiware é plataforma aberta e contém várias distribuições, sendo utilizada a Helix neste trabalho (Cabrini et al., 2019).

${ }^{3}$ dojot.com.br
} 
implementado utilizando a plataforma Fiware para obtenção de dados de tempo real e históricos de sensor de medição ruído de uma simulação de um parque. No entanto, como o foco do projeto é o mapeamento de ruídos nos vários parques da cidade de São Paulo, num cenário em que estes parques utilizem diferentes plataformas de loT, a camada proposta neste trabalho trará o benefício de permitir que esta aplicação possa obter os dados das diferentes plataformas utilizadas, garantindo maior alcance da mesma. O próximo Capítulo aborda sobre como o processo apresentado na Figura 14 foi aplicado para alcançar a portabilidade e interoperabilidade entre as plataformas Fiware e WIP, conforme as necessidades do Barulhômetro levantadas neste Capítulo, além de mostrar como diferentes elementos desta aplicação foram registrados no SToIC Panel, resultando na prova de conceito. 


\section{A PROVA DE CONCEITO}

Este Capítulo aborda sobre como os quatro passos do processo definido na Figura 14 do Capítulo 4 foram executados de acordo com as necessidades do Barulhômetro, iniciando-se pela análise dos modelos de dados das plataformas Fiware e WIP, passando pela análise comparativa dos recursos, definição do adaptador abstrato e culminando na implementação dos adaptadores do SToIC para ambas as plataformas, escolhidas como plataformas-alvo. Em seguida, a Seção 6.5 apresenta o registro de diferentes elementos do Barulhômetro no SToIC Panel, de forma a integrar a aplicação ao STolC, resultando na prova de conceito.

\subsection{Análise comparativa dos modelos de dados}

Para alcançar a interoperabilidade semântica, estudou-se os modelos de dados das plataformas e como as entidades de ambos se correlacionam. Os componentes do Fiware utilizados neste trabalho são o Orion, que segue o modelo de dados do padrão NGSIv2 ${ }^{1}$ (apresentado na Seção 3.4.3), o loT Agent ${ }^{2}$ e o Cygnus. O modelo de dados resultante está na Figura 37, onde se tem os seguintes elementos:

- Device: Representação virtual do dispositivo físico, isto é, o sensor ou atuador no mundo real. É obrigatoriamente associado a alguma e somente uma Entity. Exemplos: termômetros, sensores de ruídos e medidores de umidade;

- Entity: Abstração de objetos do mundo real em mais alto nível e diretamente associada ao do domínio do negócio. Exemplos: sala nํㅜ 200 e pessoa nํㅜ;

- Attribute: Representa alguma propriedade de um objeto de um mundo real e pertence à uma Entity, formando composição com ela. Exemplos: temperatura da sala $n^{\circ}$ 200, oxigenação da pessoa nำ3;

São atributos dos objetos do mundo real representados por Entities, formando com estes composições;

\footnotetext{
${ }^{1}$ fiware-orion.readthedocs.io/en/master/user/walkthrough_apiv2/index.html

${ }^{2}$ fiware-tutorials.readthedocs.io/en/latest/iot-agent/index.html
} 
- DeviceAttribute: É o mapeamento entre o nome de um dado coletado por um Device, se este é um sensor, ou um comando recebido, se for um atuador, e um atributo da Entity associada a este mesmo Device.

- Metadata: São dados opcionais associados a Attributes, com anotações sobre o dado representados nestes, com ambos formando uma agregação.

- MetadataAttribute: Cada uma das propriedades de um Metadata.

O WIP, por sua vez, tem seu modelo de acordo com a Figura $38^{3}$, contendo os seguintes elementos:

- Device: Representa um dispositivo, componente, ativo ou sistema registrado na plataforma que publica dados em pacotes chamados eventos. Exemplo: termometro001

- Device Type: É uma categoria que representa uma classe ou grupo de dispositivos. Exemplo: termômetro

- Event Type: De natureza semântica, representa uma categoria de eventos enviados por um Device ou Thing. Exemplo: medicao_de_temperatura, que trata todas as medições de temperaturas enviadas por um Device termômetro ou Thing quarto.

- Event Schema: Descrição da estrutura de um Event Type, associada a todos do tipo. Exemplo: \{temp : "integer", unit : "string"\}.

- Physical Interface: Abstração da interface entre um dispositivo físico e a plataforma.

- Logical Interface: Abstração de interface programada onde se normaliza os dados obtidos através da interface física.

- Mapping: Conversão de atributos entre a Physical Interface e a Logical Interface em Device ou entre a Logical Interface de um Device e a Logical Interface de um um Thing. Exemplo: o atributo t de um evento sendo convertido no atributo temperatura em um Thing

\footnotetext{
${ }^{3} \mathrm{ibm} . c o m /$ support/knowledgecenter/SSQP8H/iot/kc_welcome.html
} 
- Thing: Abstração de um elemento do mundo real, próximo ao domínio do negócio. Exemplo: Quarto001, Carro001.

- Thing Type: Uma categoria ou conjunto de Thing. Exemplo: Quarto, Carro.

Após a definição do modelo de dados da a ser oferecido, analisou-se as semelhanças e diferenças entre ambos os modelos de dados. Desta forma, faz-se as seguintes considerações:

- Há, em ambos, elementos que abstraem dispositivos físicos. No Fiware, há o Device, que é identificado unicamente pelo atributo "device_id", ao passo que no WIP, já é possível abstrair um dispositivo com os elementos Device, Device Type, Event Type, Event Schema, sendo o dispositivo identificado unicamente pela dupla (“device_type", “device_name”).

- Para abstrair elementos do mundo real próximos ao domínio do negócio, o Fiware apresenta o elemento Entity e o WIP, por sua vez, os elementos ThingType e Thing. Em ambos os modelos utiliza-se elementos intermediários para mapear a conversão de atributos que provêm dos dispositivos para eles, sendo DeviceAttribute no Fiware e o conjunto Physical Interface, Logical Interface e Mapping, no WIP. No entanto, ao passo que o Entity, no Fiware, pode existir e ser operado sem que haja a presença de dispositivo, o mesmo não acontece no WIP. Este último constrói o Thing como um elemento de composição de mapeamento de dados de diferentes dispositivos.

\subsection{Análise comparativa dos recursos oferecidos na camada de aplicação}

Com o auxílio da Tabela 7 do repositório online, que lista os recursos oferecidos na camada de suporte à aplicação das plataformas analisadas, tem-se que o Fiware oferece: i) Abstração de dispositivos; ii) Painel de controle; iii) Serviços; iv) Mensagens e Notificações; v) SDK; vi) Big Data e Analytics; vii) Marketplace; viii) Dashboards. O WIP, por sua vez, oferece: i) Abstração de Dispositivos; ii) Painel de controle; iii) Wiring tools; iv) Big Data e Analytics; v) Inteligência Artificial e Machine Learning. 
Figura 37: Modelo de Dados do Fiware.

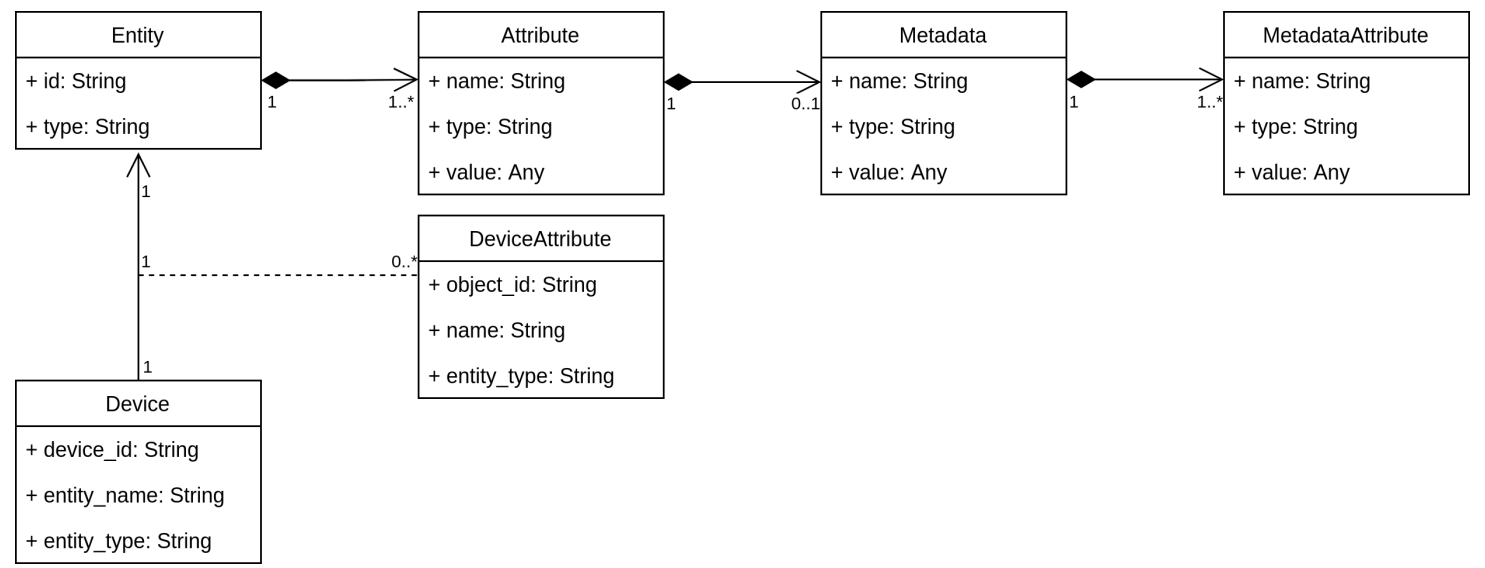

Fonte: Próprio autor.

Figura 38: Modelo de Dados do WIP.

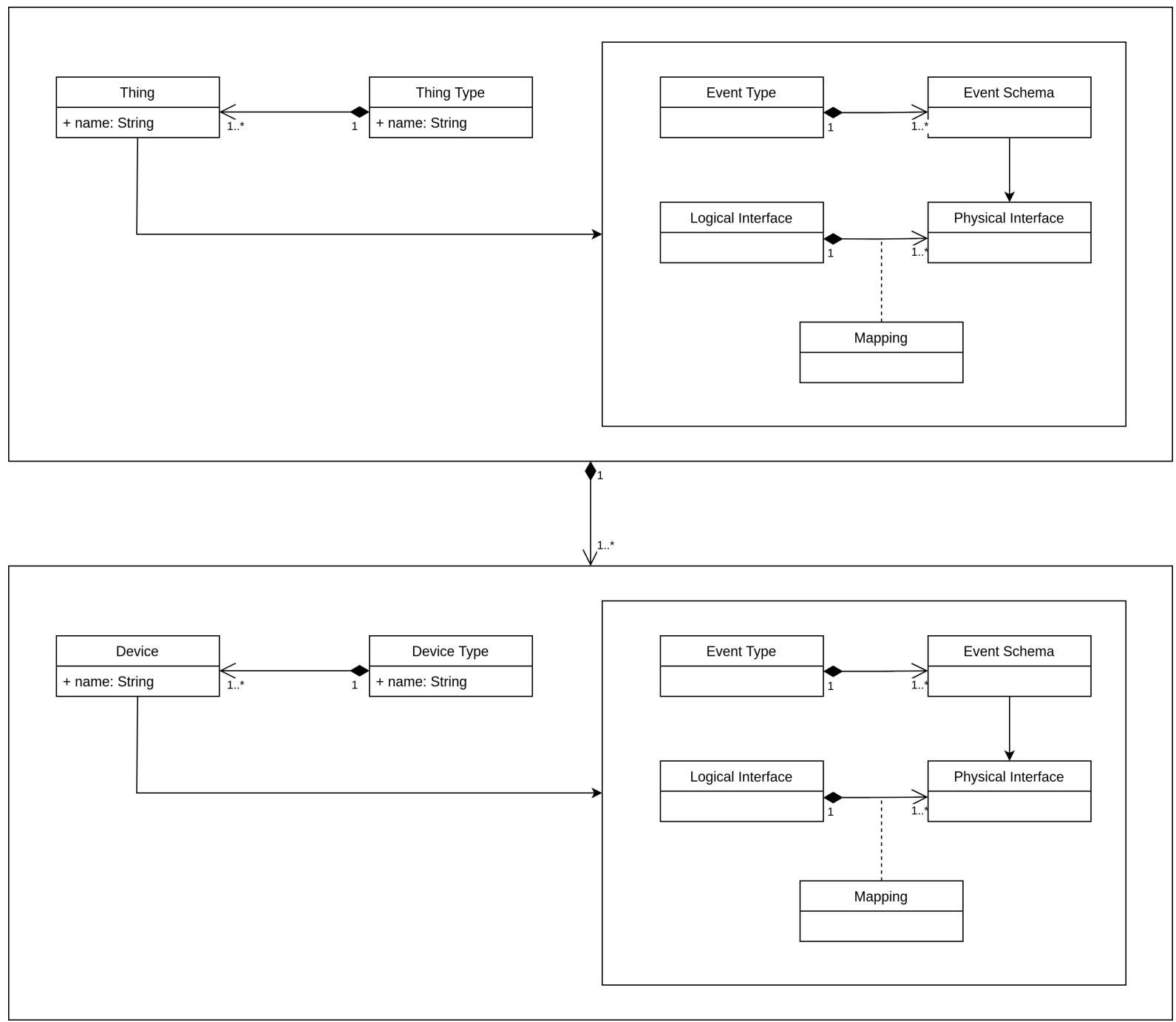

Fonte: Próprio autor.

Quanto às semelhanças, diferenças e comportamentos dos recursos desejados em ambas as plataformas, fazem-se as seguintes considerações: 
- A "abstração de dispositivos" em ambas as plataformas está fortemente relacionada a elementos de dispositivo e de abstração de elementos do mundo real do modelo de dados. A manutenção destes elementos, isto é, operações criação, edição, busca e remoção destes elementos, se dá através de endpoints Representational State Transfer (REST) (FIELDING; TAYLOR, 2000). No WIP, operações relacionadas ao elemento Thing estão em estado de teste pelo fabricante, havendo instabilidades em seu funcionamento, por isso não foi viável a sua utilização neste trabalho.

- O recurso de "agendadores e disparadores" no Fiware está acoplado a condições no contexto de elementos Entity, isto é, abstrações próximas ao domínio do negócio, ao passo que no WIP estão relacionadas a dispositivos físicos.

- O recurso de "big data e analytics", no WIP, está acoplado ao elemento Device, ao passo que no Fiware está ligado ao elemento Entity.

- Os recursos "painel de controle" e "dashboard" são altamente acoplados às plataformas, uma vez que são elementos gráficos.

Quanto aos recursos desejados faltantes na plataforma, observa-se que o elemento Thing do WIP, que é análogo ao elemento Entity do Fiware, por estar em estado de teste, além da possibilidade de ser retirado a qualquer momento, está disponível para uma quantidade limitada de usuários, podendo ser um possível ponto de falha, caso venha a ser utilizado. Desta forma, optou-se por implementar uma funcionalidade análoga ao Entity do Fiware no nível do adaptador do WIP, suprindo esta funcionalidade faltante. Além disso, esta estrutura pode ser aproveitada para implementar o "agendador e disparador", também na camada de portabilidade e interoperabilidade.

\subsection{Modelagem e codificação do adaptador abstrato}

O adaptador abstrato, que será a interface unificada a ser utilizada pela aplicação do Barulhômetro, deve ser modelado de forma a disponibilizar as funcionalidades dos recursos selecionados que se deseja prover às aplicações multiplataformas. Uma versão interativa da interface pode ser encontrada neste endereço ${ }^{4}$.

\footnotetext{
${ }^{4}$ gitlab.com/douglasllima/stoic
} 
Quanto ao modelo de dados resultante e a ser manipulado através da interface, a Figura 39 apresenta uma representação do mesmo. Seus elementos são:

- Platform: Abstração de uma instância de plataforma, com informações de seus serviços, endpoints e credenciais de autenticação. Através de seus dados realiza-se a conexão com a plataforma que se deseja.

- Device: Abstração de um dispositivo físico, atrelada a uma única instância de plataforma.

- Entity: Abstração de entidade do mundo real. Atrelada a uma ou mais instância de plataforma e a zero ou mais dispositivos de suas plataformas.

- Association: Associação entre dispositivos, entidades e mapeamento de atributos de ambos.

Figura 39: Modelo de dados implementado.

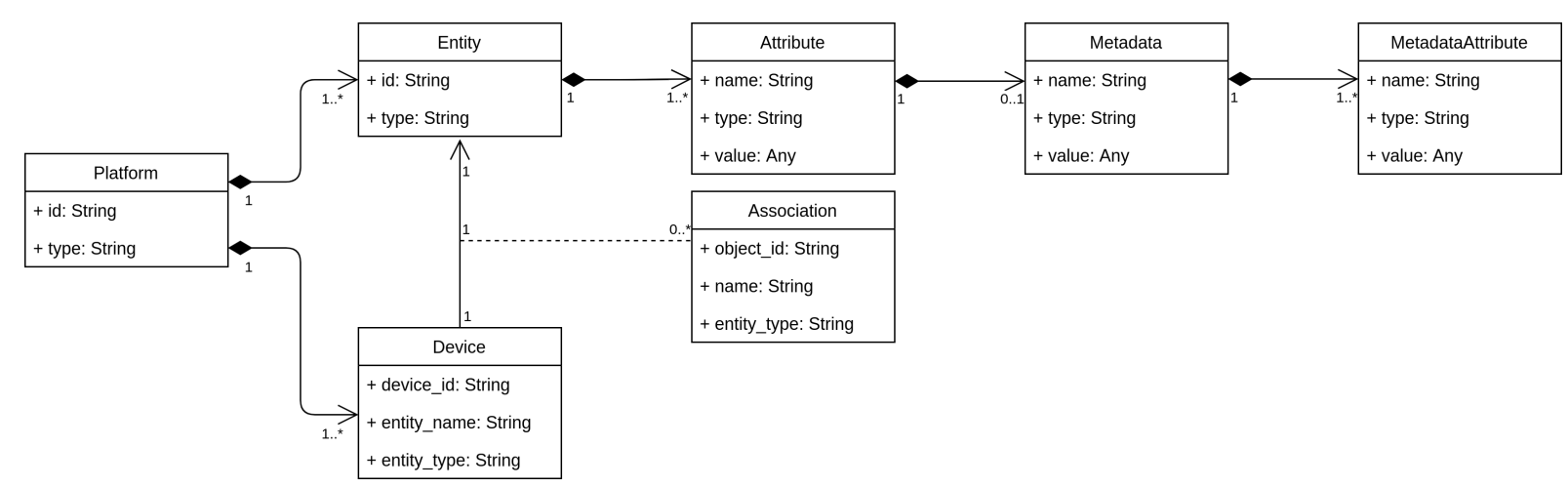

Fonte: Próprio autor.

\subsection{Implementação dos adaptadores de cada plataforma}

Esta etapa consiste em implementar os adaptadores para cada plataforma selecionada, de forma a fazer uso dos recursos nativos das plataformas para prover as funcionalidades previstas pelo adaptador abstrato, bem como suprir lacunas de funcionalidades entre recursos de diferentes plataformas e, inclusive, implementar recursos faltantes no nível do adaptador. Numa situação onde se necessitasse a criação de um adaptador para uma nova plataforma, poderia-se tanto manter o adaptador abstrato intocado quanto refiná-lo, modificando-o ou adicionando funcionalidades. Ademais, 
há recursos que por sua necessidade de interface gráfica não podem ser portados, como, por exemplo, "dashboards", "painéis de controle" e "wiring tools", sendo necessário uma implementação ao nível da camada.

Uma vez desenvolvida a implementação do SToIC, realizou-se a integração da aplicação Barulhômetro a ela. Para tal, simulou-se o cenário no qual dois parques utilizariam cada um as plataformas Fiware e WIP, ligadas a sensores de medição de ruído. Em seguida, realizaram-se adaptações no código-fonte da aplicação para que se pudesse utilizar os recursos oferecidos pela camada. Por fim, as plataformas, dispositivos, entidades, associações entre entidades e dispositivos e, por fim, tarefas que enviam dados gerados pelos dispositivos ao Barulhômetro foram registrados através do Panel. Estes passos que levaram à integração do Barulhômetro ao STolC são descritos a seguir.

Para que a aplicação fosse integrada ao SToIC, realizou-se uma intervenção no esquema do formato esperado de como o dado deveria ser recebido pelo IPT Connector, para estar de acordo com o formato da Entidade do SToIC, permitindo que a aplicação pudesse receber dados desta.

\subsection{Registro dos Elementos Necessários no STOIC Panel}

Primeiramente, realizou-se o registro de duas instâncias previamente existentes do Fiware e WIP no Panel, nomeadas de orion_fiware e wiotp_broker, respectivamente. No cenário simulado, cada uma das instâncias recebe dados de um dos dois parques, A e $B$, respectivamente. A Figura 40 apresenta as instâncias registradas.

Em seguida, registrou-se dois dispositivos, nomeados db001 e db002, respectivamente, representando dois sensores de medição de ruído, pertencentes às instâncias nomeadas orion_fiware e wiotp_broker, respectivamente, e aos parques A e B, respectivamente. A Figura 41 apresenta os dispositivos inseridos no Panel.

O próximo passo foi o cadastro de duas entidades do tipo Barulhometro, chamadas Barulhometro001 e Barulhometro002, respectivamente. A primeira pertence à instância orion_fiware, enquanto a segunda é compartilhada entre as duas instâncias, de tal forma que, através do Tangle, sempre haverá consistência entre as cópias da 
Figura 40: Instâncias de plataformas registradas no STOIC Panel

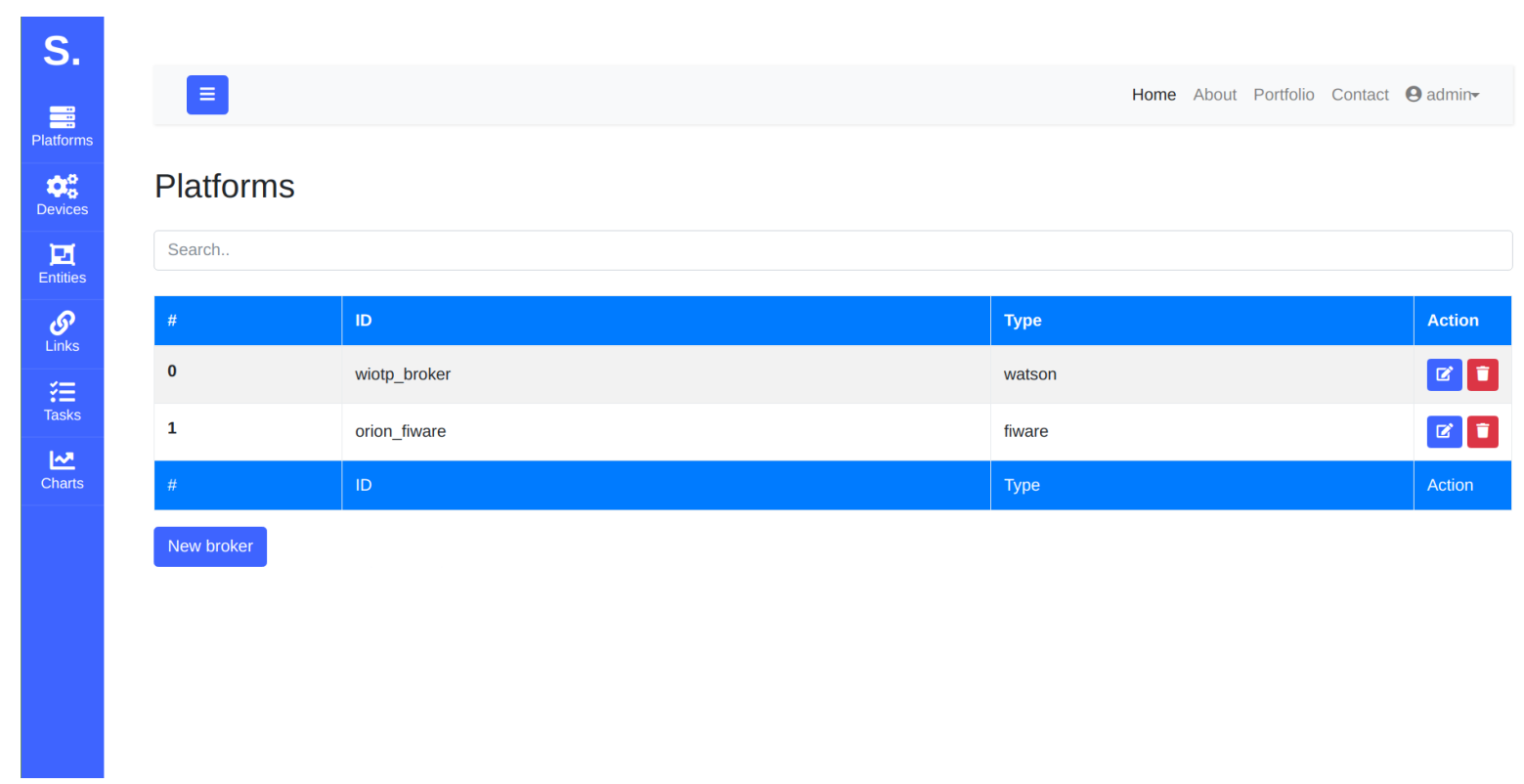

Fonte: Próprio autor.

entidade nelas. A Figura 42 mostra as entidades registradas no STOIC Panel.

Realizou-se, então, a associação entre os dispositivos e as entidades, de tal forma que o dispositivo db_001 foi associado à entidade Barulhometro001 e o dispositivo db_002 à entidade Barulhometro002. A Figura 43 apresenta as associações realizadas.

Logo depois, foram registradas duas tarefas, destacadas em vermelho na Figura 44, uma associada a cada entidade, que permitem notificar ao IPT Connector sobre cada medição de ruído. Além disso, outra tarefa inserida já no momento da criação da instância chamada orion_fiware faz com que o Fiware Cygnus seja notificado de todas as mudanças em entidades da mesma, incluindo a que é atualizada através de um dispositivo pertencente ao wiotp_broker mas tendo uma réplica na orion_fiware. Isto permite que o recurso de armazenamento de dados históricos da instância no Fiware seja utilizado pela instância no WIP, de tal forma que armazene dados históricos de ambas as instâncias e possa ser utilizado pelo Barulhômetro. Além disso, mostra a capacidade do STOIC de permitir com que uma plataforma possa fazer uso do recurso de outra no caso de falta ou desejo do desenvolvedor pela funcionalidade.

Por fim, é possível visualizar através dos gráficos do dashboard do Panel, apresentados na Figura 45, que as cópias da entidade Barulhometro002 nas duas plataformas 
Figura 41: Dispositivos registrados no STOIC Panel.

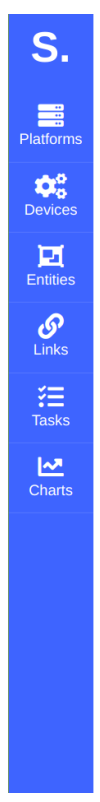

Fonte: Próprio autor.

Figura 42: Entidades registradas no STOIC Panel.

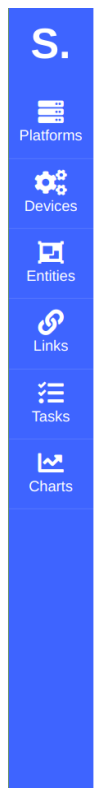

\begin{tabular}{|c|c|c|c|c|c|}
\hline$\#$ & ID & Type & Description & Broker & Action \\
\hline $\mathbf{0}$ & db001 & $d b$ & None & orion_fiware & $\pi$ \\
\hline 1 & db002 & $d b$ & Parque Ibirapuera & wiotp_broker & $\bar{\pi}$ \\
\hline \# & ID & Type & Description & Broker & Action \\
\hline
\end{tabular}

New device

Figura 42: Entidades registradas no STOIC Panel.

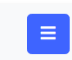

Home About Portfolio Contact 9 admin-

Entities

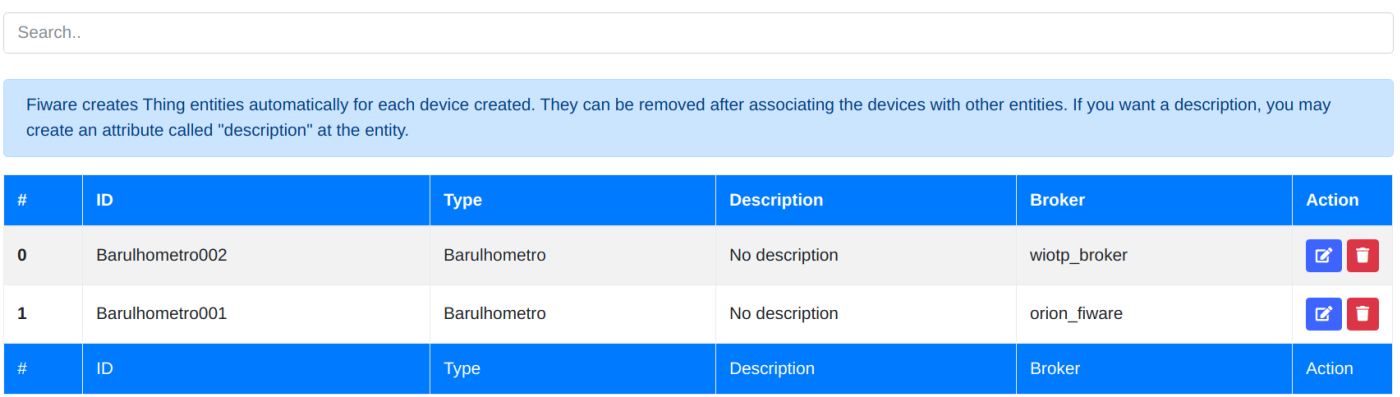

New entity

Fonte: Próprio autor.

estão apresentando os mesmos dados, com latência devido ao tempo de replicação entre as instâncias, havendo uma consistência entre elas. As Figuras 46 e 47 apresentam telas do Barulhômetro dos gráficos de medição de ruído de cada um dos dois parques. Estas telas são destinadas ao usuário final para visualização ao acessar a aplicação, onde é possível visualizar o gráfico da medição de ruído de um determinado parque. Além disso, é possível selecionar outro parque no painel para ver suas medições em decibéis. 
Figura 43: Associações realizadas entre os dispositivos e entidades no Panel.

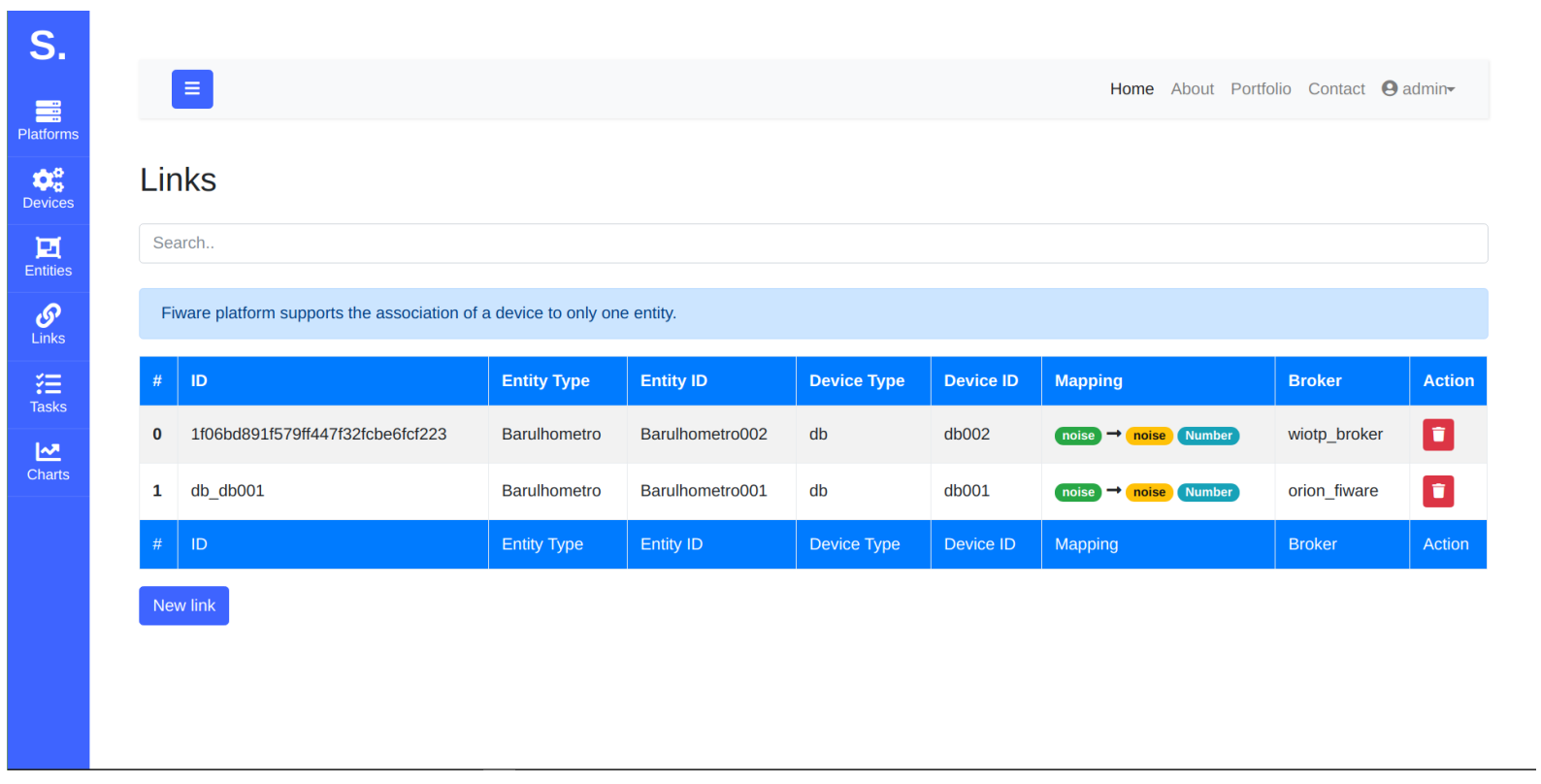

Fonte: Próprio autor.

Figura 44: Tarefas registradas no Panel.

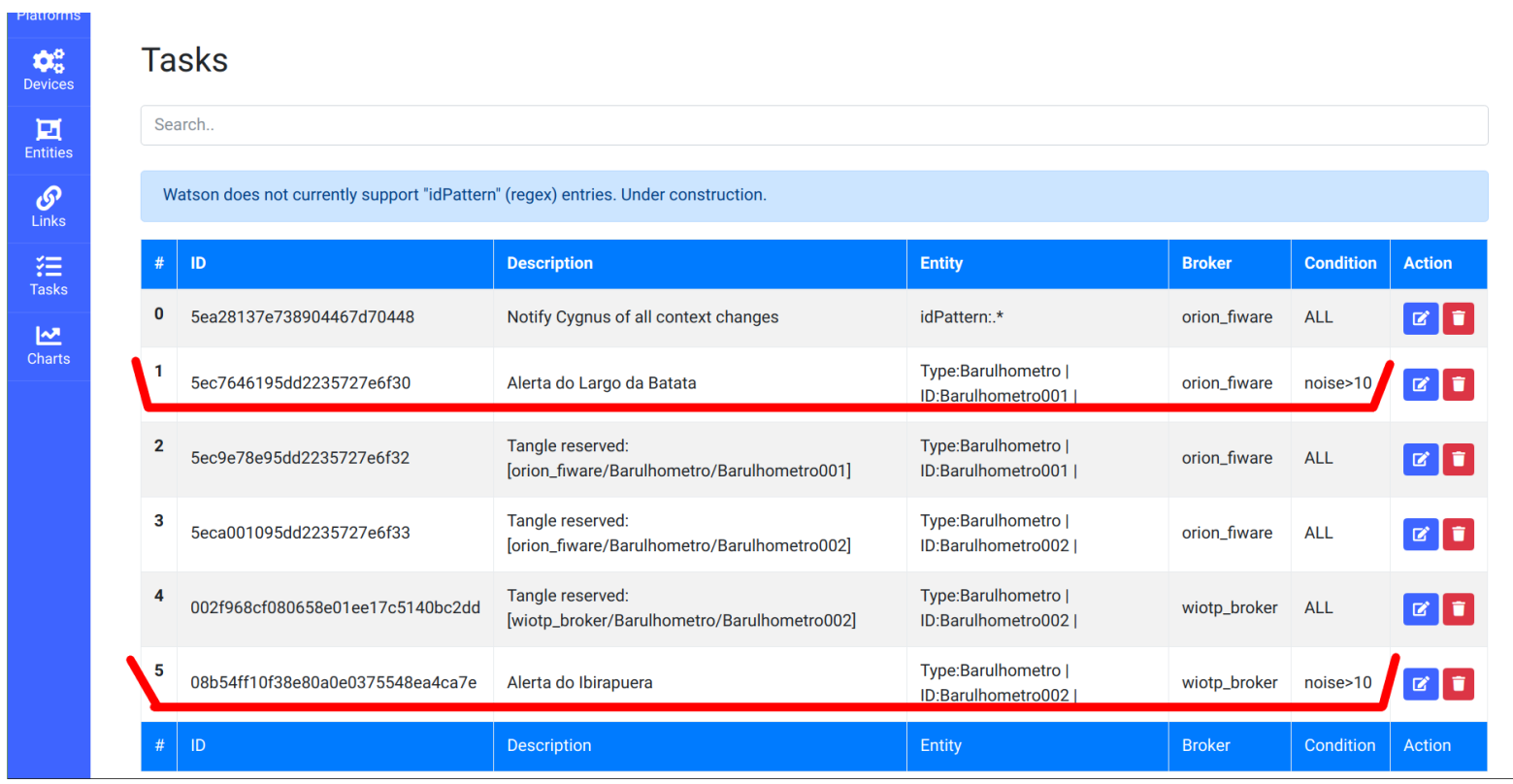

Fonte: Próprio autor.

\subsection{Considerações do Capítulo}

Este Capítulo apresentou a criação de adaptadores do SToIC para as plataformas Fiware e WIP de acordo com as necessidades do Barulhômetro. Para tal, começou-se com a análise comparativa dos modelos de dados das duas plataformas, notandose que em ambos os modelos há elementos que representam dispositivos físicos e componentes do domínio do negócio, mas implementados de maneiras diferentes. 
Figura 45: Dashboard do Panel apresentando os gráficos com medições das entidades BaruIhometro001 e Barulhometro002.
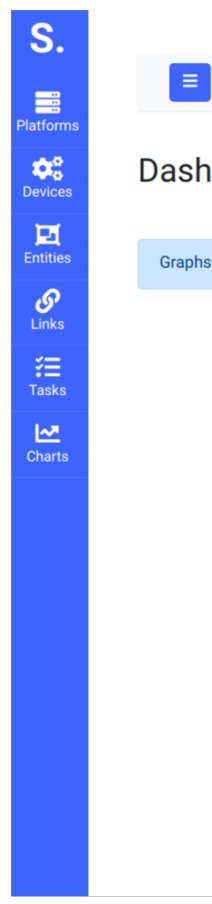

Dashboard

Graphs of entangled entities will show replicated data. This dashboard is for auditing entity data, not for end users.

\section{Barulhometro001}

address (String)

$17: 01: 42$

\{"description":"Largo da Batata"\}

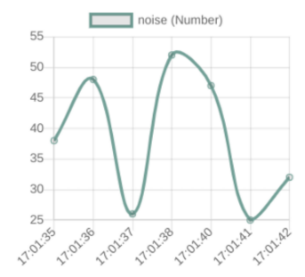

orion-fiware Baralhometro

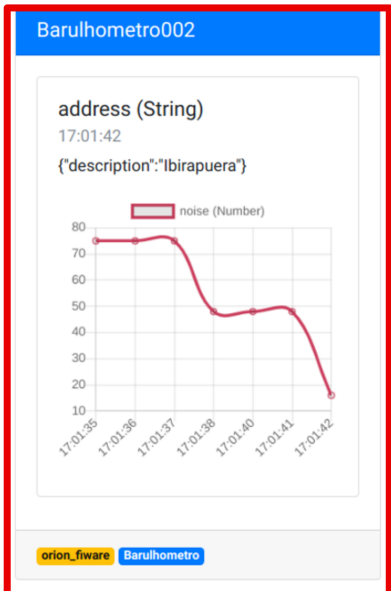

Barulhometro002

address (String)

17:01:42

("description:":"birapuera"\}

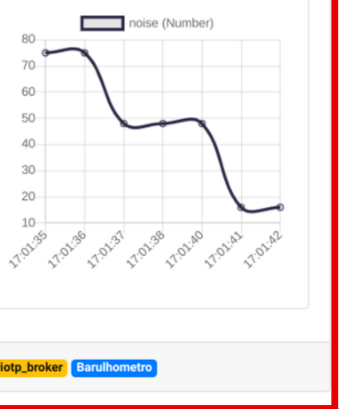

Fonte: Próprio autor.

Figura 46: Tela do Barulhômetro com medições de ruído do parque A.

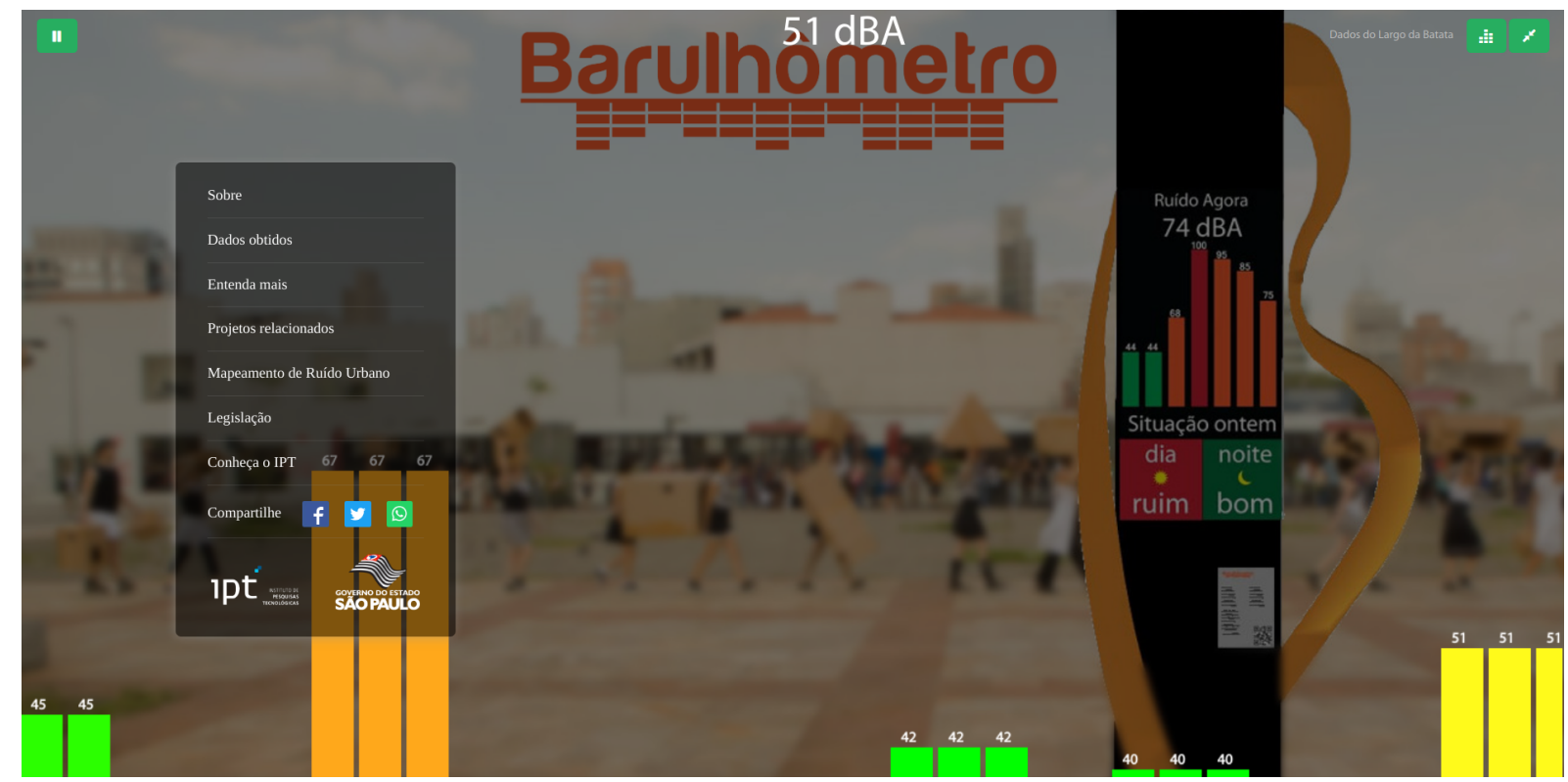

Fonte: Próprio autor.

Logo depois, seguiu-se a análise comparativa dos recursos oferecidos, verificou-se que havia recursos no Fiware necessários para uso do Barulhômetro, mas faltantes no Watson, de forma que foi desejável implementá-los no nível do adaptador, que são "agendadores e disparadores" e "big data e analytics". Em seguida, definiu-se o modelo de dados resultante do adaptador abstrato e interface para acesso aos recursos 
Figura 47: Tela do Barulhômetro com medições de ruído do parque B.

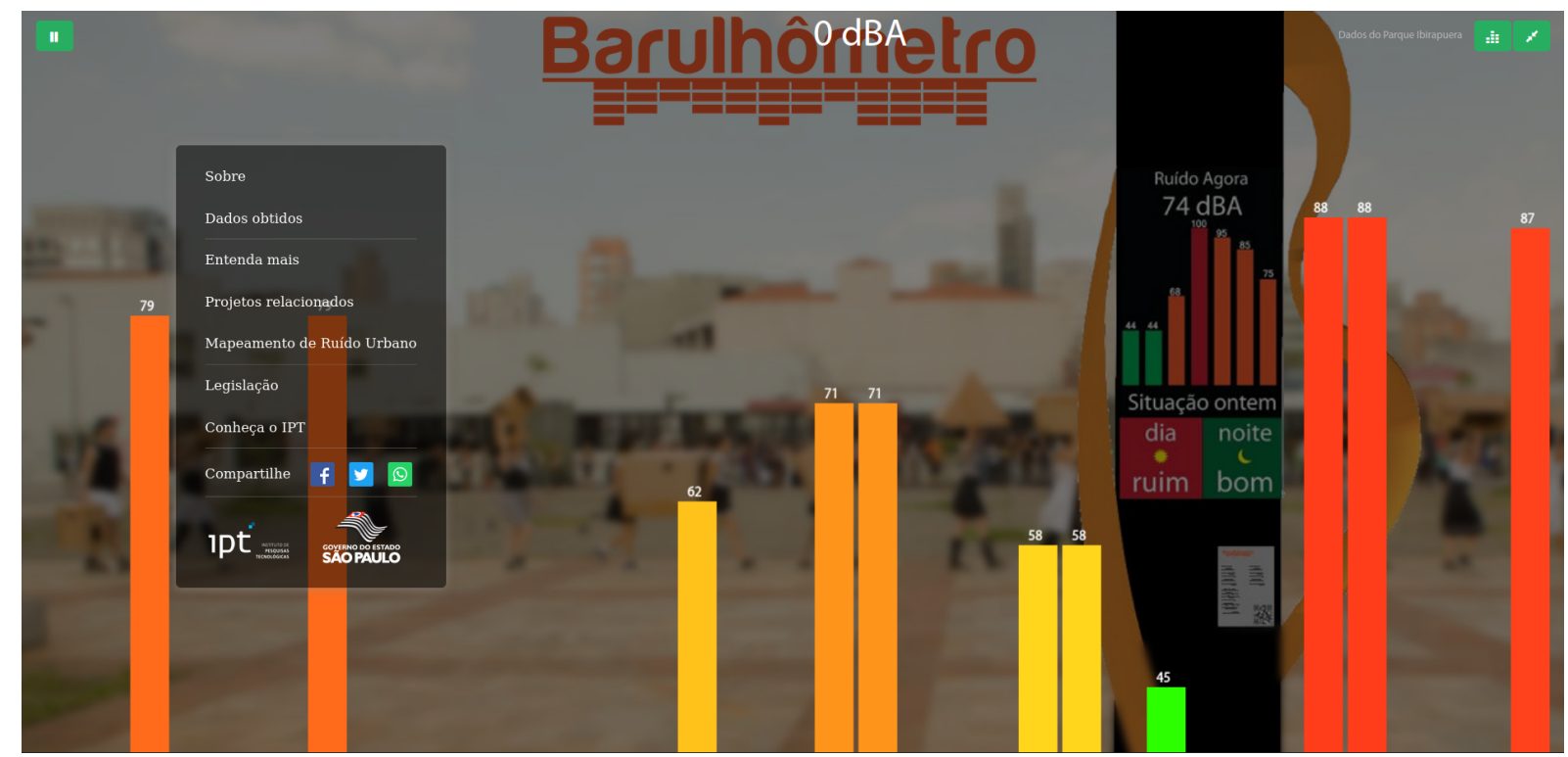

Fonte: Próprio autor.

abstratos. Por fim, implementou-se os adaptadores. Além disso, após terminada a criação dos adaptadores, realizou-se o registro dos elementos do Barulhômetro no SToIC Panel de acordo com o modelo de dados definido, permitindo a integração do mesmo como uma aplicação multiplataforma ao SToIC e provando o conceito da solução proposta. 


\title{
7 DISCUSSÃO
}

Vermesan (2018, p. 30, grifo nosso) aponta que

\begin{abstract}
A falta de interoperabilidade da plataforma causa grandes desvantagens tecnológicas e econômicas, como a impossibilidade de conectar dispositivos de loT não interoperáveis em plataformas de loT heterogêneas, impossibilidade de desenvolver aplicações de loT que explorem múltiplas plataformas, lentidão na introdução da tecnologia loT em grande escala, desestímulo na adoção da tecnologia de loT, silos verticais em ecossistemas e mercados de IoT, aumento de custos, escassa reutilização de soluções técnicas ou insatisfação do usuário.
\end{abstract}

Neste Capítulo, discute-se diferentes aspectos do trabalho realizado. A Seção 7.1 discute sobre os níveis de interoperabilidade alcançados, a Seção 7.2 apresenta os padrões de interoperabilidade presentes no projeto, a Seção 7.3 apresenta aspectos da portabilidade no contexto do SToIC, a Seção 7.4 discute limitações do trabalho realizado e, por fim, a Seção 7.5 compara o SToIC com trabalhos relacionados.

\subsection{Níveis de Interoperabilidade Alcançados}

Considerando os quatro níveis de interoperabilidade apresentados na Seção 3.2, a solução implementada neste trabalho alcança o nível semântico e, consequentemente, os níveis técnico e sintático, uma vez que um nível de interoperabilidade depende da implementação de níveis anteriores. A seguir, descreve-se como a solução implementada alcançou estes três níveis:

- Técnico: As plataformas Fiware e WIP oferecem endpoints RESTful através do protocolo HTTP (FIELDING et al., 1999). Além disso, o WIP provê uma interface que faz uso do protocolo MQTT para notificar atualizações dos dispositivos. Os adaptadores desenvolvidos para utilizar os recursos de cada plataforma fazem uso destes protocolos e o SToIC Core provê a interface unificada às aplicações multiplataformas através de endpoints RESTful usando o protocolo HTTP. Desta forma, fazendo uso de um protocolo único, o nível técnico de interoperabilidade foi alcançado. 
- Sintático: Uma vez que o SToIC Core oferece a interface através do protocolo HTTP às aplicações multiplataformas, o nível sintático foi alcançado quando, após definição do modelo de dados, definiu-se que o formato utilizado para a estrutura destes dados seria o JSON (CROCKFORD, 2006). Este formato também é utilizado por ambas as plataformas, separadamente.

- Semântico: Por fim, após a definição da utilização do protocolo HTTP e o formato de dados JSON, o modelo de dados definiu esquemas através dos quais os elementos dos modelos de dados seriam representados e utilizados pelas aplicações multiplataformas. Desta forma, apesar de ambas as plataformas utilizarem esquemas de dados distintos, os adaptadores de cada plataforma fazem essa conversão para que o SToIC Core possa prover dados em um esquema unificado. Em trabalhos futuros, poderá ser investigado o uso de ontologias, o que tem o potencial de melhorar a implementação deste nível.

Como o nível organizacional lida com questões de natureza estratégica e gerencial de diferentes organizações, que fogem ao escopo deste trabalho, não foi avaliada a implementação deste nível de interoperabilidade, sendo necessário em trabalhos futuros avaliar como este nível pode ser implantado e mensurado em organizações diferentes, partindo dos três níveis já implantados neste projeto, uma vez que são pré-requisitos para o nível organizacional.

Considerando o projeto do SToIC, é possível estender os níveis implementados para outras plataformas através do estudo do modelo de dados e dos recursos oferecidos por elas e da criação de novos adaptadores, seguindo o processo estabelecido no Capítulo 4.

\subsection{Padrões de Interoperabilidade Implementados}

Neste trabalho implementou-se três dos cinco padrões de interoperabilidade citados na Seção 3.3, a saber, "acesso interplataforma", "independência de plataforma" e "fachada de alto nível de serviços". A seguir, discute-se como cada um dos padrões foi implementado:

- Acesso interplataforma: A aplicação do Barulhômetro utiliza o recurso de 
"agendadores e disparadadores" das instâncias de duas plataformas distintas, Fiware e WIP.

- Independência de plataforma: A solução implementada permite que a aplicação utilize recursos de somente uma das plataformas, Fiware ou WIP, se necessário, o que pode ser realizado através do registro de uma ou mais instâncias de uma das plataformas no SToIC Panel, não havendo a necessidade de alterações da aplicação para isso.

- Fachada de alto nível de serviços: A solução implementada apresenta esse padrão quando faz uso do recurso nativo do Fiware de gerenciar entidades, mas implementa no nível do adaptador esta funcionalidade faltante no WIP, de forma que o SToIC Core utilizando este adaptador funciona como uma fachada que provê esta funcionalidade. Esta diferença de como o recurso é implementado não é perceptível do ponto de vista da aplicação do Barulhômetro, uma vez que o SToIC Core provê a interface unificada.

O padrão "acesso interdomínio de aplicação", embora não demonstrado no uso da solução implementada pela aplicação do Barulhômetro, é possível no caso em que, por exemplo, uma instância Fiware provesse dados de ruídos e outra instância WIP disponibilizasse dados de poluição do ar, de tal forma que uma aplicação pudesse utilizar dados de ambas as instâncias e diferentes domínios de negócio.

O padrão "independência de escala de plataforma" não foi detectado, uma vez que o Fiware e WIP estão na mesma escala, a do ambiente de nuvem, considerando os três previstos pelo padrão, que são: ambiente de nuvem, ambiente de borda e dispositivo. Para o que seja implementado, é possível analisar os recursos e modelos de dados de plataformas no nível da borda e dispositivo, seguindo o processo apresentado no Capítulo 4.

\subsection{Aspectos de Portabilidade}

Na Seção 3.1 apresentou-se três características da portabilidade. A seguir, discute-se como uma aplicação multiplataforma compatível com a implementação realizada do SToIC apresenta cada uma delas: 
- Adaptabilidade: Uma aplicação que utiliza os recursos das categorias "abstrações de dispositivo", "serviços" (na figura das "entidades", descritas no Capítulo 4) e "tarefas", poderá migrar facilmente entre ambientes que façam uso somente ou de Fiware, ou WIP, ou ambos. No caso em que se utilize somente Fiware, o adaptador para a plataforma no SToIC fará uso dos recursos nativos correspondentes nas plataformas. No segundo caso, em que haja a presença somente de WIP, o adaptador para esta plataforma utiliza nativamente o recurso de "abstrações de dispositivos" mas implementa o recurso de "serviços" e "tarefas" no nível do adaptador, uma vez é um recurso faltante na plataforma. Por fim, no caso em que se utilize ambas as plataformas, o STolC estará usando adaptador para ambas. Já o recurso da categoria "Big Data e Analytics", como está implementadado somente no adaptador do Fiware, pode comprometer a adaptabilidade de uma aplicação caso ela esteja em um ambiente que faça uso somente de WIP. No caso da aplicação do Barulhômetro, por exemplo, para apresentar dados históricos coletados através de uma instância da plataforma WIP, necessita que os mesmos tenham sido recebido pelo Fiware, através do uso do Tangle.

- Capacidade de Instalação: Para que a aplicação multiplataforma possa ser instalada e configurada em um ambiente, basta que faça uso da interface disponibilizada pelo SToIC, não havendo outros requisitos como configuração mínima de hardware ou sistema operacional de execução para que possa haver essa comunicação.

- Capacidade de Substituição: Supondo-se um cenário no qual uma aplicação esteja fazendo uso de uma instância da plataforma Fiware através do SToIC, para que esta instância seja substituída por uma da plataforma WIP, bastaria a exclusão do registro da instância do Fiware e a inserção do registro de instância do WIP, com o mesmo identificador único, desde que se esteja utilizando os recursos das categorias "abstrações de dispositivo", "serviços" e "tarefas", conforme já discutido ao considerar o aspecto da adaptabilidade.

Considerando o projeto do SToIC, a portabilidade é alcançada em maior grau à medida que os adaptadores implementados contenham um maior número de recursos na mesma categoria, sejam implementados baseados nos recursos nativos da 
plataforma ou no nível dos próprios adaptadores, quando houver recursos faltantes. Desta forma, a aplicação multiplataforma tem maior flexibilidade ao utilizar recursos abstratos que se manterão consistentes independentemente das instâncias de plataformas sobre as quais estiver operando.

\subsection{Limitações}

Dado a grande variedade de plataformas de loT existentes, recursos oferecidos por elas e a variância na funcionalidade destes recursos, por sua vez, pode ocorrer que, ao se implementar adaptadores para plataformas com recursos muito diferentes entre elas, seja necessário maior codificação na implementação dos recursos abstratos para que se possa compensar as lacunas. Uma forma de minimizar este problema é realizar a criação de adaptadores para um conjunto definido da plataformas semeIhantes nos recursos oferecidos e nas funcionalidades que estes recursos proveem, de forma que os adaptadores utilizem os recursos nativos das plataformas para suas operações ao invés de necessitar de implementações mais robustas para compensar recursos faltantes ou com funcionalidades muito diferentes entre as plataformas. Outra limitação é a portabilidade de recursos que dependem de elementos gráficos, como os pertencentes às categorias "dashboards", "painéis de controle", "wiring tools", pois muitas vezes as plataformas apresentam as telas destes recursos já renderizadas graficamente, de forma que não se pode ter acesso à construção dos gráficos. Se as plataformas oferecem endpoints que permitam obter e enviar dados em formato estruturado, como JSON e XML, por exemplo, antes da construção destes elementos gráficos, é possível a implementação de adaptadores que interajam nativamente com estes recursos. Outra forma de contornar este problema é através da criação de aplicações multiplataforma que ofereçam elementos gráficos e supram a necessidade destes recursos, como o SToIC Panel, por exemplo, que provê a necessidade de um painel de controle e dashboard dentro do contexto da implementação do SToIC realizada. 


\subsection{Comparação com Trabalhos Relacionados}

A Tabela 9 apresenta uma comparação entre o SToIC e as iniciativas do loT-EPI considerando níveis de interoperabilidade alcançados, padrões de interoperabilidade implementados e camadas do modelo de referência do ITU em que atuam. Observase que o SToIC opera utilizando recursos da camada de suporte à aplicação das plataformas de loT e encontra-se na camada de aplicação, considerando o modelo de referência ITU.

As iniciativas BIG loT e bioTope dependem que fabricantes de plataformas de loT implementem bibliotecas e padrões, respectivamente, em suas soluções, para disponibilizar suas funcionalidades em catálogos, necessitando de adesão dos mesmos às iniciativas, ao passo que o SToIC necessita apenas que se faça uma análise dos recursos e modelos de dados oferecidos por plataformas de loT e que, a partir disso, se desenvolva adaptadores para as mesmas, não necessitando da adesão de fabricantes para tal.

O symbloTe, por sua vez, permite que uma aplicação de loT busque recursos oferecidos por diferentes plataformas através de ontologias, necessitando que os provedores destas plataformas realizem modificações nas mesmas para que se integrem à solução, enquanto o SToIC oferece uma interface com recursos abstratos para aplicações e utiliza recursos nativos das plataformas dentro de seus adaptadores, não necessitando mudanças na implementação das plataformas.

O AGILE utiliza Node-RED ${ }^{1}$, uma ferramenta gráfica que permite a criação de programas através da conexão de blocos que representam diferentes funcionalidades, para permitir que o usuário utilize recursos como APIs de diferentes fontes, serviços de plataformas de loT, entre outros. No entanto, nesta abordagem o usuário deve ter um entendimento dos recursos oferecidos pelas plataformas e ele os utiliza diretamente, de forma que a aplicação se torna altamente dependente dos mesmos. No SToIC, por sua vez, as diferenças entre os recursos das plataformas são contornadas na implementação dos adaptadores, de forma que a aplicação não esteja acoplada diretamente aos recursos das plataformas. Este desacoplamento facilita a migração da aplicação entre plataformas diferentes, isto é, a portabilidade.

\footnotetext{
${ }^{1}$ nodered.org
} 
O Inter-loT desenvolve interoperabilidade em múltiplas camadas das plataformas de loT, através do mapeamento de recursos presentes nestas diferentes camadas e disponibilização para aplicações através de ontologias, enquanto o SToIC foca nas camadas de suporte à aplicação e aplicação e oferece recursos abstratos através do mapeamento de recursos nativos das plataformas nos adaptadores.

Por fim, o VICINITY disponibiliza à aplicação recursos de rede e dispositivos de diferentes plataformas através de ontologias, focando na interoperabilidade destas camadas, ao passo que o SToIC provê interoperabilidade na camada de aplicação.

A principal diferença da abordagem de interoperabilidade do SToIC em relação às iniciativas anteriores é permitir a replicação de elementos do modelo de dados em diferentes plataformas através do Tangle, conforme a necessidade da aplicação, de tal forma que se uma cópia deste elemento for alterada, suas alterações são propagadas entre as demais plataformas, considerando as especificidades de cada uma. Isto permite, inclusive, que a falta de uma funcionalidade de uma plataforma seja suprida através do uso da funcionalidade desejada em outra, desde que a plataforma que a tenha realize o processamento em uma das cópias. Além disso, o SToIC permite a portabilidade ao criar uma camada de abstração entre as aplicações multiplataformas e as plataformas, deste que os recursos utilizados estejam implementados nos adaptadores das plataformas que se queira usar, de forma que é possível deixar de se utilizar uma das plataformas em detrimento das outras em função de custos, licenças, entre outros. Questões de portabilidade não foram abordadas pelas iniciativas citadas. 


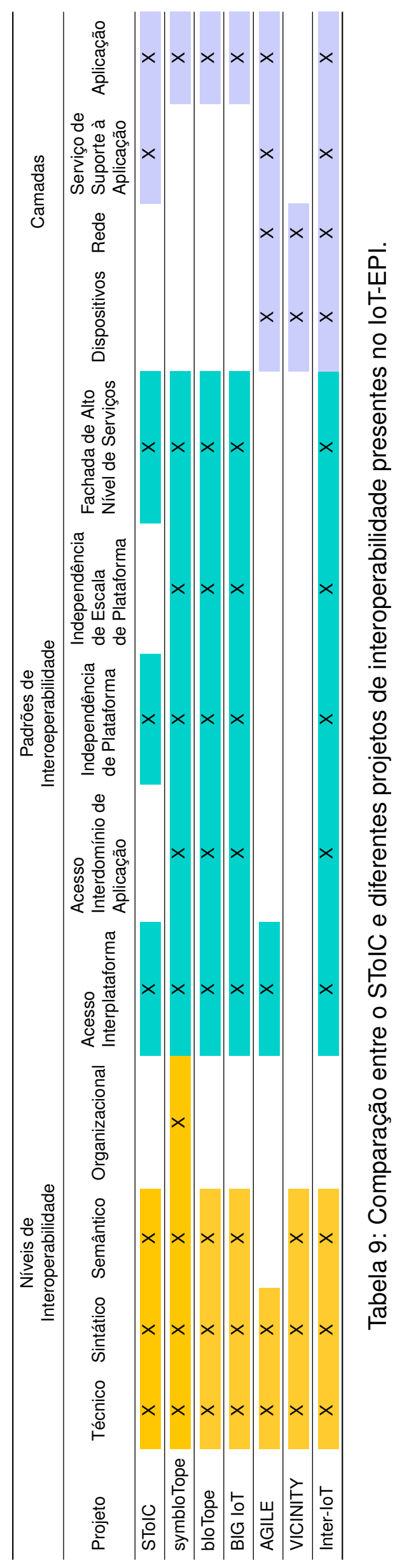




\section{CONCLUSÃO}

Este trabalho propôs o SToIC, um modelo de camada de interoperabilidade e portabilidade no nível da camada de aplicação de plataformas de loT através do mapeamento de recursos oferecidos pelas plataformas de loT, na camada de suporte à aplicação, e criação de adaptadores para prover recursos abstratos para aplicações multiplataformas.

Primeiramente, realizou-se levantamento na literatura para descobrir que recursos são oferecidas pelas plataformas de loT para o desenvolvimento de aplicações, detectando-se 11 categorias distintas de recursos, que são: "abstrações de dispositivos", "painéis de controle", "serviços", "wiring tool", "disparadores de mensagens e notificações", SDKs, "big data e analytics", "IA e ML", "marketplaces", "dashboards" e, por fim, "agendadores e disparadores".

Em seguida, definiu-se o projeto do SToIC, com o processo para se obter interoperabilidade e portabilidade de recursos a partir da análise dos modelos de dados e dos recursos oferecidos por um conjunto de plataformas-alvo e a necessidade das aplicações multiplataformas que se deseja implementar e a criação de adaptadores para as plataformas, bem como a arquitetura do SToIC.

Uma vez definidas as categorias de recursos oferecidos pelas plataformas e o projeto do SToIC, realizou-se uma dinâmica com membros de projetos do CIAM-IPT para levantar as necessidades destes projetos e detectar oportunidades de aplicações de loT. Dos projetos envolvidos, selecionou-se o projeto de análise de mapeamento de ruídos, conhecido como Barulhômetro, dentro da temática de Poluição e integrando a vertical de Cidades Inteligentes, para geração de estudo de caso.

Logo depois, com base no projeto definido e nas necessidades da aplicação do Barulhômetro, realizou-se uma implementação do SToIC tendo como base duas plataformas-alvo, WIP e Fiware, e os recursos das categorias "abstrações de dispositivo", "agendadores e disparadores" e "big data e analytics".

Em seguida, foram realizadas modificações na aplicação do Barulhômetro para que ela se tornasse multiplataforma e utilizasse os recursos abstratos oferecidos pela 
implementação do SToIC. Desta forma, a aplicação pôde obter medições de ruído das plataformas Fiware e WIP, assim como a criação de "entidades" (representações de objeto do mundo real dentro das plataformas) compartilhadas através do Tangle permitiu que o Fiware guardasse dados históricos das medições realizadas via WIP, suprindo a lacuna desta funcionalidade no mesmo.

O SToIC alcançou o nível de interoperabilidade semântico, implementou os padrões de interoperabilidade "acesso interplataforma", "independência de plataforma" e "fachada de alto nível de serviços" e operou na camada de aplicação, considerando o modelo de referencia do ITU, utilizando recursos oferecidos na camada de suporte à aplicação.

Com relação às principais dificuldades e lições aprendidas, diferentes desafios tiveram que ser superados para que este trabalho de pesquisa pudesse ser realizado, dentre os quais os principais foram os descritos a seguir:

- Definição de termos relevantes: O primeiro desafio significativo do trabalho foi a definição de diferentes termos cujo uso na literatura varia bastante, não havendo um consenso. O próprio termo "Internet das Coisas" tem diferentes definições conflitantes, diferindo quanto à necessidade de haver conexão à Internet ou não, tipos de dispositivos conectados e, muitas vezes, confundindo-se com outros termos tais como "Machine to Machine", "Sistema Cíberfísico" e outros. Outro termo que é utilizado de diferentes maneiras é "Plataforma de loT", que pode ser utilizado para definir placas de hardware (Polianytsia; Starkova; Herasymenko, 2016) capazes de conectar diferentes sensores e atuadores e diversas soluções de software relacionados à loT. Além disso, portabilidade e interoperabilidade também são termos que acabam sendo utilizados em vários momentos de maneira intercambiável. Este desafio foi enfrentado através do uso de padrões definidos por entidades regulatórias tais como Instituto de Engenheiros Eletricistas e Eletrônicos (IEEE), ITU e consulta a modelos de referências de IoT.

- A variedade de modelos de referência de IoT: Diferentemente da área de Redes, consideravelmente madura em relação à área de loT, que já contém modelos consolidados e bem-testados como o Open System Interconnection (OSI) 
e TCP/IP e consensuais na comunidade acadêmica e no mercado, ainda não há um modelo de referência consensual na área de loT, havendo muitas propostas de órgãos governamentais, grupos e instituições de pesquisa e corporações (AL-QASEEMI et al., 2016; BAKHSHI; BALADOR; MUSTAFA, 2018; TORKAMAN; SEYYEDI, 2016; BASSI et al., 2013). Estes modelos variam quanto ao grau de detalhamento, podendo ter componentes internos específicos ou genéricos, quanto às verticais de aplicações a quais se destinam, podendo ser de propósito geral ou específicos a uma vertical, como indústria, cidades inteligentes, entre outros. Optou-se pelo modelo do ITU devido à relevância do mesmo na comunidade acadêmica e ao fato do mesmo ser genérico o suficiente para identificar os componentes principais das plataformas de loT que foram encontradas no estudo.

\section{- Definição e classificação de recursos oferecidos por plataformas de loT:} Um desafio foi delimitar o que seriam os recursos oferecidos, o que foi resolvido com a própria seleção do modelo de referência do ITU, pois o mesmo propõe a Camada de Suporte à Serviço e Aplicação, que oferece estas funcionalidades. Em seguida, após o levantamento dos recursos oferecidos, um desafio foi a classificação dos mesmos em categorias, que foi realizado de maneira inspirada na Biologia Evolutiva (EL-HANI; MEYER, 2009), que classifica os seres vivos em categorias ao analisar características semelhantes e diferentes entre os mesmos. Desta forma, foram analisadas semelhanças e diferenças nas funcionalidades e propósitos dos recursos, sendo um exemplo disso a abstração de dispositivos, cuja maneira de ser realizada varia bastante entre as plataformas que o proveem, mas a funcionalidade e o propósito são semelhantes, que é permitir manter os dispositivos.

- Documentação escassa e instabilidade das plataformas: A documentação das plataformas Fiware e WIP, utilizadas neste trabalho, e outras que foram testadas, são escassas e, muitas vezes, desatualizadas. A documentação do Fiware teve vários pontos, como o orquestrador, que não se conseguiu fazer funcionar adequadamente. Além disso, muitas vezes a documentação apontava o uso de um determinado componente e descobria-se que estava depreciado, em outra documentação sem relação com a primeira e sem nem mesmo haver uma 
referência cruzada entre eles. Também houve diferentes erros na comunicação dos componentes do Fiware relacionados ao formado dos dados transmitidos que não foram encontrados em documentação, demandando esforço e tempo para solucioná-los. Quanto ao WIP, além da dificuldade de encontrar uma documentação mais completa em relação à que é disponibilizada na página inicial da plataforma, havia funcionalidades que eram consideradas como fase de teste e esperava-se encontrar na plataforma, mas ao tentar configurar, a funcionalidade estava desativada. Além disso, outras funcionalidades foram bloqueadas para manutenção por tempo indeterminado.

Pretende-se realizar os seguintes trabalhos futuros:

- Investigar como aprimorar o SToIC através do uso de ontologias para descrição de disponibilização de recursos e definições de modelos de domínios;

- Investigar como os padrões de interoperabilidade "independência de escala de plataforma" e "acesso interdomínio de aplicação" podem ser implementados. Os possíveis caminhos são o uso de ontologias de domínio e a verificação de recursos oferecidos por plataformas de loT destinados a dispositivos embarcados e computação na borda, para verificar se pertencem às mesmas categorias levantadas neste trabalho e como o SToIC poderia mapeá-las.

- Avaliar em quais cenários é viável ou não a utilização do SToIC em comparação com a implementação de aplicações que façam uso direto dos recursos das plataformas de loT, considerando a latência gerada ao ser ter uma camada realizando essa intermediação entre as aplicações multiplataformas e as plataformas, bem como a complexidade de desenvolvimento dos adaptadores. 


\section{REFERÊNCIAS}

AGGARWAL, C. C. Managing and mining sensor data. [S.I.]: Springer Science \& Business Media, 2013.

AKPINAR, K.; HUA, K. A. Thingstore-an internet of things management system. In: IEEE. 2017 IEEE Third International Conference on Multimedia Big Data (BigMM). [S.I.], 2017. p. 354-361.

AL-FUQAHA, A. et al. Internet of things: A survey on enabling technologies, protocols, and applications. IEEE Communications Surveys \& Tutorials, IEEE, v. 17, n. 4, p. 2347-2376, 2015.

AL-JAROODI, J.; MOHAMED, N.; JAWHAR, I. A service-oriented middleware framework for manufacturing industry 4.0. ACM SIGBED Review, ACM, v. 15, n. 5, p. 29-36, 2018.

AL-QASEEMI, S. A. et al. lot architecture challenges and issues: Lack of standardization. In: IEEE. 2016 Future Technologies Conference (FTC). [S.I.], 2016. p. 731-738.

ALEXANDER, C. A pattern language: towns, buildings, construction. [S.I.]: Oxford university press, 1977.

BABICH, N. A Beginner's Guide To User Journey Mapping - UX Planet. Acesso em: 28 jun. 2019. Disponível em: <https://uxplanet.org/ a-beginners-guide-to-user-journey-mapping-bd914f4c517c> .

BAHETI, R.; GILL, H. Cyber-physical systems. The impact of control technology, IEEE Control Systems Society, v. 12, n. 1, p. 161-166, 2011.

BAKHSHI, Z.; BALADOR, A.; MUSTAFA, J. Industrial iot security threats and concerns by considering cisco and microsoft iot reference models. In: IEEE. 2018 IEEE Wireless Communications and Networking Conference Workshops (WCNCW). [S.I.], 2018. p. 173-178.

BANAFA, A. lot standardization and implementation challenges. IEEE. org Newsletter, 2016.

BANDYOPADHYAY, D.; SEN, J. Internet of things: Applications and challenges in technology and standardization. Wireless Personal Communications, Springer, v. 58, n. 1, p. 49-69, 2011.

BASSI, A. et al. Enabling things to talk. [S.I.]: Springer Nature, 2013.

BASTYS, I.; BALLIU, M.; SABELFELD, A. If this then what?: Controlling flows in iot apps. In: ACM. Proceedings of the 2018 ACM SIGSAC Conference on Computer and Communications Security. [S.I.], 2018. p. 1102-1119. 
BATISTA, C. et al. A middleware environment for developing internet of things applications. In: Proceedings of the 5th Workshop on Middleware and Applications for the Internet of Things. New York, NY, USA: ACM, 2018. (M4loT'18), p. 41-46. ISBN 978-1-4503-6118-7. Disponível em: <http://doi.acm.org/ $10.1145 / 3286719.3286728>$.

BATISTA, D. M. et al. Interscity: Addressing future internet research challenges for smart cities. In: IEEE. 2016 7th International Conference on the Network of the Future (NOF). [S.I.], 2016. p. 1-6.

BERGER, W. The secret phrase top innovators use. Harvard Business Review, v. 17, 2012.

BERNABE, J. B. et al. Sociotal-the development and architecture of a social iot framework. In: IEEE. 2017 Global Internet of Things Summit (GloTS). [S.I.], 2017. p. 1-6.

BERNERS-LEE, T.; HENDLER, J.; LASSILA, O. The semantic web. Scientific american, JSTOR, v. 284, n. 5, p. 34-43, 2001.

BRÖRING, A. et al. Enabling iot ecosystems through platform interoperability. IEEE software, IEEE, v. 34, n. 1, p. 54-61, 2017.

BUSCHMANN, F. et al. Pattern-oriented software architecture: a system of patterns. [S.I.]: John Wiley \& Sons, 2008. v. 1.

Cabrini, F. H. et al. Helix sandbox: An open platform to fast prototype smart environments applications. In: 2019 IEEE 1st Sustainable Cities Latin America Conference (SCLA). [S.I.: s.n.], 2019. p. 1-6.

$\mathrm{CAl}, \mathrm{H}$. et al. lot-based big data storage systems in cloud computing: Perspectives and challenges. IEEE Internet of Things Journal, IEEE, v. 4, n. 1, p. 75-87, 2017.

CHANDRA, A. A. et al. Review on sensor cloud and its integration with arduino based sensor network. In: IEEE. IT Convergence and Security (ICITCS), 2013 International Conference on. [S.I.], 2013. p. 1-4.

CHEN, B. et al. Smart factory of industry 4.0: Key technologies, application case, and challenges. IEEE Access, IEEE, v. 6, p. 6505-6519, 2018.

CHEN, S. et al. A vision of iot: Applications, challenges, and opportunities with china perspective. IEEE Internet of Things journal, IEEE, v. 1, n. 4, p. 349-359, 2014.

CHEN, Y.-K. Challenges and opportunities of internet of things. In: IEEE. Design Automation Conference (ASP-DAC), 2012 17th Asia and South Pacific. [S.I.], 2012. p. 383-388.

CHENG, B. et al. Lightweight service mashup middleware with rest style architecture for iot applications. IEEE Transactions on Network and Service Management, IEEE, v. 15, n. 3, p. 1063-1075, 2018.

CORNO, F.; RUSSIS, L. D.; ROFFARELLO, A. M. A semantic web approach to simplifying trigger-action programming in the iot. Computer, IEEE, v. 50, n. 11, p. 18-24, 2017. 
CORNO, F.; RUSSIS, L. de; ROFFARELLO, A. M. A high-level semantic approach to end-user development in the internet of things. International Journal of Human-Computer Studies, Elsevier, v. 125, p. 41-54, 2019.

CROCKFORD, D. Rfc 4627-the application/json media type for javascript object notation (json). Network Working Group, 2006.

DAM, R. F.; TEO, Y. S.

DICKENS, C. A tale of two cities. [S.I.]: Penguin UK, 2007.

DIPSIS, N.; STATHIS, K. A restful middleware for ai controlled sensors, actuators and smart devices. Journal of Ambient Intelligence and Humanized Computing, Springer, p. 1-24, 2019.

EL-HANI, C. N.; MEYER, D. A evolução da teoria darwiniana. ComCiência, SciELO Brasil, n. 107, p. 0-0, 2009.

FAIEQ, S. et al. C2iot: A framework for cloud-based context-aware internet of things services for smart cities. Procedia Computer Science, Elsevier, v. 110, p. 151-158, 2017.

FERRERA, E. et al. Xmpp-based infrastructure for iot network management and rapid services and applications development. Annals of Telecommunications, Springer, v. 72, n. 7-8, p. 443-457, 2017.

FIELDING, R. et al. Rfc 2616: Hypertext transfer protocol-http/1.1, june 1999. Status: Standards Track, v. 1, n. 11, p. 1829-1841, 1999.

FIELDING, R. T.; TAYLOR, R. N. Architectural styles and the design of networkbased software architectures. [S.I.]: University of California, Irvine Irvine, 2000. v. 7.

FRAMEWORK, I.-C. A consensus framework for smart city architectures. Draft Release v20180208, NIST, 2018.

GAMMA, E. Helm. r., johnson, r., vlissides, j.: Design patterns: elements of reusable object-oriented software. Addison Wesley Longman, Inc, January, v. 1, n. 5, p. 1, 1995.

GUBBI, J. et al. Internet of things (iot): A vision, architectural elements, and future directions. Future generation computer systems, Elsevier, v. 29, n. 7, p. 1645-1660, 2013.

GUTH, J. et al. Comparison of iot platform architectures: A field study based on a reference architecture. In: IEEE. Cloudification of the Internet of Things (CloT). [S.I.], 2016. p. 1-6.

HORODECKI, R. et al. Quantum entanglement. Reviews of modern physics, APS, v. 81, n. 2, p. 865, 2009.

IDABC. European interoperability framework for pan-european e-government services. European Communities, 2004. 
Interaction Design Foundation. Stage 2 in the Design Thinking Process: Define the Problem and Interpret the Results.

Stage 3 in the Design Thinking Process: Ideate.

. Stage 4 in the Design Thinking Process: Prototype.

Stage 4 in the Design Thinking Process: Prototype.

.What is Design Thinking and Why Is It So Popular? 2019. Acesso em: 28 jun. 2019. Disponível em: <https://www.interaction-design.org/literature/article/ what-is-design-thinking-and-why-is-it-so-popular>.

Stage 1 in the Design Thinking Process: Empathise with Your Users. 2020.

INTERNATIONAL STANDARDS ORGANIZATION. ISO/IEC International Standard: Information technology — vocabulary. Genebra, 2015.

. ISO/IEC/IEEE International Standard: Systems and software engineeringvocabulary. Genebra, 2017. 22 p.

IPT. Planos de Desenvolvimento Institucional de Pesquisa dos Institutos Estaduais de Pesquisa no Estado de São Paulo - Sistemas Ciberfísicos como suporte à Manufatura Avançada e Cidades inteligentes e sustentáveis (Cyber-Physical System - CPS). [S.I.], 2017.

ITU-T. Next Generation Networks - Frameworks and functional architecture models. Geneva, CH, 2012. Disponível em: <https://www.itu.int/rec/T-REC-Y. 2060-201206-I>.

. Internet of things and smart cities and communities - Requirements and use cases. Geneva, CH, 2017. Disponível em: <https://www.itu.int/rec/T-REC-Y. 4115-201704-I/en>.

JARARWEH, Y. et al. An experimental framework for future smart cities using data fusion and software defined systems: the case of environmental monitoring for smart healthcare. Future Generation Computer Systems, Elsevier, 2018.

JAZDI, N. Cyber physical systems in the context of industry 4.0. In: IEEE. Automation, Quality and Testing, Robotics, 2014 IEEE International Conference on. [S.I.], 2014. p. 1-4.

KELLEY, D.; BROWN, T. An introduction to design thinking. linstitute of Design at Stanford. ISSN 2190-8370.

KHALED, A. E.; HELAL, S. A framework for inter-thing relationships for programming the social iot. In: IEEE. 2018 IEEE 4th World Forum on Internet of Things (WF-IoT). [S.I.], 2018. p. 670-675.

KIT, D.

KITCHENHAM, B.; CHARTERS, S. Guidelines for performing systematic literature reviews in software engineering. Citeseer, 2007. 
KITCHENHAM, B. et al. Systematic literature reviews in software engineering-a tertiary study. Information and software technology, Elsevier, v. 52, n. 8, p. 792-805, 2010.

Kolb, S.; Wirtz, G. Towards application portability in platform as a service. In: 2014 IEEE 8th International Symposium on Service Oriented System Engineering. [S.I.: s.n.], 2014. p. 218-229.

KRANENBURG, R. V.; BASSI, A. lot challenges. Communications in Mobile Computing, Springer, v. 1, n. 1, p. 9, 2012.

LEE, J.; BAGHERI, B.; KAO, H.-A. A cyber-physical systems architecture for industry 4.0-based manufacturing systems. Manufacturing Letters, Elsevier, v. 3, p. 18-23, 2015.

LUCERI, L. et al. Vivo: A secure, privacy-preserving, and real-time crowd-sensing framework for the internet of things. Pervasive and Mobile Computing, Elsevier, v. 49 , p. $126-138,2018$.

MEIER, T.; SCHEMMERT, U. Applying web-technologies for device state processing in iot middleware. In: ACM. Proceedings of the 19th International Middleware Conference (Posters). [S.I.], 2018. p. 13-14.

NASA. Technology Readiness Level Definitions. 2012. Disponível em: <https: //www.nasa.gov/directorates/heo/scan/engineering/technology/txt_accordion1.html>. Acesso em: 15 jan. 2019.

NEPOMUCENO, T. et al. A gui-based platform for quickly prototyping server-side iot applications. In: VDE. Smart SysTech 2018; European Conference on Smart Objects, Systems and Technologies. [S.I.], 2018. p. 1-9.

OLIVEIRA, C. T. et al. Improving security on iot applications based on the fiware platform. In: IEEE. 2018 IEEE 32nd International Conference on Advanced Information Networking and Applications (AINA). [S.I.], 2018. p. 686-693.

Opara-Martins, J.; Sahandi, R.; Tian, F. Critical review of vendor lock-in and its impact on adoption of cloud computing. In: International Conference on Information Society (i-Society 2014). [S.I.: s.n.], 2014. p. 92-97.

OSBORN, A. Applied Imagination-Principles and Procedures of Creative Writing. [S.I.]: Read Books Ltd, 2012.

Palavalli, A.; Karri, D.; Pasupuleti, S. Semantic internet of things. In: 2016 IEEE Tenth International Conference on Semantic Computing (ICSC). [S.I.: s.n.], 2016. p. 91-95.

PETROLO, R.; LOSCRI, V.; MITTON, N. Towards a smart city based on cloud of things. In: ACM. Proceedings of the 2014 ACM international workshop on Wireless and mobile technologies for smart cities. [S.I.], 2014. p. 61-66.

PFLANZNER, T.; KERTÉSZ, A. A survey of iot cloud providers. In: IEEE. Information and Communication Technology, Electronics and Microelectronics (MIPRO), 2016 39th International Convention on. [S.I.], 2016. p. 730-735. 
PINHEIRO, V. et al. Deklaer: An ontology-driven framework for generating iot applications using contextnet. In: IEEE. 2018 IEEE Symposium on Computers and Communications (ISCC). [S.I.], 2018. p. 00608-00614.

Polianytsia, A.; Starkova, O.; Herasymenko, K. Survey of hardware iot platforms. In: 2016 Third International Scientific-Practical Conference Problems of Infocommunications Science and Technology (PIC S T). [S.I.: s.n.], 2016. p. 152-153.

RAY, P. P. A survey of iot cloud platforms. Future Computing and Informatics Journal, Elsevier, v. 1, n. 1-2, p. 35-46, 2016.

ROFFARELLO, A. M. End user development in the iot: A semantic approach. In: IEEE. 2018 14th International Conference on Intelligent Environments (IE). [S.I.], 2018. p. 107-110.

ROGOJANU, T. et al. Netiot: A versatile iot platform integrating sensors and applications. In: IEEE. 2018 Global Internet of Things Summit (GloTS). [S.I.], 2018. p. 1-6.

ROSSUM, G. V. et al. Python programming language. In: USENIX annual technical conference. [S.I.: s.n.], 2007. v. 41, p. 36.

SEITZ, A. et al. Fog computing as enabler for blockchain-based iiot app marketplacesa case study. In: IEEE. 2018 Fifth International Conference on Internet of Things: Systems, Management and Security. [S.I.], 2018. p. 182-188.

SERRANO, M. et al. Internet of things iot semantic interoperability: Research challenges, best practices, recommendations and next steps. IERC: European Research Cluster on the Internet of Things, Tech. Rep, 2015.

SHI, J. et al. A survey of cyber-physical systems. In: IEEE. Wireless Communications and Signal Processing (WCSP), 2011 International Conference on. [S.I.], 2011. p. 1-6.

SUH, Y.-H.; WOO, S.-P.; PARK, D.-H. Slice: self-learnable iot common software engine. In: ACM. Proceedings of the 8th International Conference on the Internet of Things. [S.I.], 2018. p. 19.

TEH, J. H.; CHOUDHARY, V.; LIM, H. B. A smart ontology-driven iot platform. In: Proceedings of the 16th ACM Conference on Embedded Networked Sensor Systems. New York, NY, USA: ACM, 2018. (SenSys '18), p. 424-425. ISBN 978-1-4503-5952-8. Disponível em: <http://doi.acm.org/10.1145/3274783.3275215>.

TEIXEIRA, S. et al. Laura architecture: Towards a simpler way of building situationaware and business-aware iot applications. Journal of Systems and Software, Elsevier, v. 161, p. 110494, 2020.

TIDWELL, J. Designing interfaces: Patterns for effective interaction design. [S.I.]: "O’Reilly Media, Inc.", 2010.

TOLK, A.; MUGUIRA, J. A. The levels of conceptual interoperability model. In: CITESEER. Proceedings of the $\mathbf{2 0 0 3}$ fall simulation interoperability workshop.

[S.I.], 2003. v. 7, p. 1-11. 
TORKAMAN, A.; SEYYEDI, M. Analyzing iot reference architecture models. International Journal of Computer Science and Software Engineering, Dorma Trading, Est. Publishing Manager, v. 5, n. 8, p. 154, 2016.

VEER, H. van der; WILES, A. Achieving technical interoperability. European telecommunications standards institute, 2008.

VELOSA, M. P. A. et al. Gartner's Market Guide for loT Platforms. [S.I.], 2015. Disponível em: <https://www.gartner.com/en/documents/3086918>.

VERMESAN, O. Advancing iot platforms interoperability. River Publishers, 2018.

$\mathrm{XU}$, L. D.; HE, W.; LI, S. Internet of things in industries: A survey. IEEE Transactions on industrial informatics, IEEE, v. 10, n. 4, p. 2233-2243, 2014.

YAN, Z.; ZHANG, P.; VASILAKOS, A. V. A survey on trust management for internet of things. Journal of network and computer applications, Elsevier, v. 42, p. 120-134, 2014.

YANGUI, S. et al. lot end-user applications provisioning in the cloud: State of the art. In: IEEE. 2016 IEEE International Conference on Cloud Engineering (IC2E). [S.I.], 2016. p. 232-233.

ZAMORA-IZQUIERDO, M. A. et al. Smart farming iot platform based on edge and cloud computing. Biosystems Engineering, Elsevier, v. 177, p. 4-17, 2019.

ZANELLA, A. et al. Internet of things for smart cities. IEEE Internet of Things journal, IEEE, v. 1, n. 1, p. 22-32, 2014.

ZHANG, Y. et al. A runtime framework for context-sensitive device-to-device communication. In: IEEE. 2017 IEEE 86th Vehicular Technology Conference (VTC-Fall). [S.I.], 2017. p. 1-5.

ZHENG, Y. Trajectory data mining: An overview. ACM Trans. Intell. Syst. Technol., ACM, New York, NY, USA, v. 6, n. 3, p. 29:1-29:41, maio 2015. ISSN 2157-6904. Disponível em: <http://doi.acm.org/10.1145/2743025>. 


\section{APÊNDICE A - RECURSOS ENCONTRADOS NAS PLATAFORMAS ANALISADAS NA REVISÃO DA LITERATURA AGRUPADOS POR CATEGORIA}

\section{A.1 Abstrações de Dispositivos}

- Atlas Things

- IoT-DDL Web Tool: Ferramenta através do qual o fabricante descreve o dispositivo e seus serviços utilizando a linguagem utilizando loT-DDL.

- Global Sensor Network (GSN)

- Wrapper: Classe que abstrai a aquisição de dados para um determinado tipo de dispositivo. Herda-se uma classe abstrata provida pelo GSN e especifica-se a obtenção de dados.

- Virtual Sensor (VS): Recebe dados de um ou muitos wrappers, podendo armazenar, combinar e manipular dados de acordo com as necessidades das aplicações. É definido pelo Virtual Sensor Description File (VSD), que é um arquivo XML que especifica a estrutura do sensor virtual e qual(is) wrapper(s) será(ão) utilizados. Ainda é possível adicionar atributos geográficos, para posterior integração com o Google Maps.

- Google Cloud loT

- Gerenciador de Dispositivos: É o sistema onde sensores, atuadores, gateways e outros dispositivos são cadastrados, podendo-se obter dados ou controlá-los. 
- Sensor-Cloud

- Virtual Sensor Group: O End User pode criar grupos de sensores virtuais para suas aplicações, compartilhá-los com outros usuários, ativar ou desativar o uso.

- Templates: Ao inserir um novo sensor físico à plataforma, é possível definir uma abstração de sensor virtual utilizando SensorML.

\section{- Cloud4Sense}

- Sensores virtuais: Há uma ferramenta para gerenciar sensores e implementar novos sensores virtuais.

- Thethings.io

- Things: Gerenciador de dispositivos a serem utilizados com as aplicações criadas e criação de produtos. Ao criar um produto loT, o usuário adiciona dispositivos a ele.

- KNoT

- WebUl: Permite gerenciar dispositivos para interagir com a plataforma, além de definir endpoints para conexão com o FIWARE, em caso de integração com este.

\section{A.2 Painéis de Controle}

- OpenloT

- Configuration and Monitoring: Ferramenta gráfica para configuração de funcionalidades relacionadas a sensores virtuais e demais módulos do OpenloT.

- Google Cloud loT

- Gerenciador de Dispositivos: É o sistema onde sensores, atuadores, gateways e outros dispositivos são cadastrados, podendo-se obter dados ou controlá-los. 
- IBM Bluemix

- Plataforma de loT: Trata-se de um gateway onde é possível cadastrar dispositivos e obter dados deles. É possível criptografar os dados e fazer tratamentos de autorização.

- Bosch loT Rollouts: Sistema de gerenciamento de atualização de software para computação em borda, controladores e gateway.

- AWS

- Console de Gerenciamento da AWS: É uma interface web para alocar recursos do AWS lot Core, gerenciar certificados e outros elementos de infraestrutura.

- Azure

- Hub IoT: Gerenciamento de recursos de infraestrutura, dispositivos e aplicações de loT.

- DreamFactory

- Device Registry: É um inventário de dispositivos conectados a plataformas, com a possibilidade de adicionar metadados aos dispositivos, uso de tokens para conexão segura, lista negra e lista branca.

- User Management: Sistema de gerenciamento de usuários e permissões, onde cada dispositivo tem um usuário como dono e este define as permissões de acesso sobre aquele.

- Altair SmartCore

- Gerenciamento de Dispositivos e Dados: Sistema de gerenciamento de dispositivos conectados, para uso da aplicação. Permite ativar, desativar, enviar atualizações e correções de firmware remotamente. Provê coleta e envio de dados via interface RESTful.

- GrooveStreams

- Editor: Interface web onde o desenvolvedor pode montar o dashboard, cadastrar dispositivos e codificar o processamento de dados desejado. 
- Kinvey

- Identify: Provê gerenciamento de usuários, papéis e permissões, permitindo autenticação de diferentes fontes.

- SmartThings:

- Web UI: Interface web que permite o monitoramento dos dispositivos e controle dos mesmos.

- FIWARE

- Authorization PDP - AuthZForce: Provê uma API para obter decisões de autorização baseadas em políticas.

- Backend Device Management - IDAS: Provê um conjunto de pontes de protocolo, chamados de loTAgents, para comunicação com dispositivos, através de conexões LoRaWAN (REFERENCIA), JSON, LWM2M, UltraLight2.0, além da possibilidade de criar novos loTAgents.

- FogFlow: Permite a orquestração e processamento de fluxos sobre nuvem e bordas.

- Identity Management - KeyRock: Gerenciamento de usuários e autenticação para acessos a redes, serviços, aplicações e dispositivos.

- PEP Proxy - Wilma: Trabalha em conjunto com o KeyRock com a finalidade de prover métodos de segurança na autenticação.

- XMPP-based infrastructure for loT network management and rapid services and applications development

- Configuration Tool: Auxilia na fase de implementação, configuração e administração de recursos, permitindo a administração de Device Managers, que são plataformas de gerenciamento de dispositivos agregadas. Permite também o gerenciamento de conexão, para funcionalidades próprias do XMPP.

- NETIOT

- API Gateway: Provê comunicação entre a aplicação e dispositivos, além de serviços como gerenciamento de usuário, autenticação, estatísticas, dados de sensores e dashboard personalizado para visualização de dados. 


\section{A.3 Serviços}

- GSN

- Webservice: Disponibiliza dados dos sensores para serem consultados como serviço e consumido por aplicações em geral.

- Linked Sensor Middleware (LSM)

- Streaming Channel: Utiliza protocolos como XMPP ou Google Pub Sub para transmissão dos dados.

- Google Cloud loT

- Ponte de Protocolo: Permite a conexão com uma variedade de protocolos, como MQTT e HTTP, onde serviços podem publicar e subscrever.

- IoT-Oriented Data Storage Framework in Cloud Computing Platform

- HTTP Restful Service Generating: A partir de modelos que representam os dados armazenados, serviços RESTful podem ser gerados para que aplicações possam fazer operações de criação, consulta, atualização e exclusão dos dados armazenados.

- Cloud4Sense

- Criação de Webservice: É possível criar webservices à partir dos dados disponíveis.

- Azure

- Gerenciamento de API: Permite a criação de APIs e exposição de microsserviços, para permitir que outras aplicações, dentro do Azure ou não, possam integrar-se com as aplicações desenvolvidas.

- DreamFactory

- Integração MQTT: Permite a obtenção ou envio de dados de dispositivos e sistemas que se comumicam por loT e geram APIs RESTful a partir deles. 
- ThingHTTP: Permite a interação com webservices para receber e enviar dados.

- Prodea loT

- Turnkey Ecoadaptors: APIs para conexão com serviços de terceiros.

- GrooveStreams

- RESTful API: É possível disponibilizar os dados como um webservice.

- Kaa

- Server REST APIs: Webservice que permite com que aplicações possam operar o Kaa utilizando uma API RESTful.

- Oracle loT Cloud Service

- REST APIs: Disponibiliza um webservice para que aplicações externas possam interagir com as aplicações desenvolvida na plataforma.

- OpenRemote

- Agent: São interfaces para sensores, atuadores e APls e protocolos de terceiros.

- SensorCloud

- Open Data API: A plataforma oferece uma API RESTful que permite a comunicação com diferentes fontes.

- A Smart Ontology-driven loT Platform

- HTTP Restful: Disponibilização de endpoints para consulta de dados.

- Applying Web-Technologies for Device State Processingin loT Middleware

- REST APIs: Endpoints definidos pelo programador para integração da aplicação com outras soluções.

- Autolot 
- Communication Manager: Configura a conexão com um broker MQTT, para troca de informações utilizando este protocolo.

\section{- FIWARE}

- Electronic Data Exchange - Domibus: Permite que aplicações troquem dados e documentos de maneira confiável, utilizando a tecnologia CEF eDelivery.

- Fast RTPS: Serviço de publish-subscribe.

- OpenMTC: Focado em comunicação M2M, utilizando o padrão oneM2M para troca de informações.

- Stream-oriented - Kurento: Permite o desenvolvimento de aplicações interativas, com streaming de mídia.

- Lightweight Service Mashup Middleware With REST Style Architecture for IoT Applications

- RESTful API: Permite o envio de comandos, através de webservices, para gerenciamento de dispositivos e execução de comandos, como um pedido de medição, por exemplo.

- KNOT

- Generic and Specific Fog Connectors: Componentes que permitem a integração do KNoT com outras plataformas baseadas na nuvem, como o FIWARE, por exemplo. Esta plataforma, por sua vez, pode utilizar os dados recebidos do KNoT em suas aplicações de loT.

\section{- Man4Ware}

- Broker Services: Têm a função de avisar, descobrir e registrar serviços providos pelos variados componentes no ambiente de manufatura.

- Invocation Services: Permite a invocação de serviços entre os componentes do ambiente de manufatura, local ou remotamente.

- Fog Manufacturing Services: São serviços variados, distribuídos entre vários nós na borda. 
- Security Services: Provê registro em blockchain das informações compartiIhadas entre os diferentes nós, além de outros serviços de segurança.

- NETIOT

- API Gateway: Vide a Subseção A.2.

\section{A.4 Wiring Tools}

- OpenloT

- Request Definition: Uma ferramenta visual onde o desenvolvedor seleciona as fontes e desenha o processamento ligando blocos. Após o término do desenho, uma consulta SPARQL é gerada, salva como uma aplicação e enviada para o Scheduler, que é responsável pela execução das consultas e útil para serviços pagos pela quantidade de uso.

- Request Presentation

- IBM Bluemix

- Node-RED: Trata-se de uma ferramenta onde é possível programar conectando blocos. Permite o uso de vários protocolos, conexão a redes sociais, criação de webservices, obtenção dos dados de sensores e instalação de blocos personalizados.

- AT\&T Flow Designer: Ferramenta para programação ligando blocos, semeIhante ao Node-RED, mas com a possibilidade de gerar visualizações de gráficos.

- Azure

- Aplicativos Lógicos: Permite a integração de várias aplicações, inclusive softwares de gerenciamento empresarial, através de uma ferramenta de criação de fluxogramas de trabalho, automatizando processos.

- OpenRemote

- Designer : Permite a criação de painéis e aplicações com uma ferramenta visual. 
- IFTTT

- IF-THEN: Permite criar fluxos do tipo trigger-action, onde configura-se para que um conjunto de eventos dispare determinados serviços.

- XMPP-based infrastructure for loT network management and rapid services and applications development

- Composition Tool: É uma ferramenta baseada em Node-RED para criar aplicações utilizando composições de componentes e algoritmos para prover uma solução para o negócio.

\section{A.5 Disparadores de Mensagens e Notificações}

- Azure

- Hubs de Notificação: Serviço de notificação push compatível com os principais sistemas operacionais móveis. Permite selecionar alvos por idioma, região geográfica, entre outros. Pode ser usado para disparar alertas relacionados a mudança de alguma variável monitorada ou término de uma tarefa agendada, por exemplo.

- DreamFactory

- Messages: Mensagens trocadas entre dispositivos que não são armazenadas, mas sim como controle.

- ThingTweet: Permite o envio de mensagens ao Twitter, como alerta dos dados, por exemplo.

- Oracle

- Command and Control: Permite enviar mensagens para dispositivos, controlá-los e realizar consultas.

- OpenRemote

- Console: Aplicações móveis Android e iOS que executam componentes web dentro de si. Tem funcionalidades de localização geográfica e push notification. 
- Kinvey

- Engagement: Recursos de notificações push e analytics, para campanhas de marketing e interação com usuários.

- FIWARE

- Cloud Messaging - AEON: Provê canais para comunicação massiva com dispositivos e notificações, através do método publish-subscribe.

\section{A.6 Software Development Kit (SDK)}

- Atlas Things

- Atlas IDE: Ferramenta baseada em Java onde o desenvolvedor escreve projetos chamados recipes, que são árvores com que sequencial serviços e relacionamentos entre eles.

- GSN

- Biblioteca Javascript: Trata-se de uma biblioteca Javascript que permite aplicações web manipular valores na plataforma.

- Google

- Gerenciador de Dispositivos: É o sistema onde sensores, atuadores, gateways e outros dispositivos são cadastrados, podendo-se obter dados ou controlá-los.

- AWS loT Core

- AWS SDK: É um conjunto de APIs que permite acesso a vários serviços da AWS, facilitando a codificação e reduzindo a complexidade da aplicação.

- Azure

- Aceleradores de Solução do Azure loT: Um conjunto de modelos de aplicações genéricas prontas que podem ser extendidas de acordo com a necessidade do cliente. Tem como foco a transformação digital de empresas 
e manufatura inteligente. Dentre os modelos disponíveis, há relacionados a monitoramento e manutenção preventiva, por exemplo.

- Gêmeos Digitais do Azure: Permite replicar elementos existentes em um espaço físico, como o edifício de uma empresa, como dispositivos e representações das pessoas, e obter monitoramento e atuação no contexto deste espaço físico, além da simulação de processos. Pode ser aplicado em construções inteligentes.

- Mapas do Azure: Serviços cartográficos integráveis a aplicações do Azure.

- DreamFactory

- Rules Engine: É um ambiente para criar fluxos de trabalho complexos e integração, definindo limiares, condições, e ações em qualquer linguagem.

\section{- Prodea loT Service X-Change}

- Developer APIs: SDKs e APIs para integrar as funcionalidades da Prodea com aplicações móveis e web.

- Ayla IoT Platform

- Mobile SDK: Bibliotecas para iOS e Android com a finalidade de controlar dispositivos físicos e automatizar processos.

- Web SDK and APIs: Bibliotecas Javascript para desenvolver aplicações web que possam gerenciar usuários e permissões, monitorar e diagnosticar dispositivos, integrar aplicações de terceiros, analisar dados e criar dashboards.

- Altair SmartCore

- Groovy Scripts: Progração através de scripts Groovy.

- Kaa

- Kaa SDK: Kits de desenvolvimento para aplicações em C, C++, Objective-C e Java. 
- Client Library: Conjunto de bibliotecas para incluir em aplicações Java, Android e C.

- OpenRemote

- Web Componentes: Conjunto de compontens web e Javascript para criar aplicações web que interajam com o OpenRemote Manager.

- Web Applications: Conjunto de templates que podem ser personalizados para criar uma aplicação própria.

- SensorCloud

- SDK: A plataforma oferece uma API RESTful que permite a comunicação com diferentes fontes. Há também um SDK que contém bibliotecas para integração com aplicações Python, Java e C\#.

- Thethings.io

- Libraries: Conjunto de bibliotecas para diferentes plataformas de hardware utilizarem e se conectarem ao Thethings.io.

- SmartThings

- Web UI e IDE: Interface web que permite o monitoramento dos dispositivos e controle dos mesmos, além da edição, adição, remoção e criação de aplicações, através da IDE. Contém também um simulador de dispositivos, possibilitando o desenvolvimento sem a necessidade de dispositivos físicos.

- A Runtime Framework for Context-Sensitive Device-to-Device Communication

- Java API: Conjunto de bibliotecas em Java para utilizar as funcionalidades relativas ao envio e recebimento de informações entre dispositivos.

- Applying Web-Technologies for Device State Processing in loT Middleware

- Javascript Libraries: Permite a manipulação de elementos de loT através do modelo DOM do Javascript. 
- Module Manager: Trabalha analogamente a bibliotecas, para adicionar funcionalidade aos projetos. Um módulo pode ser compartilhado entre usuários, e disponibilizado em três estados possíveis: personal, test e production.

- Builder: Gera uma aplicação Flask para ser implantada como solução loT.

- $\mathrm{C2loT}$

- Service Composition: A aplicação é construída através da ligação entre vários serviços.

- Deklaer

- ClientLib: Bibliotecas Java para manipulação dos dados originários do dispositivo.

- Deklaer's Declarative Language: Uma linguagem declarativa para descrever a aplicação a ser desenvolvida, com os sensores e atuadores que serão utilizados e que eventos serão determinantes para que alguma ação seja tomada.

- FIWARE

- Application Mashup Wirecloud: Integra dados heterogêneos, lógica de aplicação e componentes de UI para criar aplicações.

- Business API Ecosystem - Biz Ecosystem RI: Oferece recursos para desenvolvimento de aplicações comerciais, como criação de catálogos de produtos, diferentes modelos de pagamento (automáticos, pay-per-use, entre outros), tratamento de eventos contábeis, entre outros.

- SLICE

- Code Generator: Gera códigos Java à partir de definições declarativas de dispositivos e seus comportamentos.

- VIVO

- Experiment: Permite a criação de aplicações de coleta de dados de usuários à partir do upload de códigos-fonte através de uma interface web. 
- Client API: Bibliotecas a serem importadas por desenvolvedores em aplicações finais para coleta de dados de usuários.

\section{A.7 BigData e Analytics}

- LSM

- SPARQL Endpoint: Permite consultas utilizando a linguagem SPARQL.

- Linked Sensor Explorer: Permite a combinação de duas ou mais fontes de dados em novos dados, que podem ser consultados usando a linguagem CQELS ou utilizando um assistente visual.

- Mashup Composer: Permite a combinação de duas ou mais fontes de dados em novos dados, que podem ser consultados usando a linguagem CQELS ou utilizando um assistente visual.

- Openlot

- Request Definition: Uma ferramenta visual onde o desenvolvedor seleciona as fontes e desenha o processamento ligando blocos. Após o término do desenho, uma consulta SPARQL é gerada, salva como uma aplicação e enviada para o Scheduler, que é responsável pela execução das consultas e útil para serviços pagos pela quantidade de uso.

- Google Cloud loT

- Big Data: Conjunto de funcionalidades relacionados a Big Data, podendo ser utilizados para processamento dos dados gerados dos dispositivos.

- IBM Bluemix

- Influx Cloud: Banco de dados especializado em séries de dados, como os gerados por sensores loT.

- Azure

- Azure Time Series Insights: Provê dados de loT contextualizados, maximizando o valor dos dados de loT. 
- DreamFactory

- Telemetry: Dados gerados por sensores que podem ser retidos e armazenados para posterior análise e processamento. As séries de dados podem ser exportadas para outros sistemas de análise, como Apache Hadoop, por exemplo.

- ThingSpeak

- Matlab Analysis: Exploração e processamento de dados.

- GrooveStreams

- Editor: Interface web onde o desenvolvedor monta o dashboard, cadastra os dispositivos e codifica o processamento de dados desejado.

- Oracle

- Stream Processing: Analisa fluxos de dados em tempo real, cadastra limiares para disparo de eventos, filtragem e correlação.

- Event Store: Envia os dados processados para serviços integrados ou aplicações empresariais para posterior uso destes.

- Kinvey

- Data: Gerenciador de arquivos e dados. Pode obter dados à partir de APIs.

- Business Logic: Criação de códigos para manipular dados, formatá-los e até agendar ações em determinados horários.

- An experimental framework for future smart cities using data fusion and software defined systems: The case of environmental monitoring for smart healthcare

- Data Fusion: Trata e combina dados de diferentes origens de forma que os dados resultantes façam sentido.

- Storage: Armazenamento dos dados obtidos a partir de Data Fusion em bancos de dados para persistência e posterior consulta. 
- Database Manager: Configura a conexão com bancos de dados.

- FIWARE

- BigData Analysis - Cosmos: Provê processamento de um grande volume de dados ou streaming de dados, de forma a extrair conhecimento destes dados.

- Cygnus: Ferramenta para processar e distribuir dados.

- Data Visualization - Knowage: Ferramenta de analytics comercial, que procura analisar dados e extrair conhecimento, gerar relatórios empresariais, fazer análise preditiva, entre outros.

- STH-Comet: Processa e armazena das históricos.

\section{A.8 Inteligência Artificial (IA) e Machine Learning (ML)}

- Google

- Inteligência Artificial: Série de recursos e algoritmos de Inteligência Artificial e Machine Learning prontos para aplicar ao problema que se quer atacar, podendo ser utilizados nos dados gerados pelos dispositivos.

- IBM Bluemix

- UnificationEngine: Plataforma onde é possível criar um sistema de Social loT, onde é possível utilizar dados gerados via redes sociais em aplicações.

- Azure

- Machine Learning Studio: Permite a criação de aplicações de inteligência artificial e preditivas, com programação através da ligação de blocos ou uso de scripts Python e $R$, fazendo com que haja a possibilidade de reaproveitamento de códigos pré-existentes.

\section{A.9 Marketplaces}

\section{- Google}


- Marketplace: Loja onde é possível comprar recursos de hardware e componentes de software para desenvolver aplicações.

\section{- COMPOSE}

- COMPOSE Marketplace: É a interface com a qual o desenvolvedor interage com o COMPOSE diretamente, publicando, compartilhando e acessando serviços reutilizáveis, além de prover uma ferramenta para criação da lógica de aplicação utilizando fluxos, bibliotecas e SDKs.

- IBM Bluemix

- Catálogo: É o diretório onde o desenvolvedor aloca um conjunto de recursos, pagos ou gratuitos, como máquinas virtuais, aplicativos de inteligência artificial, analítica, loT, entre outros. Podem ser próprios da IBM, opensources ou de terceiro.

- ThingWorx

- PTC Marketplace: Permite obter ambientes para programação e extensões para trabalhar com uma variedade de funcionalidades, além de expor as soluções criadas pelo usuário para serem utilizadas por outros desenvolvedores.

\section{- Murano}

- Exchange Marketplace: PTC Marketplace, onde é possível obter ambientes para programação e extensões para trabalhar com uma variedade de funcionalidades, além de expor as soluções criadas pelo usuário para serem utilizadas por outros desenvolvedores.

- FIWARE

- Catalogue: Um repositório de componentes que permite aos desenvolvedores adicionar novas funcionalidades a suas aplicações. Estes componentes podem ser de usos genéricos das aplicações (Generic Enablers) ou de usos específicos e orientados a negócios (Specific Enablers). 
- Marketplace: Diretório onde proprietários de dispositivos provedores de dados podem alugar os dados e desenvolvedores podem publicar suas aplicações, que consistem na combinação destes dados.

- IloT Bazaar

- Dev Store: É uma interface para que desenvolvedores podem disponibilizar suas aplicações e gerenciar as atualizações remotas delas.

\section{A.10 Dashboards}

- OpenloT

- Request Presentation: Utiliza uma ou mais das aplicações desenhadas na ferramenta anterior e exibe elementos gráficos com as saídas, em forma de painel.

- Azure

- Azure loT Central: Uma solução de SaaS de loT, onde o desenvolvedor pode disponibilizar suas aplicações de loT sem se preocupar com a complexidade da nuvem, abstraindo questões de infra-estrutura.

- DreamFactory

- Freeboard: Utiliza Freeboard para criar dashboards de visualização de dados e monitoramento.

- ThingSpeak

- Matblab Visualizations: Criação de painéis para visualização dos dados de sensores.

- Plugins: Plugins são construções personalizadas em HTML, CSS e Javascript para processamento e visualização dos dados.

- Prodea loT

- User Interfaces: Soluções para criar aplicações de backend e gerenciamento, com interface administrativa. 
- Altair SmartCore

- Criação de Dashboard: Permite a criação de painéis para monitoramento e controle.

- GrooveStreams

- Editor: Interface web onde o desenvolvedor monta o dashboard, cadastra os dispositivos e codifica o processamento de dados desejado.

- Oracle

- Asset Monitoring: Permite visualizar e consulta num mapa os dispositivos ligados a aplicação.

- OpenRemote

- Designer: Permite a criação de painéis e aplicações com uma ferramenta visual.

- Thethings.io

- Dashboard: Painéis de monitoramento, com gráficos de diferentes tipos apresentando dados dos dispositivos adicionados.

- Apps: Permite criar dashboards personalizados para clientes com dados de um produto criado.

- FIWARE

- WireCloud View: Permite a criação de dashboards com diferentes tipos de gráficos utilizando dados gerados pelo FIWARE e outras fontes.

- NetloT:

- API Gateway: Vide a Subseção A.2.

\section{A.11 Agendadores e Disparadores}


- Grade de Eventos: Sistema para criação de aplicativos orientados a eventos. Gerencia os eventos disparados dentro do Azure e invoca os callbacks associados a eles.

- ThingSpeak

- TimeControl: Automatically perform actions at predetermined times with ThingSpeak apps. Realiza ações automaticamente em tempos prédefinidos.

- React

- TallBack: Fila de comandos para o dispositivo.

- Altair SmartCore

- If-Then-Else: Programação através de expressões simples onde ações são executadas se condições pré-definidas foram alcançadas.

- SensorCloud

- Alerts: Permite criar e-mails e SMS para monitorar eventos de interesse.

- Kinvey

- Business Logic: Criação de códigos para manipular dados, formatá-los e até agendar ações em determinados horários.

- EUPont

- IF-THEN: Executa ações se condições pré-definidas forem alcançadas.

- IFTTT

- IF-THEN: Executa uma ação de um serviço, se este ou outro serviço emitir um evento, de acordo com as regras definidas pelos usuários.

- IloT Bazaar

- Smart Contracts: São contratos virtuais, com cláusulas definidas, que são acionadas automaticamente caso um ou mais eventos determinantes para isso aconteçam, fazendo com que haja troca de ativos financeiros entre as partes. 


\section{APÊNDICE B - APRESENTAÇÃO DOS CONCEITOS DE JORNADA DO USUÁRIO}




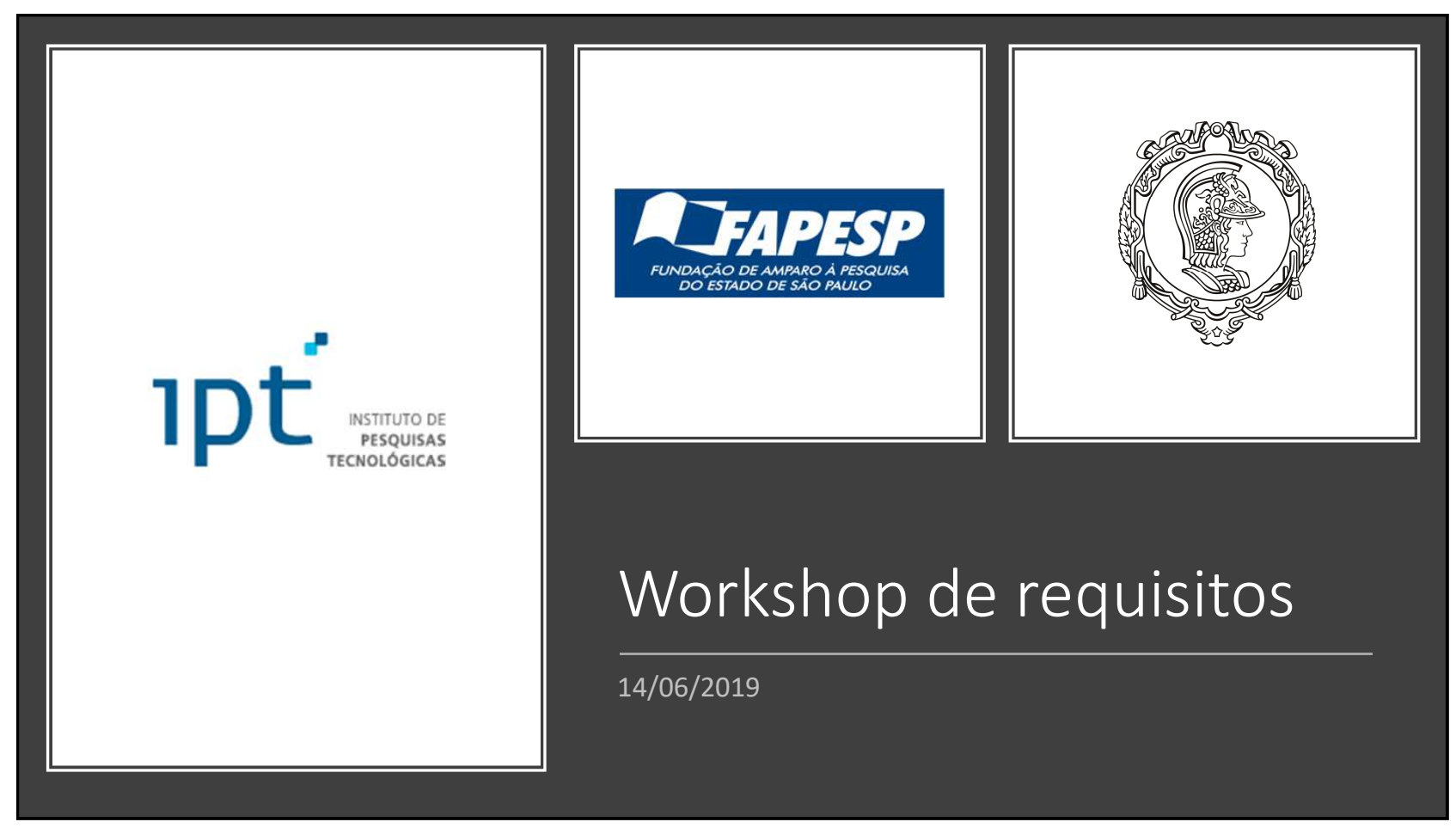

\section{Agenda}

- Abertura

- Jornada

- Ideação

- Mapeamento dos requisitos na arquitetura

- Questionário final 
Abertura

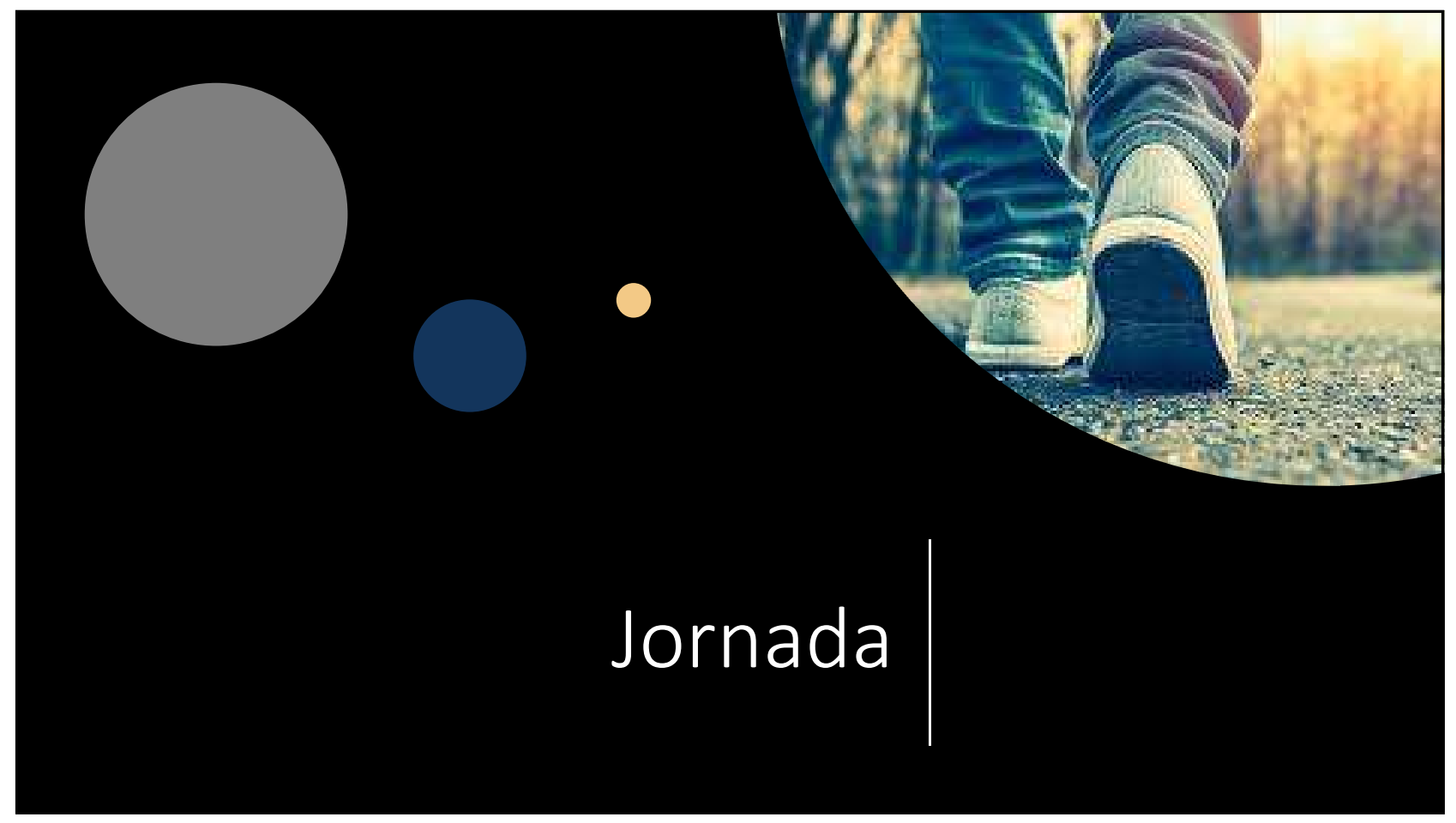


Na jornada, perspectiva do usuário!

\section{Pontos de contato}

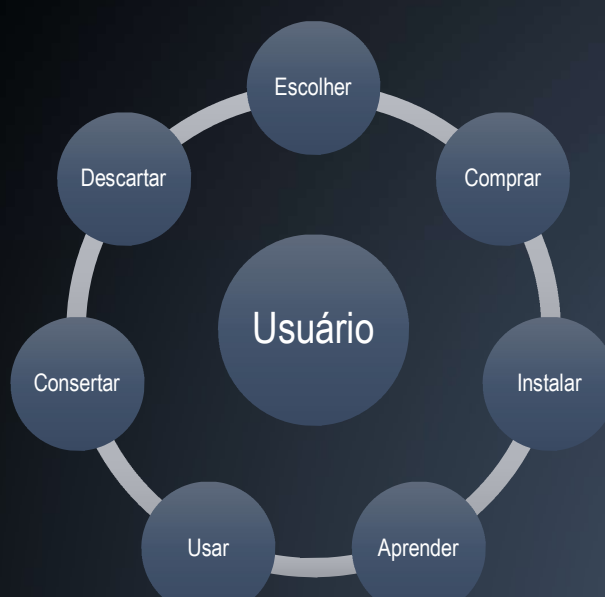



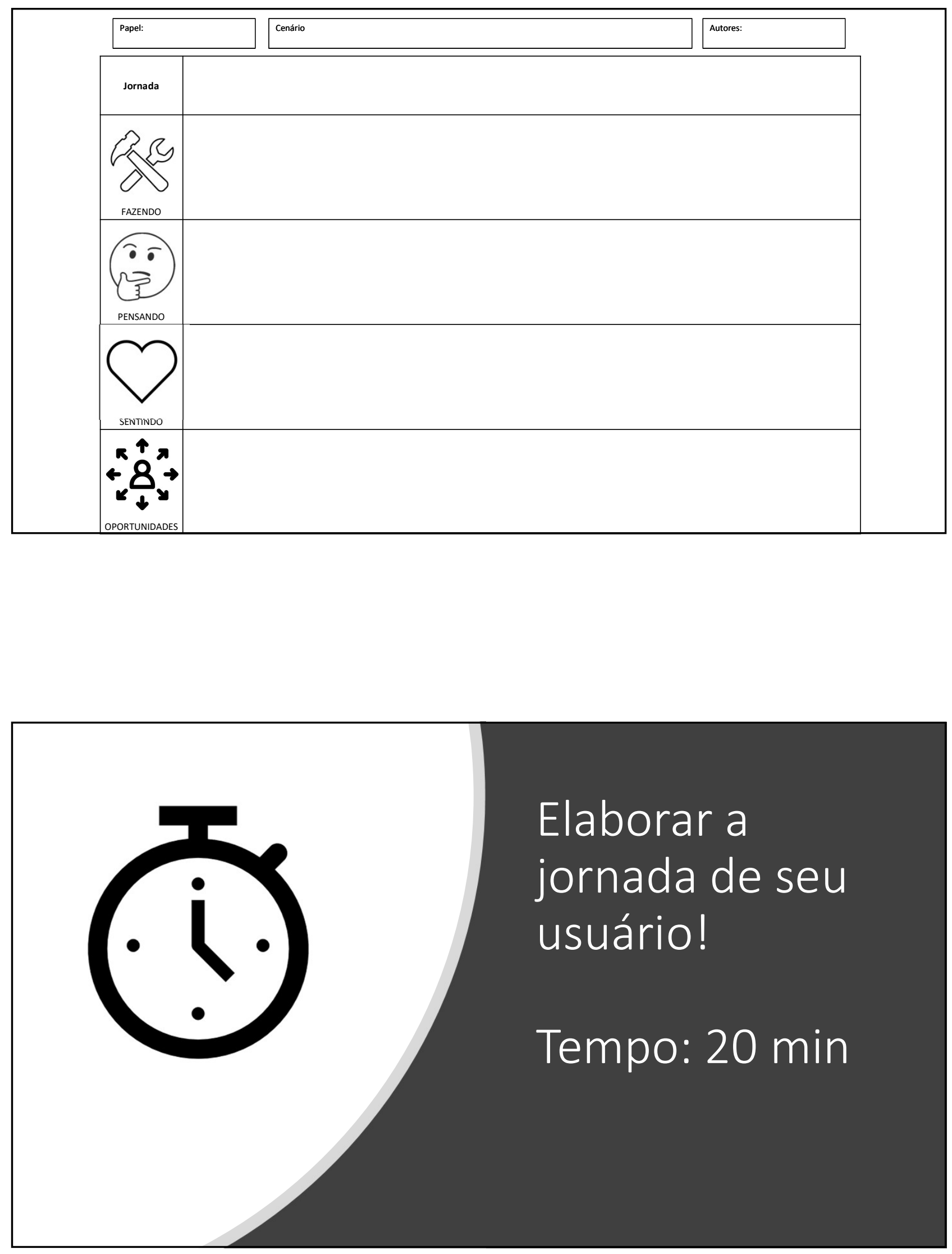


\section{APÊNDICE C - APRESENTAÇÃO DOS CONCEITOS DE HOW MIGHT WE}


Ideação

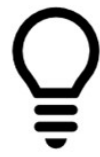

Como podemos criar oportunidades para aplicações inovadoras? 


\section{Vamos nos perguntar!}

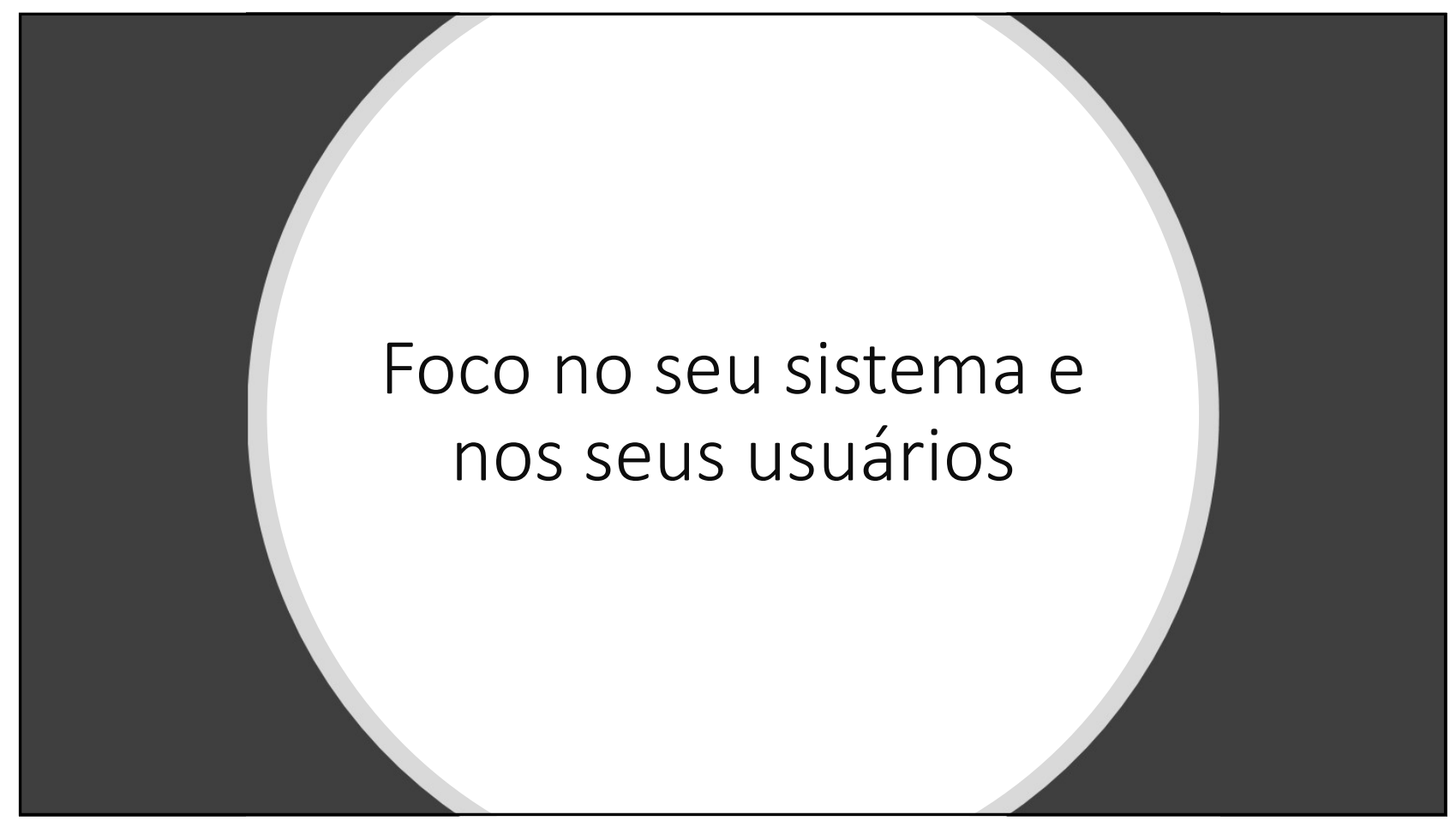


Vamos construir perguntas

\author{
iniciadas com \\ "Como podemos"
}

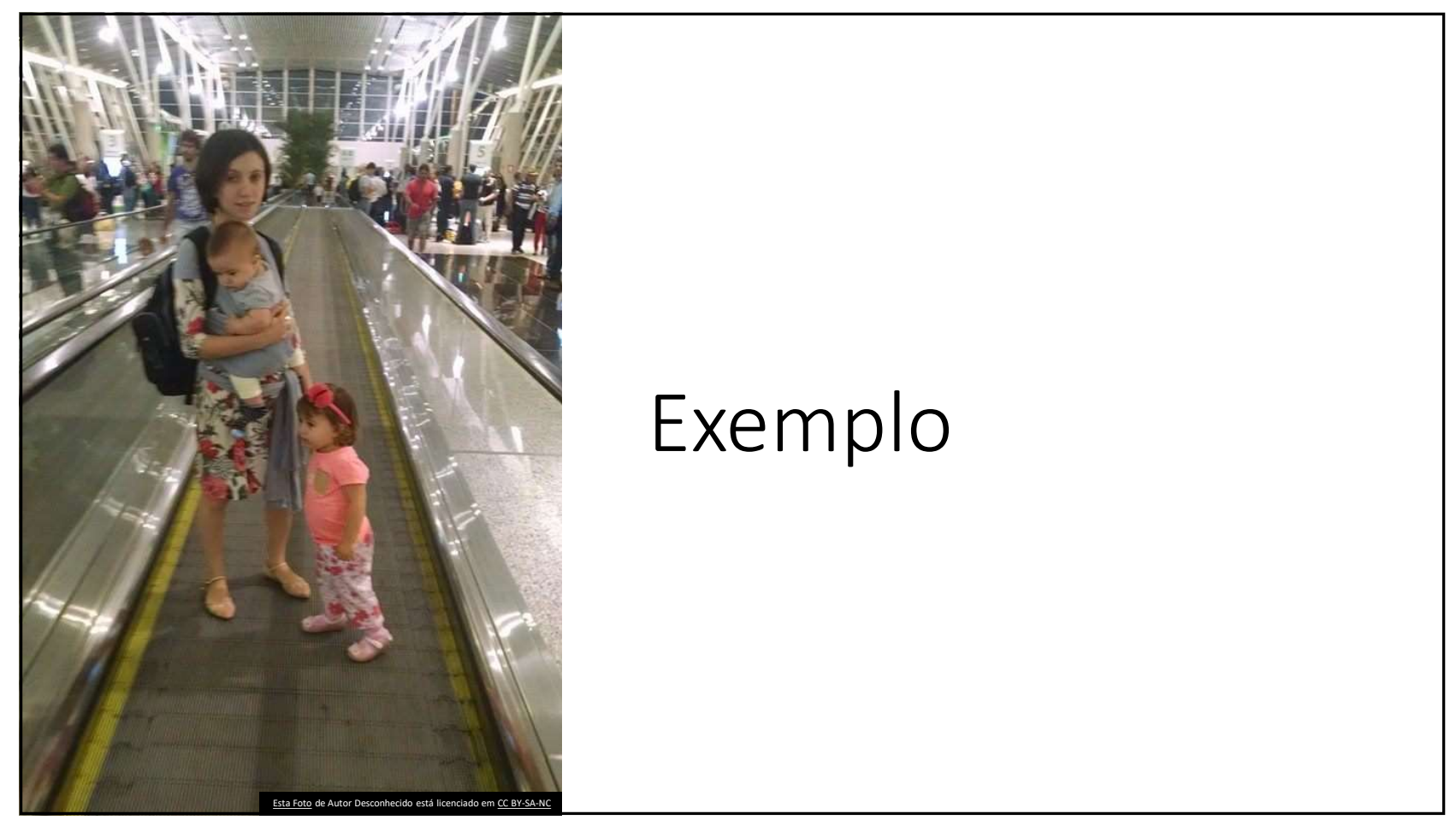




\section{Amplifique o que existe de bom!}

Como Podemos usar a energia das crianças para entreter os outros passageiros?

\section{Remova o que existe de ruim!}

Como Podemos separar as crianças dos outros passageiros? 


\section{Explore o oposto!}

Como Podemos fazer a espera ser a parte mais legal da viagem?

\section{Questione as premissas!}

Como Podemos remover completamente a espera no aeroporto? 


\section{Explore os adjetivos!}

Como Podemos fazer a pressa ser renovadora ao invés de irritante?

\section{Identifique recursos inesperados!}

Como Podemos ocupar o tempo livre dos passageiros para dividir a carga? 


\section{Crie analogias!}

Como Podemos fazer o aeroporto parecer com um SPA?

\section{Brinque com o desafio!}

Como Podemos fazer o aeroporto ser um lugar que as crianças queiram ir? 


\section{Mude o status!}

Como Podemos fazer crianças agitadas e barulhentas menos chatas?

\section{Explore os pontos de vista!}

Como Podemos relaxar a mãe? 


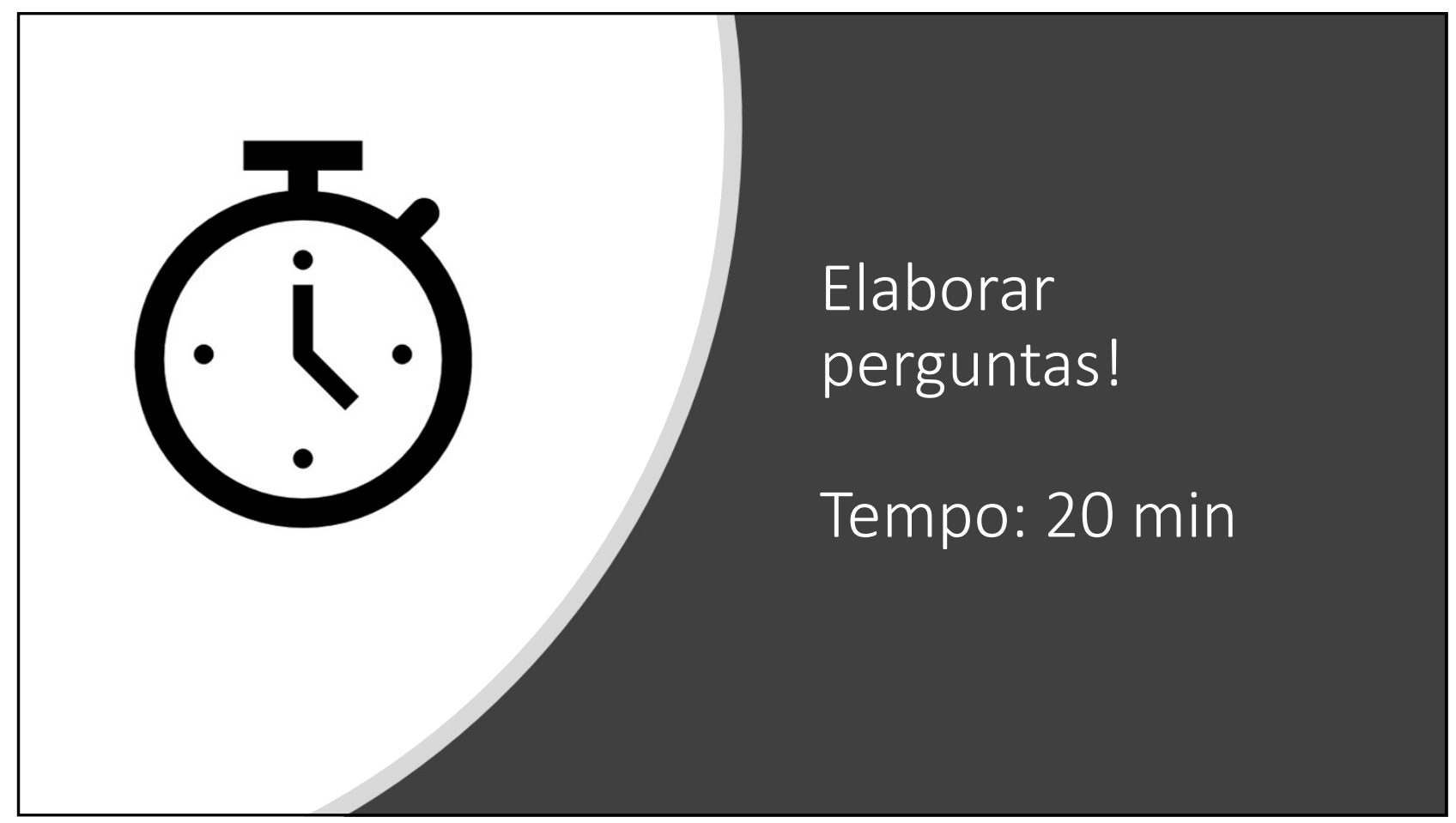

\section{Como podemos?}

Amplifique o que existe de bom!

Remova o que existe de ruim!

Explore o oposto!

Questione as premissas!

Explore os adjetivos!

Identifique recursos inesperados!

Crie analogias!

Brinque com o desafio!

Mude o status!

Explore os pontos de vista! 


\section{APÊNDICE D - APRESENTAÇÃO DAS CATEGORIAS DE RECURSOS}




\section{Mapeamento dos requisitos na arquitetura}

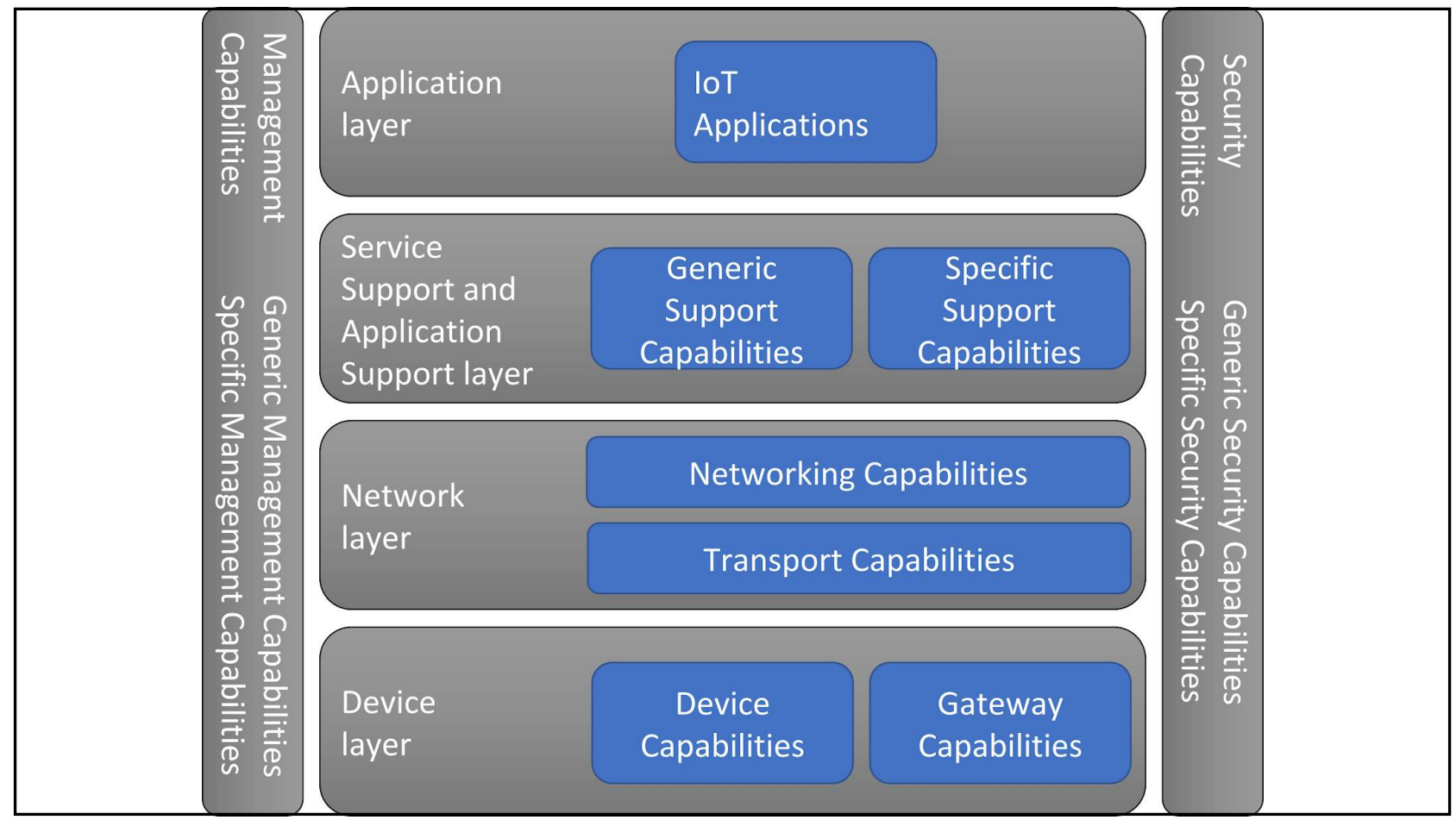


Recursos para a camada de aplicação em loT

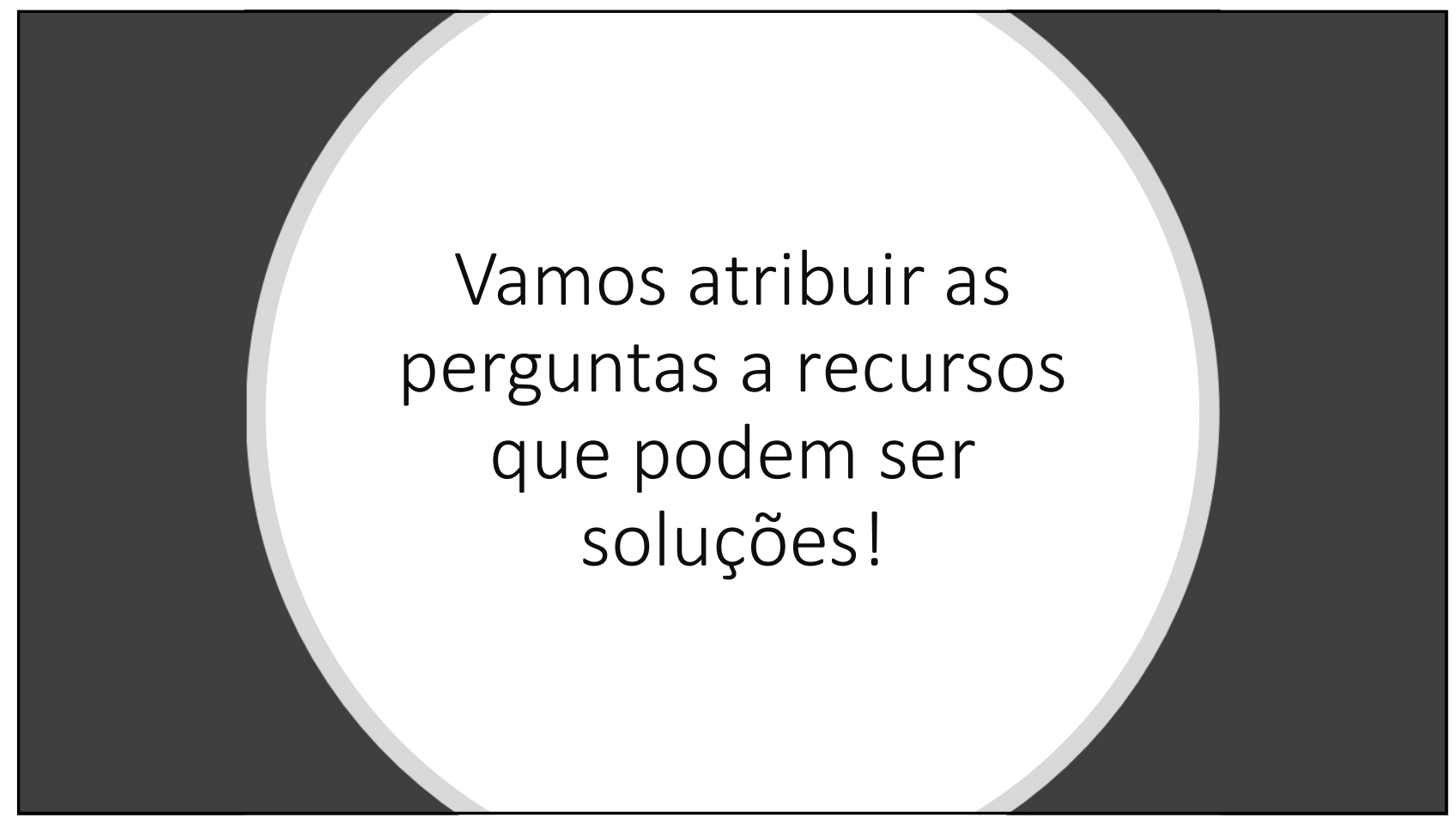




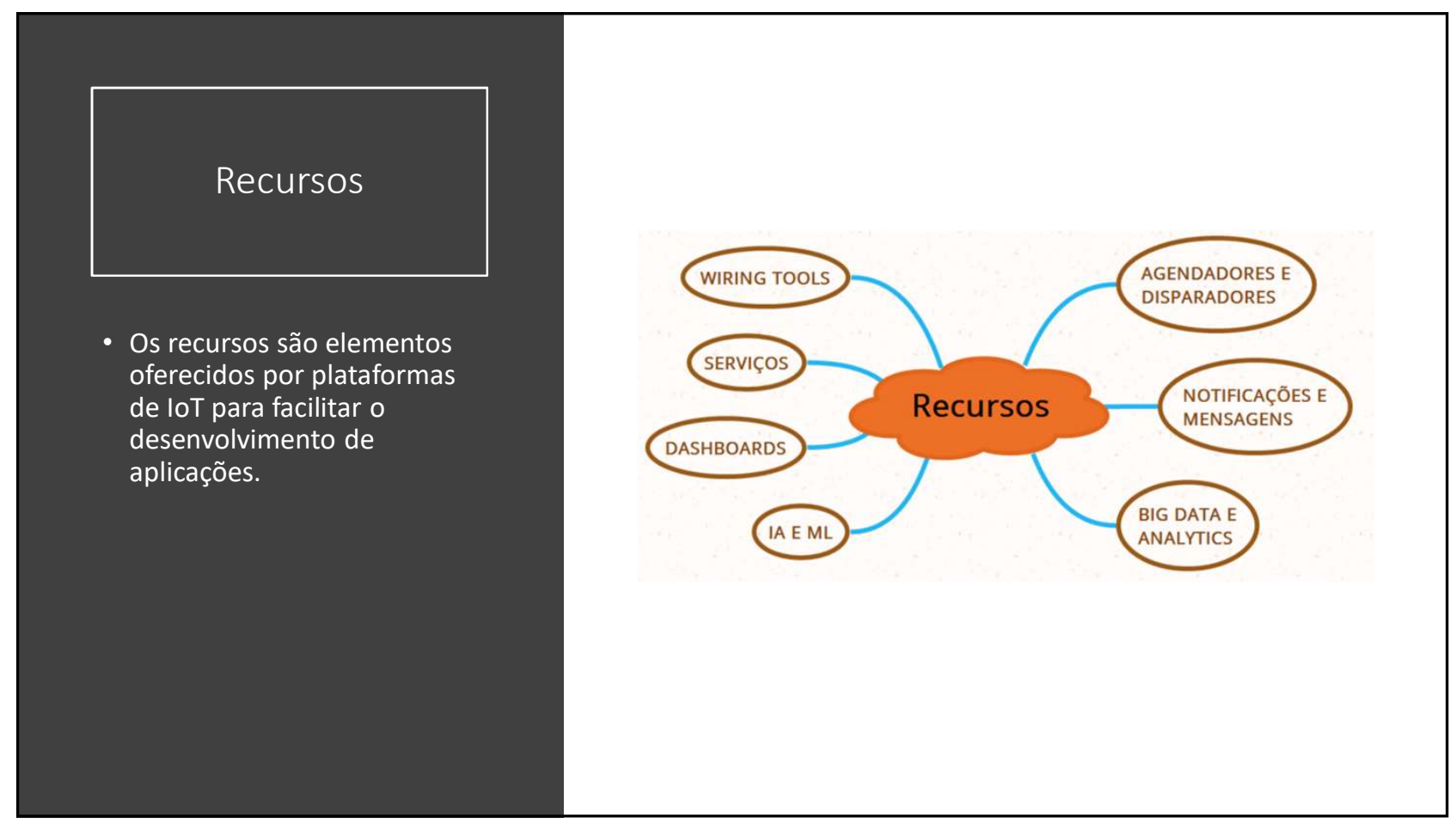

Agendadores

e

\section{Disparadores}

Execução de ações específicas em decorrência de um evento ou data/horário agendados.
Some example Recipes

\section{if 17 then $y$}

Nearly home? Direct message the person who should know

\section{if then}

Email your new iPhone photos to yourself

if 1 then 4 Spreadsheet 


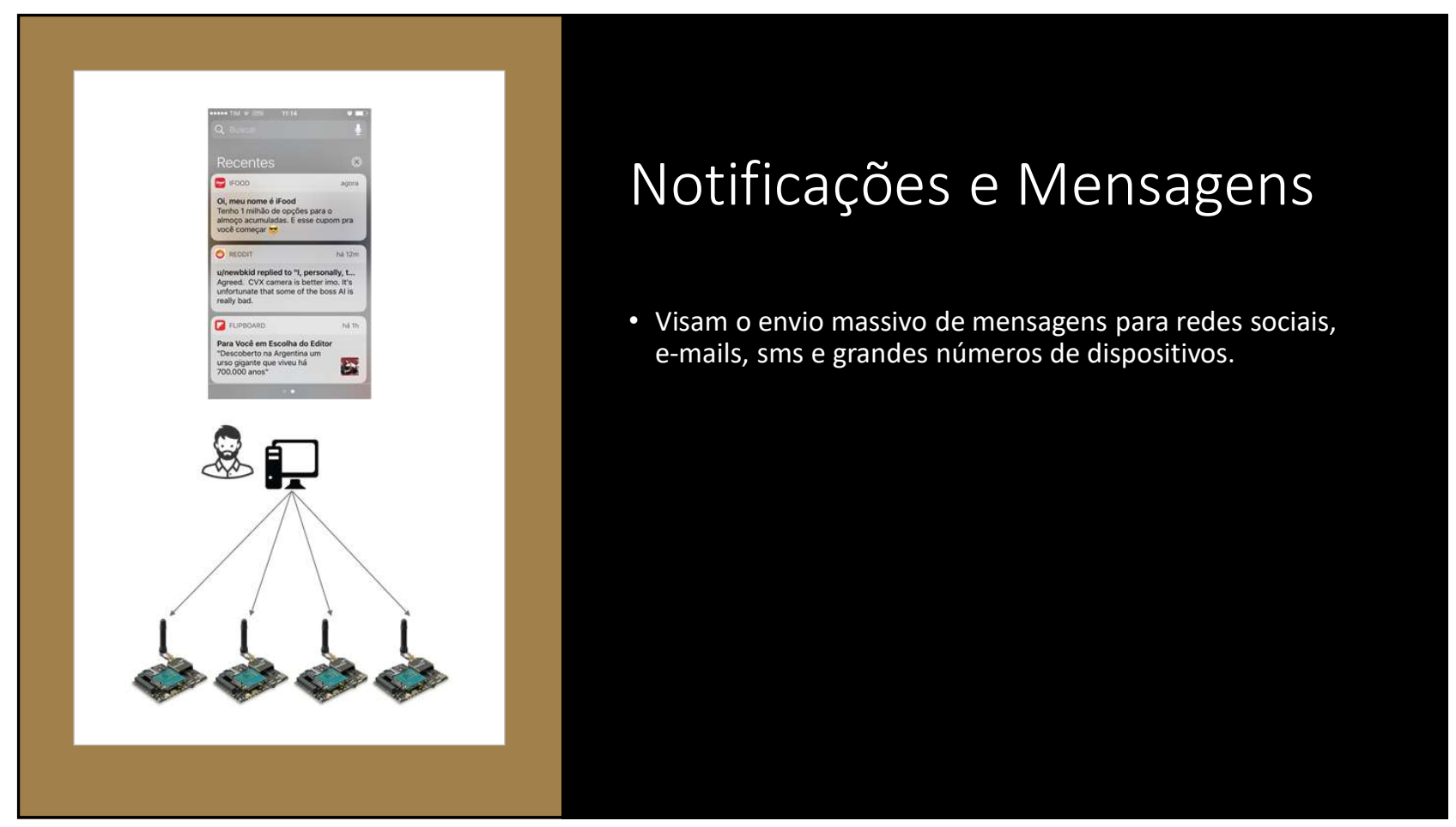

Big Data \& Analytics

- tratam do processamento e armazenamento de grandes volumes de dados, com a finalidade de dar sentido e extrair conhecimento dos mesmos, gerando relatórios e estratégias de negócio.

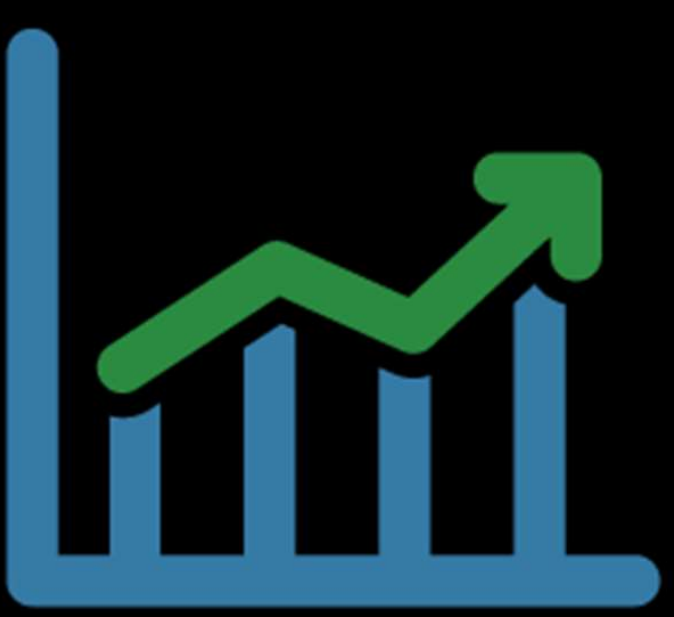




\section{Inteligência Artificial} e Machine Learning

- Integra classificadores e algoritmos de aprendizagem em aplicações, permitindo o aprendizado de novos comportamentos dado os estímulos do ambiente.
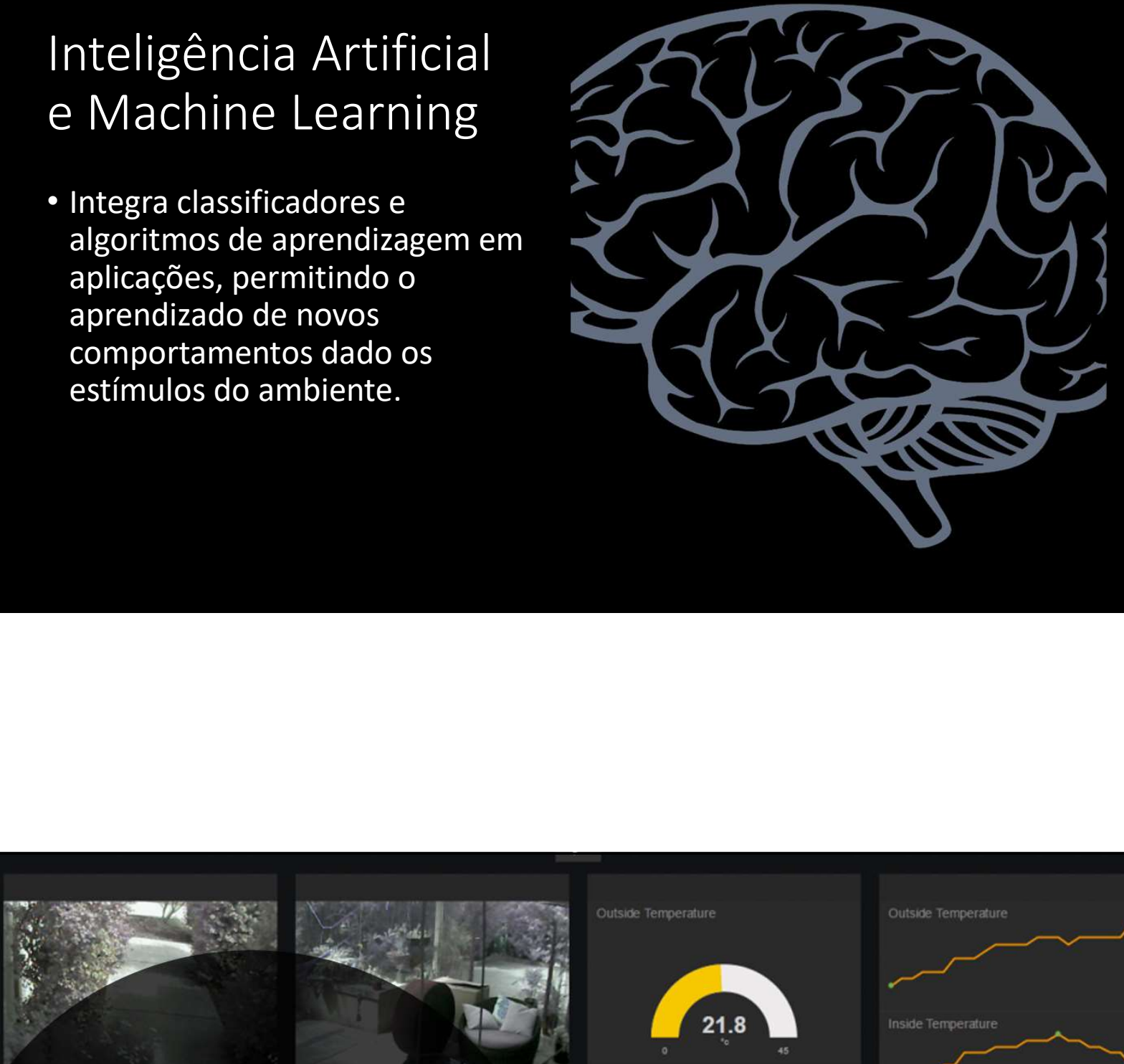

Outside Temperatur-

Dashboards

- São recursos de interface gráfica para criar painéis de visualização de dados através de gráficos, permitindo o monitoramento.
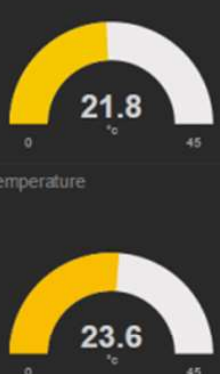

PI STATS

59 *

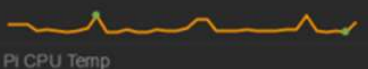

40.6

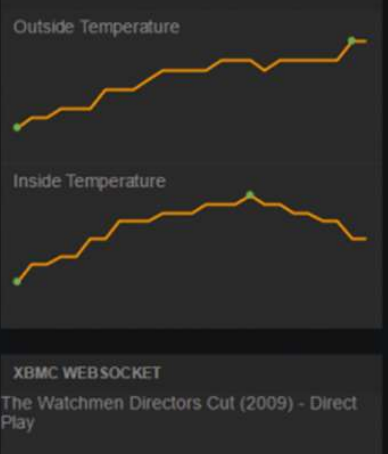

NODE-RED WEBSOCKE

64 


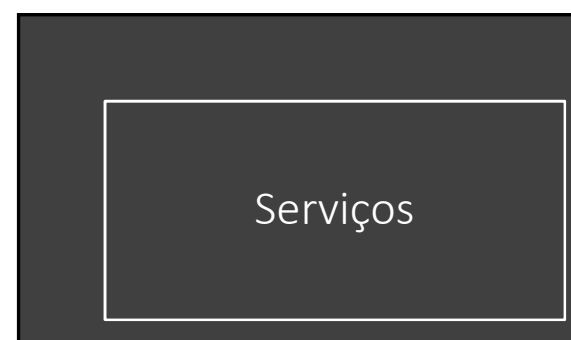

- Disponibilizam

funcionalidades e dados na

rede para serem utilizados

por terceiros (sites,

aplicativos, etc).

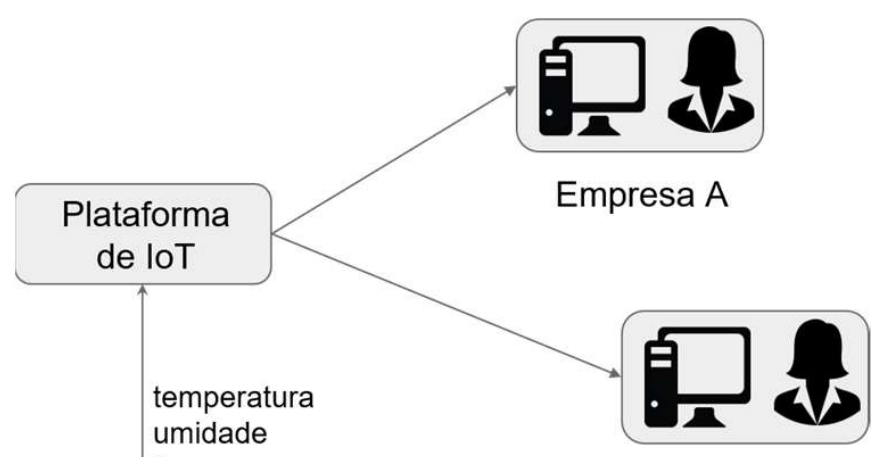

Empresa B

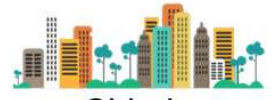

Cidade

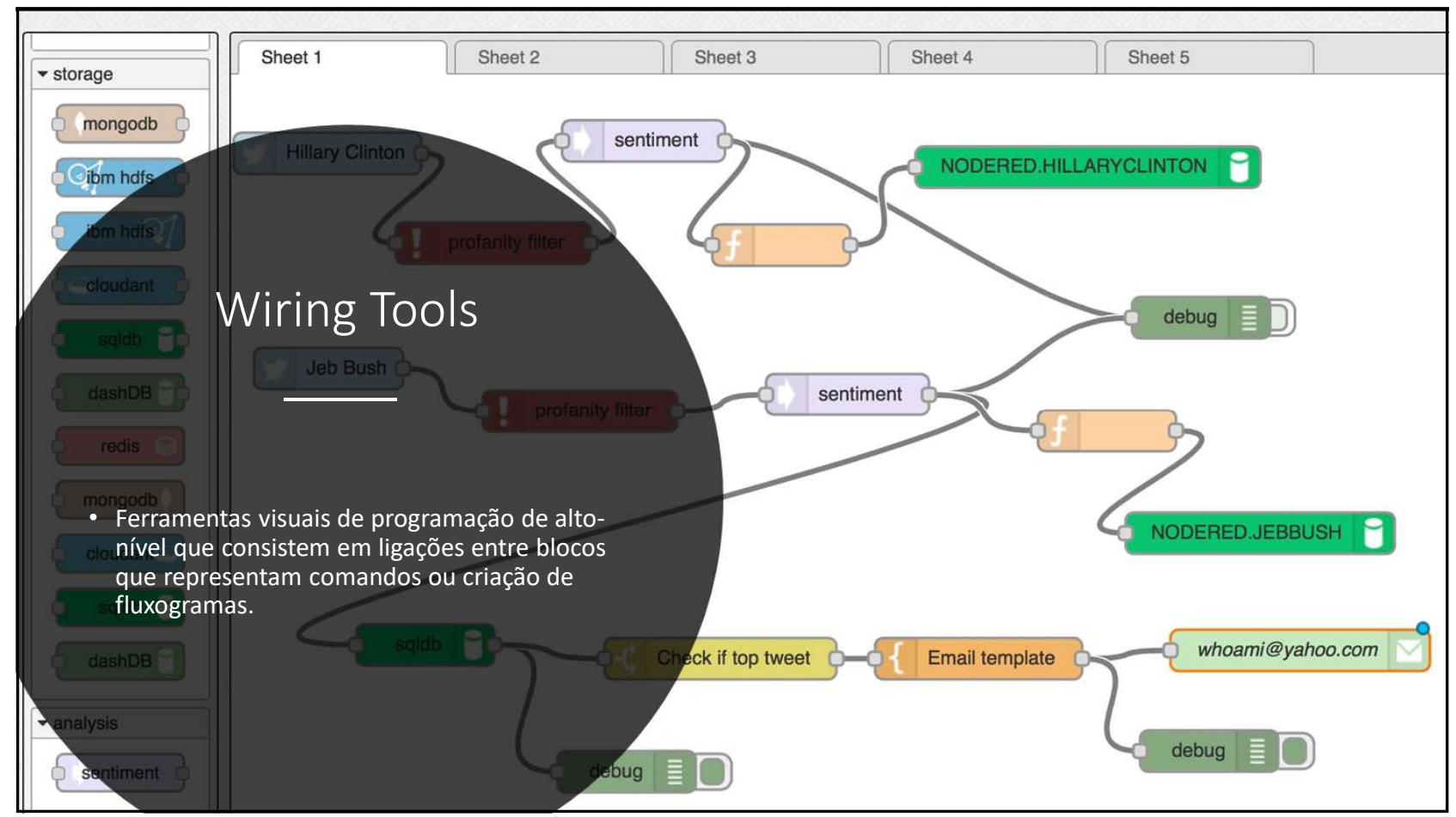




\section{APÊNDICE E - JORNADAS DO USUÁRIO (INDÚSTRIA 4.0)}




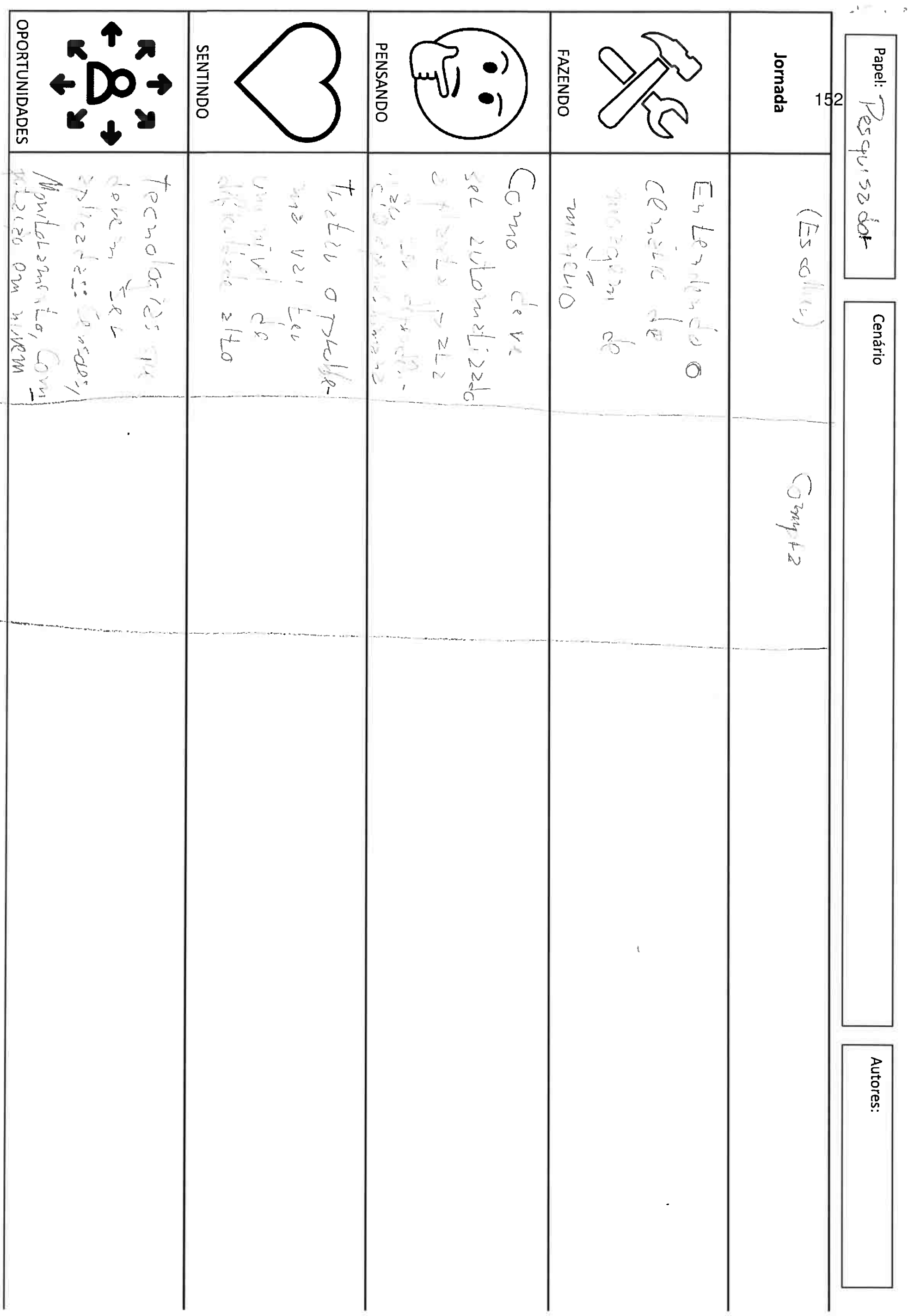




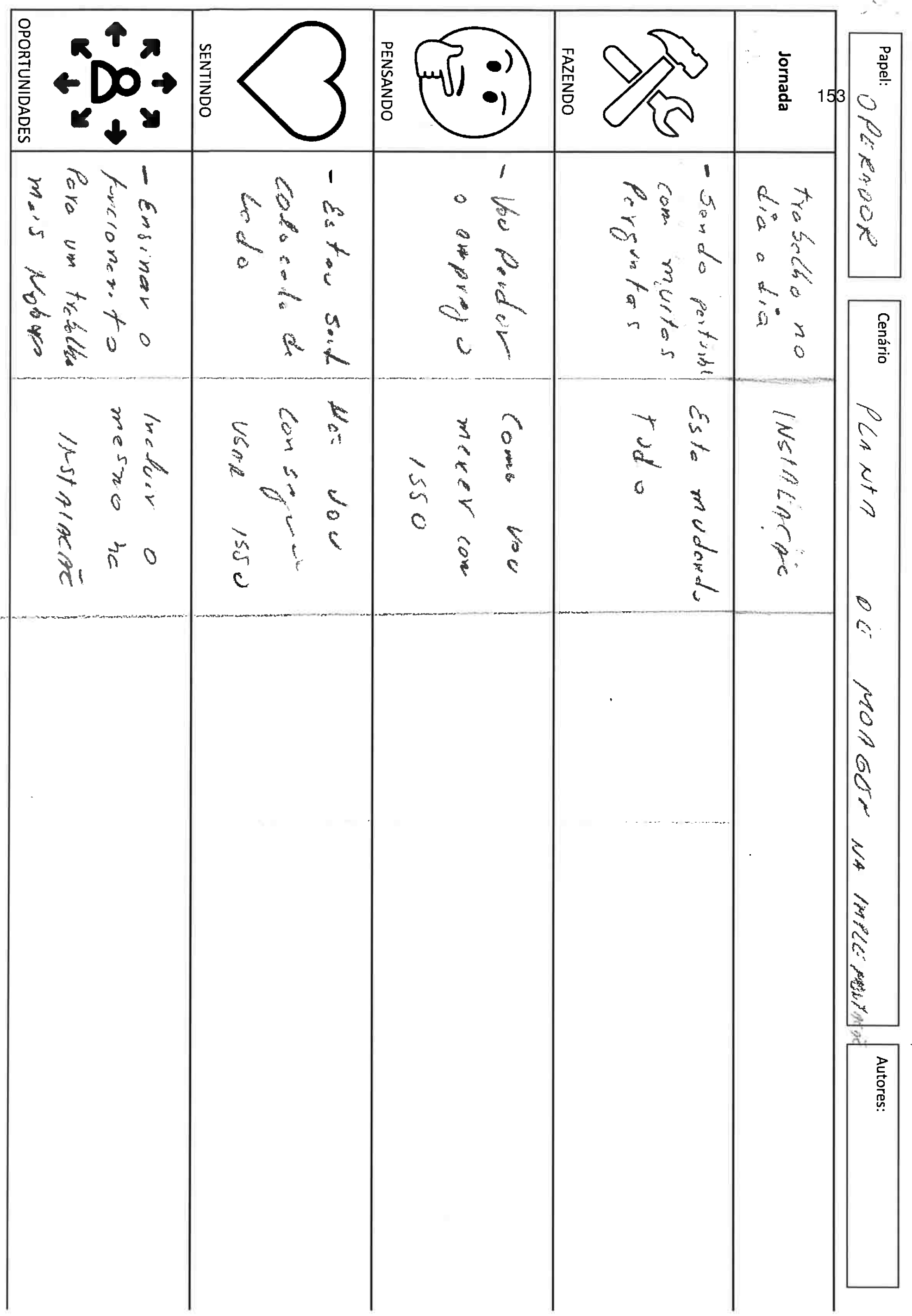




\section{APÊNDICE F - JORNADAS DO USUÁRIO (POLUIÇÃO)}




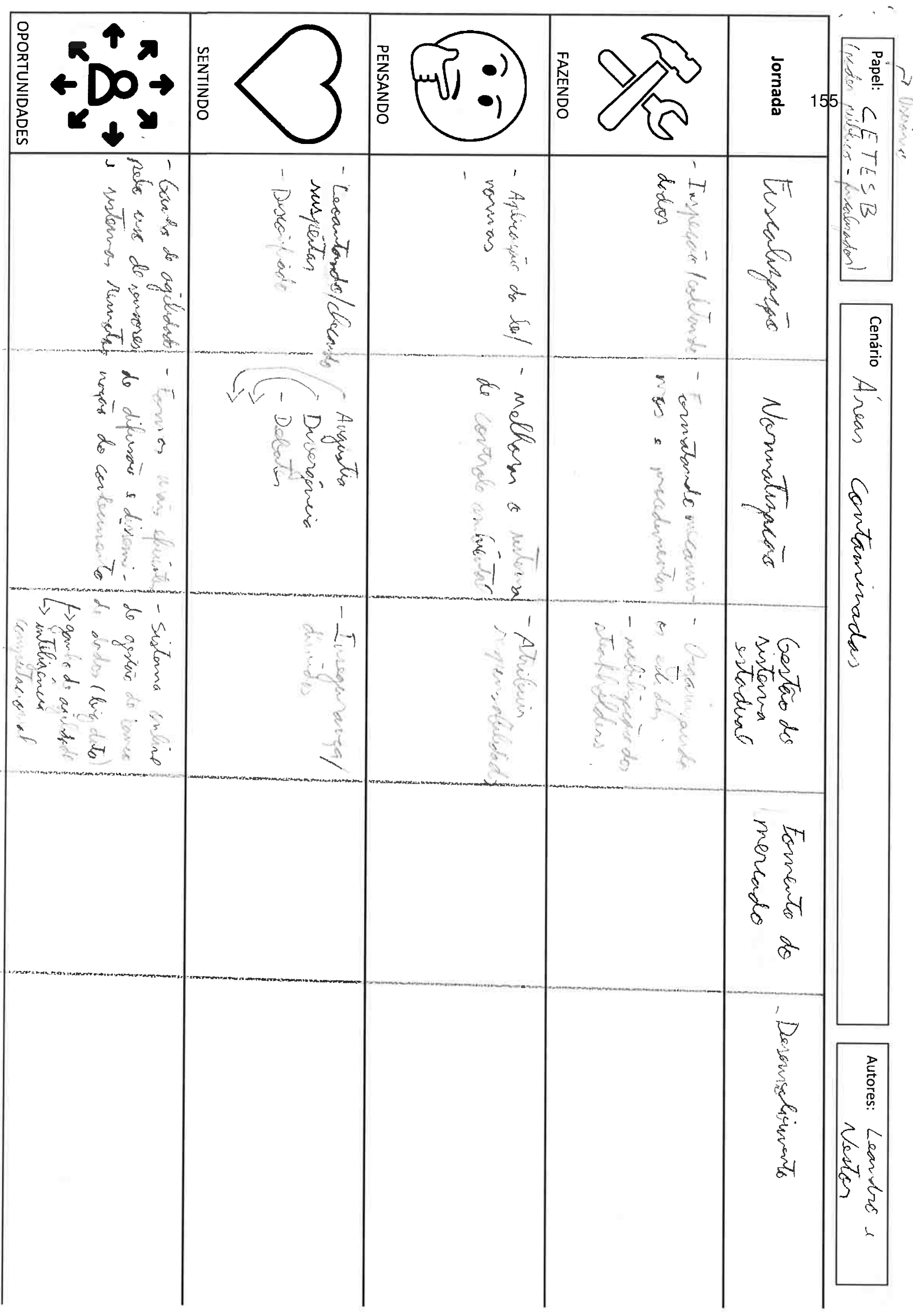




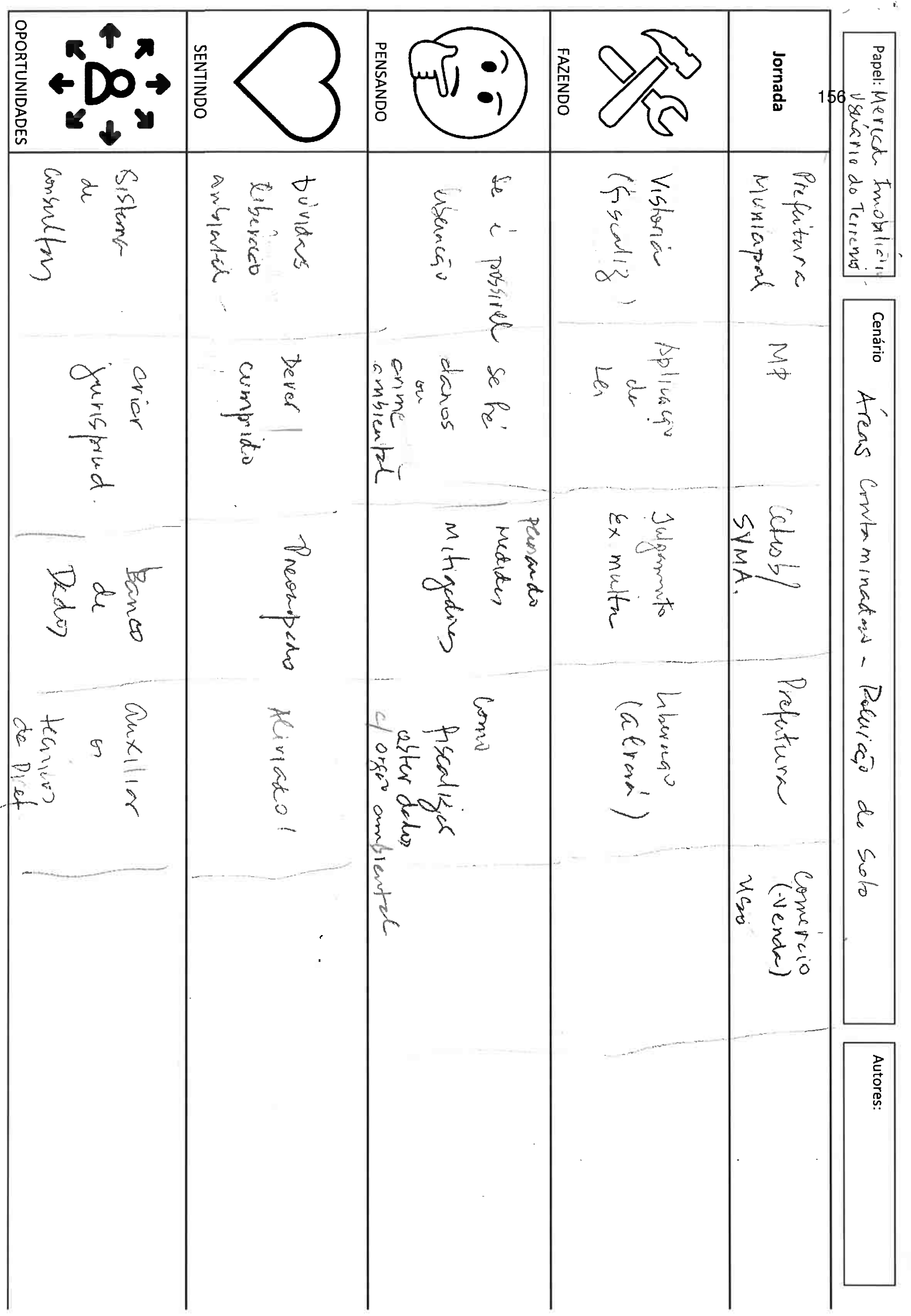




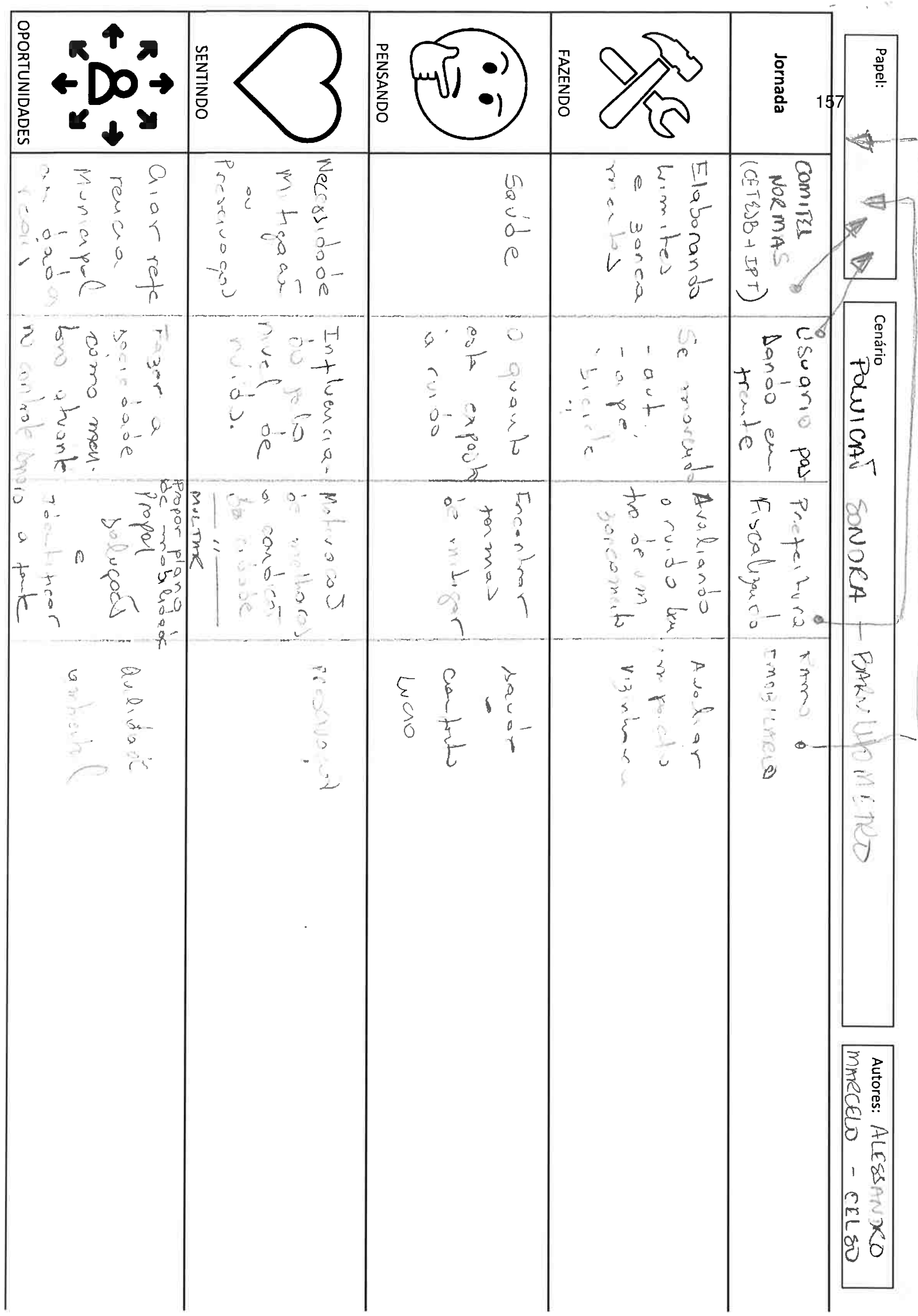




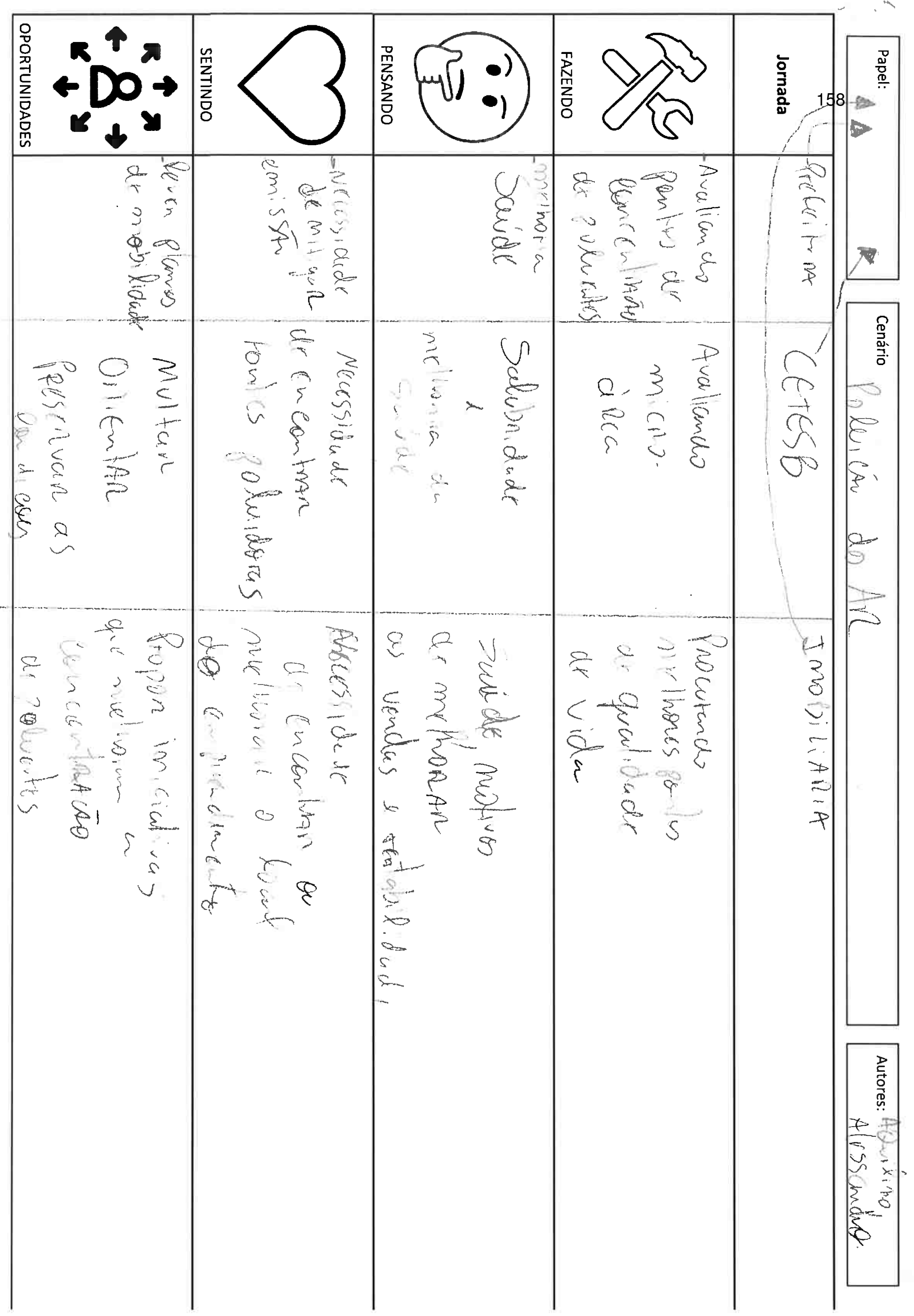




\section{APÊNDICE G - JORNADAS DO USUÁRIO (DESASTRES AMBIENTAIS)}




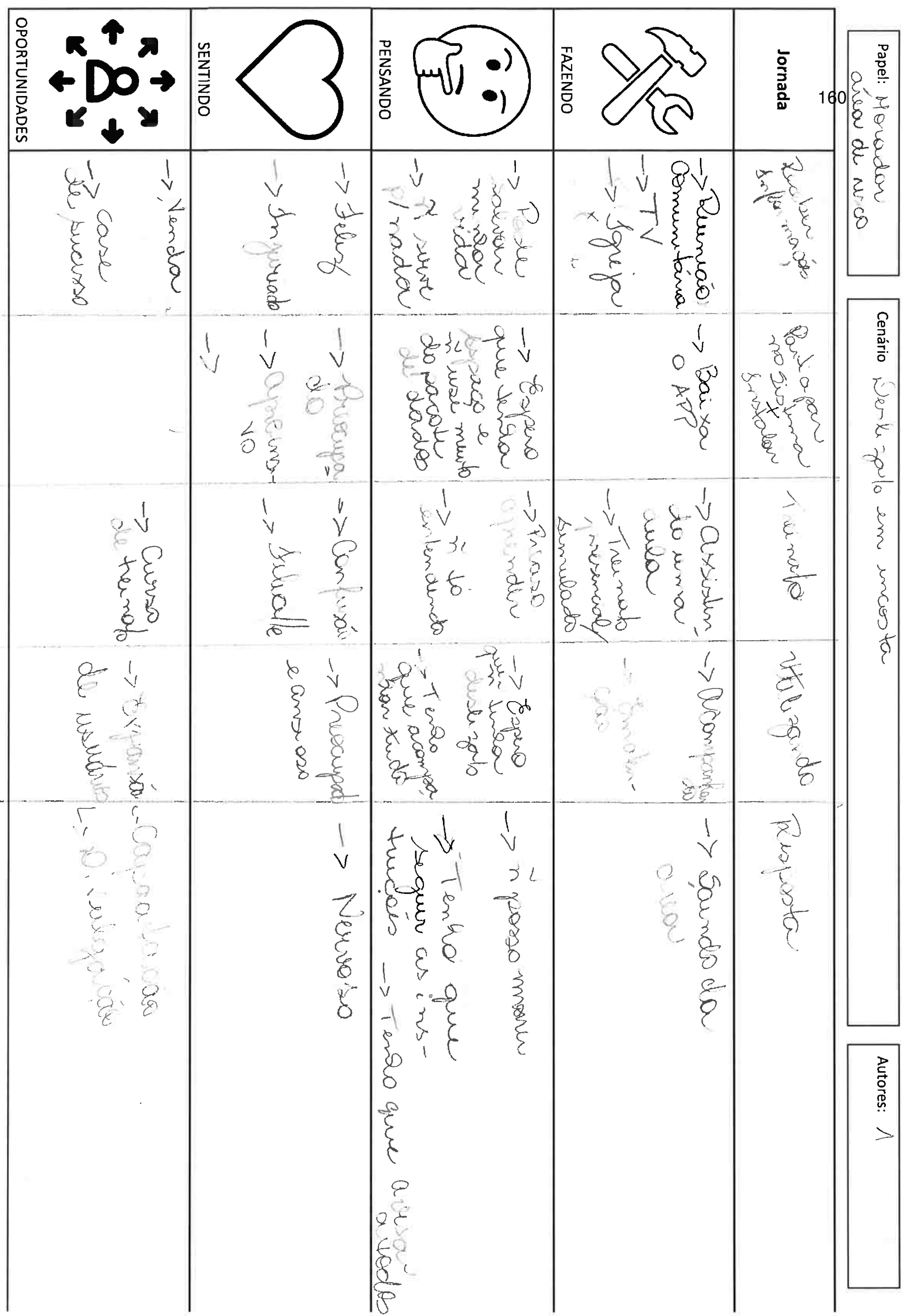




\section{APÊNDICE H - JORNADAS DO USUÁRIO (GESTÃO AMBIENTAL)}




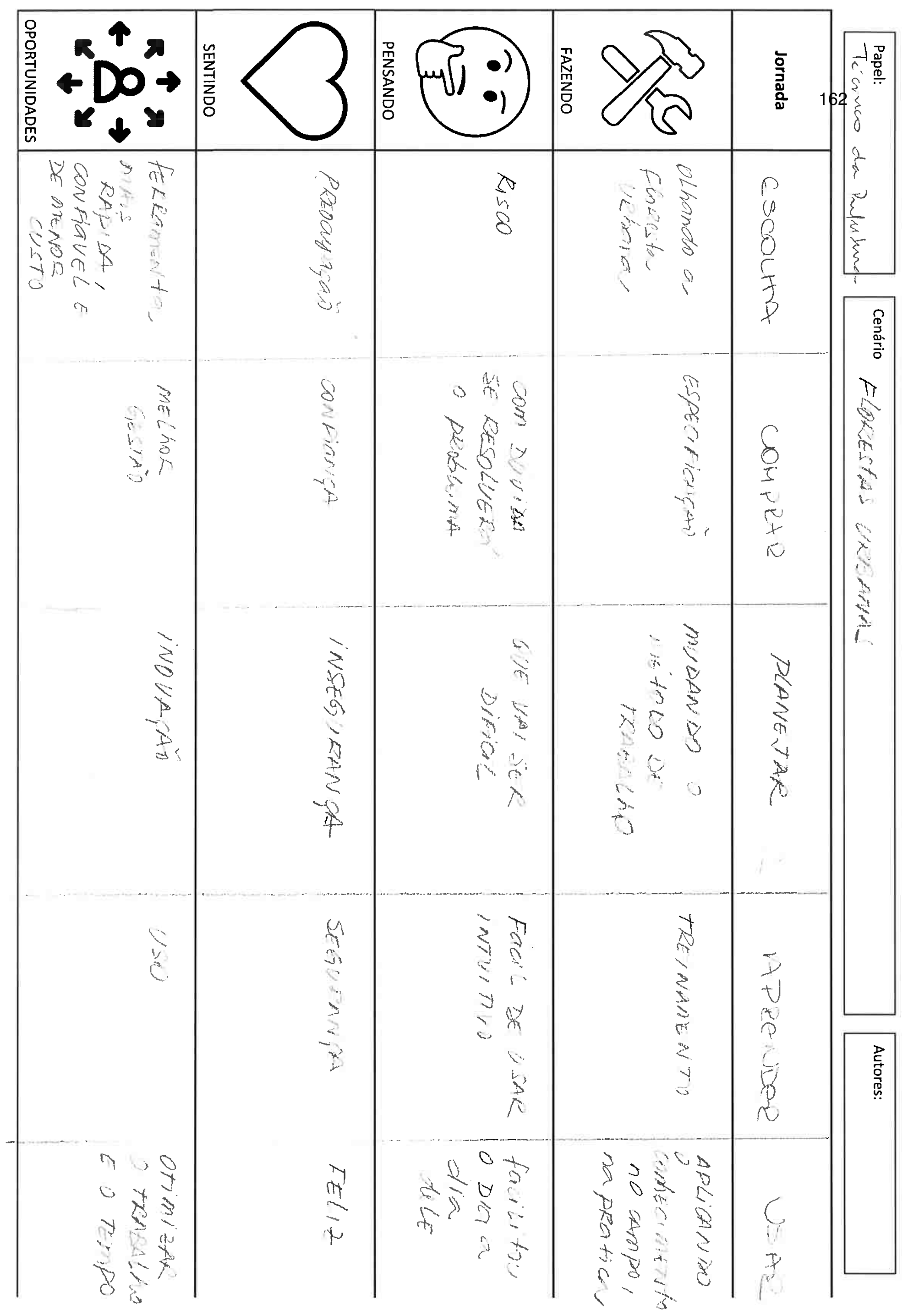




\section{APÊNDICE I - TRANSCRIÇÃO DAS QUESTÕES DE HMW OBTIDAS NAS DINÂMICAS E AGRUPADAS POR CATEGORIAS DE RECURSOS}


CP garantir que a população tenha conexão na região? CP transformar o medo do evento em coragem? CP identificar boas práticas de instrumentação na indústria de mineração?

CP disponibilizar wifif gratuito em todas as áreas? CP convencer o politico a fazer algo que talvez năo dê votos? CP manter o trabalho vivo durante várias gestões municipais e estaduais?

$\rho$

CP aquisitar os dados nas diversas regiões? CP garantir conexão com os diversos sensores? CP fazer para escapar da política particária? CP formentar atividades nas áreas de risco para motivar a população?

CP escolher a melhor plataforma para o problema? CP identificar quais mecanismos tecnológicos devem ser aplicados na soluçăo?

CP nos especializar na linha de pesquisa Indústria 4.0 com pouco tempo e dinheiro?

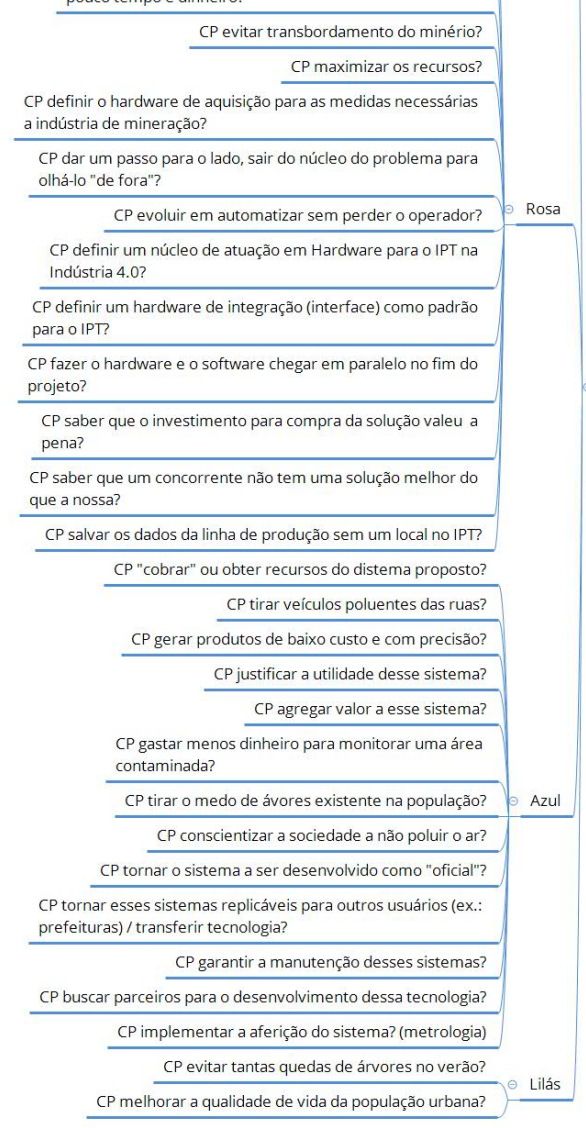

CP financiar as atividades da Defesa Civil para garantir o sistema?

CP tornar a tecnologia mais acessivivel para os mais velhos? CP inserir os app de mobilidade? CP criar lugares para abrigar a população? CP treinar pessoas de acordo com comunidade, gênero, etc? CP treinar um grande número de pessoas? CP financiar o sistema? CP envolver todos os stakeholders? CP desafiar e criar um sistema de bonificação pela participação?
CP inserir os jovens na solução? $\frac{\text { CP desafiar e criar um sistema de bonificação pela participação? }}{\text { CP inserir os jovens na solução? }}$ CP fazer treinamentos que atraiam muitas pessoas? CP engajar as crianças?

CP incentivar a população e indústria a poluir menos? CP ligar esse sistema em outros sistemas de gestão ambiental? CP buscar dados secundários de órgãos públicos? CP produzir bens e produtos poluindo menos? CP fazer a transmissão dos dados? CP criar um app para que a população ajude na gestão da floresta urbana em tempo real?

$$
\frac{\text { CP obter o histórico do diagnóstico? }}{\text { CP ajudar o poder público? }}
$$

Amarelo $\mathrm{C}$ CP evitar a morte por deslizamentos?

CP evitar faltos alarmes?

CP lembrar dos passos do treinamento na hora do susto? CP identificar corpos estranhos que não sejam o minério

Rosa $\odot$ especfíco da moagem?

CP utilizar como sistema de fiscalizaçâao?

Azul of $\mathrm{CP}$ identificar características do meio urbano que propiciamm concentração de poluentes do ar Lilás

CP disseminar o sistema junto à

população

CP envolver as comunidades para ressaltar que ruido é

problema de saúde?

CP fazer publicidade da solução?

Azul CP treinar a população nos princípios básicos de acústica? CP fazer analogia com ruídos conhecidos?

CP utilizar o sistema para educação?

- CP criar modelos de fiscalização e

Rosa $\ominus$ CP avisar os operadores sobre uma queda de energia? Como podemos aproveitar a colaboraçāo de entidades (comunidade, igreja, etc)? CP incentivar a todos os individuos a participar?

Amarelo

Como podemos divulgar mundialmente a solução? Como podemos distribuir o sistema para a mídia?

CP avaliar o desgastes das bolas?

CP avaliar a quantidade de minério processado?

Rosa

CP avaliar o gasto das esferas em função da quantidade de

minério?

CP saber que a solução de indústria 4.0 é vantajosa com relação ao que já existe?

CP mudar a forma de mobilidade das pessoas para poluir menos?

CP contabilizar os malefícios da poluição do ar?

Azul đo CP associar o nível de ruído à problemas de saúde das regiōes? (UBS, AMAS...)

CP além de medir o ruído, avaliar a incomodidade?

CP utilizar o sistema com solução direcional? (ruído direcional) Como montar algo que funcione para qualquer situação? Amarelo $\quad \mathrm{CP}$ correlacionar dados de sensores e imagens? CP estruturar dados espaciais para Big Data? CP caracterizar o estado de conservação da vegetação por imagens?

CP organizar e sistematizar dados pulverizados gerados de formas diversas?

CP automatizar a coleta de dados em larga escala para diagnóstico do estado de conservaçăo de fragmentos florestais? CP cruzar os dados de caracteristicas com a imagem? ๑) CP de forma rápida mostrar os diversos ti[p/r]os? CP obter a amostra ideal para elaborar/construir a ferramenta de diagnóstico em tempo real de florestas?

Lilás CP diferenciar os estágios de conservação de fragmentos florestais em imagens?

CP padronizar metodologias para diminuir a incerteza dos dados de diagnóstico do estado de conservação de fragmentos florestais?

CP tabular e padronizar tantos dados em um único sistema?

CP armazenar uma infinidade de fotos?

CP resumir dados tāo complexos em informaçōes simples? CP armezenar os dados?

CP predizer os eventos?

Amarelo CP calcular o risco de deslizamento? CP aumentar a velocidade do processo?

Rosa of CP diminuir o tempo de moagem? CP distribuir o minério igualmente na esteira? CP usar os resultados para mitigar o ruído?

Azul $\mathrm{O}$ CP criar esforços urbanos com ar mais limpo? CP reduzir as incertezas de risco de queda de árvores?

Lilás $\begin{aligned} & \text { CP treinar os diversos modelos? } \\ & \text { CP elaborar modelos de aprendizagem de máquina para }\end{aligned}$ compor uma ferramenta ou diagnóstico de vegetaçāo em tempo real?

CP aproximar a pesquisa da gestão pública?
CP avaliar a rotação do moinho?

Rosa $\odot \mathrm{CP}$ entregar informação que ajude a operar o sistema?

CP monitorar o minério no caminho pela planta de moagem?

CP divulgar informaçôes de modo seguro e sem complicações juridicas?

Dashboards

CP inter ligar pontos distintos de monitoramento criando um

mapa dinâmico?

CP fiscalizar indústrias e veículos poluidores?

CP passar segurança para as prefeituras usarem o sistema de gestão de florestas em tempo real?

Lilás of CP apresentar de forma amigável o resultado da anáise? CP facilitar a vida do usuário? 
APÊNDICE J - ARTIGO PUBLICADO 


\title{
Detecting IoT Applications Opportunities and Requirements Elicitation: A Design Thinking Based Approach
}

\author{
Douglas Lima Dantas ${ }^{1[0000-0002-3950-7699]}$, Lucia Vilela Leite \\ Filgueiras ${ }^{10000-0003-3791-6269]}$, Anarosa Alves Franco \\ Brandão ${ }^{1[0000-0001-8992-4768]}$, Maria Cristina Machado \\ Domingues $^{2[0000-0002-0160-8208]}$, and Maria Rosilene \\ Ferreira $^{2}[0000-0002-3465-2168]$ \\ 1 Escola Politécnica da Universidade de São Paulo, São Paulo, SP, 05508-010, Brazil \\ douglasdantas, lfilguei , anarosa.brandao@usp.br \\ http://www.poli.usp.br \\ 2 Instituto de Pesquisas Tecnológicas do Estado de São Paulo, São Paulo, SP, \\ 05508-901, Brazil cmachado,mrosif@ipt.br \\ http://www.ipt.br
}

\begin{abstract}
IoT development is complex. To reduce this complexity, IoT platforms provide a set of resources and functionalities to enable application development and support its execution. In this work, we present a human-centered approach for requirements elicitation and mapping them to application resources in IoT platforms, using empathy, definition and ideation methods. A previous study by the authors has identified 11 categories of resources provided by 47 IoT platforms to developers in their application layers. From this set, 6 categories were selected for this work: schedulers and triggers, message and notification triggers, big data and analytics, artificial intelligence and machine learning, dashboards, and services. We invited 18 members of 8 projects for a workshop and divided them in 4 teams, according their project areas, which are: Industry 4.0 (6 participants), Environmental Disasters (4 participants), Environmental Management (3 participants) and Pollution (5 participants). We divided the workshop in 3 phases: warm-up, with user journey mapping, requirements identification using "how might we" questions as a trigger and requirements clustering the questions by the 6 selected categories of resources or an extra category named "others" for those which could not be related to any previous category. Our contribution for the IoT application development is an approach for turning easier requirements elicitation using DT techniques, covering the stages of empathise, definition and ideation, with well-available materials and considering the resources present at application layer of IoT platforms.
\end{abstract}

Keywords: Design Thinking - Internet of Things · Human Centered Design · Requirement Gathering 


\section{Introduction}

Internet of Things (IoT) technology brings the potential of creating smarter and more connected solutions, making use of intelligent device networks and technological resources such as hardware devices, big data, machine learning, communication protocols, data visualization and others that integrate sensing, actuation, identification, tracking and event processing features [20]. It is expected that in 2020 the Internet has around 100 billion connected devices [21]. IoT technologies have the potential of improving processes in various business domains. However, due the heterogeneity of technologies, IoT application development is complex [17] and requires more interdisciplinary teams when compared with other development fields. For instance, in mobile application development, users' experience is based on established design guidelines $[2,3]$ and on the use of resources powered by the operating system like network access, Bluetooth connection, device sensors, notifications, among other ones [23]. A well-defined set of functionalities and a stable interaction language creates consistency across different mobile applications in different operating systems and domain areas. The same still does not occur with IoT application development, for technologies varies strongly for different projects, mainly when considering IoT applications for different domain areas. In order to reduce this complexity, companies, governments and research institutions work towards the creation of IoT platforms, which are a workbench of integrated technologies providing a set of resources and functionalities to enable application development and to support its execution. IoT platforms are generally available as cloud services, known as Platforms-asa-Service (PaaS), but are also available for installation in private servers. The mainstream of IoT research is addressing technological aspects such as security and connectivity, or in philosophical questions, such as the representation of physical elements in the digital world, for instance [18]. Nevertheless, for IoT application development, requirements elicitation and their mapping to a given platform is still a challenge. In this work, we present a human-centered approach for requirements elicitation and mapping them to application resources in IoT platforms, using Design Thinking (DT) techniques. We intend to contribute to the process of IoT application development in a platform-agnostic environment, studying how DT can help developers of different domain areas in mapping their requirements to IoT platforms. This paper is structured as follows. Section 2 presents reference IoT architecture models. Section 3 briefly introduces Design Thinking and their phases, detailing the techniques used in our experiment. Section 5 reports our experiment. In Section 6, we discuss the experiment findings.

\section{IoT applications development}

According to ITU Telecommunication Standardization Sector[22], IoT is defined as "a global infrastructure for the information society, enabling advanced services by interconnecting (physical and virtual) things based on existing and evolving 
interoperable information and communication technologies". Fig. 1 shows the evolution of the IoT. Over time, the Internet got less people-dependent, networks turned smarter and data gained crucial importance, with devices rising as main data generators. This new paradigm has a potential of application in different vertical markets such as smart cities, industry, smart homes, logistic, health and retail, for example. IoT projects use a diversity of hardware technologies, like sensors, actuators, microcontrollers and communication devices, and software resources, such as data visualization, data processing, machine learning classifiers, etc. This heterogeneity caused a lack of standardization [1]. Over time, government bodies, companies, institutions and others interested organizations have created different architecture reference models in order to standardize the IoT and define guidelines for IoT systems development. Because of these efforts, the ITU-T Architecture Reference Model, IoT Architecture Reference Model (IoT ARM) and ISO/IEC 30141 were defined and are exaples of reference models. The application layer, focus of this work, is part of these architectures, as seen in Fig. 2, and it is the place where usually business intelligence is developed. The implementation of an architecture is named IoT platform, that is an integrated solution for a specific or general purpose, reducing complexity, increasing components reuse and bringing development tools for IoT developers. We define as development resource as any set of functionalities provided by an IoT platform to an application developer. A resource can be a component, a library, an API or other form of software that can be used in the application development. A previous study by the authors has identified 11 categories of resources provided by 47 IoT platforms to developers in their application layers, listed below:

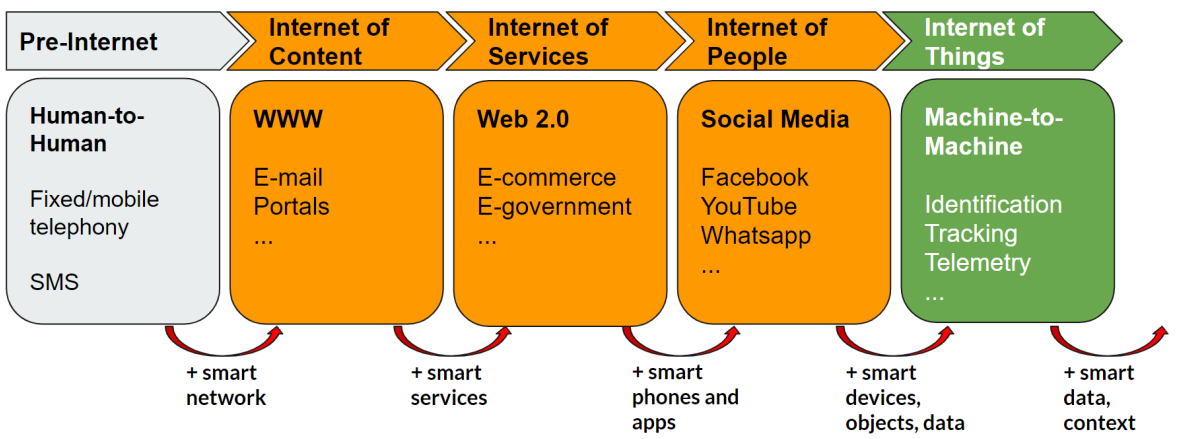

Fig. 1: IoT evolution.

- Artificial Intelligence (AI) and Machine Learning (ML): Resources that allow integrating classifiers and learning algorithms into applications.

- Big Data and Analytics: Resources that deal with the processing and storage of large volumes of data, to give meaning and to extract knowledge from them, generating reports and business strategies. 


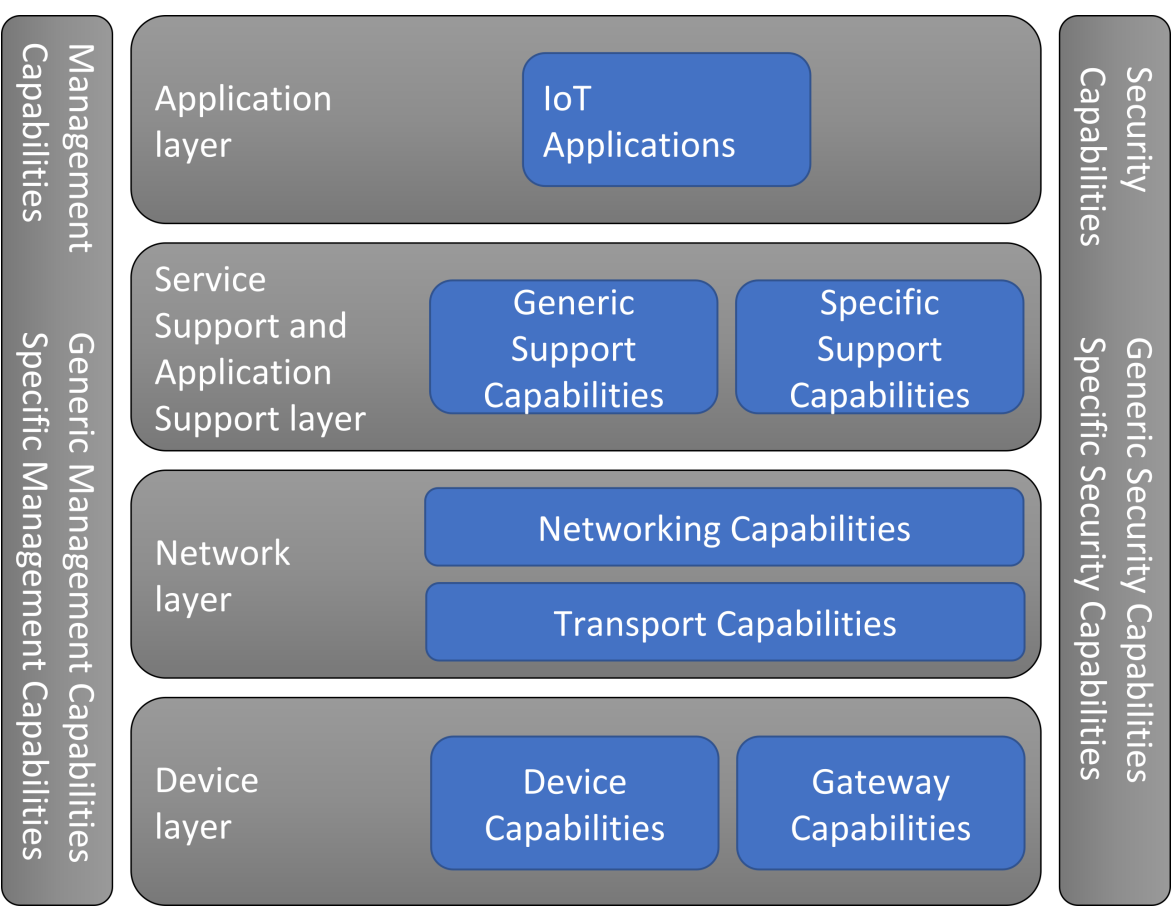

Fig. 2: The ITU-T IoT Architecture Reference Model.

- Control Panels: Resources that help the administrator to manage and to maintain the platform and its resources, these being of hardware, software, network, energy, among others. On IoT platforms, these control panels frequently provide device management, user authentication, authorization, edge computing configuration, and protocol connections.

- Dashboards: Resources of graphical interface capabilities to create graphical data visualization panels, allowing monitoring.

- Device Abstractions: Resources that abstract the functionality of devices, reducing the inherent complexity of the variety of devices.

- Marketplaces: In the context of this work, they are directories at which the developer or end user can find or make available components, applications, data and other products, which permits be commercialized, in catalogue form. These available items can be integrated into applications or used as end applications, depending on the platform.

- Message and Notification Triggers: Resources that aim to send mass messages and notifications to the most varied types of devices. This information can be control messages, event alerts or simply focusing on user interaction.

- Schedulers and triggers: These are resources that trigger actions from a given time, or an expected event. 
- Services: Resources of communication interfaces through which functionalities are made available through endpoints, for communication with other applications. The most recurrent form is through HTTP REST and SOAP webservices, in the client-server model, or MQTT, in the publish-subscribe model.

- Software Development Kit (SDK): Resources such as libraries, source codes and templates to facilitate the development of applications, allowing to use platform functionalities within the final applications.

- Wiring Tools: Resources of visual high-level programming tools that consist of links between blocks that represent commands or creation of flowcharts.

\section{Design Thinking and Requirements Elicitation}

According to Interaction Design Foundation [15], Design Thinking (DT) is "a non-linear, iterative process which seeks to understand users, challenge assumptions, redefine problems and create innovative solutions to prototype and test", and projects in different areas may use its techniques through DT dynamics, where the groups used to be multidisciplinary and their member has skills such as empathy, integrative thinking, optimism, experimentalism and collaboration. The DT process is divided in between three and seven phases, depending the variant. The Fig. 3 shows the five-stage model defined by Hasso-Plattner Institute of Design at Stanford (d.school) [16], which we explain below:

- Empathise: The comprehension of the user's point of view within the context of the project's problem. The success of this phase is crucial, once the definition and ideation processes are dependent of its outcomes. At this stage, we can use methods such as "assuming a beginner's mindset", bodystorming, asking what-how-why, conducting interviews, engaging with extreme users, among others [10].

- Define: The delimitation of the meaningful design challenge on which the team should focus. The Interaction Design Foundation [11] points three desired characteristics of a design challenge: i) human-centered; ii) broad enough for creative freedom; iii) narrow enough to make it manageable. Empathy maps, customer journey, point of view, "how might we" questions are some of the techniques that may we use at this phase.

- Ideate: The effort for idea generation in order to find solutions after one or more design challenges defined. In this phase, the team may find the innovation. There are different ways of conducting it, such as brainstorming sessions, mindmaps and provocation, for instance [12].

- Prototype: The generation of artifacts that can be in different sophistication grades, in order to testing ideas and collect feedback from users. The team may create low-fidelity prototypes, made of simple materials like paper or wood, for example, to validate initial and uncertain ideas and make highfidelity prototypes, that are closer to the final product, to test the user's behavior with already validated ideas and adjust them [13]. 
- Test: The presentation of the generated prototypes and users feedback collection. The team may use the outcomes as input for the others stages, like new ideas generation and refining the prototypes, for example [14].

There are several documented techniques to support DT phases. Our requirements elicitation approach used techniques from different DT phases: user journey maps, how might we questions and affinity diagrams.

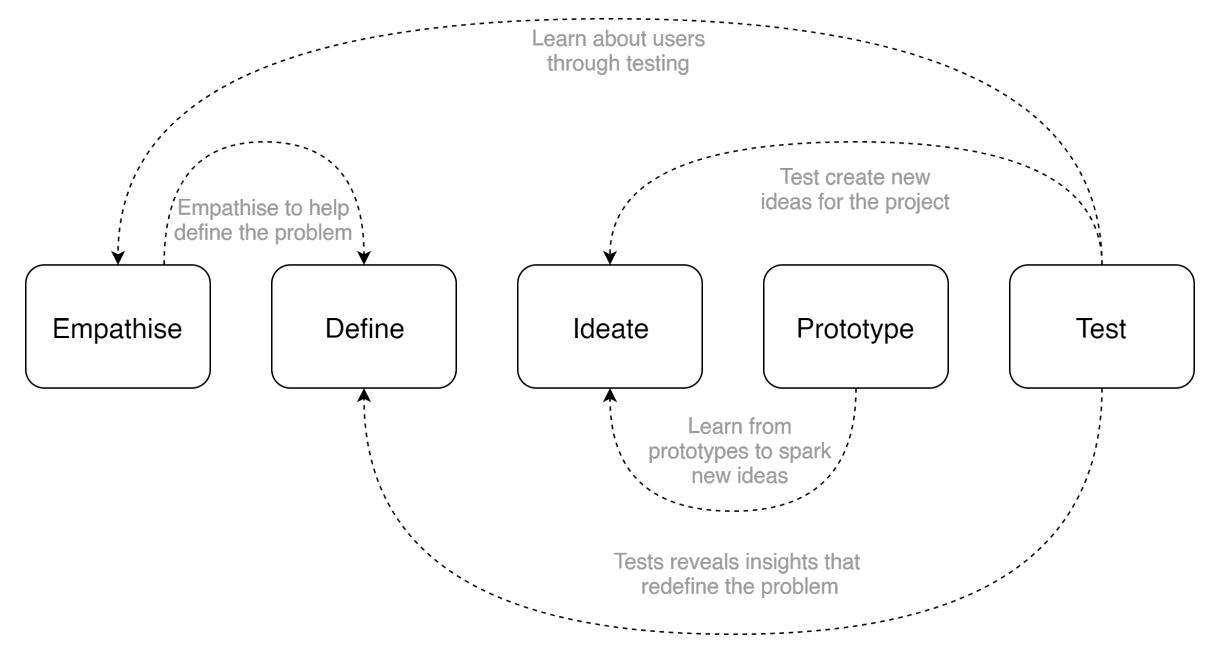

Fig. 3: The 5-stage model purposed by d.school (adapted from [9]).

\section{$3.1 \quad$ User Journey}

User journey is a technique to document the steps through which a user approaches a brand, service or product. The journey is composed by a set of touchpoints which represent the moments in which the user interacts with the brand/product/service. For each touchpoint, the map documents user's actions, thoughts and feelings. There is also space for mentioning opportunities for improvements.

The eight basic steps for mapping an user journey are: (1) define a scope of the scenarios to be analyzed; (2) define a user's profile; (3) define scenarios and expectations from the user; (4) create a list of possible actions and interaction points of the user with the product; (5) take into account the user's intentions; (6) draft the interactions step-by-step; (7) consider the user's emotional state for each step of interation; (8) validate and refine the journey [4].

Documenting the user journey is a way of constructing a Point of View (POV), i.e. a description of a problem highlighting its goal, considering the user whom the system if developed for, his needs and others characteristics which may be considered as relevant [11]. 
Documenting the user journey is one of the ways of to construct a Point of View (POV), i.e. a description of a problem highlighting its goal, considering the user whom the system if developed for, his needs and others characteristics which may be considered as relevant[11].

\subsection{How Might We (HMW) Questions}

How Might We (HMW) questions is a technique of brainstorming created by Procter \& Gamble (P\&G) in the 1970's and after adopted by companies such as Google, Facebook and IDEO [8]. Consists in a mean of ideas expression through short questions started with "How Might We", which works as a mind trigger for better ideas flowing considering a given previously defined POV. Design Kit [6] lists a four-step approach for conducing a HMW session that can be summarized as follows: (1) analyze previous statements, POV or other input; (2) rewrite the inputs as how many HMW questions as necessary; (3) verify if the HMW questions allow a variety of solutions, being good triggers for a brainstorm session; (4) verify if the HMW questions are too broad, and delimiter them if necessary.

\subsection{Affinity Diagrams}

Also known as Space Saturate and Group, is a technique which consists in clustering different types of collected data, resulting of brainstorming, research, interviews and others means, in meaning groups, comparing artifacts and deciding which are similar or different, according with some defined criteria[5].

\subsection{IoT-driven Techniques}

Besides these general-purpose techniques, researchers have proposed creativity tools for applying DT to IoT development. The Tiles IoT Inventor Toolkit ${ }^{3}$ brings tools such as representations of interfaces, virtual services and physical objects [18]. Besides that, its main characteristic is the working around the nonfamiliarity with IoT problem using augmentation strategies, i.e. adding computation capabilities to existing everyday objects, mixing existing and new functionalities to them. The toolkit consists in a set of 110 cards divided in six groups and a workshop technique, where the users are inspired for idea generation. Its roadmap contains the prototype creation as a work in progress.

The IoT Design ${ }^{4}$ Deck uses different techniques such as User Journey, System Map, Touchpoint Matrix to provide a common language for multidisciplinary teams and is available both in digital or for print versions. While Tiles focuses on the process of the IoT system, this tool is user-centered [7].

The IoT Service $\mathrm{Kit}^{5}$ also offers a card-based process with items representing things but differs for offering IoT scenario-centered boards with user journeys,

\footnotetext{
${ }^{3}$ www.tilestoolkit.io

4 www.iotdesigndeck.com

${ }^{5}$ www.iotservicekit.com
} 
design interaction and 3d-printed tokens, which represents mobile objects such as people and vehicles, for instance.

This work aims to provide empathy, definition and ideation methods for requirements gathering in IoT. It differs from others for using very simple and available tools like sticky notes and papers with user journey diagrams that may be printed or even drew. Besides that, we use "how might we"-started questions as a trigger for ideas generation and representations common resources categories offered by IoT platforms for developers. Table 1 shows a comparison between these techniques and our work considering covered stages of DT.

Table 1: Table captions should be placed above the tables.

\begin{tabular}{|l|l|l|l|l|l|}
\hline Work & Empathise & Define & Ideate & Prototype & Test \\
\hline IoT Design Deck & $\mathrm{X}$ & $\mathrm{X}$ & & $\mathrm{X}$ & \\
\hline Tiles & & & $\mathrm{X}$ & In progress & \\
\hline IoT Service Kit & & $\mathrm{X}$ & $\mathrm{X}$ & $\mathrm{X}$ & \\
\hline This & $\mathrm{X}$ & $\mathrm{X}$ & $\mathrm{X}$ & & \\
\hline
\end{tabular}

\section{$4 \quad$ Invited Projects}

Instituto de Pesquisas Tecnológicas do Estado de São Paulo (IPT) ${ }^{6}$, a state research and technology developement institute in Brazil, through the São Paulo Research Foundation (FAPESP), started the Institutional Development Plan in the Area of Digital Transformation: Advanced Manufacturing and Smart and Sustainable Cities (PDIP), that aims to implement the research area of CyberPhysical Systems (CPS), which, according to National Institute of Standards and Technology (NIST) [19], "comprise interacting digital, analog, physical, and human components engineered for function through integrated physics and logic". CPS connected to the Internet are called IoT systems. The PDIP, in turn, is divided in two research axes: 1) Advanced Manufacture; 2) Smart and Sustainable Cities. These axes contains different projects, and we needed, first, to detect IoT applications opportunities, i.e., given the problems, understand how could IoT approach solve them; second, select one of them for implementation and case studies; finally, help their members to meet the requirements of the projects. In order to achieve these goals, we invited the members for a workshop, which were technical personnel of IPT who were in charge of these different projects. The invited projects, with 18 participants, were divided into four areas, and we describe they bellow:

- Industry 4.0 (6 participants)

- Analysis of iron ore pellets degradation.

${ }^{6}$ www.ipt.br 
- Environmental Disasters (4 participants)

- Landslide risk analysis;

- Flood risk analysis;

- Forest fragments.

- Environmental Management (3 participants)

- Tree fall risk analysis and study of forest fragments conservation of.

- Pollution (5 participants)

- Noise mapping analysis.

- Air pollution analysis.

- Management of contaminated areas and environmental waste.

\section{Experiment}

As Fig. 4 shows, we divided the experiment into three phases: warm-up, requirements identification of each project and clustering the requirements by resources categories.

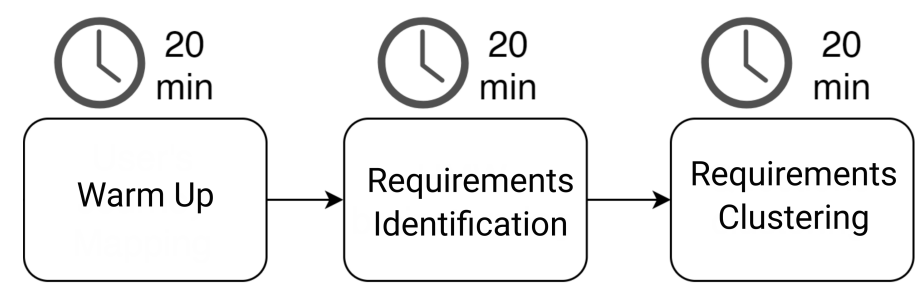

Fig. 4: Representation of the approach.

Firstly, we received the participants and explained to them the workshop goals and how it works. After, in the introducing round, each participant told his or her name, job, expectations about the workshop and described briefly the project which he or she was involved. The warm-up phase had the intention to move the mindset from the technical problems to an user perspective. After, the moderator grouped the participants into four teams according the fields of their projects as follows: 1) yellow: Environment Disasters; 2) lilac: Environmental Management; 3) pink: Industry 4.0; 4) blue: Pollution. So, he showed the user journey concept to them. So, we applied the user journey technique in which each group had to explain which are the touchpoints of their user with their systems and what happens in each stage. Hence, we shared user journeys boards, pencils, rulers and defined a time of twenty-minutes for the teams do this task. Each team chose some user profiles and each member did a board for each one, considering his interactions with the system and the attributes "doing", "thinking", "feeling" and writing, if any, detected opportunities when analyzing the journey. At the 
end of time, the moderator invited each team to present one of his boards to other teams, to create a mutual understanding of the works. Fig. 5 shows an user journey board.

Next step intended to explore the possible usages of IoT environment for applications of each project. So, the moderator explained the HMW questions techniques and the participants received sticky notes in four colors, one for each team, and pens. Hence, we requested for the teams to write HMW questions, considering the user's POVs mapped into the journeys, in a deadline of twentyminutes. Fig. 6 shows two questions created by a team.

The last step intended to explore the resources of IoT platforms, showing the opportunities could be developed using one or more IoT platform built-in solutions. Finally, the moderator presented the resources categories. From the set of eleven resource categories, we select the most commonly used, which are:

- Schedulers and triggers;

- Message and notification triggers;

- Big data and analytics;

- Artificial Inteligence and Machine Learning;

- Dashboards;

- Services

Each resource was explained in terms of what functionality is involved. For each resource category presented, we asked the teams for HMW questions that could be solved by the resource category, so they gave the sticky notes for insert around a label with the name of category in a panel. If any time they detect that a new presented category is better for solving a HWM question, could move the desired sticky notes from any previous category to this one. We made available, too, a label called "Others" for questions that could not be solved by any resource category or don't have technological solution. By this way, all the HMW questions were clustered around the labels, as Fig. 7 shows.

\section{Results and Discussion}

Fig. 8 shows how many HMW questions each team made by resource category, while Fig. 9 shows it by team. The most selected category was "Big Data and Analytics", with 24 occurrences, showing that data and its treatment are very important for these systems and, as we can see also in Fig. 9d, mainly for the ones from Environmental Management, whom the HMW questions presented worries about images processing, data correlations, image and data storage, among others.

"Service" was chosen 21 times, mainly by Environmental Disasters, once its solutions, also from the like the Pollution and Environmental Management teams, need to provide a channel of information for the target audience consume. The Industry 4.0 team, however, did not insert any HMW questions in Service category, probably due to its more operational purpose, without direct need of offering public services. 


\begin{tabular}{|c|c|c|c|c|}
\hline$\stackrel{\text { Papel: }}{\Delta \Delta \Delta}$ & $\sqrt{\mathrm{ce}}$ & cenário Poluicín do Ar & & 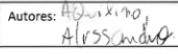 \\
\hline Jornada & Preferitona & $C E T E S B$ & IMOSILARIA & \\
\hline & 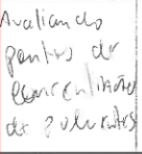 & $\begin{array}{l}\text { Avaliando } \\
\text { miciso. } \\
\text { àrea }\end{array}$ & $\begin{array}{l}\text { Procutands } \\
\text { surlhoues of in } \\
\text { a. qualidade } \\
\text { ar vida }\end{array}$ & \\
\hline & Saúde & $\begin{array}{l}\text { Salubndude } \\
\text { nie }\end{array}$ & 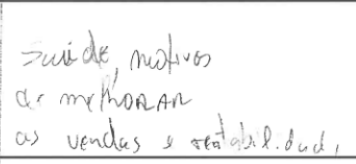 & \\
\hline SENTINDO & $\begin{array}{l}\text { Nressiade } \\
\text { de mit qur } \\
\text { missta }\end{array}$ & $\begin{array}{l}\text { Necessidide } \\
\text { ar cucontran } \\
\text { tontes poluidgras }\end{array}$ & 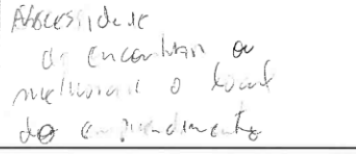 & \\
\hline & 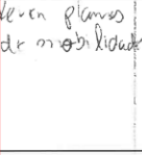 & $\begin{array}{l}\text { Multarl } \\
\text { Oritentar } \\
\text { Perscivan as } \\
\text { vendiages }\end{array}$ & 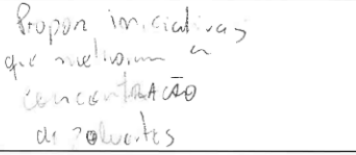 & \\
\hline
\end{tabular}

Fig. 5: One of the created user journey board. In red, the user's acts and found opportunities and, in green, the points of contact with the system.

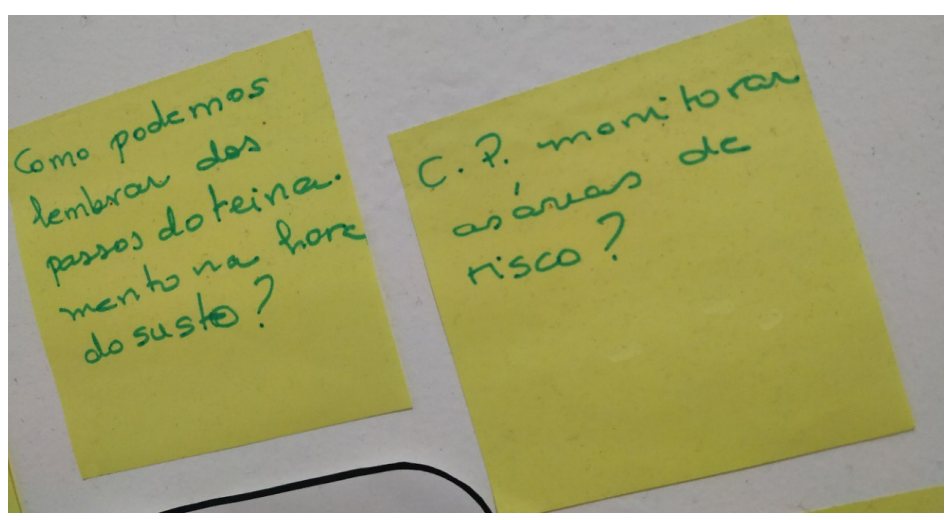

Fig. 6: Two stick notes with HMW questions elaborated by one of the teams.

The teams chose "Messages and Notifications" 12 times. Pollution and Environmental Disasters teams pointed needs focused on alert the population about events of interest and promote their solutions. Industry 4.0 team identified a need of notifying the user of its system. 


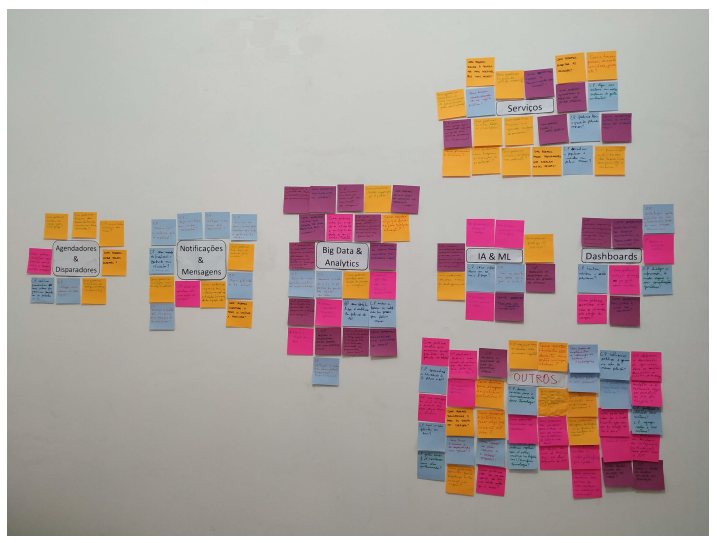

Fig. 7: Panel presenting the HMW questions clustered by resources categories, around the white labels. Sticky notes in the same color were created by the same team.

"IA \& ML" category was selected 10 times. All the teams expressed the desire of to use data collected for automatically improve the behaviors of the systems, making them more efficient.

The Environmental Management, Pollution and Industry 4.0 teams chosen the "Dashboard" category 3 times each, totalling 9 occurrences. They presented in their HMW questions characteristics related to data visualization and monitoring. Environmental Disasters didn't selected this one.

"Schedulers and Triggers" was selected 8 times, by Environmental Disasters, Pollution and Industry 4.0. They associate this resource category to automatic reactions for exception events on the systems. Environmental Management didn't selected this one.

The "Other" group, which clusterizes those HMW questions whom the teams doesn't found a category, was the most used, in these percentages: i)Environmental Disasters - 25,71\%; ii)Pollution - 34,3\%; iii)Industry 4.0 - 55,6\%; iv)Environmental Management $-11,5 \%$. These questions reflect the needs whom the resources offered by IoT platforms or even other technologies can not help directly, such as sociopolitical factors, funding, business sustainability, among others.

Some categories such as "Big Data \& Analytics", "IA \& ML" and "Dashboard" seems to see well-knew by the teams, so we noted the teams did a better correlation of their problems with these categories, like the question "how might we monitor the ore on the way through the milling plant?" which the teams related to "Dashboard" category. However, for the other categories, less familiar for them, the same not occurs, like the "Services", related to webservices creation, a more technical category, which received different questions related to general services, such as "how might we produce more goods at a lower price?", for example. 


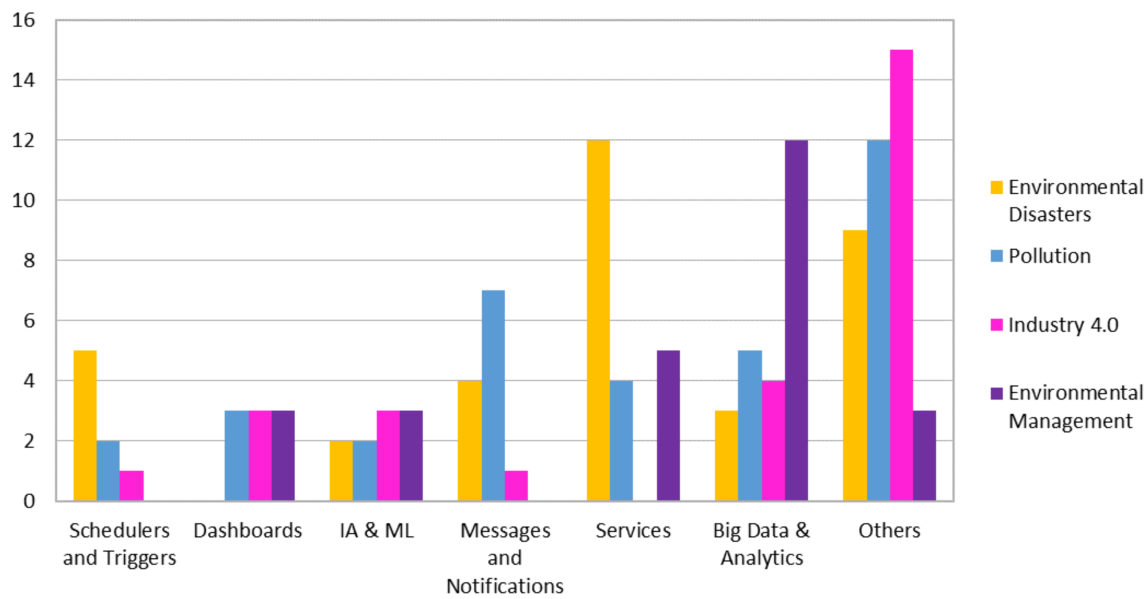

Fig. 8: Chart showing the frequency of HMW questions of the teams by resource category, from less to most selected.

A challenge was how to stimulate introvert people's people participation once they tend not to share ideas and be overshadowed by extrovert people's personalities. We worked around it by giving individual user journey boards and sticky notes for each participant in order to permit a discussion between them but letting each one to express individual opinion, yet.

About the prototype stage, once we have identified the necessary resources desired by the developer of application considering the requirements, there are the possibility of prototyping selecting a existing IoT platform for attending those needs or creating based in some architecture reference model, as the presented in Fig. 2, for instance.

We can improve the approach by creating personas, a technique that consists in creating representative characters of a population got through research, for a comprehension of users' needs. Personas are useful for a better user journey mapping, once a well-defined user's profile let us define more correctly the interactions with the system.

\section{Conclusions and Future Work}

Due to heterogeneity of technologies, IoT development is complex and needs more interdisciplinary teams when compared with other development areas. To work around this problem, IoT platforms provide a set of resources and functionalities to enable application development and support its execution. The common IoT research is addressing technological aspects such as security and connectivity, however, for IoT application development, requirements elicitation and their mapping to a given platform is still a challenge. 


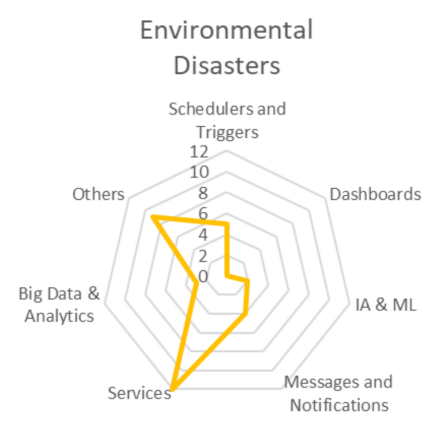

(a) Environmental Disasters Industry 4.0

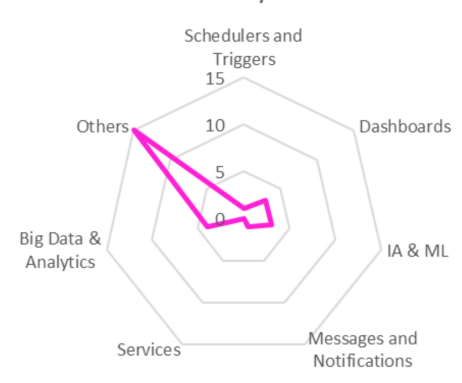

(c) Industry 4.0

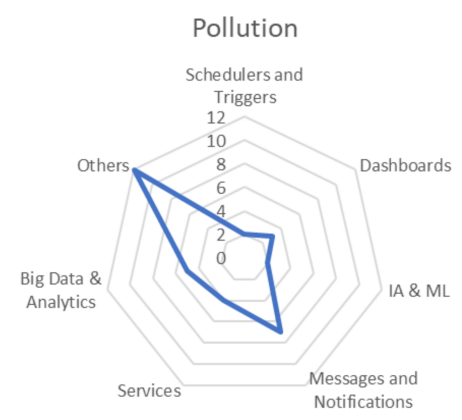

(b) Pollution Environmental Management

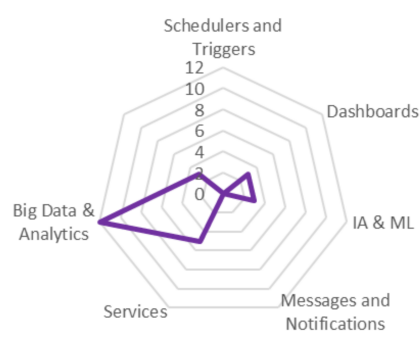

(d) Environmental Management

Fig. 9: Radar charts representing the found necessary resources for each team.

In this work, we presented a human-centered approach for requirements elicitation and mapping them to application resources in IoT platforms, using DT techniques.

Our contribution for the IoT application development is an approach for turning easier requirements elicitation using DT, with well-available materials and considering the resources present at application layer of IoT platforms. In other development areas such as mobile, web and desktop, the requirements elicitation processes are more mature, with a huge variety of techniques and less heterogeneity of technologies, in comparison with IoT development. Besides that, the teams could reflect on the needs and problems of their own projects and on the possibilities of solving them through IoT development.

The next steps, we intend to refine the approach developed, look for a method to cover the prototyping stage and review the current classification of resource categories in the application layer of IoT platforms, through the clustered requirements around the "others" label, once those are an opportunity for detecting possible lacks on current IoT platforms. 
Acknowledgements. Grant 2018/23052-0, São Paulo Research Foundation (FAPESP). Grant 2017/50343-2, São Paulo Research Foundation (FAPESP).

\section{References}

1. Al-Qaseemi, S.A., Almulhim, H.A., Almulhim, M.F., Chaudhry, S.R.: IoT architecture challenges and issues: Lack of standardization. FTC 2016 Proceedings of Future Technologies Conference (December), 731-738 (2017). https://doi.org/10.1109/FTC.2016.7821686

2. Apple: Design for Android, https://developer.android.com/design

3. Apple: Human Interface Guidelines, https://developer.apple.com/design/humaninterface-guidelines

4. Babich, Nick: A Beginner's Guide To User Journey Mapping - UX Planet, https://uxplanet.org/a-beginners-guide-to-user-journey-mapping-bd914f4c517c

5. DAM, Rikke Friis and Teo, Yu Siang: Affinity Diagrams - Learn How to Cluster and Bundle Ideas and Facts - Interaction Design Foundation, https://www.interaction-design.org/literature/article/affinity-diagrams-learnhow-to-cluster-and-bundle-ideas-and-facts

6. Design Kit: How Might We - Design Kit, https://www.designkit.org/methods/3

7. Dibitonto, M., Tazzi, F., Leszczynska, K., Medaglia, C.M.: The IoT design deck: A tool for the co-design of connected products. In: International Conference on Applied Human Factors and Ergonomics. pp. 217-227. Springer (2017)

8. Harvard Business Review: The Secret Phrase Top Innovators Use, https://hbr.org/2012/09/the-secret-phrase-top-innovato

9. Interaction Design Foundation: 5 Stages in the Design Thinking Process - Interaction Design Foundation, https://www.interaction-design.org/literature/article/5stages-in-the-design-thinking-process

10. Interaction Design Foundation: Stage 1 in the Design Thinking Process: Empathise with Your Users, https://www.interaction-design.org/literature/article/stage-1-inthe-design-thinking-process-empathise-with-your-users

11. Interaction Design Foundation: Stage 2 in the Design Thinking Process: Define the Problem and Interpret the Results, https://www.interactiondesign.org/literature/article/stage-2-in-the-design-thinking-process-define-theproblem-and-interpret-the-results

12. Interaction Design Foundation: Stage 3 in the Design Thinking Process: Ideate, https://www.interaction-design.org/literature/article/stage-3-in-thedesign-thinking-process-ideate

13. Interaction Design Foundation: Stage 4 in the Design Thinking Process: Prototype, https://www.interaction-design.org/literature/article/stage-4-in-the-designthinking-process-prototype

14. Interaction Design Foundation: Stage 4 in the Design Thinking Process: Prototype, https://www.interaction-design.org/literature/article/stage-5-in-the-designthinking-process-test

15. Interaction Design Foundation: What is Design Thinking and Why Is It So Popular?, https://www.interaction-design.org/literature/article/what-isdesign-thinking-and-why-is-it-so-popular

16. Kelley, D., Brown, T.: An introduction to Design Thinking. Iinstitute of Design at Stanford (2018). https://doi.org/10.1027/2151-2604/a000142, https://dschoolold.stanford.edu/sandbox/groups/designresources/wiki/36873/attachments/74b3d/ ModeGuideBOOTCAMP2010L.pdf 
17. Lepekhin, A., Borremans, A., Ilin, I., Jantunen, S.: A Systematic Mapping Study on Internet of Things Challenges. Proceedings of the 1st International Workshop on Software Engineering Research \& Practices for the Internet of Things pp. 9-16 (2019). https://doi.org/10.1109/SERP4IoT.2019.00009, https://doi.org/10.1109/SERP4IoT.2019.00009

18. Mora, S., Gianni, F., Divitini, M.: Tiles: A card-based ideation toolkit for the Internet of Things. DIS 2017 - Proceedings of the 2017 ACM Conference on Designing Interactive Systems pp. 587-598 (2017). https://doi.org/10.1145/3064663.3064699

19. National Institute of Standards and Technology: Cyber-Physical Systems, https://www.nist.gov/el/cyber-physical-systems

20. Ngu, Anne H and Gutierrez, Mario and Metsis, Vangelis and Nepal, Surya and Sheng, Q.Z., Ngu, A.H., Gutierrez, M., Metsis, V., Nepal, S., Sheng, Q.Z.: IoT middleware: A survey on issues and enabling technologies. IEEE Internet of Things Journal 4(1), 1—-20 (2017). https://doi.org/10.1109/JIOT.2016.2615180

21. Perera, C., Ranjan, R., Wang, L., Khan, S.U., Zomaya, A.Y.: Big data privacy in the internet of things era. IT Professional 17(3), 32-39 (2015). https://doi.org/10.1109/MITP.2015.34

22. Sector, I.T.S.: Recommendation itu-t y. 2060: Overview of the internet of things. Series Y: Global information infrastructure, internet protocol aspects and nextgeneration networks-Frameworks and functional architecture models. Retrieved from https://www. itu. int/rec/T-REC-Y pp. 2060-201206 (2012)

23. Yunisa, F., Suharijto: Push notification system to mobile game player using distributed event-based system approach. In: Proceeding - 2016 2nd International Conference on Science in Information Technology, ICSITech 2016: Information Science for Green Society and Environment. pp. 52-57. Institute of Electrical and Electronics Engineers Inc. (feb 2017). https://doi.org/10.1109/ICSITech.2016.7852607 